\title{
Molecular phylogeny, morphology, pigment chemistry and ecology in Hygrophoraceae (Agaricales)
}

\author{
D. Jean Lodge • Mahajabeen Padamsee • P. Brandon Matheny • M. Catherine Aime • \\ Sharon A. Cantrell • David Boertmann - Alexander Kovalenko • Alfredo Vizzini • \\ Bryn T. M. Dentinger • Paul M. Kirk • A. Martyn Ainsworth • Jean-Marc Moncalvo • \\ Rytas Vilgalys • Ellen Larsson • Robert Lücking • Gareth W. Griffith • Matthew E. Smith • \\ Lorelei L. Norvell • Dennis E. Desjardin • Scott A. Redhead • Clark L. Ovrebo • \\ Edgar B. Lickey • Enrico Ercole • Karen W. Hughes • Régis Courtecuisse • Anthony Young • \\ Manfred Binder • Andrew M. Minnis • Daniel L. Lindner • Beatriz Ortiz-Santana • \\ John Haight • Thomas Lassøe • Timothy J. Baroni • József Geml • Tsutomu Hattori
}

Received: 17 April 2013 / Accepted: 17 July 2013 /Published online: 6 October 2013

(C) The Author(s) 2013. This article is published with open access at Springerlink.com

\begin{abstract}
Molecular phylogenies using 1-4 gene regions and information on ecology, morphology and pigment chemistry were used in a partial revision of the agaric family Hygrophoraceae. The phylogenetically supported genera we recognize

The Forest Products Laboratory in Madison, WI is maintained in cooperation with the University of Wisconsin and the laboratory in Puerto Rico is maintained in cooperation with the USDA Forest Service, International Institute of Tropical Forestry. This article was written and prepared by US government employees on official time and is therefore in the public domain and not subject to copyright.
\end{abstract}

Electronic supplementary material The online version of this article (doi:10.1007/s13225-013-0259-0) contains supplementary material, which is available to authorized users.

\section{J. Lodge $(\bowtie)$}

Center for Forest Mycology Research, Northern Research Station, USDA-Forest Service, Luquillo, PR 00773-1377, USA

e-mail: djlodge@caribe.net

\section{J. Lodge}

e-mail: dlodge@fs.fed.us

\section{Padamsee}

Systematics Team, Landcare Research, 231 Morrin Road, Auckland 1072, New Zealand

e-mail: PadamseeM@landcareresearch.co.nz

P. B. Matheny $\cdot$ K. W. Hughes

Ecology \& Evolutionary Biology, University of Tennessee,

Knoxville, TN 37996-1610, USA

\section{C. Aime}

Department of Botany \& Plant Pathology, Purdue University, West Lafayette, IN 47907, USA

\section{S. A. Cantrell}

Science and Technology, Universidad del Turabo, Gurabo,

PR 00778-3030, USA here in the Hygrophoraceae based on these and previous analyses are: Acantholichen, Ampulloclitocybe, Arrhenia, Cantharellula, Cantharocybe, Chromosera, Chrysomphalina, Cora, Corella, Cuphophyllus, Cyphellostereum, Dictyonema,
D. Boertmann

Department of Bioscience, Aarhus University, Frederiksborgvej 399, DK-4000 Roskilde, Denmark

\section{A. Kovalenko}

Komarov Botanical Institute of the Russian Academy of Sciences, 2 Prof. Popov Str., St. Petersburg 197376, Russia

A. Vizzini $\cdot$ E. Ercole Dipartimento di Scienze della Vita e Biologia dei Sistemi, Università di Torino, Viale P.A. Mattioli 25, 10125 Torino, Italy

B. T. M. Dentinger • P. M. Kirk • A. M. Ainsworth Mycology, Royal Botanic Gardens, Kew, Richmond, Surrey TW9 3DS, UK

J.-M. Moncalvo

Royal Ontario Museum, 100 Queen's Park, Toronto, ON, Canada

R. Vilgalys

Biology Department, Duke University, Durham, NC 27708-0338, USA 
Eonema, Gliophorus, Haasiella, Humidicutis, Hygroaster, Hygrocybe, Hygrophorus, Lichenomphalia, Neohygrocybe, Porpolomopsis and Pseudoarmillariella. A new genus that is sister to Chromosera is described as Gloioxanthomyces. Revisions were made at the ranks of subfamily, tribe, genus, subgenus, section and subsection. We present three new subfamilies, eight tribes (five new), eight subgenera (one new, one new combination and one stat. nov.), 26 sections (five new and three new combinations and two stat. nov.) and 14 subsections (two new, two stat. nov.). Species of Chromosera, Gliophorus, Humidicutis, and Neohygrocybe are often treated within the genus Hygrocybe; we therefore provide valid names in both classification systems. We used a minimalist approach in transferring genera and creating new names and combinations. Consequently, we retain in the Hygrophoraceae the basal cuphophylloid grade comprising the genera Cuphophyllus, Ampulloclitocybe and Cantharocybe, despite weak phylogenetic support. We include Aeruginospora and Semiomphalina in Hygrophoraceae based on morphology though molecular data are lacking. The lower hygrophoroid clade is basal to Hygrophoraceae s.s., comprising the genera Aphroditeola, Macrotyphula, Phyllotopsis, Pleurocybella, Sarcomyxa, Tricholomopsis and Typhula.

\section{E. Larsson}

Biological \& Environmental Sciences, University of Gothenburg,

Göteborg, Sweden

R. Lücking

Science \& Eduaction, Integrative Research \& Collections (Botany),

The Field Museum of Natural History, 1400 Lake Shore Dr., Chicago,

IL 60605-2496, USA

G. W. Griffith

University of Wales, Aberystwyth, Ceredigion SY23 3DD, UK

M. E. Smith

Department of Plant Pathology, University of Florida, Gainesville, FL 32611-0680, USA

\section{L. Norvell}

Pacific Northwest Mycology Service, 6720 NW Skyline Bvd, Portland, OR 97229-1309, USA

D. E. Desjardin

Department of Biology, San Francisco State University, 1600

Holloway Ave., San Francisco, CA 94132, USA

\section{S. A. Redhead}

National Mycological Herbarium (DAOM), Science and Technology Branch, Agriculture \& Agri-Foods, Canada, 960 Carling Avenue, Ottawa, Ontario, Canada ONT K1A 0C6

\section{L. Ovrebo}

Department of Biology, University of Central Oklahoma, Edmond, OK 73034, USA

\section{E. B. Lickey}

Department of Biology, Bridgewater College, 402 E. College St., Bridgewater, VA 22812, USA
Keywords Hygrophoraceae $\cdot$ Fungi $\cdot$ Revisionary systematics $\cdot$ Nomenclatural revision $\cdot$ Phylogenetics . Pigment chemistry $\cdot$ Lamellar trama construction $\cdot$ Hymenial morphology $\cdot$ Ecology

\section{Introduction}

This paper is a contribution towards revision of the agaric family Hygrophoraceae Lotsy that integrates new molecular phylogenetic and morphological analyses with old and current data on phylogeny, morphology, pigment chemistry and ecology. The primary aim is to provide a coherent, integrated, higher-level structure for this diverse family at the ranks of subfamily, tribe, genus, subgenus, section and subsection. Recent publications on ecology, chemotaxonomy and molecular phylogenies together with our own analyses of morphology and new molecular data and phylogenies have made this revision possible.

The Hygrophoraceae has a complex history. The family may be based on Roze (1876), but his name, Hygrophorées, had a French rather than a Latin ending and was therefore invalid according to Art. 18.4 of the International Code of

R. Courtecuisse

Department of Botany, Faculty of Pharmaceutical \& Biological Sciences, Lille, France

A. Young

100 Langton Road, Blackbutt, Qld 4306, Australia

M. Binder

CBS Fungal Biodiversity Centre, Evolutionary Phytopathology, Inst. of the Royal Netherlands Academy of Arts \& Sciences (KNAW), Uppsalalaan 8, 3584 CT Utrecht, The Netherlands

A. M. Minnis · D. L. Lindner · B. Ortiz-Santana $\cdot$ J. Haight Center for Forest Mycology Research, USDA Forest Service, Northern Research Station, One Gifford Pinchot Dr., Madison, WI 53726-2398, USA

T. Læssøe

Ecology and Evolution, Department of Biology,

University of Copenhagen, Universitetsparken 15,

2100 København Ø, Denmark

T. J. Baroni

Department of Biological Sciences, SUNY - College at Cortland, Cortland, NY 13054, USA

\section{J. Geml}

Naturalis Biodiversity Center, Section National

Herbarium of the Netherlands, PO Box 9514,

2300 RA Leiden, The Netherlands

T. Hattori

Forestry \& Forest Products Research Inst.,

Kansai Research Center, Tsukuba, Japan 
Nomenclature for algae, fungi, and plants (Melbourne Code) (ICN 2012, http://www.iapt-taxon.org/nomen/main.php). Lotsy (1907) validly published Hygrophoraceae with supporting details in German, which was permissible under the ICBN rules at that time (Young 2003). The generic type for the family, the genus Hygrophorus, was published by Fries in 1836. Fries (1838) subsequently organized the species of Hygrophorus Fr. into three 'tribes' (a nomenclaturally unrecognized, infrageneric rank, not the currently recognized infra-familial rank of tribe): Limacium, Camarophyllus, and Hygrocybe. Kummer (1871) raised the Friesian tribes to genus rank as Limacium (Fr.) P. Kumm., Camarophyllus (Fr.) P. Kumm. and Hygrocybe (Fr.) P. Kumm. As noted by Young (2005), Kummer did not retain the genus name, Hygrophorus, but instead used Limacium for most of the ectomycorrhizal species with divergent lamellar trama that we now refer to as Hygrophorus s.s. Karsten (1876) recognized the genera Hygrophorus Fr. (rather than Limacium sensu Kummer), Camarophyllus and Hygrocybe (misspelled as 'Hydrocybe'). That led to confusion with Hydrocybe Fr. - a segregate of Cortinarius. Karsten corrected his misspelling of Hydrocybe to 'Hygrocybe' in later publications, but Murrill (1911-1942) perpetuated Karsten's spelling error. Murrill's Hydrocybe is regarded as an orthographic variant of Hygrocybe so his names are otherwise valid, legitimate, and corrected to Hygrocybe names and combinations.

The Hygrophoraceae was originally characterized by basidiomes with thick, distant, waxy lamellae, spores that were mostly smooth, hyaline and inamyloid, and basidia five or more times the length of their spores (Singer 1986). We now recognize these characters are not as reliable as they once seemed (Lawrey et al. 2009; Lodge et al. 2006; Matheny et al. 2006; Young 1997), leading Bas (1988) to transfer genera from the Hygrophoraceae to the Tricholomataceae. Subsequent phylogenetic analyses (i.e., Binder et al. 2010; Lawrey et al. 2009; Matheny et al. 2006; Moncalvo et al. 2002) placed most of the genera traditionally treated in Hygrophoraceae apart from the Tricholomataceae. Matheny et al. (2006) were first to show strong support for a monophyletic Hygrophoraceae. The Hygrophoraceae appears to be mostly biotrophic based on stable carbon and nitrogen isotope signatures, though only the type genus, Hygrophorus, forms ectomycorrhizal associations with tree roots (Seitzman et al. 2011; Tedersoo et al. 2010). Acantholichen, Cora, Corella, Cyphellostereum, Dictyonema, Lichenomphalia and Semiomphalina species form lichens with green algae or cyanobacteria (Lawrey et al. 2009; Matheny et al. 2006; Redhead et al. 2002), Eonema is associated with live ferns and grasses (Lawrey et al. 2009), and Arrhenia and Cantharellula are generally associated with bryophytes (Lawrey et al. 2009). Biotic relationships for the remaining genera of Hygrophoraceae are enigmatic (Seitzman et al. 2011). Currently, Hygrophoraceae comprises over 600 species (not all described) in 25 named genera and one new genus
(Tables 1 and 2), and is thus one of the larger families in the Agaricales. Moncalvo et al. (2002) identified many phylogenetic clades that were later supported as belonging to the Hygrophoraceae by Lodge et al. (2006), Matheny et al. (2006), Lawrey et al. (2009) and Binder et al. (2010). Neither Binder et al. (2010) nor Seitzman et al. (2011) found support for a monophyletic family, but Matheny et al. (2006) found Bayesian support for a monophyletic Hygrophoraceae s.l. if Camarophyllopsis and Neohygrophorus were excluded.

In this paper, we attempt to establish correct, legitimate, validly published names that correspond to phylogenetic clades in Hygrophoraceae. In some cases, we note a lack of correspondence between clades and previously established classifications. We used a conservative approach, and changed the status of names or made new combinations for names used previously in other genera or at unassigned ranks, created new names for clades or changed the placement of named taxa only when the phylogenetic evidence was strong, compelling, and consistent with morphology.

This is the culmination of a large international collaborative effort spanning 20 years and reflects both the consensus as well as the differing opinions of the many coauthors. Our efforts began in 1988-1990 with two separate collaborations formed by the Vilgalys - Moncalvo lab, one with Lodge and Cantrell, and the other with Kovalenko. The collaboration expanded greatly in 2002 with a Hygrophoraceae Systematics, Ecology and Conservation workshop at the International Mycological Congress in Oslo, Norway that was co-organized by Lodge, Cantrell, Boertmann, Courtecuisse and Kovalenko. The preliminary molecular phylogenies by Moncalvo that were presented in 2002 served as the basis for seeking specific additional sequences and for further phylogenetic analyses by Matheny. The complete data set analysis was presented at the Mycological Society of America meeting in Quebec, Canada (Lodge et al. 2006, web link), while a smaller, mostly independent data set was used in the Matheny et al.'s (2006) Assembling the Fungal Tree of Life (AFTOL) paper on Agaricales published in Mycologia. Padamsee and Aime were recruited for final analyses. Our four-gene region backbone analysis builds upon all of these previous iterations plus recent papers by Lawrey et al. (2009), Ovrebo et al. (2011) and the six-gene analysis by Binder et al. (2010). Our aim was to use two representatives per clade in the backbone analysis so as to reduce long-branch attractions while minimizing loss of bootstrap support with increasing taxa. We attempted to include a basal and a terminal representative from each clade to determine if the morphological characters used to distinguish taxonomic groups were synapomorphic. We also use independent four-gene analyses of Hygrophorus s.s. presented by Larsson (2010, and unpublished data).

In this paper, we used four gene regions: nuclear ribosomal ITS (ITS 1-2 and 5.8S), LSU (25S), and SSU (18S), and added the nuclear $\mathrm{rpb} 26 \mathrm{~F}$ to $7.1 \mathrm{R}$ region to as many of the 
Table 1 Alternative classifications for Hygrophoraceae, subfamily Hygrocyboideae using the segregate genera accepted in this paper versus the aggregate genus, Hygrocybe s.1. The order in this table is by branching order in the 4-gene backbone and Supermatrix analyses (Figs. 1 and 2)

Segregate genera accepted here

Aggregate genus Hygrocybe s.1.

Subfamily Hygrocyboideae Padamsee \& Lodge, subf. nov., type genus: Hygrocybe (Fr.) P. Kumm. Führ. Pilzk. (Zerbst): 111 (1871). Hygrocybe (Fr.) P. Kumm., Führ. Pilzk. (Zwickau): 111 (1871) [三 Hygrophorus subg. Hygrocybe Fr., Summa veg. Scand., Section Post. (Stockholm): 308 (1849)].

Tribe Hygrocybeae Kühner, Bull. Soc. Linn. Lyon 48: 621 (1979), emended here by Lodge. Type genus: Hygrocybe (Fr.) P. Kumm., Führ. Pilzk. (Zwickau): 26 (1871)

Genus Hygrocybe (Fr.) P. Kumm., Führ. Pilzk. (Zwickau): 26 (1871) [三 Hygrophorus subg. Hygrocybe Fr. (1849)], type species: Hygrocybe conica (Schaeff.) P. Kumm., Führ. Pilzk. (Zwickau): 111 (1871) [三 Hygrophorus conicus (Schaeff.) Fr., Epicr. syst. mycol. (Upsaliae): 331 (1838)]

Subgenus Hygrocybe, [autonym] (1976), type species Hygrocybe conica (Schaeff.) P. Kumm., Führ. Pilzk. (Zwickau): 111 (1871) [三 Hygrophorus conicus (Schaeff.) Fr., Epicr. syst. mycol. (Upsaliae): 331 (1838) [1836-1838]]

Section Hygrocybe [autonym] (1889), type species Hygrocybe conica (Schaeff.) P. Kumm., Führ. Pilzk. (Zwickau): 111 (1871) [三 Hygrophorus conicus (Schaeff.) Fr., Epicr. syst. mycol. (Upsaliae): 331 (1838) [1836-1838]]

Subsection Hygrocybe [autonym] (1951), type species Hygrocybe conica (Schaeff.) P. Kumm., Führ. Pilzk. (Zwickau): 111 (1871) [三 Hygrophorus conicus (Schaeff.) Fr., Epicr. syst. mycol. (Upsaliae): 331 (1838) [1836-1838]]

Subsection Macrosporae R. Haller Aar. ex Bon, Doc. Mycol. 24(6): 42 (1976), type species Hygrocybe acutoconica (Clem.) Singer (1951) (as Hygrocybe acuticonica Clem.) [= Hygrocybe persistens (Britzelm.) Singer (1940)]

Section Velosae Lodge, Ovrebo \& Padamsee, sect. nov., type species Hygrophorus hypohaemactus Corner, Trans. Br. Mycol. Soc. 20(2): 180, Figs. 5, 6, 8a (1936) [三 Hygrocybe hypohaemacta (Corner) Pegler \& Fiard, Kew Bull. 32(2): 299 (1978)]

Section Pseudofirmae Lodge \& Padamsee, sect. nov., type species Hygrophorus appalachianensis Hesl. \& A.H. Sm., North American Species of Hygrophorus: 147 (1963) [三 Hygrocybe appalachianensis (Hesl. \& A.H. Sm.) Kronaw. (as 'appalachiensis'), in Kronawitter \& Bresinsky, Regensb. Mykol. Schr 8: 58 (1998)]

Section Microsporae Boertm., The genus Hygrocybe. Fungi of Northern Europe (Greve) 1: 16 (1995), type species Hygrocybe citrinovirens (J.E. Lange) Jul. Schäff., Ber. bayer.bot. Ges. 27: 222 (1947)

Section Chlorophanae (Herink) Arnolds ex Candusso, Hygrophorus. Fungi europ. (Alassio 6: 464 (1997), type species Hygrocybe chlorophana (Fr.) Wünsche, Die Pilze: 112 (1877) [三 Agaricus chlorophanus Fr. : Fr., Syst. mycol. (Lundae) 1: 103 (1821)]

Subgenus Pseudohygrocybe Bon, Doc. Mycol. 6 (24): 42 (1976), type species Hygrocybe coccinea (Schaeff.) Fr., Epicr. syst. mycol. (Upsaliae): 330 (1838) [1836-1838]] $\equiv$ Agaricus coccineus Schaeff. Fung. Bavar. Palat. 4: 70 (1774), ([NOT Agaricus coccineus Scop., Fl. carniol., (Wein) Edn. 2: 436 (1772), an earlier homonym of a sanctiond name]

Section Coccineae Fayod, Proc. Hist. Nat. Agar. Ann. Scient. Nat. 7(9): 309 (1889), type species Hygrocybe coccinea (Schaeff.) Fr., Epicr. syst. mycol. (Upsaliae): 330 (1838) [1836-1838], 三Agaricus coccineus Schaeff. Fung. Bavar. Palat. 4: 70 (1774) [= Hygrocybe sect. Puniceae Fayod (1889), illeg., = H. sect. 'Inopodes" Singer (1943), nom. invalid]

Subsection Coccineae (Bataille) Singer, Lilloa 22: 152 (1951) [1949], type species: Hygrocybe coccinea (Schaeff.) Fr., Epicr. syst. mycol.
Genus Hygrocybe (Fr.) P. Kumm., Führ. Pilzk. (Zwickau): 26 (1871) [三 Hygrophorus subg. Hygrocybe Fr. (1849)], type species: Hygrocybe conica (Schaeff.) P. Kumm., Führ. Pilzk. (Zwickau): 111 (1871) [三 Hygrophorus conicus (Schaeff.) Fr., Epicr. syst. mycol. (Upsaliae): 331 (1838)]

Subgenus Hygrocybe, [autonym] (1976), type species Hygrocybe conica (Schaeff.) P. Kumm., Führ. Pilzk. (Zwickau): 111 (1871) [三 Hygrophorus conicus (Schaeff.) Fr., Epicr. syst. mycol. (Upsaliae): 331 (1838) [1836-1838]]

Section Hygrocybe [autonym] (1889), type species Hygrocybe conica (Schaeff.) P. Kumm., Führ. Pilzk. (Zwickau): 111 (1871) [三 Hygrophorus conicus (Schaeff.) Fr., Epicr. syst. mycol. (Upsaliae): 331 (1838) [1836-1838]]

Subsection Hygrocybe, [autonym] (1951), type species Hygrocybe conica (Schaeff.) P. Kumm., Führ. Pilzk. (Zwickau): 111 (1871) [三 Hygrophorus conicus (Schaeff.) Fr., Epicr. syst. mycol. (Upsaliae): 331 (1838) [1836-1838]]

Subsection Macrosporae R. Haller Aar. ex Bon, Doc. Mycol. 24(6): 42 (1976), type species Hygrocybe acutoconica (Clem.) Singer (1951) (as Hygrocybe acuticonica Clem.) [= Hygrocybe persistens (Britzelm.) Singer (1940)]

Section Velosae Lodge, Ovrebo \& Padamsee

Section Pseudofirmae Lodge \& Padamsee

Section Microsporae Boertm., The genus Hygrocybe. Fungi of Northern Europe (Greve) 1: 16 (1995), type species Hygrocybe citrinovirens (J.E. Lange) Jul. Schäff., Ber. bayer.bot. Ges. 27: 222 (1947)

Section Chlorophanae (Herink) Arnolds ex Candusso, Hygrophorus. Fungi europ. (Alassio) 6: 464 (1997), type species Hygrocybe chlorophana (Fr.) Wünsche, Die Pilze: 112 (1877) [三 Agaricus chlorophanus Fr. : Fr., Syst. mycol. (Lundae) 1: 103 (1821)]

Subgenus Pseudohygrocybe Bon, Doc. Mycol. 6 (24): 42 (1976), type species Hygrocybe coccinea (Schaeff.) Fr., Epicr. syst. mycol. (Upsaliae): 330 (1838) [1836-1838]] 三 Agaricus coccineus Schaeff. Fung. Bavar. Palat. 4: 70 (1774), ([NOT Agaricus coccineus Scop., Fl. carniol., (Wein) Edn. 2: 436 (1772), an earlier homonym of a sanctiond name]

Section Coccineae Fayod, Proc. Hist. Nat. Agar. Ann. Scient. Nat. 7(9): 309 (1889), type species Hygrocybe coccinea (Schaeff.) Fr., Epicr. syst. mycol. (Upsaliae): 330 (1838) [1836-1838], 三Agaricus coccineus Schaeff. Fung. Bavar. Palat. 4: 70 (1774) [= Hygrocybe sect. Puniceae Fayod (1889), illeg., = H. sect. "Inopodes" Singer (1943), nom. invalid]

Subsection Coccineae (Bataille) Singer, Lilloa 22: 152 (1951) [1949], type species: Hygrocybe coccinea (Schaeff.) Fr., Epicr. syst. mycol. 
Table 1 (continued)

Segregate genera accepted here

(Upsaliae): 330 (1838) [1836-1838] 三 Agaricus coccineus Schaeff.

Fung. Bavar. Palat. 4: 70 (1774) [= Hygrocybe subsect. Puniceae (Fayod) Arnolds ex Candusso (1997), superfluous, nom. illeg.,

= Hygrocybe subsect. "Inopodes" Singer (1952), nom. invalid]

Subsection Siccae Boertm., The genus Hygrocybe. Fungi of Northern Europe - Vol. 1: 15 (1995), type species Hygrocybe reidii Kühner, Bull. trimest. Soc. mycol. Fr. 92: 463 (1976)

Subsection Squamulosae (Bataille) Singer, Lilloa 22: 152 (1951)[1949], type species Hygrocybe turunda (Fr.) P. Karst., Bidr. Känn. Finl. Nat. Folk 32: 235 (1879), 三 Hygrophorus turundus (Fr.: Fr.) Fr., Epicr. syst. mycol. (Upsaliae): 330 (1838), 三 Agaricus turundus Fr., Observationes mycologicae 2: 199 (1818), [三 Hygrocybe subsect. Turundae (Herink) Bon, Doc. Mycol. 19(75): 56 (1989), superfluous, nom. illeg.]

Section Firmae Heinem., Bull. Jard. bot. État Brux. 33 (4): 441 (1963), emend. here by Lodge, type species Hygrocybe firma (Berk. \& Broome) Singer, Sydowia 11: 355 (1958), 三 Hygrophorus firmus Berk. \& Broome, J. Linn. Soc., Bot. 11(56): 563 (1871)

Genus Hygroaster Singer 1955, Sydowia 9(1-6): 370, type species Hygroaster nodulisporus (Dennis) Singer, Sydowia 9(1-6: 370 (1955), $\equiv$ Hygrophorus nodulisporus Dennis Kew Bull. 8(2): 259 (1953)

Tribe Humidicuteae Padamsee \& Lodge, tribe nov., type genus Humidicutis (Singer) Singer, Sydowia 12(1-6): 225 (1959) [1958]

Genus Neohygrocybe Herink Sb., Severocesk. Mus., Prír. Vedy 1: 71 (1959), emend. here by Lodge, type species Neohygrocbye ovina (Bull. : Fr.) Herink, Sb. Severocesk. Mus., Prír. Vedy 1: 72 (1959),

$\equiv$ Hygrophorus ovinus (Bull. : Fr.) Fr., Epicr. syst. mycol. (Upsaliae): 328 (1838) [1836-1838], 三 Agaricus ovinus Bull., Herbier de la France 13: t. $580(1793)$ : Fr.

Section Neohygrocybe [autonym] type species Neohygrocybe ovina (Bull. ex Fr.) Herink, Sb. Severocesk. Mus., Prír. Vedy 1: 72 (1959), $\equiv$ Hygrocybe ovina (Bull.) Kühner, Botaniste 17: 43 (1926), $\equiv$ Hygrophorus ovinus (Bull. : Fr.) Fr., Anteckn. Sver. Ätl. Svamp.: 45, 47 (1836), 三Agaricus ovinus Bull., Herbier de la France 13: t. 580 (1793)] [三 Neohygrocybe sect. "Ovinae" Herink (1959), nom. invalid],

Section Tristes (Bataille) Lodge \& Padamsee, comb. nov., emended here by Lodge to include only the type species. Lectoype designated by Singer, Lilloa 22: 151 (1951): Hygrocybe nitrata (Pers.) Wünsche, Die Pilze: 112 (1877), „Agaricus nitratus Pers., Syn. meth. fung. (Göttingen) 2: 356 (1801), 三 Neohygrocybe nitrata (Pers.) Kovalenko, Opredelitel' Gribov SSSR (Leningrad): 40 (1989), [三 "Neohygrocybe nitrata" (Pers.) Herink (1959), nom. invalid., Art. 33.2]. Basionym: Hygrocybe section Tristes (Bataille) Singer, Lilloa 22: 151 (1951) [1949] [三 Hygrophorus Fr. subgen. Hygrocybe Fr. [unranked] Tristes Bataille, Mém. Soc. émul. Doubs, sér. 8 4:183 (1910), [三Neohygrocybe sect. “Nitratae" Herink, superfluous, nom. illeg., Art. 52.1]

Genus Porpolomopsis Bresinsky, Regensb. Mykol. Schr. 15: 145 (2008), type species Porpolomopsis calyptriformis (Berk.) Bresinsky Regensb. Mykol. Schr. 15: 145, (2008), 三 Hygrocybe calyptriformis (Berk.) Fayod, Annls. Sci. Nat. Bot., sér. 7 9: 309 (1889), 三 Agaricus calyptriformis Berk., Ann. Mag. Nat. Hist., Ser. 1 1: 198 (1838)

Genus Humidicutis (Singer) Singer, Sydowia 12(1-6): 225 (1959) [1958], emended here by Lodge, type species Humidicutis marginata (Peck) Singer (1959), 三 Hygrophorus marginatus Peck, Ann. Rpt. N.Y. State Mus. Nat. Hist. 28: 50 (1876)
Aggregate genus Hygrocybe s.l.

(Upsaliae): 330 (1838) [1836-1838] 三 Agaricus coccineus Schaeff. Fung. Bavar. Palat. 4: 70 (1774) [= Hygrocybe subsect. Puniceae (Fayod) Arnolds ex Candusso (1997), superfluous, nom. illeg., = Hygrocybe subsect. "Inopodes" Singer (1952), nom. invalid]

Subsection Siccae Boertm., The genus Hygrocybe. Fungi of Northern Europe - Vol. 1: 15 (1995), type species Hygrocybe reidii Kühner, Bull. trimest. Soc. mycol. Fr. 92: 463 (1976)

Subsection Squamulosae (Bataille) Singer, Lilloa 22: 152 (1951)[1949], type species Hygrocybe turunda (Fr.) P. Karst., Bidr. Känn. Finl. Nat. Folk 32: 235 (1879), 三 Hygrophorus turundus (Fr.: Fr.) Fr., Epicr. syst. mycol. (Upsaliae): 330 (1838), 三 Agaricus turundus Fr., Observationes mycologicae 2: 199 (1818), [三 Hygrocybe subsect. Turundae (Herink) Bon, Doc. Mycol. 19(75): 56 (1989), superfluous, nom. illeg.]

Section Firmae Heinem., Bull. Jard. bot. État Brux. 33 (4): 441 (1963), type species Hygrocybe firma (Berk. \& Broome) Singer, Sydowia 11: 355 (1958), 三 Hygrophorus firmus Berk. \& Broome, J. Linn. Soc., Bot. 11(56): 563 (1871)

Subgenus or sect. Hygroaster, ined. This change would need to be made to prevent Hygrocybe s.l. from being rendered polyphyletic if the aggregate genus Hygrocybe is used.

Subgenus Neohygrocybe (Herink) Bon, Doc. Mycol. 19 (75): 56 (1989), type species Hygrocybe ovina (Bull.) Kühner, Botaniste 17: 43 (1926), 三 Hygrophorus ovinus (Bull. : Fr.) Fr., Epicr. syst. mycol. (Upsaliae): 328 (1838) [1836-1838], 三Agaricus ovinus Bull., Herbier de la France 13: t. 580 (1793) : Fr.

Section Neohygrocybe (Herink) Bon, 1989, Doc. Mycol. 19 (75): 56 (1989), type species Hygrocybe ovina (Bull.) Kühner, Botaniste 17: 43 (1926), 三 Hygrophorus ovinus (Bull. : Fr.) Fr., Anteckn. Sver. Ätl. Svamp.: 45, 47 (1836), 三Agaricus ovinus Bull., Herbier de la France 13: t. 580 (1793), [三 Hygrocybe sect. Neohygrocybe (Herink) Candusso 1997, superfluous, nom. illeg.],

Section Tristes (Bataille) Singer, Lilloa 22: 151(1951) [1949]. Lectotype designated by Singer, Lilloa 22: 151 (1951) [1949]: Hygrocybe nitrata (Pers.) Wünsche, [三 Agaricus nitratus Pers. (1801), 三Neohygrocybe nitrata (Pers.) Kovalenko (1989), [三 "Neohygrocybe nitrata” (Pers.) Herink (1959), nom. invalid. Art. 33.2]

Subgenus Humidicutis (Singer) Boertm., Fungi of Europe, 2nd ed., Vol. 1: 17 (2010), type species Hygrocybe marginata (Peck) Murrill [as 'Hydrocybe'], N. Amer. Fl. (New York) 9(6): 378 (1916), 三 Hygrophorus marginatus Peck, Ann. Rpt. N.Y. State Mus. Nat. Hist. 28: 50 (1876) 
Table 1 (continued)

Genus Gliophorus Herink, Sb. Severocesk. Mus., Prír. Vedy 1: 80 (1959), type species Gliophorus psittacinus (Schaeff. : Fr.) Herink, Sb. Severocesk. Mus., Prír. Vedy 1: 72 (1959), 三 Hygrocybe psittacina (Schaeff. : Fr.) P. Kumm., Führ. Pilzk. (Zwickau): 112 (1871), 三 Hygrophorus psittacinus (Schaeff.) Fr., Epicr. syst. mycol. (Upsaliae): 332 (1838), 三Agaricus psittacinus Schaeff. : Fr., Fung. Bavar. Palat. 4: 70, t. 301 (1774)

Section Gliophorus, [autonym] (1958), type species: Gliophorus psittacinus (Schaeff.) Herink, Sb. Severocesk. Mus., Prír. Vedy 1: 82 (1959), 三 Hygrocybe psittacina (Schaeff.) P. Kumm. (1871), $\equiv$ Hygrophorus psittacinus (Schaeff.) Fr., Epicr. syst. mycol. (Upsaliae): 332 (1838), 三Agaricus psittacinus Schaeff., Fung. Bavar. Palat. 4: 301 (1774)]. [= Gliophorus sect. 'Psittacinae"(Bataille) Herink, Sb. Severocesk. Mus., Prír. Vedy 1: 81 (1959), nom. invalid, Art. 22.2].

Section Glutinosae (Kühner) Lodge \& Padamsee, comb. nov., emend. here to exclude G. unguinosus (Fr. : Fr.) Kovalenko, Lectotype: Gliophorus laetus (Pers. : Fr.) Herink (1958) [1959], Sb. Severocesk. Mus., Prír. Vedy 1: 84, [三 Hygrocybe laeta (Pers. : Fr.) P. Kumm. (1871), $\equiv$ Hygrophorus laetus (Pers.) Fr., Epicr. syst. mycol. (Upsaliae): 328 (1838) [1836-1838], 三 Agaricus laetus Pers., Observ. Mycol. (Lipsiae) 2: 48 (1800) [1779] : Fr.]. Lectotype [H. laeta (Pers.) P. Kumm.] was inadvertently selected by Candusso, Hygrophorus. Fungi europ. (Alassio) 6: 591 (1997). Basionym: Hygrocybe sect. Glutinosae Kühner, Botaniste 17: 53 (1926). [三 Gliophorus sect. Laetae (Bataille) Kovalenko 1989, based on Hygrocybe sect. Laetae (Bataille) Singer (1949) 1951, is superfluous, nom. illeg.].

Section Unguinosae Herink, Sb. Severocesk. Mus., Prír. Vedy 1: 81 (1959), type species Agaricus unguinosus Fr. : Fr., Syst. mycol. (Lundae) 1: 101 (1821), 三 Gliophorus unguinosus (Fr.) Kovalenko, Mikol. Fitopatol. 22(3): 209 (1988), [三 “Gliophorus unguinosus” Herink, Sb. Severocesk. Mus., Prír. Vedy 1: 81 (1959), nom. invalid, Art. 41.5], 三 Hygrocybe unguinosa (Fr.: Fr.) P. Karst Bidr. Känn. Finl. Nat. Folk 32: 237 (1879), = Hygrocybe irrigata (Pers.: Fr.) Bon, Docums Mycol. 6(no. 24): 4 (1976)

Tribe Chromosereae Vizzini, Lodge Norvell \& Redhead, tribe nov., type genus Chromosera Redhead, Ammirati \& Norvell, Beih. Sydowia 10: 161 (1995), emend. Vizzini \& Ercole, Micol. Veget. Medit. 26(2): 97 (2012) [2011]

Genus Chromosera Redhead, Ammirati \& Norvell, Beih. Sydowia 10: 161 (1995), emend. Vizzini \& Ercole, Micol. Veget. Medit. 26(2): 97 (2012) [2011], type species Agaricus cyanophyllus Fr. Öfvers. Kongl. Svensk Vet.-Akad. Förh. 18(1): 23 (1861), 三 Chromosera cyanophylla (Fr.) Redhead, Ammirati \& Norvell, Mycotaxon 118: 456 (2012) [2011].

Subgenus Chromosera, [autonym], type species Agaricus cyanophyllus Fr. Öfvers. K. Svensk. Vetensk.-Akad. Förhandl. 18(1): 23 (1861), $\equiv$ Chromosera cyanophylla Redhead, Ammirati \& Norvell (2012) [2011] in Redhead, Ammirati, Norvell, Vizzini \& Contu, Mycotaxon 118: 456

Subgenus Oreocybe (Boertm.) Vizzini, Lodge \& Padamsee, comb. nov., type species: Chromosera citrinopallida (A.H. Sm. \& Hesler) Vizzini \& Ercole, Micol. Veget. Medit. 26(2): 97 (2012) [2011], 三 Gliophorus citrinopallidus (A.H. Sm. \& Hesler) Kovalenko (1999), 三Hygrocybe citrinopallida (A.H. Sm. \& Hesler) Kobayasi, Bull. natn. Sci. Mus., Tokyo 14(1): 62 (1971), 三 Cuphophyllus citrinopallidus (A.H. Sm. \& Hesler) Bon, Docums. Mycol. 21(no. 81): 56 (1991), 三 Hygrophorus citrinopallidus A.H. Sm. \& Hesler, Sydowia (1-6): 327 (1954)]. Basionym: Hygrocybe sect. Oreocybe Boertm., Nordic Jl. Bot. 10(3): 315 (1990), [三 Hygrocybe subg. Oreocybe (Boertm.) Beis., Regensburger Mykologische Schriften 10: 11 (2002)]

Subgenus Subomphalia Vizzini, Lodge \& Padamsee, subg. nov., type species: Chromosera viola (J. Geesink \& Bas) Vizzini \& Ercole, Micol. Veget. Medit. 26(2): 97 (2012) [2011], 三 Hygrocybe viola J. Geesink \& Bas, in Arnolds, Persoonia 12(4): 478 (1985a), ECuphophyllus viola (J. Geesink \& Bas) Bon, Doc. Mycol. 19(76): 73 (1989)
Subgenus Gliophorus (Herink) Heinem., Bull. Jardin bot. État. Brux.33: 452 (1963), type species Hygrocybe psittacina (Schaeff. : Fr.) P. Kumm., Führ. Pilzk. (Zwickau): 112 (1871), 三 Hygrophorus psittacinus (Schaeff.) Fr., Epicr. syst. mycol. (Upsaliae): 332 (1838), 三 Agaricus psittacinus Schaeff. : Fr., Fung. Bavar. Palat. 4: 70, t. 301 (1774)

Section Gliophorus, pro parte, combination in Hygrocybe not yet made, [ $\equiv$ Hygrocybe sect. Psittacinae (Bataille) Arnolds ex Candusso 1997, illeg., Art. 52.1]

Section Glutinosae Kühner, Botaniste 17: 53 (1926), Lectotype species inadvertently selected by Candusso 1997: Hygrocybe laeta (Pers.) P. Kumm. (1871), 三Agaricus laetus Pers. (1800) [1779], [三 Hygrocybe sect. Laetae (Battaille) Singer 1951, superfluous, nom. illeg.].

Section Gliophorus, ined, pro parte, combination in Hygrocybe not yet made

Subgenus Oreocybe (Boertm.) Beis. Regensburger Mykologische Schriften 10: 11 (2002), type species Hygrocybe citrinopallida (A.H. Sm. \& Hesler) Kobayasi, Bull. natn. Sci. Mus., Tokyo 14(1): 62 (1971), $\equiv$ Hygrophorus citrinopallidus A.H. Sm. \& Hesler (1954)

Omphalina cyanophylla (Fr.) Quél. $\equiv$ Chromosera cyanophylla (not yet combined in Hygrocybe)

Section Oreocybe Boertm., pro parte, Nordic J. Botany 10(3): 315 (1990), type species Hygrocybe citrinopallida (A.H. Sm. \& Hesler) Kobayasi, Bull. natn. Sci. Mus., Tokyo 14(1): 62 (1971), 三 Hygrophorus citrinopallidus A.H. Sm. \& Hesler, Sydowia (1-6): 327 (1954)

Section Oreocybe Boertm., 1990, pro parte, Nordic Jl. Bot. 10(3): 315, type species Agaricus cyanophyllus Fr. (1861), $\equiv$ Chromosera cyanophylla Redhead, Ammirati \& Norvell (2012) [2011] in Redhead, Ammirati, Norvell, Vizzini and Contu, Mycotaxon 118: 456 
Table 1 (continued)

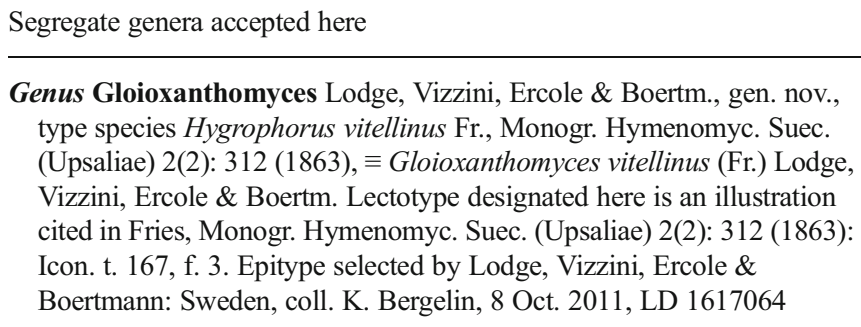

Genus Gloioxanthomyces Lodge, Vizzini, Ercole \& Boertm., gen. nov., type species Hygrophorus vitellinus Fr., Monogr. Hymenomyc. Suec. (Upsaliae) 2(2): 312 (1863), 三 Gloioxanthomyces vitellinus (Fr.) Lodge, Vizzini, Ercole \& Boertm. Lectotype designated here is an illustration cited in Fries, Monogr. Hymenomyc. Suec. (Upsaliae) 2(2): 312 (1863): Icon. t. 167, f. 3. Epitype selected by Lodge, Vizzini, Ercole \& Boertmann: Sweden, coll. K. Bergelin, 8 Oct. 2011, LD 1617064

Aggregate genus Hygrocybe s.l.

Genus Gloioxanthomyces Lodge, Vizzini, Ercole \& Boertm., [or a new subgenus or section for Hygrocybe nitida and $H$. vitellina] backbone representatives as possible. We augmented the dataset used for the backbone with additional species and specimens that had at least an LSU sequence and performed a supermatrix analysis. In addition, we present paired ITSLSU phylogenies that have greater species representation for four overlapping segments of the Hygrophoraceae. We have included more species and genera than previous analyses, though not all of the species or collections that we sequenced are presented. Our initial analyses revealed many cases where the same name has been applied to multiple, molecularly distinguishable species. We therefore sought collections from the same region as the type location to serve as reference taxa. We have retained some unknown taxa with misapplied names, however, to show the depth of the taxonomic problems that exist. We have resolved some previously known issues, while others have been raised or are in need of further work. The ITS analyses in Dentinger et al. (unpublished data) has been especially helpful in resolving species complexes and misapplied names in Hygrocybe s.l. We use this paper to establish a higher-level taxonomic framework for the Hygrophoraceae and to show where the remaining issues lie.

\section{Methods}

Species selection Lodge and Cantrell targeted several species per clade using previous unpublished preliminary analyses by Moncalvo, Vilgalys, Hughes and Matheny together with published molecular phylogenies by Moncalvo et al. (2000, 2002), Matheny et al. (2006), Lawrey et al. (2009) and Binder et al. (2010). Preference was for one basal and one distal taxon per clade and for types of genera and sections. In clades comprising difficult species complexes, we selected at least one named species known from a restricted geographic range (e.g., Hygrocybe graminicolor, Humidicutis lewellianae). The sequences that were generated in this study together with those from GenBank and UNITE are given in Online Resource 1. We generated 306 sequences for this work: 90 ITS, 109 LSU, 65 SSU and 42 RPB2. The rpb2 sequences we analyzed contain indels that caused reading frame shifts so they are not accessible in GenBank using the BLASTx protocol. The taxa for the backbone analysis were winnowed to two (rarely three) per clade based on whether all or most of the four gene regions could be sequenced, preferably from the same collection. When it was necessary to use multiple collections to obtain all the sequences, these were matched by the ITS region $(>97 \%$ similar), except for some of Kovalenko's Russian collections that were matched by LSU sequences ( $>99.5 \%$ similar in the LROR to LR7 section). Most of the names for Hygrocybe s.l. used in North America are those of species originally described from Europe/UK/Scandinavia. Many of the sequences in our initial iterations were from North American collections, but we found that they often did not match ITS sequences of European/ Scandinavian/UK collections by us, and later, published ITS sequences by Brock et al. (2009) from UK collections deposited at Kew, and Babos et al. (2011) from Hungarian collections. We therefore replaced many of our original sequences of American collections with sequences of correctly named collections from Europe/UK/Scandinavia.

DNA extraction and amplification Molecular methods generally followed either Mata et al. (2007) or Lindner and Banik (2009) with the following modifications for DNA isolation, PCR, cloning and sequencing. Small fragments of fruiting bodies, typically stipe apex or hymenial tissue, were placed in $1.5 \mathrm{~mL}$ microcentrifuge tubes with approximately $500 \mu \mathrm{L}$ filter-sterilized cell lysis solution (CLS) containing $1.4 \mathrm{M} \mathrm{NaCl}, 0.1 \mathrm{M}$ Tris-HCl, $20 \mathrm{mM}$ EDTA, and $2 \%$ hexadecyltrimethylammonium bromide (CTAB) and homogenized with plastic or glass pestles. Ground samples at the Center for Forest Mycology Research (CFMR) were stored at $-20 \mathrm{C}$ overnight. Tubes were then incubated at $65 \mathrm{C}$ for 1 or $2 \mathrm{~h}$. Following incubation the tubes were centrifuged at 16110 $\mathrm{rcf}$ for $5 \mathrm{~min}$ and the supernatants transferred to clean $1.5 \mathrm{~mL}$ microcentrifuge tubes. Five-hundred $\mu \mathrm{L}$ of $-20 \mathrm{C}$ 2-propanol (isopropanol) was added to each supernatant, tubes were inverted, incubated at $-80 \mathrm{C}$ for $15 \mathrm{~min}$ (or at $0 \mathrm{C}$ overnight by JEH at CFMR) and then centrifuged at $10621 \mathrm{rcf}$ for $20 \mathrm{~min}$ at $0 \mathrm{C}$ (or $15000 \mathrm{rcf}$ for $30 \mathrm{~min}$ at $0 \mathrm{C}$ by JEH at CFMR). Supernatants were discarded, $500 \mu \mathrm{L}$ of $75 \%$ 
Table 2 Taxonomy of Hygrophoraceae, subfamilies Hygrophoroideae and Lichenomphalioideae and the cuphophylloid grade. Taxa are organized in this table hierarchically and by the branching order in the 4-gene backbone and Supermatix analyses (Figs. 1 and 2) and the Hygrophorus ITS analysis (Online Resource 9)

Subfamily Hygrophoroideae E. Larss., Lodge, Vizzini, Norvell \& Redhead, subf. nov., type genus Hygrophorus Fr., Fl. Scan.: 339 (1836) [1835]

Tribe Chrysomphalineae Romagn., Bull. Soc., Mycol. Fr. 112(2): 135 (1996), emend. Lodge, Padamsee, Norvell, Vizzini \& Redhead, Transferred from Cantharellaceae tribe Chrysomphalineae Romagn., Doc. Mycol. 25(98-100): 135 (1996), type genus Chyrsomphalina Clémençon, Z. Mykol. 48(2): 202 (1982) [三 Cantharellaceae tribe "Paracantharelleae" Romagn., Doc. Mycol. Fr. 25(98-100): 418 (1995) nom. invalid, Art. 18.1]

Genus Chrysomphalina Clémençon, Z. Mykol. 48(2): 202 (1982), type species Chrysomphalina chrysophylla (Fr. : Fr.) Clémençon, Z. Mykol. 48(2): 203 (1982), „Agaricus chrysophyllus Fr. : Fr., Syst. mycol. (Lundae) 1: 167 (1821)

Genus Haasiella Kotl. \& Pouzar, Ceská Mykol. 20(3): 135 (1966), type species Haasiella venustissima (Fr.) Kotl. \& Pouzar ex Chiaffi \& Surault (1996), $\equiv$ Agaricus venustissimus Fr., Öfvers Kongl. Svensk Vet.-Akad, Förh. 18: 21 (1861)

Genus Aeruginospora Höhn. Sber. Akad. Wiss. Wein, Math.-naturw. Kla., Abt. 1 117: 1012 (1908), type species Aeruginospora singularis Höhn., Sber. Akad. Wiss. Wien, Math.-naturw. Kl., Abt. 1 117: 1012 (1908)

Tribe Hygrophoreae P. Henn., in A. Engler \& E.A. Prantl, Nat. Pflanzenfam. 1: 209 (1898), emend. Kühner, Bull. mens. Soc. linn. Lyon 48: 617 (1979), type genus Hygrophorus Fr., Fl. Scan.: 339 (1836) [1835]

Genus Hygrophorus Fr., Fl. Scan.: 339. (1836) [1835], type species Hygrophorus eburneus (Bull. : Fr.) Fr., Epicr. syst. mycol. (Upsaliae): 321 (1836) [1836-1838], 三Agaricus eburneus Bull., Herb. Fr. 3: tab. 118, tab. 551, fig. 2 (1783)

Subgenus Hygrophorus [autonym] (1849), Emended here by E. Larss., type species Hygrophorus eburneus (Bull.) Fr, Epicr. syst. mycol. (Upsaliae): 321 (1836) [1836-1838], 三Agaricus eburneus Bull., Herb. Fr. 3: tab. 118, tab. 551, fig. 2 (1783)

Section Hygrophorus [autonym] type species Hygrophorus eburneus (Bull.) Fr., Epicr. syst. mycol. (Upsaliae): 321 (1836) [1836-1838], 三 Agaricus eburneus Bull., Herb. Fr. 3: tab. 118, tab. 551, fig. 2 (1783)

Subsection Hygrophorus [autonym] type species Hygrophorus eburneus (Bull.) Fr., Epicr. syst. mycol. (Upsaliae): 321 (1836) [1836-1838], 三 Agaricus eburneus Bull., Herb. Fr. 3: tab. 118, tab. 551, fig. 2 (1783)

Subsection Fulventes (Fr.) E. Larss., sect. nov., type species Hygrophorus arbustivus (Fr.) Fr., Anteckn. Sver. Ätl. Svamp.: 46 (1836) [= Hygrophorus, 'Tribus' Limacium [unranked] Fulventes 1. flavi. Fries 1874, Hymen. Eur.: 408]

Section Discoidei (Bataille) Konrad \& Maubl., Icon. Sel. Fung. 6: 428 (1937), type species Hygrophorus discoideus (Pers. : Fr.) Fr., Epicr. syst. mycol. (Upsaliae): 323 (1838) [1836-1838], = Agaricus discoideus (Pers. : Fr.) : Fr., Syn. meth. fung. (Göttingen) 2: 365 (1801). Basionym: Hygrophorus [unranked] Discoidei Bataille, Mém. Soc. émul. Doubs, sér. 8 4: 162 (1910)

Section Picearum E. Larss., sect. nov., type species Hygrophorus piceae Kühner, Bull. mens. Soc. linn. Lyon 18: 179 (1949)

Subgenus Colorati (Bataille) E. Larss., stat. nov., type section Olivaceoumbrini (Bataille) Konrad \& Maubl., Icon. Sel. Fung. 6: 137 (1937). Type species Hygrophorus olivaceoalbus (Fr. : Fr.) Fr., Epicr. syst. mycol. (Upsaliae): 324 (1838) [1836-1838], 三Agaricus olivaceoalbus Fr., Observ. Mycol. (Havniae) 1: 5 (1815)], designated by Singer, Lilloa 22: 148 (1951) [1949]. Basionym Hygrophorus subg. Limacium [unranked] Colorati Bataille, Mém. Soc. Émul. Doubs, sér. 8 4: 158 (1910) [1909],

Section Olivaceoumbrini (Bataille) Konrad \& Maubl., Icon. Sel. Fung. 6: 137 (1937), type species Hygrophorus olivaceoalbus (Fr. :Fr.) Fr., Epicr. syst. mycol. (Upsaliae): 324 (1838), 三 Agaricus olivaceoalbus Fr., Observ. Mycol. (Havniae) 1: 5 (1815). Basionym: Hygrophorus [unranked] Olivaceoumbrini Bataille, Mém. Soc. émul. Doubs, sér. 8 4: 163 (1910) [三 sect. Olivaceo-umbrini (Bataille) Bon 1990, superfluous, nom. illeg. $\equiv$ sect. Colorati (Bataille) Singer (1951)[1949], superfluous, nom. illeg., Art. 52.1]

Subsection Olivaceoumbrini (Bataille) Singer, Lilloa 22: 146 (1951) [1949], type species Hygrophorus olivaceoalbus (Fr.) Fr., Epicr. syst. mycol. (Upsaliae): 324 (1838), 三.Agaricus olivaceoalbus Fr. (1815) : Fr., Observ. Mycol. (Havniae) 1: 5 (1815). Basionym: Hygrophorus [unranked] Olivaceo-umbrini Bataille, Mém. Soc. émul. Doubs, sér. 8 4: 163 (1910)

Subsection Tephroleuci (Bataille) Singer, Lilloa 22: 146 (1951) [1949], type species Hygrophorus tephroleucus (Pers.) Fr., Epicr. syst. mycol. (Upsaliae): 325 (1838), 三Agaricus tephroleucus Pers. (1801) : Fr. = Hygrophorus pustulatus (Pers.) Fr. (1838), = Agaricus pustulatus Pers. (1801) : Fr., [Bataille's name is automatically typified by the type species epithet upon which the taxon name was based, thus type NOT Hygrophorus agathosmus (Fr. : Fr.) Fr., as in Singer (1951, 1986) and Candusso (1997), Art. 22.6]. Basionym: Hygrophorus [unranked] Tephroleuci Bataille, Mém. Soc. émul. Doubs, sér. 8 4: 164 (1910)

Section Pudorini (Bataille) Konrad \& Maubl., Sel. Fung. 6: 427 (1937), type species Hygrophorus pudorinus (Fr.) Fr. Anteckn. Sver. Ätl. Svamp.: 46 (1836), 三 Agaricus pudorinus Fr., Syst. mycol. (Lundae) 1: 33 (1821), = Hygrophorus persicolor Ricek, Z. Pilzk. 40(1-2): 6 (1974). Basionym: Hygrophorus [unranked] Pudorini Bataille, Mém. Soc. émul. Doubs, sér. 8 4: 158 (1910)

Subsection Clitocyboides (Hesler \& A.H. Sm.) E. Larss., stat. nov., type species: Hygrophorus sordidus Peck, Torrey Bot. Club Bull. $25: 321$ (1898). Basionym: Hygrophorus [section Hygrophorus subsection Hygrophorus] series Clitocyboides Hesler \& A.H. Sm., North American Species of Hygrophorus: 309 (1963) [= subsect. "Pallidi" A.H. Sm. \& Hesler, Llyodia 2:32 (1939) invalid, Art. 36.1]

Subsection Pudorini (Bataille) Candusso, Hygrophorus. Fungi europ. (Alassio) 6: 72 (1997), type species Hygrophorus pudorinus (Fr.) Fr., Anteckn. Sver. Ätl. Svamp.: 46 (1836), 三Agaricus pudorinus Fr., Syst. mycol. (Lundae) 1: 33 (1821), = Hygrophorus persicolor Ricek, Z. Pilzk. 40(1-2): 6 (1974). Basionym: Hygrophorus [unranked] Pudorini Bataille, Mém. Soc. émul. Doubs, sér. 8 4: 158 (1910) [= Hygrophorus subsect. "Erubescentes" A.H. Sm. \& Hesler, Llyodia 2: 4 (1939), invalid, Art. 36.1]

Subection Salmonicolores E. Larss., subsect. nov., type species Hygrophorus abieticola Krieglsteiner ex Gröger et Bresinsky, Krieglsteiner ex Gröger et Bresinsky, Regensb. Mykol. Schr.: 15: 211 (2008) 
Table 2 (continued)

Section Aurei (Bataille) E. Larss., stat. nov., type species Hygrophorus aureus (Arrh.) Fr., Monogr. Hymenomyc. Suec. (Upsaliae) 2: 127 (1863), $\equiv$ Hygrophorus hypothejus (Fr. : Fr.) Fr., var. aureus (Arrh.) Imler, Bull. trimest. Soc. mycol. Fr. 50: 304 (1935) [1934]. Basionym Hygrophorus [unranked] Aurei, Bataille, Mém. Soc. ému. Doubs sér 8 4: 161 (1910) [1909]

Subsection Aurei (Bataille) Candusso (1997), Hygrophorus. Fungi Europaei 6: 222, type species Hygrophorus aureus Arrh. in Fr., Monogr. Hymenomyc. Suec. (Upsaliae) 2: 127 (1863), 三 Hygrophorus hypothejus (Fr. : Fr.) Fr., var. aureus (Arrh.) Imler, Bull. trimest. Soc. mycol. Fr. 50: 304 (1935) [1934], = Hygrophorus hypothejus (Fr. : Fr.) Fr., Epicr. syst. mycol. (Upsaliae): 324 (1838), 三 Agaricus hypothejus Fr., Observ. Mycol. (Havniae) 2: 10 (1818)]. Basionym Hygrophorus [unranked] Aurei, Bataille, Mém. Soc. ému. Doubs sér 8 4: 161 (1910) [1909]

Subsection Discolores E. Larss., subsect. nov., type species Hygrophorus karstenii Sacc. \& Cub., Syll. fung. (Abellini) 5: 401 (1887)

Subgenus Camarophylli (as Camarophyllus) Fr., Summa veg. Scand., Section Post. (Stockholm): 307 (1849), Emended here by E. Larss. to exclude $A$. pratensis and related species now place in Cuphophyllus, type species Agaricus camarophyllus Alb. \& Schwein.: Fr., Consp. Fung. Lusat.: 177 (1805), [Art. 22.6], 三 Hygrophorus camarophyllus (Alb. \& Schwein. : Fr.) Dumée, Grandjean \& L. Maire, Bull. Soc. mycol. Fr. 28: 292 (1912), [= Hygrophorus caprinus (Scop.) Fr. (1838), illeg., superfluous to a sanctioned name]

Section Camarophylli (as Camarophyllus) (Fr.) E. Larss., stat. nov., type species Hygrophorus camarophyllus (Alb. \& Schwein.) Dumée, Grandjean \& L. Maire. Basionym: Hygrophorus subg. Camarophylli (as Camarophyllus) Fr., Summa veg. Scand., Section Post. (Stockholm): 307 (1849)

Section Chrysodontes (Singer) E. Larss., stat. nov., type species Hygrophorus chrysodon (Batsch : Fr.) Fr., Epicr. syst. mycol. (Upsaliae): 320 (1838) [1836-1838], 三 Agaricus chrysodon Batsch, Elench. Fung., cont. sec. (Halle): 79 (1789) : Fr.. Basionym Hygrophorus sect. Hygrophorus subsect. Chrysodontes Singer (as Chrysodontini), Ann. Mycol. 3: 41 (1943)

Section Rimosi E. Larss., sect. nov., type species Hygrophorus inocybiformis A.H. Sm., Mycologia 36: 246 (1944)

Subfamily Lichenomphalioideae Lücking \& Redhead subf. nov., type genus Lichenomphalia Redhead, Lutzoni, Moncalvo \& Vilgalys Mycotaxon 83: 36 (2002)

Tribe Arrhenieae Lücking, tribe nov., type genus Arrhenia Fr., Summa. veg. Scand., Section Post. (Stockholm): 312 (1849)

Genus Acantholichen P.M. Jørg., Bryologist 101: 444 (1998), type species Acantholichen pannarioides P.M. Jørg., Bryologist 101: 444 (1998)

Genus Cora Fr., Syst. orb. veg. (Lundae) 1: 300 (1825), type species Cora pavonia (Sw.) Fr. Syst. orb. veg. (Lundae) 1: 300 (1825), $\equiv$ Thelephora pavonia Sw., Fl. Ind. Occid. 3: 1930 (1806)

Genus Dictyonema C. Agardh ex Kunth, Syn. pl. (Paris) 1: 1 (1822), type species Dictyonema excentricum C. Agardh in Kunth, Syn. pl. (Paris) 1: 1 (1822), = Dictyonema thelephora (Spreng.) Zahlbr., Cat. Lich. Univers. 7: 748 (1931) [current name], = D. sericeum (Sw.) Berk., London J. Bot. 2: 639 (1843), 三Dictyonema sericeum f. thelephora (Spreng.) Parmasto, Nova Hedwigia 29: 111 (1978) [1977]

Genus Cyphellostereum D.A. Reid, Nova Hedwigia, Beih. 18: 336 (1965), type species Cyphellostereum pusiolum (Berk. \& M.A. Curtis) D.A. Reid, Beih. Nova Hedwigia 18: 342 (1965) 三 Stereum pusiolum Berk. \& M.A. Curtis, J. Linn. Soc., Bot. 10 (no. 46): 330 (1869) [1868]

Genus Arrhenia Fr, Summa veg. Scand., Section Post. (Stockholm): 312 (1849), type species Arrhenia auriscalpium (Fr.) Fr., Summa Veg. Scand., Section Post. (Stockholm): 312 (1849), 三 Cantharellus auriscalpium Fr., Elench. Fung. (Greifswald) 1: 54 (1829), 三 Cantharellus auriscalpium Fr., Elench. fung. (Greifswald) 1: 54 (1828)]

Genus Corella Vain., Acta Soc. Fauna Flora fenn. 7(2): 243 (1890), type species Corella brasiliensis Vain., Acta Soc. Fauna Flora fenn. 7(2): 243 (1890), $\equiv$ Dictyonema pavonium f. brasiliense (Vain.) Parmasto, Nova Hedwigia 29 (1-2): 106 (1978)

Genus Eonema Redhead, Lücking \& Lawrey, Mycol. Res. 113(10): 1169 (2009), type species Eonema pyriforme (M.P. Christ.) Redhead, Lücking \&

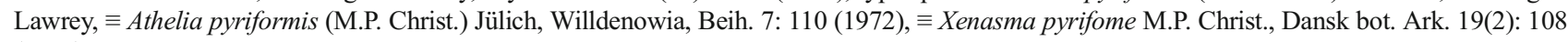
(1960)

Tribe Lichenomphalieae Lücking \& Redhead, tribe. nov., type genus Lichenomphalia Redhead, Lutzoni, Moncalvo \& Vilgalys, Mycotaxon 83: 36 (2002)

Genus Lichenomphalia Redhead, Lutzoni, Moncalvo \& Vilgalys, Mycotaxon 83: 36 (2002), type species Lichenomphalia hudsoniana (H.S. Jenn) Redhead et al., Mycotaxon 83: 38 (2002), 三 Hygrophorus hudsonianus H.S. Jenn, Mem. Carn. Mus., III 12: 2 (1936)

Subgenus Lichenomphalia [autonym], type species Lichenomphalia hudsoniana (H.S. Jenn) Redhead et al., Mycotaxon 83: 38 (2002), $\equiv$ Hygrophorus hudsonianus H.S. Jenn, Mem. Carn. Mus., III 12: 2 (1936)

Subgenus Protolichenomphalia Lücking, Redhead \& Norvell, subg. nov., type species Lichenomphalia umbellifera (L.) Redhead, Lutzoni, Moncalvo \& Vilgalys, Mycotaxon 83: 38 (2002), 三Agaricus umbelliferus L., Sp. pl. 2: 1175 (1753), sanctioned by Fr., Elench. fung. 1: 22 (1828)

Genus Semiomphalina Redhead, Can. J. Bot. 62 (5): 886 (1984), type species Semiomphalina leptoglossoides (Corner) Redhead, $\equiv$ Pseudocraterellus leptoglossoides Corner, Monogr. Cantharelloid Fungi: 161 (1966)

Tribe Cantharelluleae Lodge, Redhead \& Desjardin, tribe. nov., type genus Cantharellula Singer, Revue Mycol., Paris 1: 281 (1936)

Genus Cantharellula Singer, Revue Mycol., Paris 1: 281 (1936), type species Cantharellula umbonata (J.F. Gmel.) Singer, Revue Mycol., Paris 1: 281 (1936), 三 Merulius umbonatus J.F. Gmel., Systema Naturae, Edn. 13, 2: 1430 (1792). Basionym: Cantharellula subg. Pseudoarmillariella Singer, Mycologia 48(5): 725 (1956)

Genus Pseudoarmillariella Singer, Mycologia 48: 725 (1956), type species Pseudoarmillariella ectypoides (Peck) Singer [as $P$ 'ectyloides'], Mycologia 48(5): 725 (1956), 三Agaricus ectypoides Peck, Ann. Rep. N.Y. St. Mus. 24: 61 (1872) [1871]

Cuphophylloid grade

Genus Cuphophyllus (Donk) Bon, Doc. Mycol. 14(56): 10 (1985) [1984], type species: Cuphophyllus pratensis (Fr.) Bon Doc. Mycol. 14(56): 10 (1985)[1984], 三 Hygrocybe pratensis (Fr.) Murrill, Mycologia 6(1): 2 (1914), 三Agaricus pratensis Fr., Observ. Mycol. (Havniae) 2: 116 (1818), 
Table 2 (continued)

sanctioned by Fr., Syst. mycol. 1: 99 (1821). Basionym: Hygrocybe subg. Cuphophyllus Donk (1962), Beih. Nova Nedwigia 5: 45 (1962)

[Camarophyllus P. Kumm., (1871) is an incorrect name for this group]

Section Fornicati (Bataille) Vizzini \& Lodge, comb. nov., type species: Hygrophorus fornicatus Fr., Epicr. syst. mycol. (Upsaliae): 327 (1838), 三 Cuphophyllus fornicatus (Fr.) Lodge, Padamsee \& Vizzini, comb. nov. Basionym: Hygrophorus Fr. [subg. Camarophyllus Fr.] [unranked] Fornicati Bataille, Mém. Soc. émul. Doubs. ser. 8 4: 170 (1909) [1910], 三 Hygrocybe [subg. Neohygrocybe (Herink) Bon (1989)] sect. Fornicatae (Bataille) Bon, Doc. Mycol 14 (75): 56 (1989), 三 Dermolomopsis Vizzini, Micol. Veget. Medit. 26(2): 100 (2012) [2011]

Section Adonidum (Singer) Lodge \& M.E. Sm., comb. nov., type species Camarophyllus adonis Singer, Sydowia 6(1-4): 172 (1952), 三 Cuphophyllus adonis (Singer) Lodge \& M.E. Sm., comb. nov. Basionym Camarophyllus sect. Adonidum (as Adonidi) Singer, Sydowia Beih. 7: 2 (1973)

Section Cuphophyllus [autonym], type species Cuphophyllus pratensis (Fr.) Bon, Doc. Mycol. 14(56): 10 (1985)[1984], 三 Hygrocybe pratensis (Fr.) Murrill, Mycologia 6(1): 2 (1914), 三 Agaricus pratensis Fr., Observ. mycol. (Havniae) 2: 116 (1818), sanctioned by Fr., Syst. mycol. 1: 99 (1821)

Section Virginei (Bataille) Kovalenko, in Nezdoiminogo, Opredelitel Gribov SSSR (Leningrad): 37 (1989), type species Cuphophyllus virgineus (Wulfen : Fr.) Kovalenko (1989), 三 Hygrocybe virginea P.D. Orton \& Watling, Notes R. bot. Gdn Edinb. 29(1): 132 (1969), 三 Agaricus virgineus Wulfen, in Jacquin, Miscell. austriac. 2: 104 (1781), sanctioned by Fr., Syst. mycol. 1: 100 (1821)

Genus Ampulloclitocybe Redhead, Lutzoni, Moncalvo \& Vilgalys, Mycotaxon 83: 36 (2002), type species Ampulloclitocybe clavipes (Pers.) Redhead,

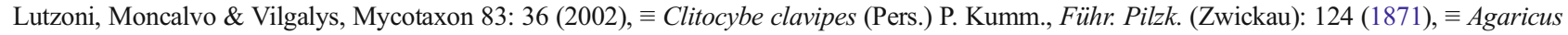
clavipes Pers., Syn. meth. fung. (Göttingen) 2: 353 (1801), [三 Clavicybe clavipes (Pers.) Harmaja, Karstenia 42(2): 42 (2002), nom. illeg., Art. 52.1]

Genus Cantharocybe H.E. Bigelow \& A.H. Sm., Mycologia 65(2): 486 (1973), emend. Ovrebo, Lodge \& Aime, Mycologia 103(5): 1103 (2011), type species Cantharocybe gruberi (A.H. Sm.) H.E. Bigelow, Mycologia 65: 486 (1973), 三 Clitocybe gruberi A.H. Sm., Mycologia 36(3): 245 (1944)

ethanol (v/v) was added and tubes were centrifuged at 16110 rcf for $5 \mathrm{~min}$ at room temperature. Supernatants were removed, pellets air dried at room temperature for $10 \mathrm{~min}$ and pellets resuspended in $50 \mu \mathrm{L}$ sterile water.

DNA in aqueous solution was then cleaned at CFMR using GeneClean III kits (Qbiogene) following the manufacturer's protocol with the following modifications. Fifty $\mu \mathrm{L}$ of aqueous DNA solution was combined with $150 \mu \mathrm{L}$ of NaI solution and $5 \mu \mathrm{L}$ of glassmilk provided with kit. Tubes were agitated followed by centrifugation at $16110 \mathrm{rcf}$ for $8 \mathrm{~s}$. The supernatant was discarded and the pellet washed three times using $1 \mathrm{~mL}$ of New Wash solution provided with the kit. After removal of New Wash, pellets were air-dried for $15 \mathrm{~min}$ and template DNA eluted in $50 \mu \mathrm{L}$ of water. DNA was extracted at the University of Tennessee in Knoxville (UTK) using the chloroform method as described in Mata et al. (2007), so further cleaning was not needed.

PCR amplification of the ribosomal ITS1-5.8S-ITS2 region was carried out with primers ITS1F (Gardes and Bruns 1993) and ITS4 (White et al. 1990). PCR of the ribosomal large subunit 3' end was carried out with primers LR7 (Moncalvo et al. 2000) and LROR or rarely LR3R (CFMR) or ITS3 (UTK \& CFMR) (White et al. 1990). Amplification of the nuclear ribosomal small subunit (SSU) at CFMR was carried out using primer sets NS1 and NS2, NS3 and NS4, NS5 and NS8 or ITS2. Primers used for PCR of the most variable region of the nuclear ribosomal $\mathrm{rpb} 2$ gene between domains 6 and 7 were rpb2-b6F and rpb2-b7.1R (Matheny 2005). PCR was performed using $1 \times$ Green GoTaq reaction buffer or GoTaq DNA polymerase (Promega, Madison, Wisconsin) and 0.025 units of GoTaq DNA polymerase were added per $\mu \mathrm{L}$ of reaction volume. Each primer had a final concentration of $0.2 \mu \mathrm{M}$ and each dNTP (Promega, Madison, Wisconsin) had a final concentration of $200 \mu \mathrm{M}$. Template DNA was typically diluted 1:50 in the final reaction volume. Thermocycler conditions for ITS and LSU primers were as follows: initial denaturing at $94 \mathrm{C}$ for $3 \mathrm{~min}$; 30 cycles of denaturing at $94 \mathrm{C}$ for $1 \mathrm{~min}$, annealing at 53 or $50 \mathrm{C}$ for $40 \mathrm{~s}$, and extension at $72 \mathrm{C}$ for $1.5 \mathrm{~min}$; and a final extension step of $72 \mathrm{C}$ for $10 \mathrm{~min}$. For SSU, annealing was changed to $53 \mathrm{C}$ for $2 \mathrm{~min}$ with a 2 min extension time. Samples with poor amplification were rerun using a touchdown program with annealing temperatures ranging from $63 \mathrm{C}$ down to $45 \mathrm{C}$. Thermocycler conditions for RPB2 primers followed the less stringent, stepped protocol of Matheny (2005).

Following amplification $3 \mu \mathrm{L}$ of product was run on a $1.5 \%$ or $1.8 \%$ agarose gel stained with ethidium bromide to verify the presence of amplification products. In preparation for sequencing, amplification products were treated with Exonuclease I (EXO) and Shrimp Alkaline Phosphatase (SAP) (USB Corporation, Cleveland, Ohio) as follows: for $15 \mu \mathrm{L}$ PCR reactions, a solution containing $3.12 \mu \mathrm{L}$ water, $0.80 \mu \mathrm{L} \mathrm{SAP}$ and $0.08 \mu \mathrm{L}$ EXO was added to each reaction; the reactions with EXO/SAP were heated to $37 \mathrm{C}$ for $15 \mathrm{~min}$ and then heated to $80 \mathrm{C}$ for $20 \mathrm{~min}$.; after cooling, $35 \mu \mathrm{L}$ of water was added to each reaction.

Sequencing reactions were performed following the BigDye terminator protocol (ABI Prism) with the following sequencing primers: ITS1F, ITS2, ITS3, ITS4, and ITS5 (White et al. 1990; ITS primers); LR5, LR3R, and LROR (Moncalvo et al. 2000; LSU primers); the same NS primer sets that were used for PCR of the SSU (SSU primers); rpb2-b6F and rpb2-b7.1R, rpb2 primers. Sequencing products were cleaned using CleanSeq (Agencourt) magnetic beads following the manufacturer's protocol. Sequencing products were analyzed at the University of Wisconsin Biotech Center and final sequences were aligned using Sequencher 4.2 (GeneCodes Corporation). 
Cloning Cloning of ITS PCR products at CFMR and UTK was accomplished using pGEM-T Vector System II kits and JM109 competent cells from Promega (Madison, Wisconsin) following manufacturer's instructions when direct sequencing did not resolve a sequence. To amplify cloned regions from bacterial colonies at CFMR, a PCR reaction was prepared as previously described with the exception that template DNA was added by placing a small amount of a transformed bacterial colony into the reaction using a sterile $200 \mu \mathrm{L}$ pipette tip. To amplify cloned regions at UTK, the bacterial colony was transferred to water, boiled, followed by PCR; PCR was repeated on dilutions of boiled DNA if no product was obtained. Thermocycler conditions were as follows: initial denaturing at $94 \mathrm{C}$ for $10 \mathrm{~min}$; 30 cycles of denaturing at $94 \mathrm{C}$ for $40 \mathrm{~s}$, annealing at $53 \mathrm{C}$ for $40 \mathrm{~s}$, and extension at $72 \mathrm{C}$ for $90 \mathrm{~s}$; and a final extension step of $72 \mathrm{C}$ for $10 \mathrm{~min}$. Following PCR the reactions were checked for product, treated with EXO/SAP and sequenced as previously described. Five clones per collection were sequenced.

Consensus sequences Consensus sequences were produced using multiple sequences in Sequencher 4.8. Self-chimeric LSU sequences (containing out-of-sequence partial forward and back reads) were used to correct bp in the full sequences by segmenting them at splices and aligning them to reference sequences together with full sequences.

Phylogenetic analyses Three sets of alignments were constructed from the resulting sequences. The first set consisted of the nuclear ribosomal large subunit (LSU, 25S, D1, D2 and D3), and PhyML analysis rooted with Typhula phacorrhiza. The second set comprised four partially overlapping data sets from the Hygrophoraceae constructed from the nuclear ribosomal internal transcribed spacer (ITS) region (ITS 1-2 and 5.8S) together with the LSU and an outgroup based on phylogenies in Binder et al. (2010), Matheny et al. (2006) and the LSU analysis above; each data set was aligned separately to minimize loss of data from the ITS, and ML analysis was used. Outgroups were Hygroaster albellus for Group 1 (Hygrocybe s.s.); Hygrophorus eburneus for Group 2 (Neohygrocybe, Porpolomopsis, Gliophorus, Gloioxanthomyces, Haasiella, Humidicutis, Chromosera and Chrysomphalina); Neohygrocybe ingrata for Group 3 (Hygrophorus ss, Neohygrocybe, Chromosera, Chrysomphalina, Arrhenia, Dictyonema, Lichenomphalia and Pseudoarmillariella); Macrotyphula fistulosa for Group 4 (Ampullocliticybe, Cantharocybe and Cuphophyllus). Sequences were initially aligned using the default settings in MAFFT version 6 (Katoh and Toh 2008) and then manually aligned using SeAl version 2.0a11 (Rambaut 2002). Ambiguously aligned positions and sequence ends were pruned from the datasets before running maximum likelihood (ML) analyses in GARLI v0.951 (Zwickl 2006) using a general time reversible model of nucleotide substitution with a gamma distributed rate heterogeneity and a proportion of invariant sites $(\mathrm{GTR}+\mathrm{G} \gamma+\mathrm{I})$. ML searches were repeated three times for each dataset. GARLI was used to generate 100 ML nonparametric bootstrap replicates (MLBP) with the generation threshold halved to 5,000 as suggested by the program; the replicates were used to calculate a majority rule consensus tree in PAUP* 4.0b10 (Swofford 2002) to assess clade support.

The third set, henceforth referred to as the 4-gene backbone analysis, consisted of four loci including the nuclear ribosomal gene regions $(5.8 \mathrm{~S}, 18 \mathrm{~S}$, and $25 \mathrm{~S})$ and the RNA polymerase II $(\mathrm{rpb} 2)$ region between conserved domains 5 and 7. Positions deemed ambiguous in alignment were pruned from the nexus file before conversion to Phylip format using SeaView 4.2.4 (Gouy et al. 2010). Nexus and Phylip files of the four-gene region data set can be obtained from http://www.bio.utk.edu/ matheny/Site/Alignments_\%26_Data_Sets.html. In the final concatenated alignment, rRNA gene regions occupied positions 1-2854; the rpb2 region comprised positions 2855-3995. The four-gene region data set was analyzed using maximum likelihood (ML) in RAxML 7.0.3 (Stamatakis 2006a) with rapid bootstrapping (Stamatakis et al. 2008) and by Bayesian inference using the parallel version of MrBayes 3.1.2 (Altekar et al. 2004; Huelsenbeck and Ronquist 2001; Ronquist and Huelsenbeck 2003) on the Newton cluster at the University of Tennessee. For both ML and Bayesian analyses, the rRNA gene regions were treated as a single partition following Aime et al. (2006; see Appendix I). First, second, and third codon partitions of $r p b 2$ were partitioned separately. Thus, four partitions were assigned and modeled separately. One thousand rapid bootstraps and a thorough ML search were conducted in RAxML using four distinct models/ partitions with joint branch length optimization. All free model parameters were estimated by RAxML and incorporated a GAMMA+P-Invar model of rate heterogeneity, a GTR substitution rate matrix, and empirical base frequencies for the final ML search. Rapid bootstrapping was done using a GTRCAT model (Stamatakis 2006b). Bayesian inference was performed using a mixed models analysis run in parallel for up to 50 million generations. Four chains were run with trees sampled every 5,000 steps with the heating temperature set to 0.1. Convergence diagnostic features were used to guide burn-in choice. All analyses were rooted with Plicaturopsis crispa (Amylocorticiales; Binder et al. 2010).

The fourth data set used a Supermatrix with 1,000 bootstrap replicates (SMBS) to analyze a more comprehensive data set comprising multiple representatives of taxa from various geographic regions, and utilizing all the available ITS, LSU, SSU and RPB2 sequences except those with only ITS sequences. All sequences were from single collections. The four gene partitions used were: rRNA 1-3164, rpb2 1st 
codon pos 3165-3915/3, rpb2 2nd codon pos 3166-3915/3, rpb2 3rd codon pos 3167-3915/3. In the rRNA partition, SSU comprised pos 1-1754, 5.8S 1755-1956, LSU 1957-3164. A GTRGAMMA model was assigned to each partition. This analysis was restricted to the hygrophoroid clade as delineated by the 4-gene $\mathrm{ML}$ analysis above. Trees were rooted with Cantharocybe based on the 4-gene backbone analysis above. The data set was divided into four parts and examined to ensure a minimum representation of each gene region in each part of the tree to prevent skewing: 59-95\% for ITS, 91-98\% for LSU, 32-83\% SSU, and 29-54 \% RPB2 except for the Hygrophorus-Chromosera group with $15 \%$ rpb2.

Specimens examined and drawings All of the cited types, specimens sequenced, and the specimens illustrated by drawings were examined by DJ Lodge with the exceptions noted below. Aeruginospora singularis had a type study by E Horak (FH). Types and collections of Hygrophorus spp. s.s. were examined by E Larsson, except A Kovalenko examined those from Russia and DJ Lodge examined those from Belize, the Dominican Republic and Japan. Types and collections sequenced in subf. Lichenomphalioideae were examined by $\mathrm{R}$ Lücking, SA Redhead and LL Norvell, except for Lichenomphalia hudsoniana and L. umbellifera which were collected and examined by $\mathrm{J} \mathrm{Geml}$, and Cantharellula umbonata and C. humicola which were examined by DE Desjardin and DJ Lodge. T Læssøe collected and examined Chromosera and Haasiella from Russia and Danish collections of Chrysomphalina and Pseudoomphalina. G Griffith examined collections from Wales. Collections at Kew were matched to reference ITS sequences, and M Ainsworth (B Dentinger et al., unpublished) re-determined them with microscopy. D Boertmann examined some collections from Hungary, but they are not deposited in recognized fungaria. Drawings of hand cut sections were made by DJ Lodge with the aid of an Olympus microscope and drawing tube.

Locations where collections that were sequenced are deposited are given in Online Resource 1. Collection numbers for drawings are given in the figure captions; these collections are deposited at CFMR, except for Aeruginospora singularis (BO); Cantharellula umbonata and C. humicola (SFSU); Hygrocybe appalachianensis (DMWV); Humidicutis pura (K); Ampulloclitocybe clavipes, Cuphophyllus acutoides var. pallidus, C. aff. pratensis, Gloioxanthomyces vitellinus, Humidicutis auratocephalus and Pseudoarmillariella ectypoides (TENN).

\section{Results and discussion}

Ecology The Hygrophoraceae is known to comprise genera with different nutritional strategies, including known biotrophic associations with ectomycorrhizal plants, algae, cyanobacteria and mosses (Lawrey et al. 2009; Seitzman et al. 2011; Tedersoo et al. 2010). The remaining genera in Hygrophoraceae were putatively regarded as saprotrophic, but recent data derived from stable isotope ratios are at variance with that assumption (Griffith et al. 2002; Griffith 2004; Seitzman et al. 2011). Knowledge about nutritional strategies is important for conservation of species of Hygrophoraceae, and many species are reported as threatened in Europe and Australia (Boertmann 2010; Gärdenfors 2010; Griffith 2004; Griffith et al. 2002, 2004; Kearney and Kearney 2000; Young 2005). Furthermore, nutritional strategies are moderately conserved within lineages in Hygrophoraceae (Seitzman et al. 2011), and are more likely to be adaptive than many morphological features used in agaric systematics. Ecology may therefore provide informative synapomorphic characters if new nutritional strategies were the foundation of adaptive radiations. Hence, we summarize results of studies on the ecology of genera in Hygrophoraceae below, with emphasis on nutritional strategies.

Hygrophorus s.s. represents an independent evolutionary acquisition of the ectomycorrhizal lifestyle in basidiomycete fungi (Tedersoo et al. 2010), though recent micromorphological evidence indicates the relationship in $H$. olivaceoalbus may be parasitic rather than mutualistic (Agerer 2012). Individual species of Hygrophorus s.s. are considered host specialists but this has only been definitively shown for a handful of species (Jacobsson and Larsson 2007; Larsson and Jacobsson 2004; Molina et al. 1992). Thus they represent an adaptive radiation within Hygrophoraceae. Species of Hygrophorus s.s. fruit primarily in undisturbed forest habitats dominated by ectomycorrhizal (ECM) plants (Visser 1995; Singer 1949). While the genus has long been considered symbiotic with roots (e.g. Frank 1888; Noack 1889), Kropp and Trappe (1982) provided definitive proof when they synthesized ECM of Hygrophorus purpurascens in pure culture with Tsuga heterophylla. More recently, molecular methods have confirmed the presence of Hygrophorus species on the roots of both angiosperms and gymnosperms from a variety of habitats in the Northern Hemisphere (see Online Resource 2). According to Hobbie and Agerer (2010), species of Hygrophorus s.s. form "contact", "short", or "mediumsmooth" exploration-type ECM that are hydrophilic and lack rhizomorphs. The restricted soil volume exploited by Hygrophorus ectomycorrhizae may explain why some species are considered "nitrophilic" and respond positively to high nitrogen inputs (Lilleskov et al. 2001, 2002; Vineis et al. 2010) and why some respond negatively to liming (Kjøller and Clemmensen 2009; Pena et al. 2010). In addition to limitations of potential benefits to the host from Hygrophorus mycorrhizae due to limited soil exploration by the fungus, Agerer (2012) showed that the intracellular development of H. olivaceoalbus in Picea roots was characteristic 
of a parasitic infection. Proliferation of $H$. olivaceoalbus in defensive tannin droplets within host cells was also consistent with the high activity of phenoloxidase (Agerer et al. 2000) and laccase (Agerer 2012) in that species. Further evidence for parasitic rather than mutualistic association comes from the low isotopic $\partial^{15} \mathrm{~N}$ of $H$. olivaceoalbus basidiomes $(-3.6-0.1 \%$ in Taylor et al. 2003; $2.7 \pm 3.5 \%$ in Trudell et al. 2004), which is generally below the range of $\partial^{15} \mathrm{~N}$ found in typical ectomycorrhizal fungal basidiomes (3$18 \% \partial^{15} \mathrm{~N}$, Taylor et al. 2003; Trudell et al. 2004; Agerer et al. 2012; Seitzman et al. 2011). While such low $\partial^{15} \mathrm{~N}$ signatures might indicate saprobic growth in litter low in ${ }^{15} \mathrm{~N}$ (Hobbie et al. 1999; Zeller et al. 2007), Agerer (2012) argued that partial digestion of host-derived nitrogen during intracellular growth was a more likely source given the limited extraradical growth of $H$. olivaceoalbus.

Hygrophorus s.s. species are mostly restricted to the temperate regions of the world and the highest species diversity is in the Northern Hemisphere (Arora 1986; Tedersoo et al. 2010; Singer 1949). A few species of Hygrophorus s.s. are present in Australia and in the montane Quercus forests of Central America and Columbia (Halling and Mueller 2005; Young and Wood 1997), but they are largely absent from ECM forests in lowland tropical habitats. An exception is represented by an uncultured clone from Pisonia grandis (Nyctaginaceae) roots in the Seychelles (FN296256, Online Resources 2). That most species occur at high latitude or altitude is consistent with the habit of Hygrophorus s.s. to fruit preferentially during the coldest parts of the mushroom season (Cooke 1891). In Europe, Hygrophorus forms ectomycorrhiza with trees in the Fagaceae, Corylaceae, Betulaceae, Cistaceae, Tiliaceae and Pinaceae. Many species show strong host specificity and also associations with certain environmental conditions such as nutrient rich soil on calcareous ground (e.g. $H$. chrysodon and $H$. poetarum), nutrient poor Pinus forests $(H$. calophyllus) or Picea forest on calcareous ground ( $H$. discoideus) (Larsson, unpublished data). Eighteen of the ca. 40 Hygrophorus species in the Nordic countries (Kovalenko 2012; Larsson et al. 2011) are rare and declining and are listed as threatened in the Red List of Swedish species (Gärdenfors 2010, www.artdata.slu.se/rodlista). The reason for this decline is unclear but may be caused by acidification or eutrophication of forest soils resulting from nitrogen inputs in air pollution.

Members of the genus Hygrocybe s.l. (Hygrocybe, Neohygrocybe, Gliophorus, Porpolomopsis) and Cuphophyllus fall into distinct clades but occur together and are therefore often treated as a group for conservation purposes (e.g., Boertmann 2010). The ecology of this group is enigmatic as they are generally found in contrasting habitats in Europe versus the Americas and elsewhere. In northern Europe, Greenland and Newfoundland, these species are associated with nutrient-poor grasslands where they are often the dominant macrofungal component (based on basidiocarp abundance), whereas in most other parts of the world the same or sister species are usually less abundant and found in forests from the tropics to the boreal zone. Additionally a few species are associated with tundra habitats or are found in bryophyte dominated bogs.

Historically, species in genera of the Hygrophoraceae that are not known to be ectomycorrhizal or moss or lichen symbionts s.l. have been considered as saprotrophs (Keizer 1993) based on the absence of consistent associations with known ectomycorrhizal host plants and the failure to find obvious mycorrhizal structures. However, other features of their biology such as absence or very limited basidiospore germination under a range of conditions (Griffith, unpub. data) and stable carbon and nitrogen isotope ratios unlike those of known saprotrophs (Griffith et al. 2002, 2004; Trudell et al. 2004; Seitzman et al. 2011) suggest more complex nutrient requirements. There are only two confirmed examples of successful axenic culture of species in this group (confirmed by ITS sequencing), namely G. laetus (L Deacon, 2003, pers. comm. to Griffith in Roderick 2009) and C. virgineus (Roderick 2009), though cultures of the latter are listed in the CBS culture collection, and Griffith retains a subculture.

Other aspects of the biology of Hygrocybe spp. also exhibit patterns similar to those found in ectomycorrhizal basidiomycetes, for instance their sensitivity to inorganic forms of nitrogen, and hence their occurrence in nitrogen poor habitats (Seitzman et al. 2011). Their current rarity in most European grasslands is attributed to the widespread application of inorganic fertilizers (Griffith et al. 2002, 2004). Furthermore, examination of the carbon and nitrogen isotopic patterns of these fungi suggests that they are not saprotrophic as all species examined so far exhibited highly elevated $\partial 15 \mathrm{~N}$ and low 213C signatures in both European grasslands (Griffith 2002 and unpublished data) and North American woodland habitats (Seitzman et al. 2011). The depletion in ${ }^{13} \mathrm{C}$ has not been fully explained, but Seitzman et al. (2011) postulated that some genera of Hygrophoraceae with unknown nutritional strategies may derive part of their carbon from mosses, algae or cyanobacteria as mutualists, parasites, necrotrophs or perhaps as saprotrophs. Seitzman et al. (2011) found a similar degree of ${ }^{13} \mathrm{C}$ in a collection of Galerina sp. resembling G. paludosum - a species previously shown to be biotrophic on sphagnum moss (Redhead 1981). Furthermore, species of Hygrocybe s.l. and Cuphophyllus often occur with mosses in both European grasslands and North American woodlands (Boertmann 2010; Seitzman et al. 2011). Persoh (2013) recovered sequences of Hygrocybe coccinea from leaves, suggesting it may be an endophyte.

The abundance of Hygrocybe and Cuphophyllus spp. in European grasslands in contrast to their woodland distribution elsewhere may be a legacy of the post-glacial history of these habitats. Bakker et al. (2004) dispute the dogma that deforestation and the prehistoric balance between woodlands and grasslands was the result of human influence. They make a 
convincing case that fluctuations in numbers of large mammalian herbivores (not necessarily the result of human livestock management) have led to a vegetation cycle as follows: grassland - thorny scrub - woodland establishment - closed canopy woodland - parkland - grassland. If one considers European grasslands as (temporarily) treeless woodlands, then it may be the ability of these Hygrocybe and Cuphophyllus spp. to survive these cyclical changes in vegetation (in contrast to other macrofungi requiring the presence of live woody hosts or dead woody resources), which explains their present abundance in these habitats. Alternatively, it could be argued that Hygrocybe s.l. and Cuphophyllus spp. are more tolerant of the harsher climatic conditions of grassland habitats (large diurnal/seasonal fluctuations in temperature and humidity) from which even soil organisms are only partially insulated. This latter factor may explain why these species are often latefruiting in European grasslands, a feature also found in Hygrophorus spp. Young (2005) suggested that shady forests and dense thickets in Australia may provide a humid microclimate close to the ground.

Despite stable isotope ratios that suggest that most Hygrophoraceae are biotrophic, a search of GenBank using BLAST searches of ITS sequences from two species per clade found mainly Hygrophorus s.s. sequences from root tips (Online Resource 2). A sequence of an unknown species was obtained from an unidentified bryophyte (GenBank AM999704, Kauserud et al. 2008) and similar ITS sequences were obtained from live Deschampsia grass roots (Poaceae) in the boreal zone (GenBank FJ517589-FJ517592, Tejesvi et al. 2010, Online Resource 2). These root and moss associated sequences cluster near Chromosera in our ITS analysis (Online Resource 3), but support is low for placement in tribe Chromosereae (20\% MLBS in our analysis, Online Resource 3; $33 \%$ MLBS in the analysis by Ercole, pers. com., 16 Nov. 2012). The ecology of the moss-grass root clade is more consistent with tribe Lichenomphaleae, and it might eventually be placed there once more gene regions have been sequenced and analyzed. BLAST Searches of GenBank (November 2012) using ITS sequences of two species per clade revealed many Cuphophyllus and Hygrocybe sequences from soil or litter but not roots, which suggests they are neither mycorrhizal nor endophytic, though Persoh (2013) and Tello et al. (2013) has since presented evidence of Hygrocybe and Cuphophyllus as endophytes. A study of fungi in the rhizosphere of Picea glauca in Canada by Lamarche, Seguin and Hamelin (unpublished, study described in Lamarche and Hamelin 2007, fungal sequences deposited in Genbank 2008), showed 5 clones of Hygrocybe cf. splendidissima (EU690689 and others), 26 clones of $H$. aff. punicea (GenBank EU690689 and others), 33 clones of $H$. chlorophana (EU690793 and others), $>23$ clones in the $H$. ceracea-H. insipida clade (EU690866 and others), and 39 clones of $H$. reidii (EU690490 and others). Little is known regarding transfer of plant compounds to rhizosphere fungi, though the fungal-specific Mrt gene in Metarrhizium robertsii was shown to function in transport of sucrose and raffinose-related oligosaccharides from root exudates (Fang and St. Leger 2010).

Species of Chrysomphalina were assumed to be saprotrophic because they grow on wood and are associated with white rot (Norvell et al. 1994). Lignicolous fungi, however, have various nutritional strategies (Huhndorf et al. 2004). Stable isotope analyses would be useful in determining whether the ratios in Chrysomphalina match those of wood decomposers or biotrophic fungi. The clade comprising Cantharellula umbonata and Pseudoarmillariella ectypoides is sister to the Lichenomphalia-Dictyonema clade (but without BS support) in our 4-gene backbone and Supermatrix analyses (Figs. 1 and 2). While the trophic nature of P. ectypoides is unknown, C. umbonata is associated with mosses (Lawrey et al. 2009).

At least two lichenized lineages appear within Hygrophoraceae, if Lichenomphalia including L. umbellifera is considered monophyletic (Lawrey et al. 2009). Lichenomphalia forms omphalinoid fruiting bodies associated with green, eukaryotic photobionts, whereas the Dictyonema s.l. clade (including Cyphellostereum, Acantholichen, Corella and Cora) features cyphelloid or corticioid basidiocarps and invariably associates with a novel cyanobacterial lineage, Rhizonema (Lawrey et al. 2009; Lücking et al. 2009). Both lineages are primarily tropical montane to temperate and often co-occur over soil and between bryophytes on the ground. Seitzman et al. (2011) suggested that biotrophic relationships appear throughout Hygrophoraceae and that nutritional strategies were moderately conserved within lineages. The well documented ectomycorrhizal genus Hygrophorus and the lichen and moss symbionts in the genera Lichenomphalia, Dictyonema, Cora, Corella, Cyphellostereum, Eonema and Acantholichen (Lawrey et al. 2009) fall between Cuphophyllus at the base of the Hygrophoraceae and Hygrocybe, Gliophorus and Neohygrocybe in more distal branches of our 4-gene phylogenetic tree (Fig. 1). Categorization of genera by combined nitrogen and carbon isotope ratios in Seitzman et al. (2011) was partly concordant with the molecular phylogeny, pairing Hygrocybe with Gliophorus, while leaving Cuphophyllus, Hygrophorus and Humidicutis in separate groups. Seitzman et al. (2011, Fig. 4) found that some Cuphophyllus and Humidicutis species were unlike ectomycorrhizal and

Fig. 1 Four-gene backbone analysis of Hygrophoraceae, representatives of the Hygrophoroid clade (Phyllotopsis, Pleurocybella, Macrotyphula, Tricholomopsis, Typhula and Sarcomyxa), and representatives of outgroups from the Entolomataceae, Marasmiaceae, Mycenaceae, Pleurotaceae and Tricholomataceae ss, rooted with Plicaturopsis crispa. Genes analyzed were ITS (ITS1, 5.8S \& ITS2), LSU (LROR-LR5), SSU and RPB2 (between domains 6 and 7). ML bootstrap values $\geq 50 \%$ appear above the branches. Heavily bolded branches have $\geq 70 \%$ and lightly bolded branches have 50-69\% ML bootstrap support 


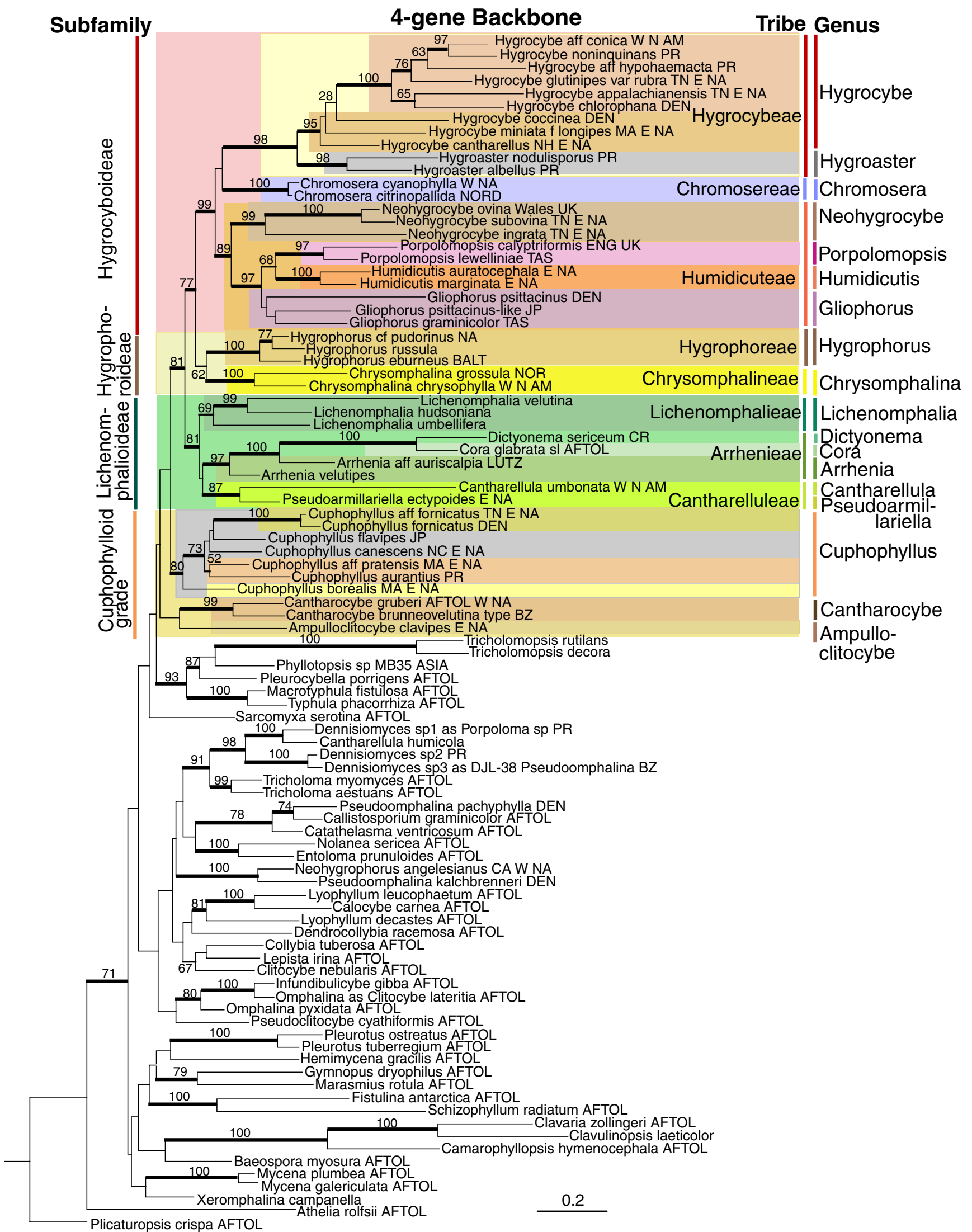


saprotrophic species while others were unclassified based on their $\partial^{15} \mathrm{~N}$ signatures, and all Cuphophyllus and Humidicutis species were unlike ectomycorrhizal and saprotrophic species based on their $\partial^{13} \mathrm{C}$ signatures. Gliophorus laetus, Lichenomphalia, Dictyonema and all Hygrocybe species resembled ectomycorrhizal, but not saprotrophic species based on their $\partial^{15} \mathrm{~N}$, but neither ectomycorrhizal nor saprotrophic species based on their $\partial^{13}$ C (Fig. 4 vs 3 in Seitzman et al. 2011). Although ectomycorrhizal associations have evolved independently many times in the Basidiomycota (Hibbett et al. 2000) including at least 11 independent origins in the Agaricales (Matheny et al. 2006), they arose only once in the Hygrophoraceae in the monophyletic genus Hygrophorus (Moncalvo et al. 2002; Seitzman et al. 2011, our data). These data support the finding of moderate conservation of nutritional strategies in Hygrophoraceae by Seitzman et al. (2011) though the nutritional mode of many genera remains enigmatic.

Pigments and other taxonomically informative metabolites The basidiocarp pigments of members of the Hygrophoraceae are among the most diverse and striking in fungi. While the adaptive significance of many of these pigments is uncertain, their utility in chemotaxonomy has long been recognized. For example, Singer (1958) noted the contrasting effects of $10 \%$ $\mathrm{KOH}$ on the yellow-orange pigments of Hygrocybe flavescens and Humidicutis marginata, Cibula (1976) and Bresinsky and Kronawitter (1986) found pigment chemistry distinguished major groups in Hygrophoraceae, while Bresinsky (2008) described the genus Porpolomopsis based on pigment chemistry. Furthermore, Redhead et al. (2002) used metabolites with other characters in describing Ampulloclitocybe, and Norvell et al. (1994) suggested a close relationship between Haasiella and Chrysomphalina based on shared carotenoid pigments (Arpin and Fiasson 1971) and pachypodial hymenium construction - a relationship supported by our analyses (Online Resource 3). Though carotenoids are widespread in fungi, notably the Cantharellales (Mui et al. 1998), they are infrequent in Hygrophoraceae where instead the yellow-red pigments are mostly tyrosine-derived betalains (Online Resource 4).

Betalain pigments are found elsewhere only among higher plants in the Caryophyllales (except those containing anthocyanins) and a few Amanita spp. (A. muscaria, A. caesaria and A. phalloides, Grotewold 2006). In plants, tyrosinasemediated hydroxylation of tyrosine to form DOPA by the action of tyrosinase, extradiol ring cleavage catalyzed by a DOPA-dioxygenase leads to the formation of 4,5-seco-DOPA (Online Resource 5). Spontaneous recyclization leads to the formation of betalamic acid (6-membered heterocyclic ring) (Online Resource 5). Conjugation of betalamic acid with either cycloDOPA (formed via the oxidation of DOPA by tyrosinase) to form betanidin or with various amino acids/amines leads to
Fig. 2 Supermatrix Maximum Likelihood analysis of Hygrophoraceae ss. All taxa with LSU sequences were included; ITS (ITS1, 5.8S \& ITS2), LSU (LROR-LR5), SSU and RPB2 (between domains 6 and 7) were also included, if available. ML bootstrap values $\geq 50 \%$ appear above the branches. Heavily bolded branches have $\geq 70 \%$ and lightly bolded branches have 50-69\% ML bootstrap support

the formation respectively of diverse violet (betacyanin) or yellow (betaxanthine) pigments.

The major yellow water soluble pigment in basidiocarps of many Hygrocybe spp. is muscaflavin (Steglich and Strack 1990), an unusual betalain pigment first identified as a minor pigment in A. muscaria (Steglich and Preuss 1975; Von Ardenne et al. 1974). Cibula (1976) partially characterized the same pigment calling it flavohygrocybin. Muscaflavin comprises a 7-membered heterocyclic ring, formed by the action of a 2,3- DOPA dioxygenase on DOPA followed by spontaneous recyclization of the resulting 2,3-seco-DOPA intermediate (Steglich and Preuss 1975; Von Ardenne et al. 1974) (Fig. 4). Betalamic acid is also present in A. muscaria and H. conica (Musso 1979; Terradas and Wyler 1991a, b). Examination of the peptide sequences of the fungal, bacterial and plant DOPA dioxygenases shows little similarity, suggesting that these pathways have all evolved independently (Grotewold 2006; Novotna et al. 2004).

Whilst the major red pigments of Amanita muscaria (e.g. muscapurpurin) are derived from betalamic acid, the orangered pigments of Hygrocybe spp. (hygroaurins) are apparently derived from muscaflavin via conjugation with amino acids. Bresinsky and Kronawitter (1986) confirmed the involvement of threonine but the precise nature of the red pigment(s) remains unknown. Cibula (1976) partially characterized a magenta pigment ('rhodohygrocybin', a type of hygroaurin), which was quantitatively correlated with the redness of the pileus, and he also noted its chemical similarity to muscaflavin (with these two pigments accounting for $>80 \%$ of the light absorption of pilei). Thus with muscaflavin (flavohygrocybin sensu Cibula) absorbing light below $500 \mathrm{~nm}$ (reflecting light at 500-700 nm-i.e., yellow) and 'rhodohygrocybin' absorbing light at $480-590 \mathrm{~nm}$, the combined effect of these pigments is reflection of bright red. Cibula also found that muscaflavin was present at much higher concentrations (ca. $1200 \mathrm{ppm}$ ) than 'rhodohygrocybin' (ca $60 \mathrm{ppm}$ ) even in species with bright red pilei, with the latter also being less stable (Online Resource 4). The presence of an amino group (ninhydrin positive) in rhodohygrocybin further suggests that it is a hygroaurin, as discovered by Bresinsky and Kronawitter (1986), possibly conjugated with cyclo-DOPA (as found in betanidin) or an aromatic amino acid to achieve absorbance in the 500-600 nm region. The blackening of older or bruised basidiocarps of $H$. conica is also linked to muscaflavin synthesis, probably the result of melanin formation following oxidation of DOPA to DOPA-quinone and ultimately melanin by tyrosinase (Steglich and Preuss 1975). 


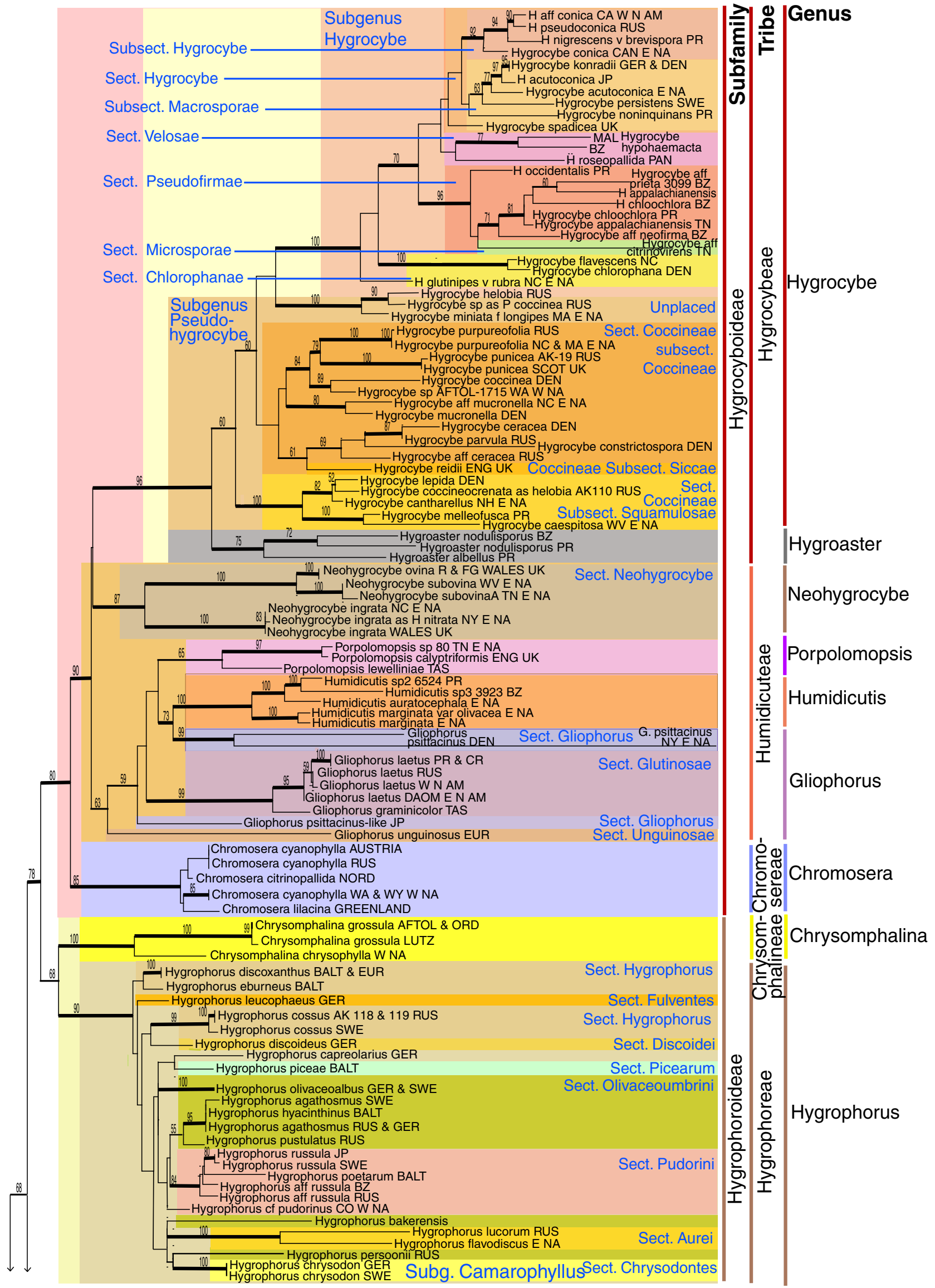



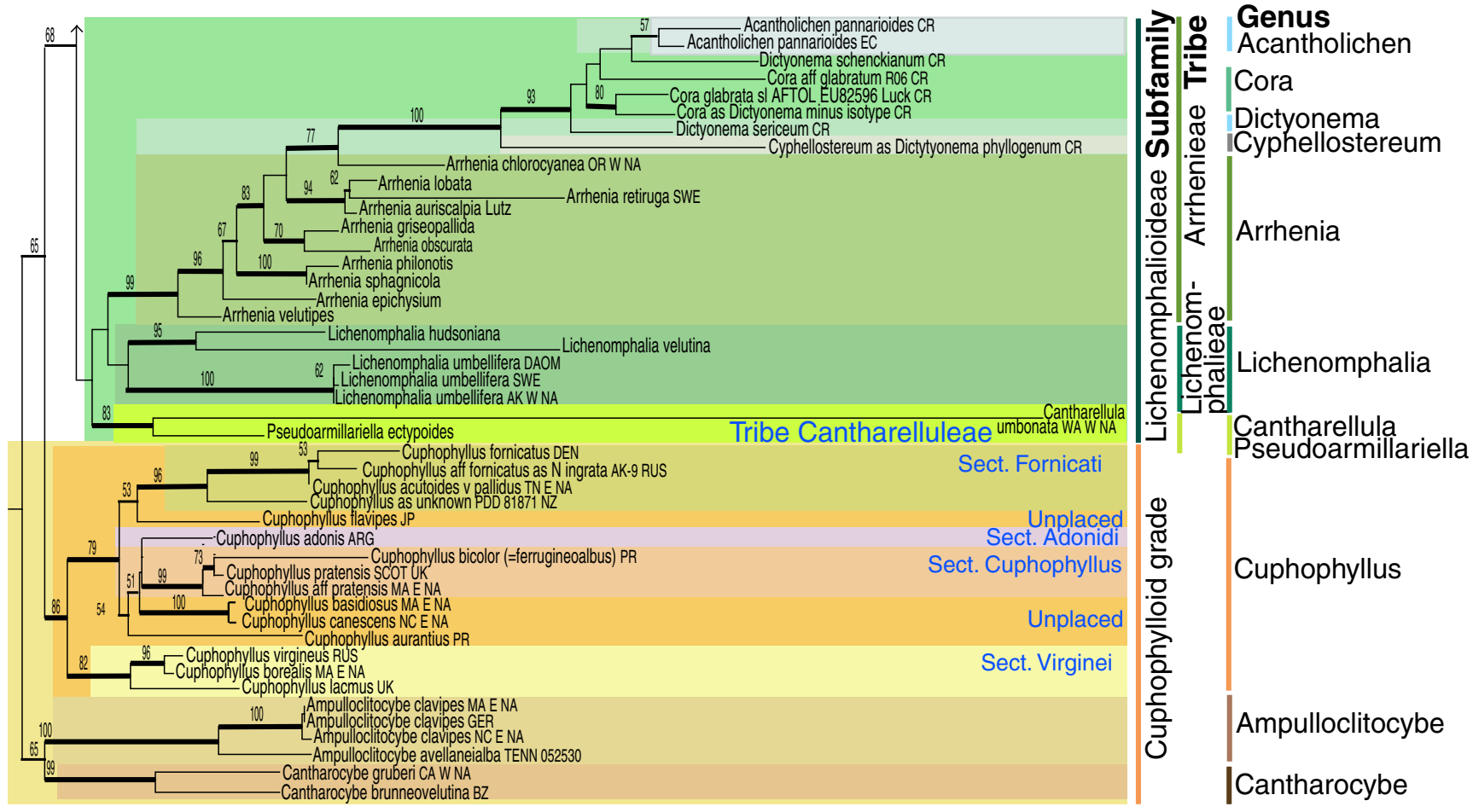

Fig. 2 (continued)

The distribution of the betalain pigments is taxonomically informative, since muscaflavin is the dominant pigment in all of the 30 species of Hygrocybe hitherto studied, with hygroaurins also being found in all of these (Bresinsky and Kronawitter 1986; Cibula 1976; Steglich and Strack 1990) (Fig. 4). Muscaflavin and hygroaurins were also detected in $H$. ovina but not other species of Neohygrocybe (Bresinsky and Kronawitter 1986), with muscaflavin only being found in a few Hygrophorus species (Bresinsky and Kronawitter 1986; Lübken 2006; Steglich and Strack 1990) (Online Resource 4). Equally informative is the absence of betalains in Chromosera (2 spp.), Cuphophyllus (4 spp.), Gliophorus (5 spp.), Humidicutis marginata and Porpolomopsis calyptriformis (Online Resource 4), differences in the concepts of some species globally (e.g. 'Gliophorus' vitellina) can cause confusion. The nature of the pigments in these other groups is unknown. Cibula (1976) found that the yellow pigment of Gliophorus spp. was a non-carotenoid polyene but was unable to characterize the highly unstable ('fugaceous') cyan pigment of $G$. psittacinus. For several, such as in $C$. pratensis, the insolubility of the pigments in diverse organic solvents hindered further analysis. Muscaflavin is absent from Cuphophyllus fornicatus.

Several unpigmented metabolites have been characterized from basidiocarps of Hygrophoraceae, including polyacetylenic acids from Cuphophyllus virginea (Farrell et al. 1977), hygrophoric acid (a lactone derived from caffeic acid) and hygrophorones (cyclopentone derivatives) from several Hygrophorus spp. (Lübken et al. 2006); it is possible that some of these are precursors of pigments. Hygrophorones were shown to have antifungal and antibacterial activity (Lübken 2006) so they likely have adaptive significance. A new type of antifungal compound derived from fatty acids, chrysotrione, was found in Hygrophorus chrysodon (Gillardoni et al. 2006). Whilst the basidiocarps of Hygrophoraceae are not noted for their toxicity to humans, both Cuphophyllus virginea and Hygrophorus chrysodon arrest Drosophila development with an $\mathrm{LD}_{100}$ of $\leq 5 \mathrm{mg} / \mathrm{ml}$ in growth medium (Mier et al. 1996). Ampulloclitocybe clavipes produces an aldehyde dehydrogenase inhibitor (Cochran and Cochran 1978; Yamaura et al. 1986) and a tyrosine kinase inhibitor named clavilactone (Cassinelli et al. 2000).

Molecular analyses The ITS region has high heterozygosity in some Hygrophoraceae, especially Hygrocybe, Gliophorus, Neohygrocybe and Porpolomopsis (personal experiences, Hughes et al. 2009; Babos et al. 2011), which necessitated cloning the ITS region for many collections. There are also many insertions in the LSU and SSU of Hygrophoraceae that disrupt amplification. Especially troublesome are introns inserted close to the primers and secondary structural loops that cause out-of-sequence chimeric reads. Cloning was sometimes used to obtain full sequences. In other cases, 5-15 amplification and sequencing runs were obtained per gene region using different combinations of primers to yield a full sequence. In difficult species only one or two full $3^{\prime}$ to $5^{\prime}$ sequences were obtained. Group I introns inserted 14-15 nt to the right of the NS5 primer 
(position 943) in the SSU disrupted amplification or yielded mixtures of amplicons with and without introns. Group I introns were confirmed in Gliophorus psittacinus, Lichenomphalia umbellifera, Hygrocybe hypohaemacta, and $H$. miniata f. longipes. However, it is likely that introns are more frequent in other members of the group for the following reasons: length polymorphisms were commonly revealed in the PCR gels of other taxa in this study, there is a PCR bias against copies with introns, and primer NS6 anneals across an intron insertion site and therefore, does not amplify intron-containing rDNA repeats (Hibbett 1996; Wang et al. 2009). The introns were 375-444 bp in length and matched other fungal Group I introns (Hibbett 1996; $80-83 \%$ similarity in BLAST searches). The conserved Group I intron regions ( $\mathrm{P}, \mathrm{Q}, \mathrm{R}$ and $\mathrm{S}$ ) defined by Davies et al. (1982) and reported in Wang et al. (2009) were all located, with three changes. In the $\mathrm{R}$ region, the last three

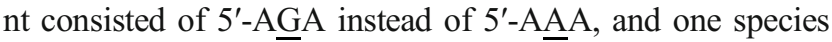
(H. hypohaemacta) had a $\mathrm{CW}$ insertion after a 5 '-gtt (i.e., GTTCWCAGAGACTAGA). The introns in all species had a single substitution of $\mathrm{G}$ for $\mathrm{A}$ in the $\mathrm{S}$ region (i.e., AAGGUAUAGUCC). None of the intron sequences appeared to code for a functional endonuclease, but a 16 aa protein translation from the $3^{\prime}$ end matched a Rho GTPase activator in two ascomycete fungi, Trichophyton and Arthroderma. In Neohygrocybe ovina, there was a partial tandem repeat of the NS5-6. Some self-chimeric LSU sequences resulted from using the LR5 primer and were likely caused by secondary structure, but no intron sequences were recovered in either G. psittacinus or Hygrocybe aff. citrinopallida DJL05TN10, the two species examined in detail. Reverse reads proceeded to near the LR3, where 31-37 nucleotides were missing, followed by a forward read beginning in or near the LROR.

Group I introns have frequently been reported from mitochondrial genomes of ciliates, green algae, plants, fungi and slime molds, and are transmitted both vertically and horizontally (De Wachter et al. 1992; Gargas et al. 1995; Hibbett 1996; Wang et al. 2009). Group I fungal introns of about $400 \mathrm{bp}$ have previously been found in nuc-rDNA SSU sequences of several basidiomycetes including Artomyces pyxidatus, Auriscalpium vulgare and Lentinellus and Panellus stipticus (Lickey et al. 2003; Hibbett and Donoghue 1995). BLAST searches in the NCBI database using the intron sequence revealed additional basidiomycetes with similar introns, including Descolea maculata (Cortinariaceae) AFTOL-1521, DQ440633), Piloderma fallax (Atheliaceae, GU187644), Galerina atkinsoniana (Strophariaceae, AFTOL-1760, DQ440634), Tubaria serrulata (Strophariaceae, AFTOL-1528, DQ462517), Porotheleum fimbriatum (MeripilaceaeAFTOL-1725, DQ444854) and Oudemansiella radicata (Physalacriaceae, AY654884).
Results of phylogenetic analyses are reported under each taxon and compared to previously published analyses. Maximum Likelihood bootstrap support (MLBS) values $>69 \%$ and Bayesian posterior probabilities (BPP) $>0.94$ are considered significant (strong).

\section{Taxonomy}

The following text and tables are arranged according to the branching order of clades in the four-gene backbone and Supermatrix analyses (Figs. 1 and 2, respectively). The synonymy shown is incomplete but includes obligate synonyms that are needed to trace names to their basionym, a few facultative synonyms, synonyms that are invalid or illegitimate and misapplied names.

Hygrophoraceae subfam. Hygrocyboideae Padamsee \& Lodge, subf. nov.

MycoBank MB804066.

Type genus: Hygrocybe (Fr.) P. Kumm., Führ. Pilzk. (Zwickau): 111 (1871).

$\equiv$ Hygrophorus subg. Hygrocybe Fr., Summa veg. Scand., Section Post. (Stockholm): 308 (1849).

Basidiomes fleshy; colors usually bright, rarely dull; lamellae, usually thick, yielding a waxy substance when crushed, rarely absent; true veils lacking, rarely with false peronate veils formed by fusion of the gelatinous ixocutis of the pileus and stipe, and fibrillose partial veils formed by hyphae emanating from the lamellar edge and stipe apex; basidiospores thinwalled, guttulate, hyaline (though species with black staining basidiomes may have fuscous inclusions), smooth or ornamented by conical spines, inamyloid, acyanophilous; basidia guttulate, mono- or dimorphic, if dimorphic then basidia emanating from the same fascicle differing in length and width; mean ratio of basidia to basidiospore length 3-7; pleurocystidia absent; pseudocystidia sometimes present; true cheilocystidia usually absent but cystidia-like hyphoid elements emanating from the lamellar context or cylindric or strangulated ixo-cheilocystidia embedded in a gelatinous matrix sometimes present; lamellar trama inamyloid, regular or subregular but not highly interwoven, divergent or pachypodial; comprised of long or short hyphal segments with oblique or perpendicular cross walls, often constricted at the septations, usually thinwalled but hyphae of the central mediostratum sometimes slightly thickened. Pileipellis structure a cutis, disrupted cutis, ixocutis, ixotrichodermium or trichodermium, but never hymeniform; clamp connections present or absent; habit terrestrial, rarely on wood or arboreal, often associated with mosses, growing in forests or grasslands; possibly biotrophic but not known to form ectomycorrhizae with woody plants.

Phylogenetic support Support for a monophyletic clade representing subf. Hygrocyboideae was high in the 4-gene 
backbone (99 \% MLBS, Fig. 1; 1.0 B.P. Online Resource 6), and Supermatrix (80 \% MLBS, Fig. 2) analyses, but fell below $50 \%$ in the LSU and ITS-LSU analyses (Figs. 3 and 5). The ITS analysis by Dentinger et al. (unpublished) shows $98 \%$ MLBS support for subf. Hygrocyboideae. Support for subf. Hygrocyboideae as the sister clade to subf. Hygrophoroideae was highest in the Bayesian 4-gene backbone analysis (1.0 PP), while bootstrap support was moderately high in all the ML analyses except the LSU (78 \% Supermatrix, and $77 \% 4$ gene backbone). Moncalvo et al. (2002) found Bayesian support for two sister clades, one with Hygrocybe and Chromosera and another with Hygrophorus and Chrysomphalina, and Lodge et al. (2006) recovered the same topology without support, but the topology was more complex in the Supermatrix analysis by Matheny et al. (2006).

Tribes included Hygrocybeae, Humidicuteae, stat. nov. and Chromosereae, tribe nov.

Hygrophoraceae [subfam. Hygrocyboideae] tribe Hygrocybeae Kühner, Bull. Soc. Linn. Lyon 48: 621 (1979)

Type genus: Hygrocybe (Fr.) P. Kumm., Führ. Pilzk. (Zwickau): 26 (1871).

\section{Emended here by Lodge}

Basidiomes lacking carotenoid pigments, typically with betalain, DOPA based compounds that usually appear as bright colors (muscaflavin, flavohygrocybin, rhodohygrocybin), but these sometimes converted to fuscous forms, or as colorless forms (hygroaurin, formed by conjugation of muscaflavin with amino acids) or pigments completely absent; true veils lacking but rarely with false peronate veils formed by fusion of the gelatinous ixocutis of the pileus and stipe, and fibrillose partial veils formed by hyphae emanating from the lamellar edge and stipe apex; lamellae usually present, thick, yielding a waxy substance when crushed; basidiospores thin-walled, guttulate in $\mathrm{KOH}$ mounts, hyaline, sometimes with fuscous inclusions in staining species, smooth or rarely ornamented by conical spines, inamyloid, acyanophilous, non-metachromatic; basidia guttulate, mono- or dimorphic, if dimorphic then basidia emanating from the same fascicle differing in length and often width; mean ratio of basidia to basidiospore length 3-7; context not dextrinoid; pleurocystidia absent; pseudocystidia may be present, true cheilocystidia usually absent but cystidia-like hyphoid elements emanating from the lamellar context commonly present, rarely with true cheilocystidia; lamellar trama regular to subregular, never divergent, pachypodial or highly interwoven; clamp connections usually present in context and hymenium unless spores are ornamented with spines or basidia bisporic; clamps normal or medallion type, rarely toruloid; habit terrestrial, bryophilous, rarely on wood or arboreal, growing in forests or grasslands; possibly biotrophic, cloned from the rhizosphere but not plant roots, not forming ectomycorrhizae with woody plants.
Fig. 3 LSU analysis (LROR-LR5) of Hygrophoraceae together with representatives of the hygrophoroid clade (Sarcomyxa and Xeromphalina) and several outgroups (Mycena and Omphalina), rooted with Macrotyphula phacorrhiza. ML bootstrap values $\geq 50 \%$ appear above the branches. Heavily bolded branches have $\geq 70 \%$ and lightly bolded branches have 50-69 \% ML bootstrap support

Phylogenetic support Support for Tribe Hygrocybeae is strong in our LSU (85 \% MLBS, Fig. 3), 4-gene backbone (98\% MLBS \& 1.0 B.P. Fig. 1 and Online Resource 6), and Supermatix (96\% MLBS, Fig. 2) analyses. Dentinger et al. (unpublished) show $93 \%$ MLBS support for tribe Hygrocybeae in their ITS analysis. Previous studies show similarly high support for a monophyletic Hygrocybeae using a maximum parsimony analysis of LSU (98\% MPBS, Moncalvo et al. 2002), ITS (100\% MPBS, Seitzman et al. 2011) and a multigene analysis (100\% MLBS and 1.0 B.P. Matheny et al. 2006) but none of those analyses included Hygroaster.

Genera included Hygrocybe and Hygroaster.

Comments As noted by Bas (1990), the citation by Arnolds (1990) as tribe Hygrocybeae (Kühner) Bas \& Arnolds was incorrect because only names at or below genus are recombined (Art. 6.7), so authors of higher taxa remain the same when they are transferred to another position. Bas (1990) and Arnolds (1990) treated tribe Hygrocybeae in the Tricholomataceae instead of Hygrophoraceae.

Hygrocybe (Fr.) P. Kumm., Führ., Pilzk. (Zwickau): 26 (1871)

$\equiv$ Hygrophorus subg. Hygrocybe Fr. (1849).

Type species: Hygrocybe conica (Schaeff.) P. Kumm., Führ. Pilzk. (Zwickau): 111 (1871)

$\equiv$ Hygrophorus conicus (Schaeff.) Fr., Epicr. syst. mycol. (Upsaliae): 331 (1838) [1836-1838],

$\equiv$ Agaricus conicus Schaeff., Fung. Bavar. Palat. 4: 2 (1877)].

Characters as in tribe Hygrocybeae. Differing from Hygroaster in usually having bright pigments, and basidiospores that are typically smooth, but if conical warts are present, the spores are broadly ellipsoid rather than globose or subglobose and the outline is usually subangular.

Phylogenetic support Hygrocybe s.s. is strongly supported as monophyletic in our 4-gene backbone (95 \% MLBS, 1.0 B.P. Fig. 1 and Online Resource 6), LSU (87\% MLBS, Online Resource 7) and ITS-LSU analyses (90\% MLBS, Fig. 4); support is lower in our Supermatix analysis (60\% MLBS; Fig. 2). Previously, Moncalvo et al. (2002) found a monophyletic Hygrocybe using LSU, but it lacked significant BS support. Others subsequently showed $100 \%$ BS or 1.0 Bayesian PP support for a monophyletic Hygrocybe including Binder 


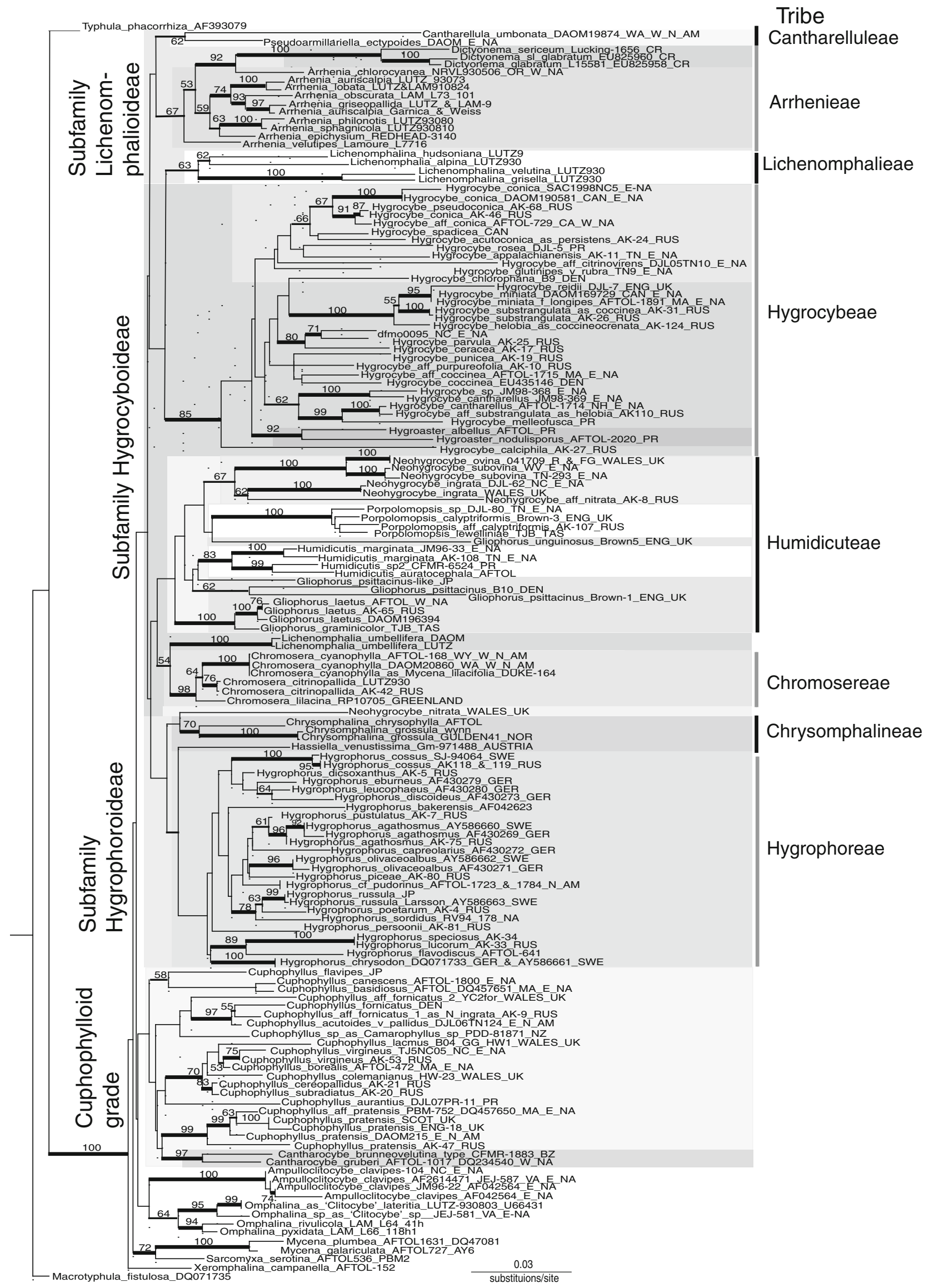


et al.'s (2010) six gene analysis (RAxML and Bayesian), Lawrey et al.'s (2009) ITS-LSU (ML and MP), Matheny et al.'s multigene Supermatrix (MP and Bayesian), Seitzman et al.'s (2011) ITS (MP) and Vizzini et al.'s (2012) ITS-LSU (ML, MP and Bayesian). Babos et al. (2011) found lower support using only ITS (70 \% MLBS). We find high support for Hygrocybe as the sister clade to Hygroaster in the 4-gene backbone (98 \% ML BS, 1.0 B.P. and Supermatrix analyses (96\% MLBS).

Subgenera included Hygrocybe s.s. is currently treated as comprising two subgenera, Hygrocybe and Pseudohygrocybe. Other subgenera that have previously been included in Hygrocybe s.l. are treated as segregate genera here but are listed in Table 1.

Comments The name Hygrocybe was not validly published in Fries (1821) or (1838), but was validated as Hygrophorus subgen. Hygrocybe in Fries (1849). Though Rabenhorst (1844) pre-dates this, he did not list Hygrocybe among the infrageneric names he accepted, which indicates he rejected them as synonyms of genus Agaricus, [unranked] Hygrophorus, [unranked] Hygrocybe (pers. com. Shaun Pennycook, 28 Oct. 2010 to S.A. Redhead). Kummer (1871) was thus the first to validly use Hygrocybe Fr. at genus rank. Kovalenko (1988) treated the current subgenera as separate genera: Hygrocybe and Pseudohygrocybe (Bon) Kovalenko. Herink (1959) previously attempted to separate the two main Hygrocybe groups at genus rank using Godfrinia Maire (1902), nom. illeg., with type species G. conica (Scop. ex Fr.) R. Maire, and an emended Hygrocybe. Except for inclusion of H. punicea, Maire's (1902) "Godfrinia" illeg. is concordant with the current Hygrocybe subg. Hygrocybe. Because "Godfrinia" (1902) is predated by Hygrocybe (Kummer 1871) and shares the same type species, it is superfluous and therefore illegitimate (Art. 52.10). Heim (1936)

\section{Group 1: Tribe Hygrocybeae ITS-LSU}

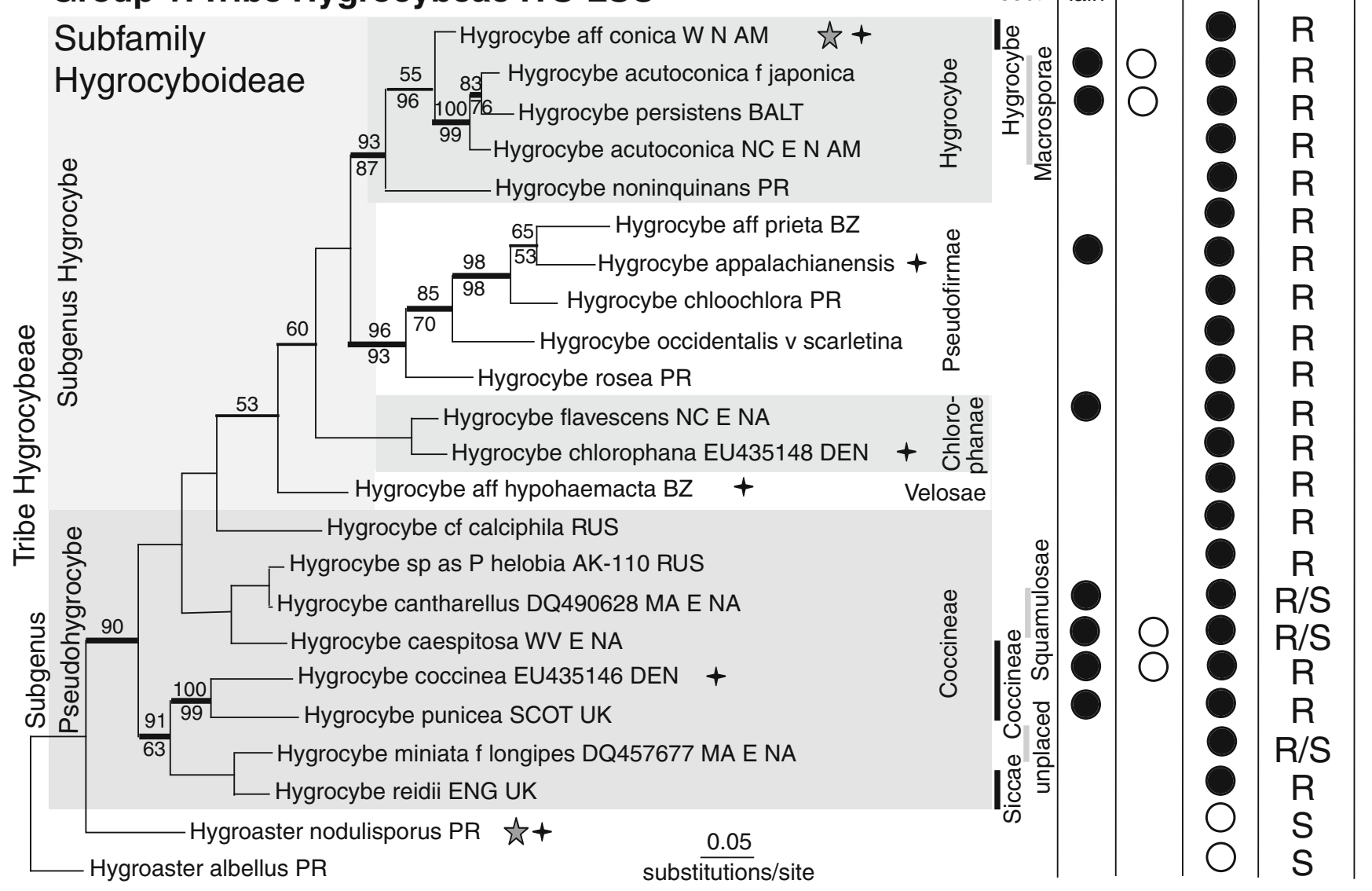

Fig. 4 Tribe Hygrocybeae (Group 1) ITS-LSU analysis, rooted with Hygroaster albellus. Genes analyzed were ITS (ITS1, 5.8S \& ITS2), LSU (LROR-LR5). Presence of betalain (DOPA based) and carotenoid pigments and presence of clamp connections in forms with 4-spored basidia are denoted by filled circles while empty circles denote their absence. Lamellar trama types are: $\mathrm{R}$ for regular (parallel) and $\mathrm{S}$ for subregular. ML bootstrap values $\geq 50 \%$ appear above the branches. Heavily bolded branches have $\geq 70 \%$ and lightly bolded branches have 50-69\% ML bootstrap support 


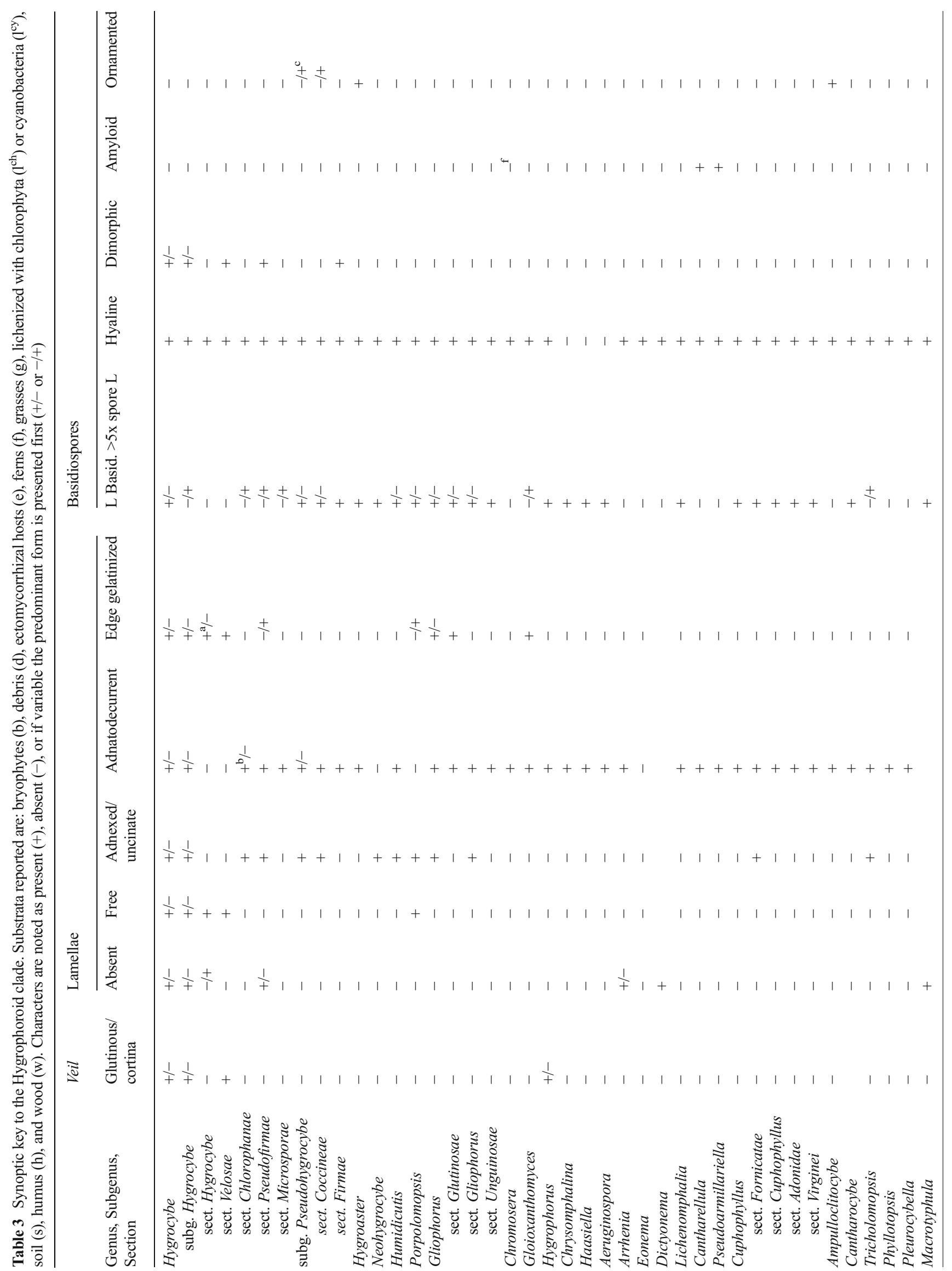




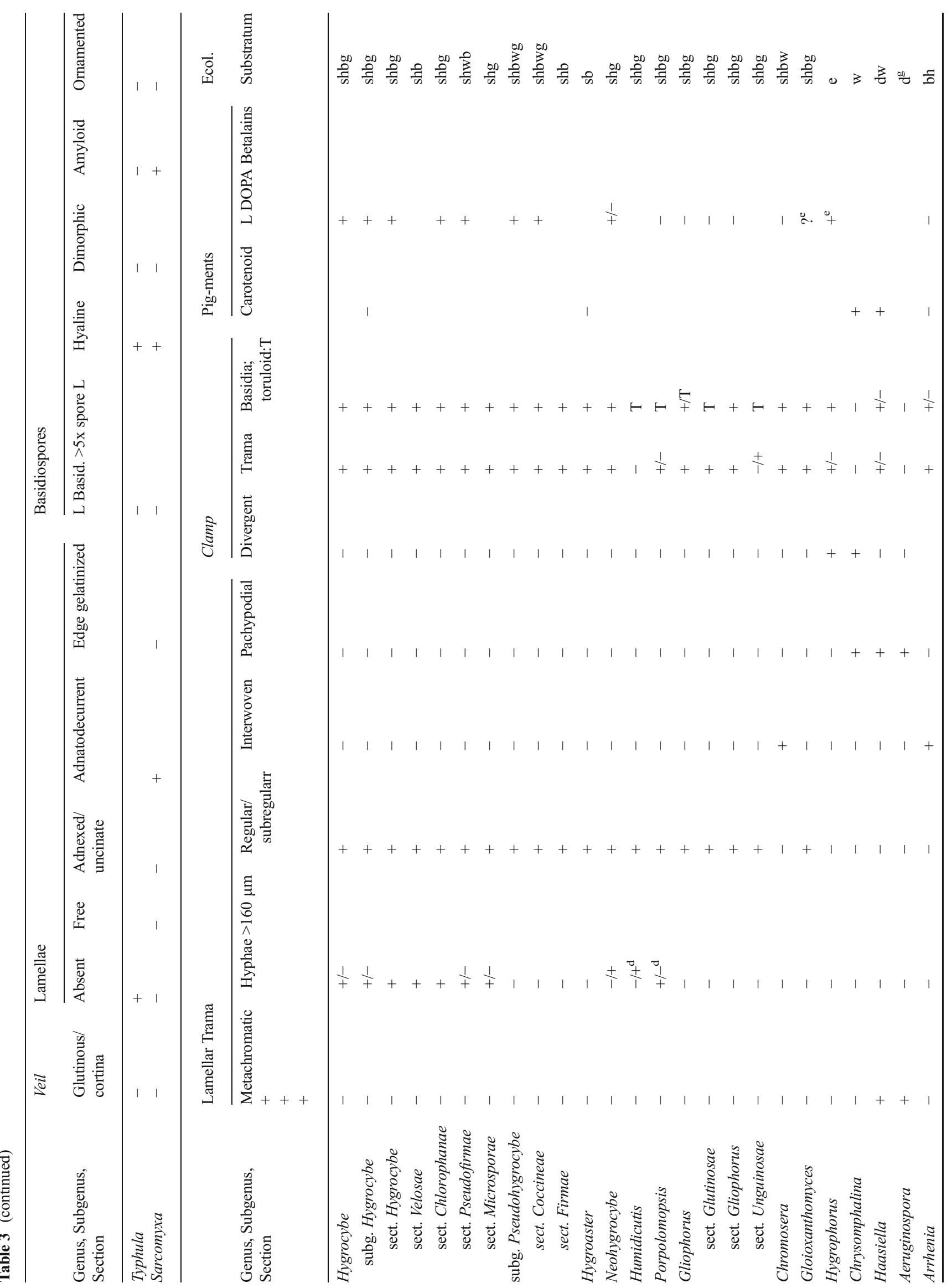




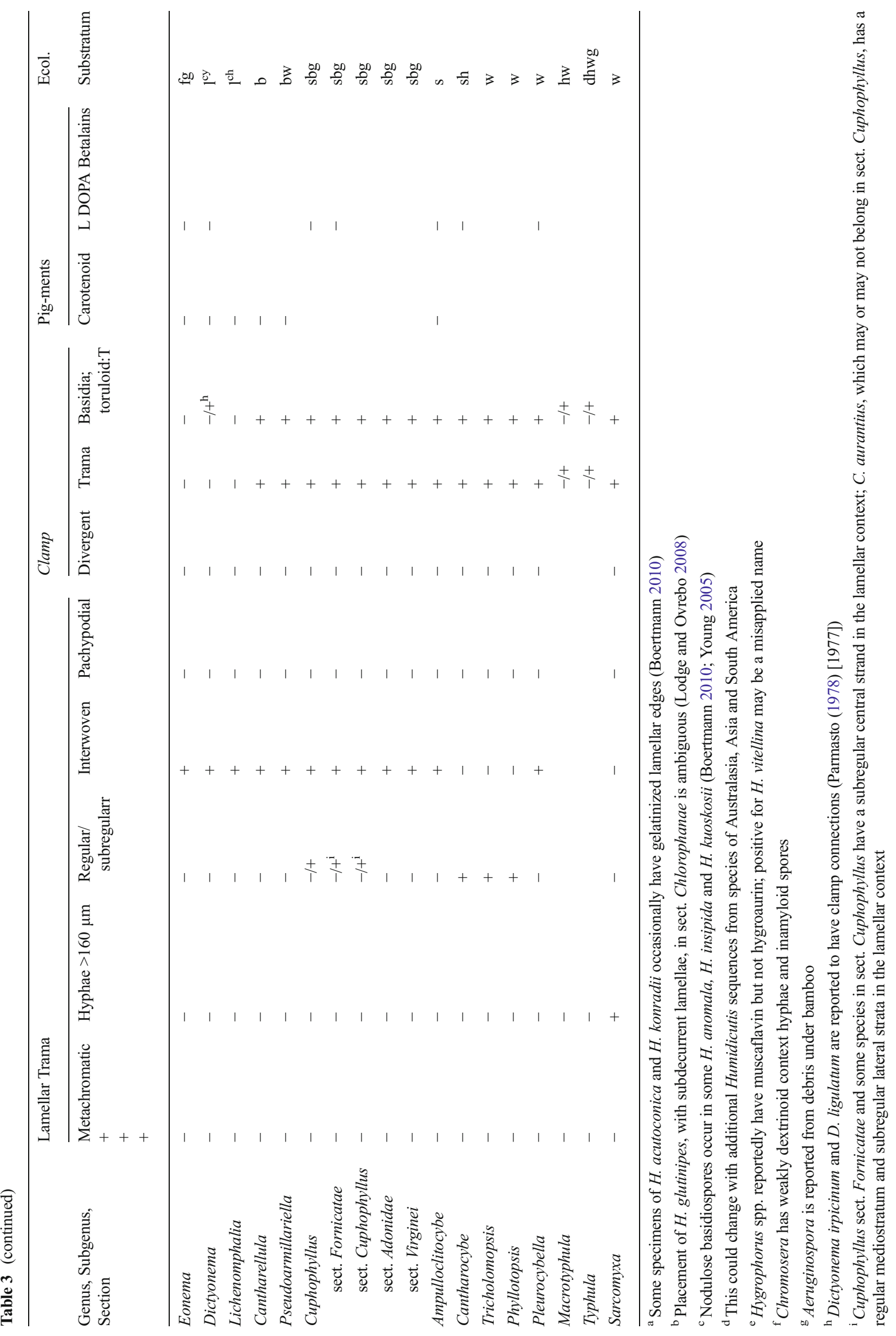


named a new genus, Bertrandia, to accommodate a conical blackening species from Africa that exudes copious latex when cut, but the type species is now correctly classified as Hygrocybe astatogala (Heim) Heinem. (1963) in subg. Hygrocybe [sect. Hygrocybe] subsect. Hygrocybe, rendering Bertrandia a synonym of Hygrocybe. Although the composition of Herink's (1959) emended Hygrocybe (H. miniata, $H$. coccinea, H. marchii, H. miniato-alba and H. turunda) corresponds to the current subg. Pseudohygrocybe, he was incorrect in attempting to replace the type species of Hygrocybe ( $H$. conica) with $H$. miniata. Babos et al. (2011) erroneously reported that Candusso (1997) transferred Hygrocybe to the Agaricaceae, apparently mistaking the early history of the Hygrophoraceae (pp. 33-44), in which all agaric species were first placed in Agaricus by Scopoli, Schaeffer and Fries, for the classification accepted by Candusso (pp. 313-323).

As delineated by Fries (1849) and Bataille (1910), Hygrocybe included terrestrial species with a pileus that was thin, tender, sometimes striate, with a moist, lubricous or viscid surface; stipe hollow or stuffed, splitting or fibrillose, generally smooth at the apex, with a moist or viscid surface. Hygrocybe species are frequently brightly colored, though gray-brown ones also occur. DOPA betalain pigments are found throughout the pigmented Hygrocybe ss, but rarely outside this group, while carotenoid pigments are apparently absent from Hygrocybe s.s. (Table 3, Online Resource 4). As in other members of the family, the lamellae of Hygrocybe are waxy and yield an oily substance when crushed (Young 1997), and they are usually but not always thick (Lodge et al. 2006). The lamellar trama structure is always regular or subregular in Hygrocybe s.s. and s.l., differentiating it from the typically interwoven arrangement in Cuphophyllus, the divergent trama in Hygrophorus, and the pachypodial arrangement in Chrysomphalina and Haasiella (Norvell et al. 1994) and now Aeruginospora (Table 3). The hyphae typically have clamp connections. The basidiospores of Hygrocybe s.s. and s.l. are always hyaline, inamyloid, thin-walled, and typically smooth but occasionally with conical warts. While most Hygrocybe s.s. and s.l. are terrestrial, often growing in grasslands in Europe and forests in North America and the tropics, a few tropical species are now known to be arboreal (e.g., $H$. hapuuae Desjardin and Hemmes 1997; H. pseudoadonis S.A. Cantrell and Lodge 2004; and H. rosea, Lodge et al. 2006). Although they appear to be biotrophic based on isotopes, their biotic relationships are enigmatic (Seitzman et al. 2011). Hygrocybe have been sequenced from the rhizosphere of plant roots (see Ecology section), which may explain how they obtain plant carbon.

Hygrocybe subgen. Hygrocybe [autonym] (1976).

Type species: Hygrocybe conica (Schaeff.) P. Kumm., Führ. Pilzk. (Zwickau): 111 (1871),

$\equiv$ Hygrophorus conicus (Schaeff.) Fr., Epicr. syst. mycol. (Upsaliae): 331 (1838) [1836-1838], $\equiv$ Agaricus conicus Schaeff., Fung. Bavar. Palat. 4: 2 (1877).

Pileus usually colored red, orange, yellow, green or purple from DOPA based betalain pigments, rarely colorless or fuscous with age or bruising from transformation of DOPA; fibrillose or glutinous partial veils occasionally present; lamellae usually free or narrowly attached, rarely broadly attached by a decurrent tooth; lamellar trama hyphae strictly parallel, usually with tapered ends and exceeding $140 \mu \mathrm{m}$ (some $>1000 \mu \mathrm{m}$ ) in length, unless the basidia and spores are dimorphic; basidia usually 3-5 times the length of their basidiospores, vs $>5$ times in subg. Pseudohygrocybe (Table 3).

Phylogenetic support Subg. Hygrocybe is strongly supported as a monophyletic clade in two of our analyses without inclusion of $\mathrm{H}$. helobia (100\% MLBS in the Supermatrix, $100 \%$ MLBS and BPP in the 4-gene backbone analyses, Fig. 1 and Online Resource 6), but only weakly supported by analyses of ITS-LSU (53\% MLBS, Fig. 4), and LSU (54\% \& $32 \%$ MLBS, Fig. 3 and Online Resource 7). Previous analyses using fewer species found strong support for a monophyletic subg. Hygrocybe (100\% MLBS in the multigene analysis by Matheny et al. 2006; $95 \%$ MPBS in the LSU analysis by Moncalvo et al. 2002; $96 \%$ support in the analysis of mostly ITS data by Seitzman et al. 2011). Support for a monophyletic subg. Hygrocybe using ITS sequences alone is not significant for the two spp. in Babos et al. (2011), our 24 spp. (37\% MLBS, Online Resource 8) but high for the $18 \mathrm{spp}$. in Dentinger et al. (unpublished data, $83 \%$ MLBS).

Sections included Type section Hygrocybe; includes existing sections Chlorophanae and Microsporae, and new sections Pseudofirmae and Velosae.

Comments Our various phylogenetic analyses, as detailed below, reveal six clades or segments of grades of which four are concordant with currently named sections and subsections. These are sect. Hygrocybe with subections Hygrocybe and Macrosporae R. Haller Aar. ex Bon, sect. Chlorophanae (Herink) Arnolds ex Candusso, and sect. Microsporae Boertm. In addition, we describe two new sections to accommodate monophyletic clades that comprise most of the species with dimorphic spores and basidia, which were previously assigned to sect. Firmae. The position of H. helobia is unstable among analyses, but it also belongs in subg. Hygrocybe.

Hygrocybe [subgen. Hygrocybe] sect. Hygrocybe. [autonym] (1889).

Type species: Hygrocybe conica (Schaeff.) P. Kumm., Führ. Pilzk. (Zwickau): 111 (1871)

$\equiv$ Hygrophorus conicus (Schaeff.) Fr., Epicr. syst. mycol. (Upsaliae): 331 (1838) [1836-1838], 
三Agaricus conicus Schaeff., Fung. Bavar. Palat. 4: 2 (1877).

Pileus conical or conico-campanulate; lamellae free or narrowly attached; lamellar trama hyphae parallel, some $200 \mu \mathrm{m}$ in length, with tapered ends and oblique septa.

Phylogenetic support Sect. Hygrocybe support varies from high in our 4-gene backbone analysis (97\% MLBS and $100 \%$ BPP; Fig. 1 and Online Resource 6), ITS-LSU analyses (93\% MLBS and $87 \%$ MPBS including H. noninquinans (a replacement name for $H$. konradii var. antillana, $55 \%$ MLBS and $87 \%$ MPBS excluding it; Fig. 4) and ITS (77\% MLBS, Online Resource 8) to low in our Supermatrix and Hygrocybe LSU and ITS analyses (Fig. 2, Online Resources 8). A previous ITS analysis by Seitzman et al. (2011) shows $96 \%$ MLBS support while the ITS analysis by Babos et al. (2011) shows $83 \%$ neighbor joining (NJ) BS and $79 \%$ MLBS support for sect. Hygrocybe.

Subsections included Type sect. Hygrocybe; includes subsect. Macrosporae.

Hygrocybe [subg. Hygrocybe sect. Hygrocybe] subsect. Hygrocybe [autonym].

[= subsect. "Nigrescentes" (Bataille) Arnolds, invalid as the type species of the genus is included (Art. 22.2)].

Type species: Hygrocybe conica (Schaeff.) P. Kumm., Für Pilzk. (Zwickau): 111 (1871)

$\equiv$ Hygrophorus conicus (Schaeff.) Fr., Epicr. syst. mycol. (Upsaliae): 331 (1838),

$\equiv$ Agaricus conicus Schaeff., Fung. Bavar. Palat. 4: 2 (1877).

Characters as in sect. Hygrocybe; pileus surface sometimes fibrillose. Usually differs from subsect. Macrosporae in presence of black staining reactions and fibrillose pileus.

Phylogenetic support This subsection was moderately to highly supported by the various phylogenetic analyses. Support is highest in the Supermatrix (92\% MLBS) and LSU analyses (67 \% and $89 \%$ MLBS; Figs. 2 and 3, Online Resource 7), and moderate in our ITS analysis (51\% MBS, Online Resource 8). Dentinger et al. (unpublished data) and Babos et al. (2011) also showmoderate to high support for the $H$. conica species complex (61\% MLBS, respectively and $98 \%$ NJBS) using ITS sequences.

Species included Type species: Hygrocybe conica (Schaeff.) P. Kumm. 1871. Species confirmed by molecular phylogenies include $H$. conica varieties, $H$. nigrescens var. brevispora, and H. singeri (A.H. Sm. \& Hesler) Singer. Species placed here based on morphology alone include H. astatogala (R. Heim) Heinem., H. atrosquamosa Pegler and H. olivaceonigra (P.D. Orton) M.M. Moser. The status of other named species is unresolved as this group is in need of revision, including $H$. cinereifolia Court. \& Priou, $H$. cuspidata (Peck) Murrill, $H$. riparia Kreisel, $H$. conicopalustris R. Haller Aar., $H$. pseudoconica J.E. Lange and $H$. veselskyi Singer \& Kuhtan. Hygrocybe cortinata Heinem., described from Africa, closely resembles $H$. conica except for the presence of a cortinoid partial veil, so it likely belongs in subsect. Hygrocybe. Hygrocybe noninquinans is excluded based on the absence of black staining reactions, a silky-fibrillose pileus surface, and placement at the base of subsect. Macrosporae in the Supermatrix analysis; $H$. spadicea may also belong in subsect. Macrosporae.

Comments This subsection is often referred to as the staining conica group as all of the confirmed species have blackish staining reactions and a conic or cuspidate pileus, the surface sometimes with coarse fibrils or appressed squamules. Hygrocybe cuspidata (Peck) Roody is a blackening species described from eastern North America, but the name has been misapplied to collections from Europe of H. acutoconica in the non-staining conica group under the name $\mathrm{H}$. acutoconica var. cuspidata (Peck) Arnolds (1985a) (see Boertmann 2010). The Japanese $H$. conica sequences comprise a distinct clade in our ITS analysis ( $88 \%$ MLBS). The type species, H. conica, has micromorphology that is typical of subg. Hygrocybe including parallel lamellar trama hyphae that are long and tapered at the ends with oblique septa (Fig. 5). The longest hyphae are rare and are best viewed by teasing the trama hyphae apart in smash mounts.

Hygrocybe [subg. Hygrocybe sect. Hygrocybe] subsect. Macrosporae R. Haller Aar. ex Bon, Doc. Mycol. 24(6): 42 (1976).

Type species: Hygrocybe acutoconica (Clem.) Singer (1951) [as H. acuticonica Clem.]

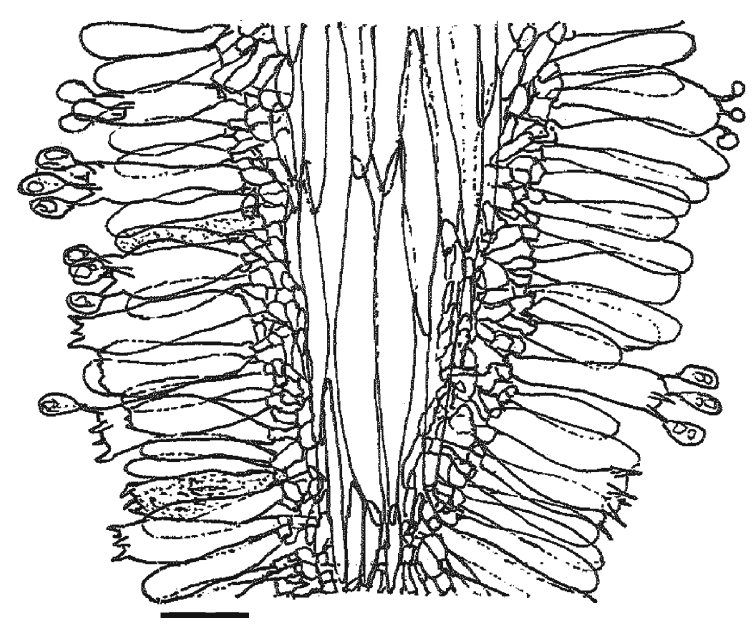

Fig. 5 Hygrocybe (subg. Hygrocybe) sect. Hygrocybe. Hygrocybe conica lamellar cross section (DJL05TN89). Scale bar $=20 \mu \mathrm{m}$ 
三 Mycena acutoconica Clem., Bot. Surv. Nebraska 2: 38 (1893),

= Hygrocybe persistens (Britzelm.) Singer (1940),

$\equiv$ Hygrophorus conicus var. persistens Britzelm. (1890)].

Characters of sect. Hygrocybe; lacking dark staining reactions, though the stipe base may slowly stain gray; surface usually radially fibrillose-silky and viscid or glutinous but some with dry surface even when young; some spore lengths exceed $10 \mu \mathrm{m}$. Differs from subsect. Hygrocybe in absence of dark staining reaction and often a smoother pileus surface texture.

Phylogenetic support Strong support for subsect. Macrosporae is shown in our ITS analysis (99\% MLBS, with $77 \%$ support as the sister clade to subsect. Hygrocybe; Online Resource 8). Support for this subsection in our other analyses varies depending on whether species in the basal part of the grade are included or excluded. The Hygrocybe acutoconica complex, including $H$. acutoconica (Clem.) Singer var. acutoconica, collections of this variety from Europe previously referred to as $H$. persistens (Britzelm.) Singer, and $H$. acutoconica f. japonica Hongo, form a strongly supported clade (99\% ML and $100 \%$ MPBS in the ITS-LSU; $99 \%$ MLBS in the ITS), but with weaker support in the Supermatrix analysis (63\% MLBS). Placement of $H$. spadicea is ambiguous, with strongest support for inclusion in subsect. Macrosporae using ITS (99\% MLBS), ambiguous placement using LSU (Fig. 3 and Online Resource 7) and basal to both subsect. Hygrocybe and Macrosporae in the Supermatrix analysis (Fig. 2). Similarly, both Babos et al. (2011) and Dentinger et al. (unpublished data) show ambiguous placement of $H$. spadicea lacking significant BS support. In our ITS analysis, H. noninquinans is basal to both subsections (69 \% ML BS) making subsect. Macrosporae paraphyletic if included. Similarly, including H. noninquinans makes subsect. Macrosporae paraphyletic in our ITS-LSU analysis as a species in the staining conica group (subsect. Hygrocybe) falls between $H$. noninquinans and other nonstaining spp. with high BS support. The 4-gene backbone analysis places $H$. noninquinans with $H$. aff. conica in sect. Hygrocybe with high support (97 \% ML, 1.0 BPP), while the Supermatrix places it as a basal member in sect. Macrosporae but with low support (Supermatrix, $24 \%$ MLBS). In an ITS analysis by Dentinger et al. (unpublished data), however, $H$. noninquinans (as H. konradii var. antillana) is basal to subsect. Conica with low support as part of a paraphyletic grade corresponding to subsect. Macrosporae. Hygrocybe subpapillata is unplaced in our ITS analysis, but is basal to spp. in sect. Pseudofirmae and sect. Macrosporae in an ITS analysis by Dentinger et al. (unpublished data).

Species included Type species: H. acutoconica. All of the varieties of $H$. acutoconica are included. Hygrocybe persistens (Britzelm.) Singer is currently considered a synonym of H. acutoconica (Boertmann 2010; Cantrell and Lodge 2000), as is H. subglobispora P.D. Orton (Boertmann 2010). Hygrocybe spadicea P. Karst. is tentatively included based on high support in our ITS analysis, though support for inclusion is weak or ambiguous in our other analyses and Dentinger et al.' (unpublished) ITS analysis, and the fibrillose pileus surface which fits better in subsect. Hygrocybe. Hygrocybe noninquinans is included based on its similarities to $H$. acutoconica var. konradii, and its placement basal to other species of sect. Macrosporeae in our Supermatrix analysis. Hygrocybe zuluensis Boertmann is included based on morphology.

Comments This subsection is often referred to as the nonstaining conica group. Boertmann (2010) regards H. konradii as a wide-spored variety of $H$. acutoconica. The ITS analysis by Dentinger et al. (unpublished), however, suggests that while there are wide-spored collections embedded in the $H$. acutoconica clade, there is also a well-supported sister clade to $H$. acutoconica comprised of $H$. konradii s.s. collections (100\% support for the clade, $77 \%$ MLBS support as sister to $H$. acutoconica var. acutoconica). Hygrocybe noninquinans was described as $H$. konradii var. antillana, but it is raised here to species rank based on phylogenetic analyses that place it apart from $H$. konradii. The name $H$. antillana was occupied, so a new name is provided.

Hygrocybe noninquinans Lodge \& S.A. Cantrell, nom. nov., stat. nov.

MycoBank MB804045.

Replaced synonym: Hygrocybe konradii var. antillana Lodge \& Cantrell, Mycol. Res. 104(7): 877-878 (2000).

Type: PUERTO RICO, Mun. Río Grande, El Yunque National Forest (Caribbean National Forest), Caimitillo Trail, 16 Jun 1997, CFMR-PR 4555, CFMR.

Hygrocybe [subg. Hygrocybe] sect. Velosae Lodge, Ovrebo \& Padamsee, sect. nov.

MycoBank MB804047.

Type species: Hygrophorus hypohaemactus Corner, Trans. Br. Mycol. Soc. 20(2): 180, Figs. 5, 6, 8a (1936)

$\equiv$ Hygrocybe hypohaemacta (Corner) Pegler \& Fiard, Kew Bull. 32(2): 299 (1978).

Pileus and stipe red or pink, covered in a thin to thick glutinous layer, glutinous layer of pileus and stipe surface connected, rupturing when pileus expands leaving an appendiculate gelatinous margin on the pileus and sometimes leaving a glutinous annulus on the stipe, resembling a peronate veil but the glutinous layer not separated from the pileus or stipe surface hyphae by a differentiated layer; lamellar trama hyphae fusiform, with tapered ends and oblique septa, some exceeding $140 \mu \mathrm{m}$ in length; lamellar edge with pseudocystidia originating in the context, swollen, containing 
many vacuoles with oleaginous contents, sometimes with glutinous coating, simple or branched, projecting from the lamellar margin where they intertwine with similar but less vacuolated structures emanating from the stipe apex above the glutinous zone, these structures forming an arachnoid connection between the lamellae and stipe; sometimes hyphal strands connecting the pileus margin and stipe leave a fibrillose layer above the glutinous annulus; annulus sometimes obscure; basidia and spores dimorphic: macrobasidia clavate or somewhat capitate-stipitate, 4-sterigmate, with oleaginous contents and basal clamp connection; microbasidia clavate; basidiospores globose, subglobose to broadly ellipsoid.

Etymology Velo-veil, referring to the fibrillose and glutinous partial veil.

Phylogenetic support Our Supermatrix (Fig. 2) and Hygrocybe LSU analyses (Online Resource 7) place $H$. roseopallida in the same clade with $H$. hypohaemacta and $H$. aff. hypohaemacta from the neotropics, but with low bootstrap values. Lodge and Ovrebo (2008) show stronger support (76\% MLBS) for a monophyletic H. roseopallida$H$. hypohaemacta clade using ITS and LSU sequences; its inclusion in sect. Pseudofirmae has low support (53\%). In the 4-gene backbone analysis there is $100 \%$ MLBS (0.9 B.P. support for placing the $H$. hypohaemacta clade apart from the Pseudofirmae clade (H. appalachianensis). In both the ML and Bayesian backbone analyses, H. hypohaemacta (sect. Velosae) falls between. sect. Hygrocybe on one side. and $H$. glutinipes (sect. Chlorophanae) and sect. Pseudofirmae on the other side. The ITS-LSU analysis (Fig. 4) has a wellsupported sect. Pseudofirmae clade (96\% MLBS, $93 \%$ MPBS) that excludes $H$. hypohaemacta; instead, $H$. hypohaemacta appears basal to sect. Chlorophanae. The Supermatrix analysis has high support for paleotropical $H$. hypohaemacta (LSU only) and neotropical $H$. afn hypohaemacta as sister species (77\%) but Dentinger (personal comm.) shows higher support (99 \% MLBS) in an LSU analysis. Our Hygrocybe LSU analysis has moderate support (62 \% MLBS; Online Resource 7) for placing $H$. aff. hypohaemacta and $H$. hypohaemacta together. In our 4-gene backbone analyses (Fig. 1 and Online Resource 6) and our ITS analysis, $H$. hypohaemacta appears in a grade with $H$. glutinipes, but $H$. glutinipes is included in sect. Chlorophana in our Supermatrix analysis, far from H. hypohaemacta.

Species included Type species: Hygrocybe hypohaemacta. Inclusion of two neotropical species, $H$. aff. hypohaemacta and H. roseopallida Ovrebo \& Lodge, is phylogenetically and morphologically supported.

Comments Singer (1986) placed H. hypohaemacta in subg. Hygrocybe owing to the regular lamellar trama composed of long, fusiform elements - a placement confirmed by our molecular phylogenies. Others, including Pegler and Fiard (1978) and Lodge and Pegler (1990) placed H. hypohaemacta in subg. Pseudohygrocybe sect. Firmae, though Cantrell and Lodge (2004) noted the resemblance of trama structure to subg. Hygrocybe and suggested that molecular phylogenies were needed to resolve placement. Neotropical collections identified as $H$. hypohaemacta will need a new name as the spores differ somewhat in shape and size and the LSU sequences diverge by $12.6 \%$ from the SE Asian sequence. Hygrocybe roseopallida is included in sect. Velosae based on moderate molecular support and shared characters, i.e., subglobose to broadly ellipsoid macro- and microspores, a glutinous peronate pseudoveil, cortinoid connections between the lamellar edge and stipe apex partly formed by vacuolated pseudocystidia emanating from the lamellar edge (Lodge and Ovrebo 2008). Although Corner (1936) stated that the glutinous layer of the pileus margin was not connected to the stipe in H. hypohaemacta, a projecting glutinous margin is visible on the pileus, a vague glutinous annulus is visible in photos of the H. hypohaemacta collection from Malaysia that was sequenced, and a glutinous annulus can be seen in a photo of $H$. aff. hypohaemacta from Puerto Rico (Fig. 25 insert). Pseudocystidia emanating from the lamellar edge in both $H$. aff. hypohaemacta and H. roseopallida that form the inner fibrous portion of the veil are shown in Fig. 6. Inner fibrous and outer glutinous veil elements were clearly visible in the type and other collections of $H$. roseopallida (Lodge and Ovrebo 2008).

Hygrocybe [subg. Hygrocybe] sect. Pseudofirmae Lodge, Padamsee \& S.A. Cantrell, sect. nov.

MycoBank MB804048.

Type species: Hygrophorus appalachianensis Hesl. \& A.H. Sm. North American Species of Hygrophorus: 147 (1963),

$\equiv$ Hygrocybe appalachianensis (Hesl. \& A.H. Sm.) Kronaw. (as 'appalachiensis'), in Kronawitter \& Bresinsky, Regensb. Mykol. Schr. 8: 58 (1998).

Pileus usually viscid or glutinous, often perforated in the center. Basidiospores and basidia dimorphic; ratio of macrobasidia to macrospore length usually $<5$, macrobasidia expanded in upper part, typically broadly clavate or clavatestipitate; lamellar trama hyphae parallel, long or short, with or without oblique septa; pileipellis a cutis, disrupted cutis or trichoderm, overlain by a thin to thick ixocutis which if ephemeral then leaves a thin patchy gelatinous coating on the cuticular hyphae.

Etymology Pseudo $=$ false firmae - referring to sect. Firmae.

Phylogenetic support Support for a monophyletic sect. Pseudofirmae, including $H$. rosea, is strongest in the ITS- 
Fig. 6 Hygrocybe (subg.

Hygrocybe) sect. Velosae.

Pseudocystidia emanating from

the lamellar edge, which

contributes to an inner, fibrous

pseudoveil: a. Hygrocybe aff.

hypohaemacta (BZ-1903); b.

Hygrocbe roseopallida (type).

Scale bar $=20 \mu \mathrm{m}$

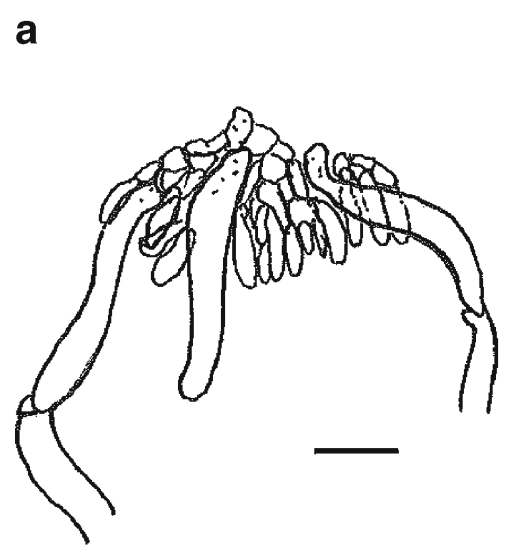

LSU analysis (96 \% MLBS and $93 \%$ MPBS; Fig. 4). ITS support is high (94\% MLBS, not shown) for the clade comprising $H$. appalachianensis, $H$. chloochlora, $H$. aff. chloochlora and $H$. aff. prieta, but declines to $42 \%$ MLBS if $H$. rosea is included; $H$. occidentalis, $H$. cf. neofirma and $H$. trinitensis are placed in a neighboring clade with low support. A similar paraphyletic grade topology is shown in our ITS analysis (Online Resource 8), but our Hygrocybe LSU (Online Resource 7) shows Pseudofirmae as monophyletic. Similarly, an LSU analysis by Dentinger (pers. com.) shows sect. Pseudofirmae as a single clade comprised of $H$. appalachianensis, $H$. occidentalis and $H$. rosea, but with high support (94\% MLBS). Our Supermatrix analysis also has high support for the Pseudofirmae clade (96\% MLBS; Fig. 2), but the type of sect. Microsporae (Hygrocybe aff. citrinovirens) is embedded close to the base, possibly from long-branch attraction though the ITS analysis by Dentinger et al. (unpublished) also shows the same topology; H. rosea is not included in Dentinger et al.'s ITS and LSU analyses.

Species included Type species: Hygrocybe appalachianensis (Hesler \& A.H. Sm.) Kronaw. Hygrocybe chloochlora, H. occidentalis, $H$. cf. neofirma (MCA-1721), $H$. aff. neofirma (BZ-1926), H. aff. prieta, H. rosea and H. trinitensis (Dennis) Pegler are included here based on both molecular and micromorphological data. The following species are included based on macrobasidia morphology: $H$. amazonensis Singer, $H$. brunneosquamosa Lodge \& S.A. Cantrell, $H$. campinaranae Singer, H. chamaeleon (Cibula) D.P. Lewis \& Ovrebo, $H$. cheilocystidiata Courtec., $H$. cinereofirma Lodge, S.A. Cantrell \& T.J. Baroni, H. earlei (Murrill) Pegler, $H$. flavocampanulata S.A. Cantrell \& Lodge, H. guyanensis Courtec., $H$. helvolofirma Pegler, H. hondurensis Murrill, $H$. laboyi S.A. Cantrell \& Lodge, H. lutea (Beeli) Heinem., $H$. megistospora Singer, H. miniatofirma S.A. Cantrell \& Lodge, H. mississippiensis D.P. Lewis \& Ovrebo, H. naranjana
Pegler, H. neofirma Lodge \& S.A. Cantrell, H. nouraguensis Courtec., H. olivaceofirma Lodge, S.A. Cantrell \& NievesRiv. and Hygrophorus alutaceus Berk. \& Broome.

Comments Species in sect. Pseudofirmae, such as $H$. appalachianensis, often have staggered development of the macro- and microbasidia. The holotype of $H$. appalachianensis was not fully mature, and the description of basidia was only for microbasidia while the immature macrobasidia were described as pleurocystidia. There were mature macrobasidia in the holotype on the lamellae close to the juncture of the stipe and pileus, which accounts for the macrospores that were described; the microspores, however, were present but ignored.

Hygrocybe rosea was found upon re-examination to have weakly dimorphic basidia and spores, consistent with phylogenetic placement as a basal species in sect. Pseudofirmae. Macrobasidia in all of the species in the H. appalachianensis clade are clavate-stipitate (Fig. 7) while those in the $H$. occidentalis- - . neofirma clade are clavate and expand gradually toward the apex (Fig. 8), so they might eventually be accorded status of subsections in Pseudofirmae. Macrobasidia of sect. Pseudofirmae are clavate or clavate-stipitate whereas those of $H$. firma, which is now placed in subg. Pseudohygrocybe, are cylindric to narrowly clavate. Furthermore, the ratio of macrobasidia to macrospore length is generally less than 5 in Pseudofirmae, as typical of subg. Hygrocybe, and exceeds 5 in H. firma, typical of subg. Pseudohygrocybe. Further revision of sect. Pseudofirmae with greater taxon sampling for molecular analyses is needed. Hygrophorus alutaceus was erroneously listed as a synonym of Hygrocybe firma by Pegler (1986) because it bears the same collection number (Petch 880) as the type of H. firma, but the diagnoses described the pileus as glabrous in $H$. alutaceus whereas the pileus of $H$. firma was described as tomentose. Annotation of the type of $H$. alutaceus by DJL and SAC shows the macrobasidia are broadly clavate (39$46 \times 10.7-18 \mu \mathrm{m})$ and the pileipellis is a repent ixocutis, unlike 


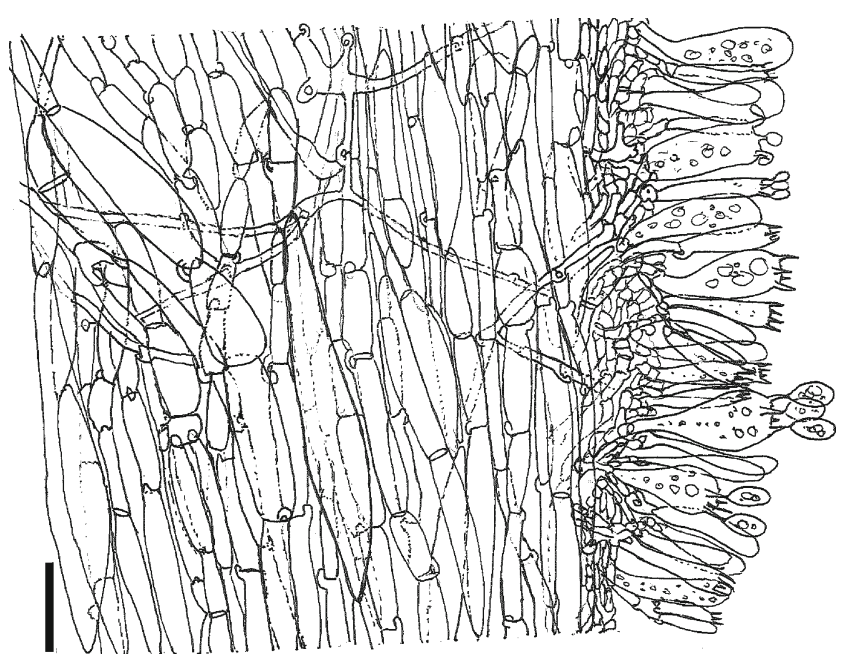

Fig. 7 Hygrocybe (subg. Hygrocybe) sect. Pseudofirmae. Hygrocybe appalachianensis lamellar cross section, showing macrobasidia rooted more deeply in the hymenium than the microbasidia (Roody, DMWV00953). Scale bar $=20 \mu \mathrm{m}$

the type of $H$. firma with narrowly clavate macrobasidia of (36-60×6.4-7.2 $\mu \mathrm{m})$, and a disrupted cutis transitioning to a trichodermium that is lacking gelatinization.

Hygrocybe [subg. Hygrocybe] sect. Microsporae Boertm., The genus Hygrocybe. Fungi of Northern Europe (Greve) 1: 16 (1995).

Type species: Hygrocybe citrinovirens (J.E. Lange) Jul. Schäff., Ber. bayer. bot. Ges. 27: 222 (1947) [三 Camarophyllus citrinovirens J.E. Lange, Dansk Botanisk Arkiv 4(4): 20 (1923)].

Pileus conical or conico-campanulate, surface dry and appressed tomentose, squamulose or loosely fibrillose, red, orange or yellow; basidiospores mostly less than $10 \mu \mathrm{m}$ long; pileipellis a trichoderm at least in the center.

Phylogenetic support Support for a monophyletic sect. Microsporae (H. citrinovirens, $H$. intermedia and an $H$. intermedia-like collection from Tennessee labeled $H$. aff.

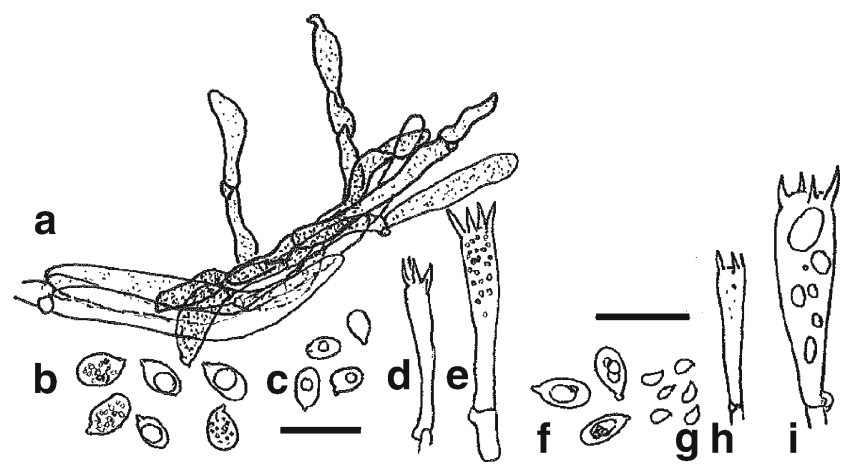

Fig. 8 Hygrocybe (subg. Hygrocybe) sect. Pseudofirmae. Hygrocybe neofirma (M.C. Aime, Guyana): a. pileipellis; b. macrospores; c. microspores; d. microbasidium; e. macrobasidium. Hygrocybe occidentalis (E. Cancerel, Puerto Rico): f. macrospores; g. microspores; h. microbasidium; i. macrobasidium. Scale bar $=20 \mu \mathrm{m}$ citrinovirens) is strong in our ITS analysis (73\% MLBS, Online Resource 8). These species plus H. helobia appear as a paraphyletic grade in the ITS analysis by Dentinger et al. (unpublished data). Support for placing H. helobia in subg. Hygrocybe using ITS sequences is strong in Dentinger et al. (unpublished), weak in our analysis (Online Resource 8), its position is unstable among analyses and it has decurrent rather than adnexed to free lamellae, so we leave it unplaced.

Species included Type species: H. citrinovirens. Hygrocybe intermedia and $H$. aff. citrinovirens from Tennessee are included based on molecular and morphological data and $H$. virescens (Hesler \& A.H. Smith) Montoya \& Bandala is included based on morphological data.

Comments Though some spores in $H$. intermedia are up to $13 \mu \mathrm{m}$ long, most are less than $10 \mu \mathrm{m}$ long, the pileipellis is similar to that of the type, and phylogenetic support for the clade is strong so it is included here. Hygrocybe aff. citrinovirens differs from $H$. intermedia only in having a smooth instead of a fibrillose stipe, but ITS sequences places it closer to H. citrinovirens.

Hygrocybe [subg. Hygrocybe] sect. Chlorophanae (Herink) Arnolds ex Candusso, Hygrophorus. Fungi europ. (Alassio) 6: 464 (1997),

$=$ Godfrinia R. Maire em. Herink, sect. Ceraceae Herink, subsect. Chlorophaninae Herink, Acta. Mus. Bot. Sept. Lib. 1: 66 (1959).

Type species: Hygrocybe chlorophana (Fr. : Fr.) Wünsche, Die Pilze: 112 (1877)

$\equiv$ Agaricus chlorophanus Fr. : Fr., Syst. mycol. (Lundae) 1: 103 (1821).

Pileus viscid or glutinous, red, orange or yellow, stipe viscid or not, hymenophoral trama hyphae parallel, exceeding $200 \mu \mathrm{m}$ in length, with tapered ends and oblique septa; pileipellis an ixocutis or ixotrichodermium.

Phylogenetic support Support for the H. chlorophana $-H$. flavescens clade is strong in the Supermatrix, ITS and LSU analyses (100 \% MLBS; Figs. 2 and 3). The 4-gene analyses place $H$. chlorophana as sister to the clade containing $H$. hypohaemacta (100\% MLBS and 1.0 BPP). Hygrocybe glutinipes appears as part of a grade near $H$. chlorophana in the Supermatrix, one of our LSU analyses (Fig. 3) and ours and Dentinger et al.'s (unpublished) ITS analyses with varying levels of support. Lodge and Ovrebo (2008) found different topologies for placing $H$. glutinipes with or apart from $H$. chlorophana, and bootstrap support for the two together of $<50 \%$ up to $86 \%$.

Species included Type species: $H$. chlorophana. Possibly $H$. flavescens, if distinct from $H$. chlorophana; placement of $H$. glutinipes is ambiguous but it is tentatively included. 
Comments Hygrocybe flavescens (Kauffman) Singer was described from Michigan, and may be a distinct species, especially if it corresponds to the eastern North American clade labeled $H$. flavescens. In fact, one of the soil clones from Michigan (GU174284) matched the ITS sequences of specimens identified as H.flavescens. Hygrocybe flavescens is said to have a viscid stipe whereas $H$. chlorophana has a moist or dry stipe, but this character is not always reliable. A hybrid ITS sequence was found in a collection with a viscid stipe from the Great Smoky Mountain National Park despite a 9$12 \%$ divergence in ITS sequences between the two clades (Hughes et al. 2010; in press). Hygrocybe glutinipes may be part of a grade within subg. Hygrocybe near H. chlorophana but is unstable in its position; it could be retained in sect. Chlorophanae based on morphology.

\section{Species unplaced in subgen. Hygrocybe.}

Hygrocybe glutinipes appears in a grade near $H$. hypohaemacta in the 4-gene backbone analyses, suggesting a relationship with sect. Velosae. Unlike spp. in sect. Velosae, H. glutinipes lacks a partial veil and has spores that are narrow and strangulated, so we regard it as unplaced.

Hygrocybe helobia resembles species in subg. Pseudohygrocybe, sect. Squamulosae, except that the long lamellar trama hyphae exceeding $400 \mu \mathrm{m}$ indicate placement in subg. Hygrocybe (Boertmann 1995, 2010). Support for placing $H$. helobia in subg. Hygrocybe is strong in the ITS analysis by Dentinger et al., confirming Boertmann's placement (1995, 2010). The position of $H$. helobia is unstable, however. Our ITS analysis places $H$. helobia as sister to sect. Microsporae, Dentinger et al.'s (unpublished) places it sister to H. intermedia and near $H$. citrinovirens, whereas our Supermatrix and LSU analyses place it with high support (90\%-100\% ML BS) in the $H$. miniata clade in subg. Pseudohygrocybe. The $H$. helobia clade appears to be a species complex that is strongly supported in our ITS analysis (91\% MLBS, Online Resource 8) as well as in the ITS analysis by Dentinger et al. (unpublished, $100 \%$ MLBS).

Hygrocybe subgen. Pseudohygrocybe Bon, Doc. Mycol. 6 (24): 42 (1976).

Type species: Hygrocybe coccinea (Schaeff.) Fr., Epicr. syst. mycol. (Upsaliae): 330 (1838) [1836-1838],

EAgaricus coccineus Schaeff. Fung. Bavar. Palat. 4: 70 (1774),

E Pseudohygrocybe coccinea (Schaeff.: Fr.) Kovalenko (1988).

[NOT Agaricus coccineus Scop., Fl. carniol., (Wein) Edn. 2: 436 (1772), an earlier homonym of a sanctioned name]

Lamellar trama typically subregular, hyphal elements generally $<140 \mu \mathrm{m}$ long, frequently $<80 \mu \mathrm{m}$ long, mostly with right-angled septations. Basidia and spores mostly monomorphic in size in one section and dimorphic in length in the other section, spore walls hyaline, usually smooth, rarely with spines; mean ratio of basidiospore to basidia length usually $>5$. Basidiomes typically with bright DOPA based pigments, rarely colorless or with browning reactions from conversion of DOPA pigments.

Phylogenetic support Subg. Pseudohygrocybe appears as a paraphyletic grade with the monophyletic subg. Hygrocybe clade on a long branch in our 4-gene backbone, Supermatrix, ITS-LSU analysis and ours and Seitzman et al.'s (2011) ITS analyses. Our LSU analysis of tribe Hygrocybeae (not shown), however, has strong support (87\% MLBS) for subg. Pseudohygrocybe as sister to subg. Hygrocybe. Similarly strong support for a monophyletic Pseudohygrocybe as sister to subg. Hygrocybe was previously found in a multigene Supermatrix analysis by Matheny et al. (2006, $100 \%$ MLBS, 1.0 BPP). While the same sister-clade topology appears in our full LSU and our Hygrocybe LSU analyses, as well as in an LSU analysis by Moncalvo et al. (2002) and an ITS analysis by Babos et al. (2011), bootstrap support is lacking in those analyses.

\section{Sections included Coccineae and Firmae.}

Comments The basionym of the type species, $H$. coccinea, has sometimes been confused with Agaricus coccineus Scop. (a diminutive species of Mycena), which is an earlier homonym of a conserved name. In pers. comm. from $\mathrm{S}$. Pennycook (13 Apr 2012), he explained: "In the sanctioning work (p. 105), Fries referred (indirectly) the name to "Pers Obs. Myc. 2. p. 49. Syn. 334. Wulf. In Jacq. Coll. 2. p. 106. [etc.]". Wulfen is the earliest of the numerous references. However, Wulfen (Misc. Austriac. 2: 106. 1781) explicitly referred the name to Schaeffer, and so did Persoon (Syn. Meth. Fung.: 334. 1801). In the 1821 volume index (p. 508), Fries cited the name as "coccineus Wulf."; and in Syst. Mycol. Index Alphabeticus (1832, p. 13; also part of the sanctioning works) he cited the sanctioned $A$. coccineus as "Wulf. Pers." (along with four unsanctioned $A$. coccineus homonyms), but in Epicrisis (1838, p. 330) and Hymen. Eur. (1874, pp. 417418), he made the indirect reference explicit, citing the basionym of Hygrophorus coccineus as Agaricus coccineus Shaeff. [Fung. Bavar. Palat. Nasc. 4: 70. 1774]."

Hygrocybe species in subg. Pseudeudohygrocybe typically differ from those in subg. Hygrocybe in having relatively short lamellar trama hyphae with right-angled septa and long basidia relative to spore length (Fig. 9). Currently, subg. Pseudohygrocybe s.s. has one widely recognized section Coccineae, while sect. Firmae Heinem. with dimorphic spores and basidia has been recognized by some tropical agaricologists (Cantrell and Lodge 2001, Courtecuisse 1989, Heim 1967, Pegler 1983), but not others (Horak 1971, Singer 1986, Young 2005). Our Hygrocybe LSU analysis (Online Resource 7) strongly recovers a sister relationship with subg. 


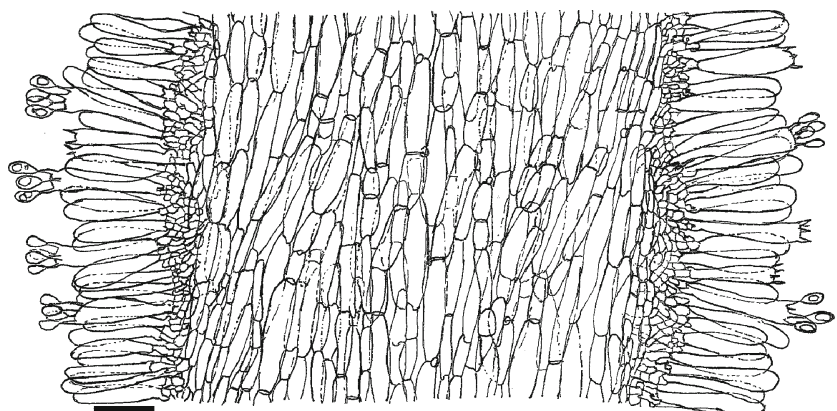

Fig. 9 Hygrocybe (subg. Pseudohygrocybe) sect. Coccineae, Hygrocybe purpureofolia lamellar cross section (NC-64, DJL05NC64). Scale bar $=20 \mu \mathrm{m}$

Hygrocybe, albeit without bootstrap support. Though $H$. miniata is universally regarded as belonging to the same section as $H$. coccinea (i.e., in sect. Coccineae), our LSU analysis of tribe Hygrocybeae instead places $H$. miniata in a strongly supported clade that is sister to sect. Firmae s.s. (100\% MLBS). We have retained sect. Firmae and leave the unnamed $H$. miniata clade unplaced. The remaining former sections of subg. Pseudohygrocybe are treated here as segregate genera. The genus Hygroaster could be reduced to a subgenus or to section rank in subg. Pseudohygrocybe to keep the genus Hygrocybe s.l. monophyletic (i.e., including the segregate genera Hygroaster, Neohygrocybe, Humidicutis, Gliophorus, Porpolomopsis and Chromosera in Hygrocybe). Sect. Coccineae s.s. currently has three subsections: Puniceae, Siccae and Squamulosae. Additional sections and subsections will likely be named in Hygrocybe subg. Pseudohygrocybe with further sampling of gene regions and taxa.

Hygrocybe sect. Coccineae Fayod, Proc. Hist. Nat. Agar. Ann. Scient. Nat. 7(9): 309 (1889).

Lectotype species: Hygrocybe coccinea (Schaeff.) Fr., Epicr. syst. mycol. (Upsaliae): 330 (1838) [1836-1838], designated by Singer (1951) [1949],

EAgaricus coccineus Schaeff. Fung. Bavar. Palat. 4: 70 (1774),

三 Pseudohygrocybe coccinea (Schaeff.: Fr.) Kovalenko (1988)].

[= Hygrocybe sect. Puniceae Fayod (1889), superfluous, illegit.],

[= Hygrocybe sect. "Inopodes" Singer (1943), nom. invalid].

Characters as in subg. Pseudohygrocybe except basidia and spores always monomorphic.

Phylogenetic support There are too few species in our 4-gene backbone analyses to draw conclusions regarding subg. Pseudohygrocybe sections. The ITS-LSU analysis shows strong (91\% MLBS) support for a branch connecting subsects. Coccineae and Siccae, while subsect. Squamulosae appears as a separate clade. The grade in our Supermatrix analysis has a branch with low support (44\% MLBS) subtending subsects. Coccineae and Siccae, while subsect. Squamulosae is basal (60\% MLBS). Our Hygrocybe LSU analysis (Online Resource 7) shows sect. Coccineae as a grade with strong support for subsect. Squamulosae (97\% MLBS).

Subsections included There are currently three validly named subsections in sect. Coccineae, namely Coccineae, Siccae and Squamulosae.

Comments Both Hygrocybe sects Coccineae and Puniceae were first validly published by Fayod (1889) in the same publication. Singer [(1949) 1951, p. 152] recognized that the type species of these two sections, $H$. coccinea and $H$. punicea, belonged in the same section, and between the two competing names he selected Coccineae over Puniceae. Thus sect. Coccineae is the correct name for this group. Previously, Singer (1943) had erected sect. "Inopodes", nom. invalid, which contained $H$. punicea (lacking a Latin description, Art. 36.1).

Hygrocybe [subg. Pseudohygrocybe sect. Coccinea] subsect. Coccineae (Bataille) Singer, Agar. Mod. Tax., Lilloa 22: 152 (1951)[1949].

[= Hygrocybe subsect. Puniceae (Fayod) Arnolds ex Candusso (1997), superfluous, illeg. = Hygrocybe subsect. "Inopodes" Singer (1952), nom. invalid].

Type species: Hygrocybe coccinea (Schaeff.) Fr., Epicr. syst. mycol. (Upsaliae): 330 (1838) [1836-1838]] [三 Agaricus coccineus Schaeff. Fung. Bavar. Palat. 4: 70 (1774), $\equiv$ Pseudohygrocybe coccinea (Schaeff.: Fr.) Kovalenko (1988)].

Pileus brightly colored, lubricous or viscid at least when young. Lamellae broadly adnate or slightly sinuate, sometimes with a decurrent tooth. Basidiospores usually narrow (mean Q 1.5-2.4), often constricted; mean ratio of basidia to basidiospore length $>5$. Pileipellis a persistent or ephemeral ixocutis or mixed ixocutis-ixotrichodermium with narrow hyphae (2-5 $\mu \mathrm{m}$ wide) embedded in gel over hyphae of moderate diameter (6-12 $\mu \mathrm{m}$ wide). Chains of ellipsoid to subglobose hyphal elements generally absent from the hypodermium.

Phylogenetic support Our ITS-LSU analysis strongly supports subsect. Coccineae as a monophyletic clade comprising $H$. coccinea and $H$. punicea (100\% MLBS, Fig. 4). Our Supermatrix strongly supports subsect. Coccineae $(H$. coccinea, $H$. punicea and $H$. purpureofolia) if $H$. mucronella is excluded (84\% MLBS), but support drops to $46 \%$ MLBS if the $H$. mucronella complex is included. Our large LSU analysis has $100 \%$ MLBS support for a monophyletic clade comprising the $H$. coccinea species complex, our LSU analysis of tribe Hygrocybeae has modest support (50\% ML BS) 
for a clade comprising $H$. coccinea, $H$. punicea and $H$. purpureofolia, and our ITS analysis has only weak support for the subsect. Coccineae clade. Support for including $H$. ceracea and H. constrictospora in Coccineae is low in the Supermatrix analysis (44\% MLBS), absent in our LSU analysis of tribe Hygrocybeae (Online Resource 7) and absent in ITS analyses (ours and Dentinger et al., unpublished data). Dentinger et al. (unpublished data) shows moderate support (61\% MLBS) for a clade comprising $H$. coccinea, $H$. punicea and $H$. splendidissima.

Species included Type: Hygrocybe coccinea. Hygrocybe punicea and $H$. purpureofolia are included in subsect. Coccineae based on molecular and morphological data. $H$. aurantiosplendens is similar to species in sect. Coccineae, and an ITS analysis by Dentinger et al. (unpublished data) places this species near H. coccinea, so we include it in subsect. Coccineae. There is some molecular support for including $H$. splendidissima, but we exclude it based on the dry pileus surface, narrowly attached lamellae and broader spores, which are all deviating characters. Hygrocybe ceracea, $\mathrm{H}$. constrictospora, H. insipida, H. miniata, H. mucronella, $H$. salicis-herbaceae and $H$. subminutula are tentatively excluded, though the morphology of $H$. salicis-herbaceae matches the diagnosis of $H$. subsect. Coccineae.

Comments In 1943 Singer erected Hygrocybe subsect. "Inopodes", nom. invalid, then reduced the rank to subsect. in 1951 (1949) and designated H. punicea as the type species. The name is invalid because neither it nor its basionym had a Latin description (Art. 36.1). Thus subsect. Coccineae (Bataille) Singer (1951) is the only validly published subsection name for this group in Hygrocybe. The type of $H$. subsect. Puniceae (Fayod) Arnolds ex Candusso (1997) falls into this subsection, making it superfluous, thus a nom. illegitimate.

Boertmann $(1995,2010)$ included H. aurantiosplendens, H. ceracea, H. insipida, H. punicea and H. salicis-herbacea in subsect. Coccineae. Only $H$. ceracea, $H$. coccinea and $H$. punicea are included in our Supermatrix analysis, which provides only weak support for them as comprising the same clade with $H$. constrictospora, $H$. purpureofolia, $H$. subminutula and H. mucronella. All of these species, however, share the diagnostic characters of subsect. Coccineae. Arnolds (1986a), however, placed H. constrictospora in subsect. Squamulosae instead of subsect. Coccineae based on pileipellis structure. Our Supermatrix and ITS analyses $(<50 \%$ ML BS support), and the ITS analysis by Dentinger et al. (7 \% MLBS) place H. mucronella near $H$. ceracea and $H$. insipida (plus $H$. quieta and H. salicis-herbacea in Dentinger et al., unpublished). Kovalenko (1989), Arnolds (1990) and Bon (1990) regarded H. insipida as closely related to $H$. mucronella, but Boertmann thought it was related to $H$. coccinea and $H$. ceracea. If all these species belong to the same group, then all are in agreement. Alternatively, $H$. mucronella, $H$. ceracea, $H$. insipida and $H$. subminutula may be best regarded as unplaced (see Online Resource 8). Although our Supermatrix analysis weakly supports $(61 \%$ MLBS) inclusion of $H$. reidii as basal in the $H$. ceracea $-H$. constrictospora clade, $H$. reidii differs in having a dry pileipellis with a mixture of vertical and horizontal elements, and is the type of subsect. Siccae (see below).

Hygrocybe [subg. Pseudohygrocybe sect. Coccineae] subsect. Siccae Boertm., The genus Hygrocybe, Fungi of Northern Europe (Greve) 1:15 (1995).

Type species: Hygrocybe reidii Kühner, Bull. trimest. Soc. mycol. Fr. 92: 463 (1976).

Pileus smooth, matt, dry or slightly greasy when young from an ephemeral ixicutis. Stipe dry and smooth. Pileipellis hyphae of intermediate diameter (3-9 $\mu \mathrm{m}$ wide), with interwoven horizontal and vertical elements; ovoid to subglobose elements absent from the hypodermium. Basidiospores constricted and rather narrow, mean Q 1.6-2.1; mean ratio of basidia to basidiospore length $>5$. Some species have characteristic odors.

Phylogenetic support Elements of subsect. Siccae are weakly supported in ITS analyses (27\% MLBS for $H$. reidii and $H$. constrictospora in our analysis, Online Resource 8, and $34 \%$ MLBS in Dentinger et al., unpublished). These two species appear in the same clade in our Supermatrix analysis (61\% MLBS) but together with $H$. parvula and $H$. ceracea. Using ITS analyses, $H$. quieta appears on a separate branch emerging from the backbone in our analysis, while it appears near $H$. ceracea and $H$. mucronella in the analysis by Dentinger et al. (unpublished data). In our ITS-LSU analysis, $H$. reidii is recovered as sister to $H$. miniata (Fig. 4). We have tentatively retained sect. Siccae because the type species is not included with strong support in other clades.

Species included Type species: H. reidii Kühner. There is morphological and some phylogenetic support for including $H$. constrictospora in this subsection.

Comments Boertmann (1995) included H. constrictospora, $H$. quieta, $H$. splendidissima, $H$. phaeococcinea, and $H$. aurantia in subsect. Siccae. The position of H. quieta is unresolved. Candusso (1997, p. 532) and Arnolds (1990) have used Hygrocybe obrussea (Fr.) Wünsche (1877) is an earlier name for Hygrophorus quietus Kühner (1947), but as noted by Bon (1990) and Boertmann (1995, 2010), the diagnosis in Fries (1821) of Agaricus obrusseus is too vague to be sure of what species was intended, and therefore a nomem dubium. As it is not the intent of this paper to resolve such issues when they do not involve type species of genera or infrageneric taxa, we have used the name $H$. quieta as we are certain that our DNA sequences represent that species. While $H$. 
phaeococcinea fits subsect. Siccae morphologically, it is allied with $H$. miniata in ITS analyses by us and Dentinger et al. (unpublished). ITS analyses (ours and Dentinger et al., unpublished data) place $H$. splendidissima as sister to $H$. punicea with strong support, but the morphological characters fit subsect. Siccae and not Coccineae. Our molecular phylogenies show H. aurantia belongs in Cuphophyllus.

Hygrocybe [subg. Pseudohygrocybe sect. Coccineae] subsect. Squamulosae (Bataille) Singer, Lilloa 22: 152 (1951) [1949]

[三 Hygrocybe subsect. Turundae (Herink) Bon, Doc. Mycol. 19(75): 56 (1989), superfluous, nom. illeg.].

Type species: Hygrocybe turunda (Fr.) P. Karst., Bidr. Känn. Finl. Nat. Folk 32: 235 (1879)

$\equiv$ Hygrophorus turundus (Fr.: Fr.) Fr., Epicr. syst. mycol. (Upsaliae): 330 (1838),

$\equiv$ Agaricus turundus Fr., Observationes mycologicae 2: 199 (1818).

Pileus subglobose at first, depressed in center, often deeply depressed or infundibuliform at maturity; surface dry, squamulose or minutely tomentose; stipe dry and smooth. Lamellae often arcuate-decurrent. Pileipellis a trichoderm at the center, of broad hyphae (6-8-25 $\mu \mathrm{m}$ wide), typically with subglobose to ovoid elements in the hypoderm. Basidiospores relatively broad, Q 1.2-1.7 (-1.8); mean ratio of basidia to basidiospore length $>5$, constricted or not.

Phylogenetic support The core of subsect. Squamulosae is strongly supported as a monophyletic clade in our Supermatrix, full LSU, Hygrocybe LSU and ITS analyses (100\%, $99 \%, 97 \%$ and $84 \%$ MLBS, respectively). The Squamulosae clade in our Supermatrix analysis comprises $H$. caespitosa, $H$. cantharellus and H. melleofusca. Support for this branch falls below $50 \%$ in our ITS-LSU ML analysis. Babos et al. (2011), show $98 \%$ BS support for the clade comprising H. turundus and H. lepida (as H. cantharellus; see Arnolds 1986b), while Dentinger et al. (unpublished data) show $100 \%$ MLBS support for the clade comprising $H$. cantharellus s.s., H. lepida (as $H$. cantharellus), $H$. caespitosa, $H$. coccineocrenata, $H$. melleofusca and $H$. turunda using ITS alone. The ITS analsysis by Babos et al. (2011) shows moderately high support for including $H$. quieta in this clade (74\%), but the analysis by Dentinger et al. (unpublished) does not support inclusion of $H$. quieta in subsect. Squamulosae. In our ITS analysis, the subsect. Squamulosae clade comprises $H$. caespitosa, H. cantharellus, H. lepida, H. melleofusca, $H$. papillata and $H$. turunda with $84 \%$ MLBS support, but $H$. quieta appears on a long branch in a separate clade. Although $H$. miniata is traditionally treated in subsect. Squamulosae, which is consistent with the micromorphology and an ITS analysis by Babos et al. (2011) that places H. miniata in a sister clade to subsect. Squamulosae s.s.
(78 \% MLBS). Our ITS analysis (Online Resource 8) places the clade containing $H$. miniata and $H$. phaeococcinea near sect. Firmae, and the ITS analysis by Dentinger et al. shows strong support (93\% MLBS) for sect. Firmae as sister to the H. miniata-H. phaeococcinea clade, but not near subsect. Squamulosae.

Species included Type species: Hygrocybe turunda (Fr.) P. Karst. Hygrocybe cantharellus (Schwein.) P. Karst. H. caespitosa Murrill, H. coccineocrenata (P.D. Orton) M.M. Moser, H. lepida Arnolds, H. melleofusca Lodge \& Pegler (if different from $H$. caespitosa), H. substrangulata (Peck) P.D. Orton \& Watling, and H. turunda (Fr.) P. Karst. are included based on molecular and morphological data. Although the H. miniata complex has similar morphology, we tentatively exclude it from subsect. Squamulosae because it appears in a clade with sect. Firmae (H. firma, H. martinicensis), $H$. andersonii, and H. phaeococcinea in our ITS analysis, and as a strongly supported sister to sect. Firmae in our LSU analysis and the ITS analysis by Dentinger et al. (unpublished data).

Comments Singer [1949 (1951)] inadvertently combined Bataille's Hygrophorus [unranked] Squamulosi at subsection rank in the genus Hygrocybe. Konrad and Maublanc (1953) combined Bataille's Squamulosae at higher (section) rank (neither with a designated type species) and Herink published a different name, Turundae, for this group in the genus Hygrocybe with the same type (H. turundua) as Singer's subsection and he included a Latin diagnosis; Herink included $H$. cantharellus and an ambiguous species, H. marchii sensu Karsten. Excluding H. marchii, Herink's section refers to the same clade as Hygrocybe subsect. Squamulosae. Bon (1989) reduced Turundae to subsect. rank and included only the type species, which is characterized by having a pileus with darkening squamules. Hygrocybe turunda is in subsect. Squamulosae Singer (1951), making subsect. Turundae (Herink) Bon (1989) superfluous (nom. illeg.). If this clade is recognized at section rank, the correct name is Hygrocybe sect. Squamulosae (Bataille) Konrad and Maubl. (1953) based on priority.

Our Supermatrix and ITS analyses strongly support inclusion of $H$. caespitosa, H. coccineocrenata, H. lepida, $H$. melleofusca, $H$. substrangulata, and $H$. turunda in subsect. Squamulosae. Lodge and Pegler (1990) and Cantrell and Lodge (2004) incorrectly placed H. melleofusca in Hygrocybe sect. Neohygrocybe based on the brown staining reactions while Arnolds (1995) had correctly placed its sister species, H. caespitosa, in subsect. Squamulosae based on micromorphology of the pileus trama and pellis. Although Singer [(1949) 1951)], Bon (1990) and Boertmann (1995, 2010) all treated H. miniata in subsect. Squamulosae, and we have not found characters that would separate them, 
phylogenetic support for retaining $H$. miniata in subsect. Squamulosae is lacking so we have tentatively excluded it along with other species in that clade.

Hygrocybe [subg. Pseudohygrocybe] sect. Firmae Heinem., Bull. Jard. bot. État Brux. 33: 441 (1963).

Type species: Hygrocybe firma (Berk. \& Broome) Singer, Sydowia 11: 355 (1958)

$\equiv$ Hygrophorus firmus Berk. \& Broome, J. Linn. Soc., Bot. 11: 563 (1871).

Emended here by Lodge to exclude species with macrobasidia broader than the microbasidia and basidia less than 5 times the length of their basidiospores.

Characters as in Hygrocybe, sect. Coccineae, subsect. Squamulosae but differing in presence of dimorphic basidiospores and basidia. Shares dimorphic basidia and spores with Hygrocybe, subg. Hygrocybe, sect. Pseudofirmae but differs in having basidia exceeding 5 times the length of their basidiospores, narrow macrobasidia that differ from the microbasidia primarily in length (not width), presence of chains of subglobose elements in the pileus hypoderm, often a trichodermial pileipellis rather than an interrupted cutis, and long lamellar trama hyphal elements always absent.

Phylogenetic support Sect. Firmae appears in a separate, strongly supported clade in our Hygrocybe LSU analyses (85\% MLBS, Online Resource 7), and ITS analyses of Dentinger et al. (82\% MLBS, unpublished data), but it appears as a grade in our ITS analysis (Online Resource 8). Our LSU (100\% MLBS, Online Resource 7) and Dentinger et al.'s ITS ( $93 \%$ MLBS) analyses strongly support placing sect. Firmae as sister to the $H$. miniata clade, and we show only weak ITS support (47\% ML BS) for including the type of sect. Firmae in the $H$. miniata clade. The sect. Firmae $-H$. miniata clade is weakly (39\% MLBS) supported as sister to subsect. Squamulosae in our LSU analysis of tribe Hygrocybeae (Online Resource 7), (but these clades are apart in our ITSLSU analysis. The ITS analysis by Dentinger et al. (unpublished data) does not place sect. Firmae near subsect. Squamulosae.

Species included Type species: Hygrocybe firma. Hygrocybe martinicensis Pegler \& Fiard is included based on phylogenetic and morphological data. Based on morphology of the pileipellis and mean ratios of basidia to basidiospore lengths, H. anisa (Berk. \& Broome) Pegler and possibly H. batistae Singer are tentatively included.

Comments Sect. Firmae was delineated by Heinemann (1963) based on presence of dimorphic basidiospores and basidia, and has been recognized by some tropical agaricologists (Cantrell and Lodge 2001, Courtecuisse 1989, Heim 1967; Pegler 1983), but not others (Horak 1971, Singer 1986, Young 2005). It is now apparent based on our phylogenetic analyses that dimorphic basidiospores and basidia arose several times, appearing in two clades of subg. Hygrocybe (sects. Pseudohygrocybe and Velosae) and one strongly supported monophyletic clade (sect. Firmae ss, Dentinger et al., unpublished data) in subg. Pseudohygrocybe. Species in sect. Firmae can be differentiated from those with dimorphic spores and basidia in subg. Hygrocybe based on the micromorphological features noted in the emended diagnosis above. Species in sect. Firmae have narrow macrobasidia, broad hyphae in the pileipellis and globose mixed with stipitate-capitate elements in the hypodermium, similar to the globose to subglobose elements in the hypoderm of $H$. cantharellus and related species in subsect. Squamulosae (Fig. 10). Other than the presence of dimorphic basidiospores and basidia, sect. Firmae micromorphologically resembles species in subsect. Squamulosae, where Singer (1986) placed it, and the $H$. miniata species complex, which Singer and others also placed in subsect. Squamulosae. Despite the micromorphological similarities, phylogenetic analyses by us and by Dentinger et al. (unpublished data) suggest a strong relationship between sect. Firmae and the H. miniata complex, but a weak or absent relationship between that combined clade and subsect. Squamulosae. Additional analyses including more species and gene regions will be needed to resolve relationships among these clades. In keeping with making minimal changes in classification unless strongly justified by phylogenetic analyses, we have retained sect. Firmae and left the $H$. miniata clade unplaced.

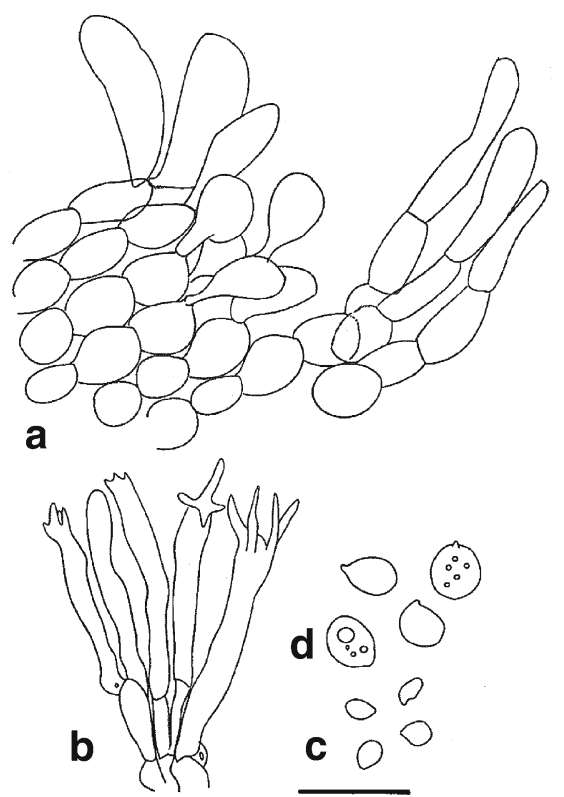

Fig. 10 Hygrocybe (subg. Pseudohygrocybe) sect. Firmae. Hygrocybe firma (type): a. pileipellis; b. hymenium showing macro- and microbasidia; c. microspores; d. macrospores. Scale bar $=20 \mu \mathrm{m}$ 


\section{Species unplaced subgen. Pseudohygrocybe}

Hygrocybe miniata, $H$. miniata $f$. longipes, and $H$. phaeococcinea appear in a well supported clade that is sister to sect. Firmae in our ITS analysis of Hygrocybe s.s. Similarly, the $H$. miniata species complex falls in a strongly supported ( $85 \%$ MLBS) sister clade to sect. Firmae (H. firma s.s. and H. martinicensis) in our LSU analysis of tribe Hygrocybeae (Online Resource 7). Hygrocybe miniata shares with subsect. Squamulosae large diameter pileipellis hyphae $(5-18 \mu \mathrm{m})$, presence of subglobose elements in the pileus hypoderm and small mean spore Q (1.3-1.6). Consequently, Singer [(1949) 1951), Bon (1990) and Boertmann (1995, 2010)] all treated $H$. miniata in subsect. Squamulosae. The H. miniata - sect. Firmae clade (100\% MLBS) appears as sister to subsect. Squamulosae (97 \% MLBS) with low support (39\% MLBS) in our LSU analysis of tribe Hygrocybeae while the H. miniata complex and sect. Squamulosae appeared in sister clades with strong support (77 \% MLBS) in the ITS analysis by Babos et al. (2011). In our Supermatrix analysis, $H$. miniata $\mathrm{f}$. longipes is included in the basal clade of subgen. Hygrocybe with $H$. helobia, but without significant bootstrap support (32\% ML); the short lamellar trama hyphae in $H$. miniata argues against that placement. Inclusion of $H$. firma, the type of sect. Firmae, as sister to the H. miniata clade, and these together as sister to sect. Coccineae subsect. Squamulosae is problematical on several levels. Species in sect. Firmae have dimorphic spores and basidia, but otherwise they have all the diagnostic characters of subsect. Squamulosae and species in the H. miniata clade. Singer (1986), Horak (1990) and Young (2005) treated Hygrocybe with dimorphic basidia as members of subg. Pseudohygrocybe, and the phylogenetic placement and micromorphology of the basidiomes of $H$. firma are concordant with that placement. Singer (1986) frequently included dimorphic basidiospores and basidia in his description of Hygrocybe sect. Coccineae, subsect. Squamulosae, but the phylogenetic analyses presented here and the analysis by Dentinger et al. (unpublished) place the sect. Firmae - H. miniata clade either weakly together with or apart from subsect. Squamulosae. Placing the H. miniata complex as a new subsection of sect. Firmae is one possible solution, but it would neccesitate emending the description of sect. Firmae to include species with monomorphic basidia and spores. There is currently no valid name for a subsection typified by $H$. miniata. Recognizing the $H$. miniata clade at section rank is another option, but sect. Miniatae Singer (1943) was not validly published (Art. 36.1). Raising subsect. Squamulosae to section rank also needs to be considered. We have refrained from making such changes, leaving the $H$. miniata clade unplaced, and sect. Firmae and sect. Coccineae, subsect. Squamulosae at their present ranks.

Hygrocybe calciphila has all the characters of sect. Coccineae subsect. Squamulosae, but its position is unstable between ITS and paired ITS-LSU analyses. In our ITS-LSU analysis and Dentinger et al.'s (unpublished) ITS analysis, $H$. calciphila falls between subg. Hygrocybe and Pseudohygrocybe without support.

\section{Hygroaster Singer, Sydowia 9(1-6): 370 (1955).}

Type species: Hygroaster nodulisporus (Dennis) Singer, Sydowia 9(1-6): 370 (1955)

三 Hygrophorus nodulisporus Dennis, Kew Bull. 8(2): 259 (1953).

Emended here by Lodge to exclude temperate species, basidiomes with bright pigments and basidiospores that are subangular or are not globose or subglobose.

Pileus indented, not viscid, fuscous or white, lacking bright pigments. Lamellae thick, decurrent, distant or subdistant. Basidiospores subglobose or globose, not polygonal in outline; spines long conical with blunt or acute apices, hyaline, inamyloid, not cyanophilous; ratio of basidia to basidiospore lengths (excluding ornaments) $>5$; lamellar trama subregular, hyphal elements short, central strand pigmented in pigmented species; clamp connections usually absent throughout the basidiomes; pigments mostly vacuolar, but pileipellis hyphae may be lightly encrusted; habit terrestrial in wet tropical forests, so far confined to the neotropics. Differing from Omphaliaster in lacking heavily encrusting pigments, if pigmented, absence of pseudocystidia in the hymenium, subregular rather than regular lamellar trama, absence of clamp connections, growing on mineral soil or humus rather than with mosses on small shrubs and rotting wood, and tropical rather than primarily temperate-boreal in distribution.

Phylogenetic support Support for a monophyletic clade represented by H. nodulisporus and H. albellus is strong in the 4-gene backbone analysis (98\% MLBS and $100 \%$ BPP), LSU analysis (92\%), and Supermatrix (75\% MLBS). Support for Hygroaster as sister to Hygrocybe is strong (98\%, and $96 \%$, MLBS in our 4-gene backbone and Supermatrix, analyses, respectively).

Species included Type species: H. nodulisporus. Placement of $H$. albellus Singer in Hygroaster is confirmed by molecular phylogeny. It is ambiguous as to whether $H$. cleefii FrancoMolano \& López-Quintero belongs in Hygroaster as the presence of clamp connections, broadly ellipsoid rather than globose spore shape and viscid pileus are deviating characters.

Comments Hygroaster was originally described as a monotypic genus by Singer (1955) to accommodate Hygrophorus nodulisporus Dennis (1953) from Trinidad. Singer then added H. albellus in 1989. While both of Singer's species lack the bright pigments that are typically found in Hygrocybe s.s., the morphology of the lamellar trama and subhymenium are typical of Hygrocybe (Fig. 11), and the molecular phylogenies strongly support it as the sister clade to Hygrocybe. It is 


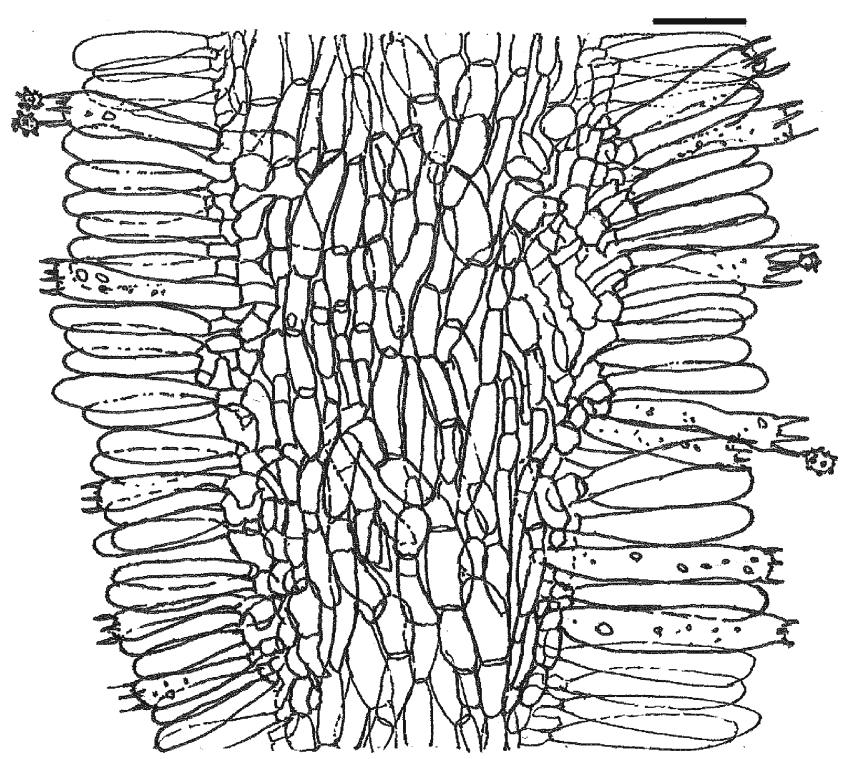

Fig. 11 Hygroaster nodulisporus lamellar cross section (PR-6378, Puerto Rico). Scale bar $=20 \mu \mathrm{m}$

unknown if the dark pigment in H. nodulisporus is a betalain, as in Hygrocybe. If the segregate genera (e.g., Gliophorus, Humidicutis, Neohygrocybe and Porpolomopsis) are treated as sections within the genus Hygrocybe, Hygroaster would need to be reduced in rank to keep Hygrocybe from being polyphyletic. Hesler and Smith (1963) reduced the rank of Hygroaster to a section, but in the genus Hygrophorus rather than Hygrocybe. Treatment of nodulose-spored species of Hygroaster among the smooth spored Hygrocybe is not unreasonable. Several species of Hygrocybe have variants that produce spores with conical spines, such as $H$. anomala, $H$. insipida and H. kula (Boertmann 1995; Young 2005). It is therefore likely that the presence or absence of spines on spores in Tribe Hygrocybeae results from mutation or repression/derepression a single gene. It is unkown if the fuscous pigment in H. nodulisporus is a DOPA betalaine, as in Hygrocybe, or another type (Online Resource 4).

In the original description by Singer, the lamellar trama of the type species, H. nodulisporus, was bilateral with a central slightly interwoven strand and divergent hyphae in a gelatinous matrix in the lateral strands. Neither we nor Hesler and Smith (1963) found evidence of gelatinization or bilateral structure in the type, and we have not seen these characters in subsequent collections of $H$. nodulisporus (Fig. 11), though the central part of the trama is darkly pigmented. In 1986, Singer changed the diagnosis of the trama to subbilateral with pigmented central strand in pigmented species.

Singer's (1986) tribe Hygroastreae comprises Hygroaster and Omphaliaster, but is polyphyletic, as is Ludwig's (1997) concept of Hygroaster in which he combined species of Omphaliaster in the genus Hygroaster. As noted by FrancoMolano and López-Quintero, most of the species placed in Hygroaster belong elsewhere. The European species described in Hygroaster by Horak (1966, H. kyrtosporus and $H$. nauseodulcis) were transferred by Noordeloos (1983) to Omphaliaster (between Tricholomataceae tribe Lyophylleae and the Tricholomatoid clade in Moncalvo et al. 2002; in the Tricholomatoid clade in Matheny et al. 2006). Kühner (pers. com. to EH) suggested that $H$. kyrtosporus did not belong with $H$. asterosporus and $H$. borealis (both now in Omphaliaster). The caulocystidia and the small, smooth ovoid spores attached to basidia in $H$. kyrtosporus are consistant with Omphalina spp., while the very large nodulose spores might be chlamedospores of a parasite as they closely resemble those of Nyctalis parasitica. Singer (1962) [1961] transferred Omphalia asterospora into Hygroaster, but Lamoure (1971) transferred it to Omphaliaster. The transfer of Rhodocybe ianthinocystis into Hygroaster by Ludwig (1997) is rejected in favor of placement by Baroni (1981) in Omphaliaster based on the presence of pseudocystidia in the hymenium, parallel lamellar trama hyphae and lower ratio of basidia to basidiospore lengths (4-4.5 according to Baroni, but up to 5.2 according to Singer, versus 5.5-7 in Hygroaster). Singer (1986) suggested an alternative placement of this species in Asproinocybe. While Hygroaster lacteus E. Ludw. and Ryberg (Ludwig 1997) described from Europe has nodulose spores, it deviates from Hygroaster s.s. in having prominent pseudocystidia and clamp connections. The nodulose spore ornamentation in H. lacteus is unlike the ornaments on Omphaliaster spores, and DNA sequencing will likely be needed to resolve its affinities. Placement of several tropical species assigned to Hygroaster is also complex. The South American $H$. iguazuensis Lechner \& J.E. Wright is bright orange and has spores that are more elongated and polygonal in outline, resembling nodulose-spored forms in Hygrocybe anomala, and it likely belongs in Hygrocybe s.s. (Franco-Molano and LópezQuintero 2007). It is uncertain where the Asian H. sulcatus (Z.S. Bi) T.H. Li \& Z.S. Bi and H. trachysporus Bi belong, but presence of pleurocystidia in the former, a glutinous pileus in the latter, and presence of bright pigments, clamp connections and small Lepista-like ornamentation on broadly ellipsoid spores in both species argue against placement in Hygroaster. Hygroaster fucatus Vrinda \& Pradeep. described from India (Vrinda et al. 2012) deviates from Hygroaster in having orange pigments in the pileus, lamellae that are adnexed rather than decurrent and tinted lilac, ellipsoid spores with inocyboid ornamentation, and presence of clamp connections and pleuro- and cheilocystidia; H. fucatus is likely conspecific with or close to Asprinoinocybe russuloides that was described from Africa. The data on $H$. agumbensis Sathe \& S.M. Kulk from India are insufficient to place this species.

Tribe Humidicuteae Padamsee \& Lodge, tribe nov. MycoBank MB804050.

Type genus: Humidicutis (Singer) Singer, Sydowia 12(1-6): 225 (1959) [1958]. 
Basidiomes brightly colored or gray brown, differing from Hygrocybe in absence of DOPA based pigments except for in a few species of Neohygrocybe. Clamp connections at the base of basidia and basidioles often toruloid and then differing from those in Chromosera. Also differing from Chromosera in having regular or subregular but not interwoven lamellar context, inamyloid pileus context, and strong odors in some species.

Phylogenetic support The tribe comprising Neohygrocybe, Gliophorus, Humidicutis, and Porpolomopsis consistently appears either as a single clade that is sister to Hygroaster (with Hygroaster basal to Hygrocybe) (4-gene backbone and LSU analyses) or in adjacent clades (ITS-LSU and Supermatrix analyses). Support for a monophyletic tribe Humidicutae comprising all four genera is $89 \%$ MLBS in the 4-gene backbone analysis (99\% MLBS for it being a sister to tribes Hygrocybeae and Chromosereae), but support falls below $50 \%$ in our LSU analysis. In the ITS-LSU analysis, Neohygrocybe appears as sister to the Humidicutis Porpolomopsis clade. These four genera are usually basal to Hygroaster-Hygrocybe s.s. (tribe Hygrocybeae) and distal to Hygrophorus and other genera of Hygrophoraceae. Based on the strongly supported placement of Hygroaster-Hygrocybe s.s. as sister to the Gliophorus - Humidicutis - Neohygrocybe - Porpolomopsis clade, it is untenable to treat these groups as sections within subg. Pseudohygrocybe, where the first three have traditionally been placed. Prior to Horak (1990), Young (2005) and Boertmann (2010), who placed Porpolomopsis species in Humidicutis, Porpolomopsis was treated in subg. Hygrocybe because it has long, tapered lamellar trama hyphae - an untenable placement that would render subg. Hygrocybe polyphyletic.

Genera included Comprising the type genus, Humidicutis, together with Gliophorus, Gloioxanthomyces, Neohygrocybe and Porpolomopsis.

Comments These segregate genera are often treated at subgenus or section rank within the genus Hygrocybe (Table 1), which is justifiable as long as the genus Hygroaster is reduced to a subgenus so it doesn't render Hygrocybe polyphyletic. We have selected subgeneric over section ranks for recommended names when using Hygrocybe s.l. (Table 1) because they are strongly divergent, and there are more validly published names available when they are treated at this rank.

Neohygrocybe Herink, Sb., Severocesk. Mus., Prír. Vedy 1: 71 (1959).

Type species: Neohygrocbye ovina (Bull. : Fr.) Herink, Sb. Severocesk. Mus., Prír. Vedy 1: 72 (1959)

इ Hygrophorus ovinus (Bull. : Fr.) Fr., Epicr. syst. mycol. (Upsaliae): 328 (1838) [1836-1838],
三Agaricus ovinus Bull., Herbier de la France 13: 592 and plate 580 (1793)] Lectotype here designated as fig. $\mathbf{M}$ in Bulliard, Herbier de la France 13: plate 580 (1793)]; Epitype here designated GEDC0877, coll. Griffith, Ffriddoedd Garndolbenmaen, Wales, UK, 19 Oct 2006, K(M)187568, GenBank sequences KF291228, KF291229, KF291230.

Pileus hemispherical or campanulate, center usually umbonate and margin incurved when young, often plane or convex or with depressed center and margin lobed with age; surface dry or moist, minutely tomentose, appressed squamulose or fibrillose, often rimose; pigments grayish brown, mostly with oxidation reactions that produce red, then fuscous colors upon bruising, DOPA pigments present or absent; lamellae adnexed sinuate or broadly adnate, thick, waxy, distant and fragile; stipe central, often compressed or channeled, surface smooth, context stuffed or hollow; flesh usually with distinct odors (nitrous, chlorine or fruity); basidiospores hyaline, thin-walled, ellipsoid, oblong or broadly ellipsoid, rarely broadly ovoid or subglobose, not strangulated, guttulate in $\mathrm{KOH}$, guttules with oily contents, inamyloid; basidia 2- or 4-sterigmate, with modest basal clamp connections; basidia more than 5 times the length of the spores; lamellar trama subregular or regular, hyphae up to $200-400 \mu \mathrm{m}$ in length, with clamp connections; pseudocystidia absent or present, emanating from the context and protruding from the lamellar edge or sides, sometimes with dissolved fuscous pigment; pileipellis a loose cutis, disrupted cutis or trichoderm, often with dissolved fuscous pigment. Differs from Humidicutis, Porpolomopsis and most Gliophorus species in lacking bright pigments and clamp connections at the base of the basidia and basidioles not toruloid; differs from Gliophorus in absence of glutinous surfaces; differs from Porpolomopsis in having subregular rather than regular lamellar trama, and fuscous rather than purple pigments.

Phylogenetic support Support for a monophyletic Neohygrocybe is strong in our 4-gene backbone, Supermatrix and ITS-LSU analyses $(99 \%, 87 \%$ and $76 \%$, respectively), and moderate in our ITS analysis (Online Resource 3, $61 \%$ MLBS); $N$. nitrata was dropped from these analyses, however, because it caused instability. Support is moderate (67\% MLBS) in our LSU analysis, excluding $N$. nitrata from Turlogh Hill in North Wales, UK but including $N$. aff. nitrata from Russia (there is no significant backbone support separating the two representatives identified as $N$. nitrata). The ITS analysis of subf. Humidicutae by Dentinger et al. (unpublished) places $N$. nitrata apart from the other Neohygrocybe species along the backbone.

Sections included Neohygrocybe and Tristes.

Comments The genus Neohygrocybe was described by Herink (1959) to accommodate the gray-brown species formerly treated in Hygrocybe that lacked viscid surfaces, had 
strong odors and usually had tissues that bruised red and then fuscous. It has previously been accepted at genus rank by Kovalenko (1989), or treated within the genus Hygrocybe at the rank of either subgenus (Bon, 1990) or section (Boertmann 2010; Candusso 1997; Cantrell and Lodge 2004; Lodge and Pegler 1990, Pegler and Fiard 1978). Bon (1989) validly combined it in Hygrocybe as subg. Neohygrocybe (Herink) Bon (citing the basionym and source publication, and indirectly inferring the type species, H. ovina, was the same as the type of Neohygrocybe, as allowed in Art. 37.3). We recognize two sections in Neohygrocybe: sects. Neohygrocybe (the correct name for sect. "Ovinae" Herink, nom. invalid, Art. 22.1), and sect. Tristes (Bataille) Singer, which replaces the superfluous sect. Nitratae Herink (illeg., Art. 52.1). We have emended the diagnosis of sect. Tristes to match the narrower limits of Herink' sect. Nitratae rather than Singer's broader sect Tristes.

Herink (1959) made an attempt to erect a provisional section, "Metapodiae"nom. invalid, in Neohygrocybe for a fuscous, red-staining species with smooth, amyloid spores, Porpoloma metapodium. Singer (1986) later placed Porpoloma in the Tricholomataceae, Tribe Leucopaxilleae - a placement supported by molecular phylogenetic analysis of LSU sequences (Moncalvo et al. 2002) (see excluded genera).

Herink designated $N$. ovina as type of Neohygrocybe, mentioning both Bulliard and Fries. Thus the type of the generic name is N. ovina (Bull. : Fr.) Herink (basionym Agaricus ovinus Bull. : Fr.) and it is the type of this species epithet that is the type of the genus. The nomenclatural history of Agaricus ovinus Bull. : Fr. is complex. Fries (1821) placed Agaricus metapodius Fr. (1818) in synonymy with A. ovinus Bull. : Fr., and the figures in Bulliard's plate 580 (Herb. Fr., 1793) that Fries cited (excluding figs. a and $\mathrm{b}=$ Dermoloma) indeed represent a mixture of $A$. ovinus and A. metapodium (the latter species now in Porpoloma, Tricholomataceae), though Fries later clearly distinguished these two species (1838: 328). Agaricus ovinus Bull.: Fr., however, is a sanctioned name (Systema Mycol. 1: 109, 1821) and is thus protected against competing synonyms and homonyms (including $A$. metapodium); moreover, H. ovinus (1793/1801) has priority over A. metapodius (1818), regardless of protected status (S. Pennycook, pers. comm. 27 June 2013). Thus the use of 'type Hygrocybe ingrata' by Candusso (1997: 323) and recognition by Della Maggiora and Matteucci (2010) of H. nitiosa (A. Blytt) M.M. Moser (1967), with Hygrocybe ovina (Bull.: Fr.) Kühner ss Kühner (1926) as a facultative synonym, and exclusion of Agaricus ovinus Bull. is problematic on many levels. As Fries did not designate a type, the material cited by Fries represents a mixture of species (and collections) and we have not found a subsequent lectotype designation for A. ovinus Bull. : Fr., we have instead chosen to stabilize its concept according to Art. 9.2, 9.10, and 9.11 by designating figure $M$ in Bulliard plate 580 (Herb. Fr., 1793) as the lectotype of
Agaricus ovinus Bull. : Fr., and by designating a photo documented and sequenced collection from Wales (GEDC0877, $\mathrm{K}(\mathrm{M}) 187568$ ) as an epitype. The designated lectotype and epitype closely resemble each other and conform to the original diagnosis (both have an innately scaly pileus with split margins, a compressed stipe which indicates they are stuffed or hollow, and a slight flush of pink in the gray lamellae (but neither shows a distinct red staining, which is a character not included in the original diagnosis). The absence of characters from the diagnosis (e.g., pink staining reaction and nitrous odor, as noted by Candusso, 1997) are ignored as it is the characters that are present in a diagnosis that must match the selected lectotype and epitype. We have instead selected the lectotype and epitype based on the following characters that were included in the original diagnosis (Bull., Herb. Fr., 1793: 592) of $A$. ovinus Bull.: stipe swollen, stuffed, becoming hollow; pileus 2-6 cm diam., hemispherical, becoming umbonate, smooth to scaly, margin becoming fissured, brick colored to fuscouscinereous; lamellae few, sublunate, uncinate, broad, venose, white at first, becoming cinerous. Porpoloma metapodium has a solid, non-compressed stipe and lamellae that are not veined.

Neohygrocybe sect. Neohygrocybe. [autonym]

[三 Neohygrocybe sect. "Ovinae" Herink (1959), nom. invalid and illeg.]

Type species: Neohygrocybe ovina (Bull.: Fr.) Herink, Sb. Severocesk. Mus., Prír. Vedy 1: 72 (1959)

[三 Hygrocybe ovina (Bull.: Fr.) Kühner, Le Botaniste 17: 43 (1926), 三 Hygrophorus ovinus (Bull. : Fr.) Fr., Epicr. syst. mycol. (Upsaliae): 328 (1838) [1836-1838],

$\equiv$ Agaricus ovinus Bull., Herbier de la France 13: t. 580 (1793)].

Characters as in genus Neohygrocybe, some part of the flesh always bruising red, then fuscous; most with a distinctive nitrous, ammonia or fruity odor.

Phylogenetic support Support for a monophyletic sect. Neohygrocybe is strong in our 4-gene backbone, LSU, Supermatrix and ITS-LSU analyses $(99 \%, 67 \%, 87 \%$ and $76 \%$ MLBS, respectively). Support is moderate in our ITS analysis (61\%, Online Resource 3$)$.

Species included Type species: Neohygrocybe ovina. Additional species included based on molecular phylogenies and morphology are N. ingrata and N. subovina (Hesl. \& A.H. Sm.) Lodge \& Padamsee, comb. nov. (below). Neohygrocybe lawsonensis (A.M. Young) Lodge \& Padamsee, comb. nov. (below) is included based on morphology.

Comments This section contains most of the species known in Neohygrocybe including the type, but it has previously been called Neohygrocybe sect. "Ovinae" Herink (nom. invalid), and Hygrocybe [unranked] Ovinae Bataille. Herink (1959) 
supplied a Latin diagnosis for the unranked group, Ovini Bataille (1910), but Herink failed to cite the basionym and its place of publication as required beginning in 1953 (nom. invalid, Art. 33.4). Regardless, sect. Ovinae is invalid because the section contains the type of the genus so the name has to repeat the genus name exactly (Art. 22.1), making sect. Neohygrocybe the correct name for this group. The combinations in Hygrocybe, sect. Neohygrocybe (Herink) Bon, and immediately below it, $N$. subsect. Neohygrocybe (Herink) Bon (1989), were both validly published making Hygrocybe sect. Neohygrocybe (Herink) Candusso (1997) superfluous, nom. illeg. (Candusso, 1997: 323, was also incorrect in stating the type species of the section was $H$. ingrata; see Art. 7.4).

Neohygrocybe subovina (Hesl. \& A. H. Sm.) Lodge \& Padamsee, comb. nov.

MycoBank MB804063.

Basionym: Hygrophorus subovinus Hesler \& A. H. Sm., North American species of Hygrophorus: 162 (1963).

Type: TENNESSEE, Cade's Cove, Great Smoky Mt. National Park, 8 Jun 1957, on soil in deciduous woods, Hesler 22583, TENN.

Neohygrocybe lawsonensis (A. M. Young) Lodge \& Padamsee, comb. nov.

MycoBank MB804064.

Basionym: Hygrocybe lawsonensis A. M. Young in A. M. Young \& A. E. Wood, Austral. Syst. Bot. 10(6):981 (1997).

Type: AUSTRALIA, New South Wales, on soil in sclerophyll forest, T. Lawson, 30 May 1992, UNSW 92/211.

Neohygrocybe sect. Tristes (Bataille) Lodge \& Padamsee, comb. nov.

MycoBank MB804067.

Basionym: Hygrophorus [unranked] Tristes Bataille, Mém. Soc. émul. Doubs, sér. 8 4:183 (1910).

$\equiv$ Hygrocybe sect. Tristes (Bataille) Singer, Lilloa 22: 151 (1951) [1949]

[三 Neohygrocybe sect. "Nitratae" Herink, superfluous, nom. illeg., Art. 52.1],

Lectoype designated by Singer (1951): Hygrocybe nitrata (Pers.) Wünsche, Die Pilze: 112 (1877),

$\equiv$ Agaricus nitratus Pers., Syn. meth. fung. (Göttingen) 2: 356 (1801),

$\equiv$ Neohygrocybe nitrata (Pers.) Kovalenko, Opredelitel' Gribov SSSR (Leningrad): 40 (1989),

[三 "Neohygrocybe nitrata" (Pers.) Herink (1959), nom. invalid., Art. 33.2].

$N$. Sect. Tristes is emended here by Lodge to include only the type species.

Odor nitrous. Differs from sect. Neohygrocybe in flesh not staining red when bruised.

Phylogenetic support The collection sequenced from North Wales (as $H$. nitrata) matches the type description, so we assume that the collection sequenced from Russia is an unnamed cryptic species in sect. Nitratae. The collection identified as $N$. nitrata from N.Y. in the Supermatrix analysis is apparently $N$. ingrata. Inclusion of species of sect. Nitratae in phylogenetic analyses caused instability, but we retained them in the LSU analysis. $N$. nitrata and $N$. aff. nitrata appeared in separate clades in the LSU analysis. The LSU sequence from the Russian collection appears on a long branch near the base of sect. Neohygrocybe while the sequence from the Welsh Turlogh Hill collection appears on a long branch from the backbone. The ambiguous support for this group indicates a need for further revision with greater taxon sampling, so we have tentatively retained the section.

Species included Type species: Neohygrocybe nitrata. An unnamed taxon from Russia resembling $N$. nitrata likely also belongs here based on morophology and molecular sequences.

Comments Sect. Tristes (Bataille) Singer (1951) replaces the superfluous sect. Nitratae Herink (1959) based on priority, but we retained Herink's narrower circumscription for this group. Some collections of $N$. nitrata reportedly have faint staining reactions, (DMB) and the placement of these needs to be verified with DNA sequencing.

Porpolomopsis Bresinsky, Regensb. Mykol. Schr. 15: 145 (2008).

Type species: Porpolomopsis calyptriformis (Berk.) Bresinsky, Regensb. Mykol. Schr. 15: 145 (2008)

$\equiv$ Hygrocybe calyptriformis (Berk.) Fayod, Annls. Sci. Nat. Bot., sér. 7 9: 309 (1889),

三Agaricus calyptriformis Berk., Ann. Mag. Nat. Hist., Ser. 11: 198 (1838).

Pileus conic, conico-campanulate, convex-umbonate or cuspidate, frequently splitting through the pileus and lamellar context near the pileus margin; pigments nonencrusting and insoluble in alkali, salmon, pink, lilac, vinaceous or absent (white); lamellae narrowly attached (adnexed, narrowly sinuate) or free; pileipellis hyphae radially arranged, fusiform; basidia usually 5 or more times longer than the spore length; basidiospores hyaline, thin-walled, inamyloid, not metachromatic, ellipsoid or broadly ellipsoid, not stangulated; lamellar trama strictly regular, of long, fusiform hyphae often exceeding $140 \mu \mathrm{m}$ in length, with right-angled septa; clamp connections typically absent or rare in context and the pellis, but toruloid clamps present at base of basidia and/or basidioles. Differing from Humidicutis in narrowly attached or free lamellae, splitting of the context through the pileus and lamellae, and long, parallel, fusiform trama hyphae.

Phylogenetic support Support for a monophyletic Porpolomopsis is strong in our ITS-LSU, ITS and 4-gene 
backbone analyses (100\% MLBS, $100 \%$ MLBS, and $97 \%$ MLBS and $100 \%$ BPP), but weaker in our Supermatrix analysis (65\% ML BS). The ITS analysis by Vizzini and Ercole (2012) [2011] shows a single representative of Porpolomopis (as Humidicutis calyptriformis) on a separate, long branch emanating from the backbone that also gave rise to the Gliophorus clade.

Species included Type: Porpolomopsis calyptriformis. Species included based on molecular data are Porpolomopsis lewelliniae (Kalchbr.) Lodge, Padamsee and Cantrell, comb. nov. (below), and three unnamed species from the USA, UK and Russia. Hygrocybe pura (Peck) Murrill) is included based on morphology.

Comments Porpolomopsis was segregated from Hygrocybe by Bresinsky (2008) based on the color and absence of DOPA pigments. Most previous authors placed the type and related species in groups corresponding to Hygrocybe subg. Hygrocybe because of the conic pileus and the long lamellar trama hyphae with tapered ends (Fig. 12; Bon 1990; Candusso 1997; Kovalenko 1989, and tentatively by Singer 1986; Hesler and Smith 1963 as Hygrophorus sect. Hygrocybe, subsect. Hygrocybe; Herink 1959 as Godfrinia). Exceptions were Horak (1990) and Young (2005) who placed these species in Humidicutis, and Boertmann (2010) who placed H. calyptriformis in Hygrocybe subg. Humidicutis based on the pigments, absence or rarity of clamp connections in the context and pellis, and presence of spectacular toruloid clamp connections at the base of the basidia and basidioles. The molecular phylogenies detailed below place this clade as sister to Humidicutis.

Porpolomopsis lewelliniae (Kalchbr.) Lodge, Padamsee \&

S.A. Cantrell, comb. nov.

MycoBank MB MB804065.

Basionyn: Hygrophorus lewelliniae Kalchbr. (as 'lewellinae'), Proc. Linn. Soc. N.S.W. 7(1-2): 105 (1882)

$\equiv$ Humidicutis lewelliniae (Kalchbr.) A.M. Young, Fungi of Australia: 159, (2005).

Type: AUSTRALIA, Western Port, Victoria, 14 June 1880, M.M.R. Lewellin, holotype RB MSS A11 (MEL).

Humidicutis (Singer) Singer, Sydowia 12(1-6): 225, 1959 [1958].

Type species: Humidicutis marginata (Peck) Singer (1959),

$\equiv$ Hygrocybe marginata (Peck) Murrill [as 'Hydrocybe'], N. Amer. Fl. (New York) 9(6): 378 (1916),

$\equiv$ Hygrophorus marginatus Peck, Ann. Rpt. N.Y. State Mus. Nat. Hist. 28: 50 (1876).

Basionym: Tricholoma subg. Humidicutis Singer, Sydowia 2(1-6): 28 (1948).

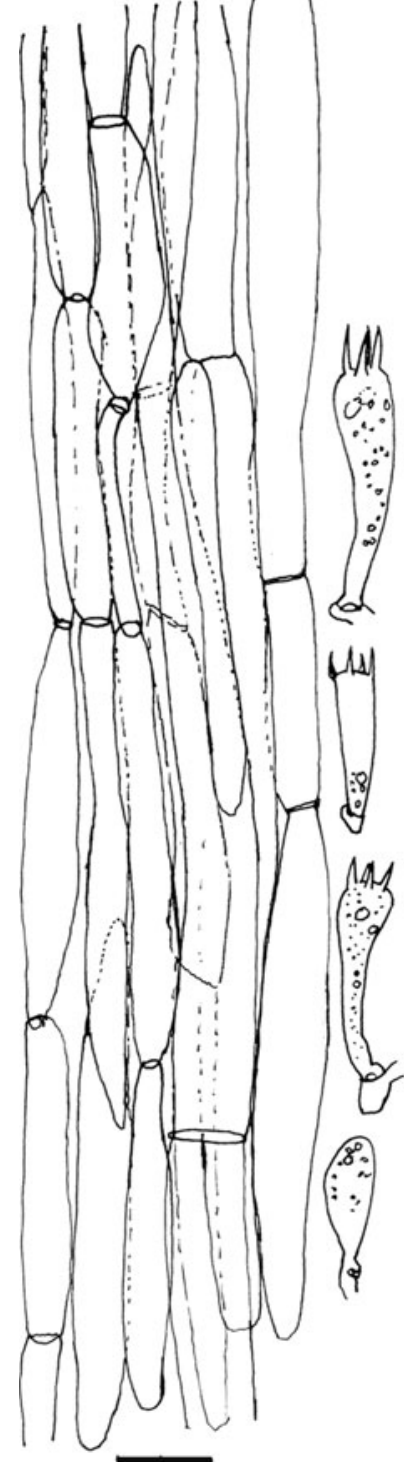

Fig. 12 Porpolomopsis aff. calyptriformis lamellar cross section (DJL05TN80). Scale bar $=20 \mu \mathrm{m}$

Humidicutis is emend. here by Lodge to include species with a viscid pileipellis.

Pileus convex, convex-umbonate or conic, margin rarely and not deeply splitting; surface subhygrophanous, moist, rarely viscid (e.g., Humidicutis arcohastata and $H$. auratocephala), colors usually bright orange, yellow, pink, reddish purple or green but can be dull olivaceous or absent; lamellae thick, sinuate or broadly adnate, often with a decurrent tooth; odor absent or disagreeable; carotenoid pigments usually present, encrusting pigments may also be present on cuticular hyphae, not soluble in alkaline solutions; pileipellis hyphae parallel, prostrate, cylindric; basidia usually 5 or more times longer than the spore length; basidiospores hyaline, thin-walled, inamyloid, not metachromatic, ellipsoid or 
broadly ellipsoid, not constricted; lamellar trama subregular or regular, of hyphae $<150 \mu \mathrm{m}$ long, rarely tapered, with rightangled septa; clamp connections absent in context and pellis, but toruloid clamps present at the base of basidia and/or basidioles.

Phylogenetic support There is $100 \%$ ML BS support for a monophyletic Humidicutis in the 4-gene backbone (Fig. 1; 1.0 B.P. Online Resource 6), and Supermatrix analyses (Fig. 2), $96 \%$ MLBS support in the ITS-LSU analysis (Fig. 6), $77 \%$ MLBS in the ITS analysis (Online Resource 3) and $83 \%$ MLBS support in the LSU analysis (Fig. 3).

Species included Type species: Humidicutis marginatus. Species included based on molecular phylogeny and morphology are Humidicutis auratocephalus (Ellis) Vizzini and Ercole (2012) [2011], two undescribed species from Puerto Rico and one from Belize. Species included based on morphology alone include $H$. arcohastata (A.M. Young) A.M. Young, $H$. bagleyi (A.M. Young) A.M. Young, H. helicoides (A.M. Young) A.M. Young, H. lilacinoviridis (A.M. Young) A.M. Young, H. luteovirens (Horak) Horak, H. multicolor (Horak) Horak, H. peleae Desjardin \& Hemmes, H. poilena Desjardin $\&$ Hemmes and $H$. viridimagentea A.M. Young \& Syme. It is uncertain whether H. taekeri (A.M. Young) A.M. Young and H. woodii (A.M. Young) A.M. Young belong here as their lamellar trama hyphae are fusiform and exceed $140 \mu \mathrm{m}$ in length. Some species placed by Horak (1990) in Humidicutis cannot be verified without analysis of the lamellar trama and molecular sequence data.

Comments Humidicutis was first described as a subgenus of Tricholoma by Singer (1948), then raised to generic rank by Singer in 1959 [1958]. It encompasses mostly brightly colored species that lack alkaline soluble pigments and lack clamp connections, except for toruloid clamps in the hymenium. Species of Humidicutis typically have rather short lamellar trama hyphae (Fig. 13) as compared to Porpolomopsis. While these appear as sister genera in the ITS-LSU and 4-gene backbone analyses, support for the branch that subtends both genera is lacking in the former and moderate (66 \% MLBS and 0.67 B.P. in the latter. We retain separate genera here as they represent two strongly supported clades, and they can be separated morphologically by the lamellae which are broadly attached in Humidicutis versus adnexed to free in Porpolomopsis, and the long, parallel tramal hyphae which corresponds to a tendency for the pileus to split down through the lamellae in Porpolomopsis versus shorter, subregular trama hyphae and rarely splitting context in Humidicutis. Nevertheless, when treated within the genus Hygrocybe, Boertmann's combination of subgen. Humidicutis in Hygrocybe

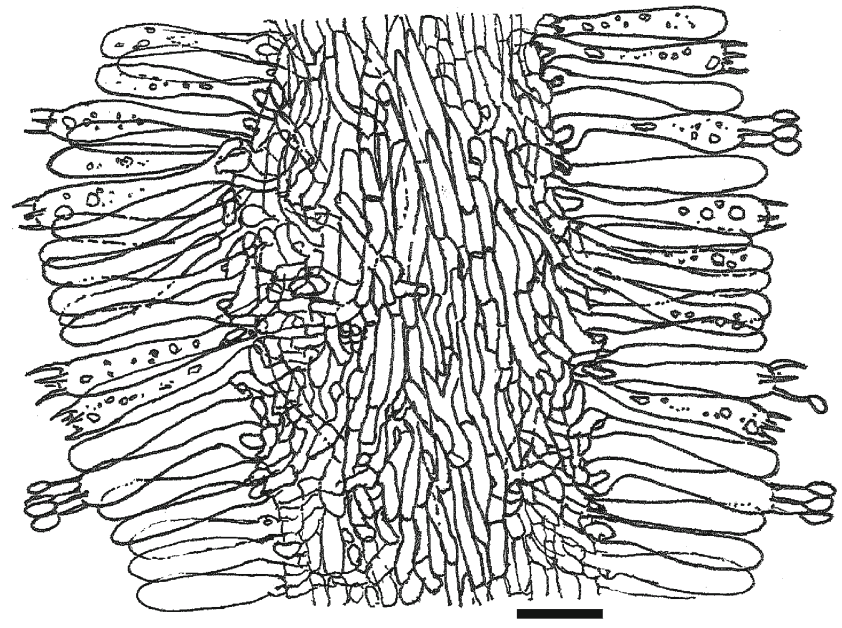

Fig. 13 Humidicutis auratocephalus lamellar cross section (DJL05TN81, Tennessee, Great Smoky Mt. Nat. Park, USA). Scale bar $=20 \mu \mathrm{m}$

(2010, Fungi of Northern Europe 1 (2nd ed): 17) is useful as it reflects the close relationship between these genera. Indeed, Young (2005) included species of Porpolomopsis in Humidicutis. If using the aggregate genus Hygrocybe s.l., the diagnosis of Hygrocybe subg. Humidicutis (Singer) Boertm. will need emending to include basidiomes with either splitting or non-splitting margins and regular or subregular lamellar context composed of either short or long trama hyphae.

Humidicutis auratocephala (Ellis) Vizzini \& Ercole, Micol. Veg. Medit. 16(2): 99 (2012) [2011],

$\equiv$ Hygrophorus auratocephalus (Ellis) Murrill, Mycologia 9(1): 40 (1917),

$\equiv$ Agaricus auratocephalus Ellis, Bull. Torrey Bot. Club 6: 75(1876).

Neotype of Agaricus auratocephalus designated here, USA: New Jersey, Newfield, in swamp, 28 July 1876, Ellis 3033, NY 774739.

Comments Murrill $(1916,1917)$ did not find the type among Ellis's collections. Hesler's annotation of Ellis' two collections of A. auratocephalus at NY says that while they are authentic, they were apparently collected after the species was described. Ellis 3033 was collected in July 1876, while the journal cover date was February 1876 (released December 1876). The Ellis \& Everhart North American Fungi exsiccatti No. 1911 noted by Hesler and Smith (1963) was collected in Aug. 1887, also after the publication date. We selected Ellis 3033 as the neotype as it was authentic material from the topotype location, and Hesler and Smith (1963) found that it matched the protologue in spore dimensions and habitat. 
Gliophorus Herink, Sb. Severocesk. Mus., Prír. Vedy 1: 72 (1959).

Type species: Gliophorus psittacinus (Schaeff. : Fr.) Herink, Sb. Severocesk. Mus., Prír. Vedy 1: 72 (1959),

$\equiv$ Hygrocybe psittacina (Schaeff. : Fr.) P. Kumm., Führ. Pilzk. (Zwickau): 112 (1871),

$\equiv$ Hygrophorus psittacinus (Schaeff.: Fr.) Fr., Epicr. syst. mycol. (Upsaliae): 332 (1838),

$\equiv$ Agaricus psittacinus Schaeff. : Fr., Fung. Bavar. Palat. 4: 704: 70, t. 301 (1774).

Pileus and stipe glutinous; DOPA based pigments absent, colors include blue, violet, pink, salmon, green, ochre yellow, yellow, brick red, gray-brown or mixtures of these, not bright red; lamellae narrowly or broadly attached, sinuate or decurrent, sometimes with a gelatinized edge; odor absent or of burned rubber; basidiospores ellipsoid, ovoid or obovoid, rarely constricted, hyaline, thin-walled, inamyloid, not metachromatic; ixocheilocystidia present or absent; basidia mostly 4-sterigmate, these and/or basidioles often with toruloid clamp connections, about five times the length of the basidiospores; lamellar trama subregular, of short elements $<140 \mu \mathrm{m}$ long; subhymenium sometimes gelatinized; clamp connections present but sometimes rare in the trama; ixotrichoderm of the pileipellis with toruloid clamps.

Phylogenetic support Gliophorus appears as a monophyletic clade only in our 4-gene backbone ML analysis (18\% MLBS, Fig. 1). Similarly, Vizzini and Ercole (2012) [2011] analysis of ITS shows a monophyletic clade lacking MLBS and Bayesian support. Our ML Supermatrix, LSU, ITS-LSU, ITS and Bayesian 4-gene analyses all show Gliophorus as a grade that is basal or sister to Porpolomopsis and Humidicutis. Support for Gliophorus as sister to the Humidicutis - Porpolomopsis clade is weak, except in our 4-gene backbone ML analysis (97\% BS).

Sections included Gliophorus, Glutinosae comb. nov. and Unguinosae.

Comments Herink (1959) erected the genus Gliophorus for species of Hygrocybe that had glutinous surfaces and usually bright pigments. The group was validly recombined as Hygrocybe subg. Gliophorus (Herink) Heinem. (1963). Bon (1990) noted the spectacular basal clamp connections on basidia in this group (termed toruloid by Young 2005) - a character shared with Humidicutis. Herink described sect. Insipidae in Gliophorus, but our molecular phylogenies placed the viscid yellow type species, $H$. insipida, in Hygrocybe subg. Pseudohygrocybe. The three remaining sections delineated by Herink (1959) are concordant with Gliophorus clades or grades in all of our phylogenetic analyses: Gliophorus (replaces G. sect. Psittacinae), Glutinosae (replaces G. sect. Laetae) and Unguinosae. In Hygrocybe subg. Gliophorus, we avoided making new combinaitions for sections as the topology of this group is unstable and may change with greater taxon sampling. Gliophorus sect. Glutinosae Kühner (1926) is valid, but would need a new combination as Hygrocybe sect. Gliophorus because Herink's basionym (1959) has priority at section rank over sect. Psittacinae (Bataille) Arnolds ex Candusso (1997). Unranked names such as Bataille's (1910) Psittacinae do not have a date for priority until they are validly combined at a designated rank (e.g., 1997 in this example). Bon (1990) treated the $H$. unguinosae-H. irrigata group and the $H$. psittacina complex together as stirps within $H$. sect. Psittacinae, which is concordant with the topology in our ITS-LSU analysis. These two groups could also be treated as subsections of Hygrocybe sect. Gliophorus, in which case, $H$. subsect. Psittacinae (Bataille) Arnolds ex Candusso (1997) is available, but $G$. sect. Unguinosae would need to be recombined in Hygrocybe at subsection rank (Table 1).

\section{Gliophorus, sect. Gliophorus [autonym]}

[= Gliophorus sect. "Psittacinae" (Bataille) Herink, Sb. Severocesk. Mus., Prír. Vedy 1: 81 (1959), nom. invalid, Art. 22.1, 22.2].

Type species: Gliophorus psittacinus (Schaeff.) Herink, Sb. Severocesk. Mus., Prír. Vedy 1: 82 (1959),

$\equiv$ Hygrocybe psittacina (Schaeff.) P. Kumm. (1871),

$\equiv$ Hygrophorus psittacinus (Schaeff.) Fr., Epicr. syst. mycol. (Upsaliae): 332 (1838),

$\equiv$ Agaricus psittacinus Schaeff., Fung. Bavar. Palat. 4: 301 (1774)].

Characters as in sect. Gliophorus, but pileus conicocampanulate or convex, some plano-convex with or without an umbo; colors typically green, purple, salmon or brick red, not gray-brown as in sect. Unguinosae; differs from sect. Glutinosae in usually having a pileus that is conicocampanulate or convex instead of plano-convex or indented, sinuate rather than decurrent lamellae, uninucleate spores, absence of gelatinization in the lamellar edge and subhymenium, and absence of ixocheilocystidia; differing from sects. Glutinosae and Unguinosae in form of basal clamp connections on basidia and basidioles (not toruloid).

Phylogenetic support There is no phylogenetic support for a monophyletic sect. Gliophorus in our analyses. Similarly, the ITS analysis by Dentinger et al. (unpublished data) shows that G. psittacinus is polyphyletic. Additional analyses with greater taxon sampling and genes are needed in this group. While this section may be polyphyletic, the long branches in this group likely contribute to topological instability and there is little or no support for separating the two putative $G$. psittacinus collections from Denmark and Sweden. It is not clear which, if either, of our two sequenced reference collections represents the type species, G. psittacinus, as both match 
the protolog and type painting. Nevertheless, they are $42.7 \%$ divergent in their ITS and $24.8 \%$ divergent in their LSU sequences. Based on ITS sequences, the collection from Denmark is only $6.2 \%$ divergent from a Hungarian collection but $18 \%$ divergent from an eastern N. American collection, while the collection from S. Sweden is conspecific $(1.3 \%$ divergence) with a collection from Japan.

Species included Type species: Gliophorus psittacinus. Additional species included based phylogeny and morphology: Gliophorus perplexus (A.H. Sm. \& Hesler) Kovalenko, plus G. europerplexus Dentinger, A.M. Ainsw., \& P.F. Cannon and G. reginae Dentinger, A.M. Ainsw., \& P.F. Cannon (Ainsworth et al., 2013) Hygrocybe stevensoniae T.W. May \& A.E. Wood is included based on morphology.

Comments Herink (1959) described this as sect. "Psittacinae", nom. invalid (Art. 22.2) and Kovalenko (1989) corrected the name to Gliophorus because this section contains the type species of the genus so it must repeat the genus name exactly but without author (Art. 22.1). We have retained Herink's (1959) and Kovalenko's (1989) narrow circumscription for this group in Gliophorus but Bon's (1990) broader circumscription in Hygrocybe (latter combination unpublished) to avoid making changes that are not strongly supported by phylogentic analyses. The extraordinarily high sequence divergence among collections identified as $H$. psittacinus indicates this is a species complex and is in need of further study. Specifically, an epitype needs to be selected and sequenced from the Austrian Alps or Bavarian Forest to stabilize the concept of the genus and sect. Gliophorus.

Gliophorus sect. Glutinosae (Kühner) Lodge \& Padamsee, comb. nov.

MycoBank MB804064.

Basionym: Hygrocybe sect. Glutinosae Kühner, Botaniste 17: 53 (1926).

Lectotype: Gliophorus laetus (Pers.: Fr.) Herink (1959) [1958], Sb. Severocesk. Mus., Prír. Vedy 1: 84, selected by Candusso, Hygrophorus. Fungi europ. (Alassio) 6: 591 (1997).

$\equiv$ Hygrocybe laeta (Pers. : Fr.) P. Kumm. (1871),

$\equiv$ Hygrophorus laetus (Pers. : Fr.) Fr., Epicr. syst. mycol. (Upsaliae): 328 (1838) [1836-1838,

三Agaricus laetus Pers., Observ. Mycol. (Lipsiae) 2: 48 (1800) [1779] : Fr.].

[三 Gliophorus sect. Laetae (Bataille) Kovalenko 1989, based on Hygrocybe sect. Laetae (Bataille) Singer (1949) 1951, is superfluous, nom. illeg.].

G. sect. Glutinosae is emended here by Lodge to exclude Gliophorus unguinosus (Fr. : Fr.) Kovalenko.

Characters as in Gliophorus; pileus plano-convex and often indented in center; colors green, olive, blue, violet, pink, salmon, yellow, buff, orange or orangish brown; differs from the other sections in having decurrent lamellae and a subhymenium that is gelatinized, at least near the lamellar edge in age, and ixocheilocystidia embedded in a gelatinous matrix; differs from sect. Gliophorus in having a flatter pileus that lacks an umbo and is often indented, spores that are often bi- rather than uninucleate, according to Kühner, and basidia with toruloid clamp connections; differs from sect. Unguinosae in usually having bright pigments and a gelatinized lamellar edge.

Phylogenetic support There is strong support for a monophyletic sect. Glutinosae in all of our phylogenetic analyses. ML bootstrap support is $100 \%$ in our ITS-LSU, $100 \%$ in our LSU and $99 \%$ in our Supermatrix and ITS analyses. Dentinger et al. (unpublished data) also show strong support (100\% MLBS) for sect. Glutinosae in their ITS analysis, after correcting misdeterminations.

Species included Type species: Gliophorus laetus (Pers.) Herink. Gliophorus graminicolor E. Horak is included based on molecular analyses and morphology. Species included based on morphology alone are G. lilacipes E. Horak, $G$. pallidus E. Horak, H. pseudograminicolor A.M. Young, G. versicolor E. Horak, Hygrocybe chromolimonea (G. Stev.) T.W. May \& A.E. Wood, H. flava (Boertm.) F. Rune, $H$. noelokelani Desjardin \& Hemmes and H. viscidobrunnea Bougher \& A.M. Young.

Comments Sect. Glutinosae was described by Kühner in 1926 and has priority over the unranked name 'Laetae' Bataille that was combined in Hygrocybe at section rank by Singer in 1951 (superfluous, nom. illeg.). Kühner indicated that since he showed that $H$. punicea was not in the same group as $H$. laeta Pers., he renamed Fayod's sect. Puniceae as Glutinosae (placing H. punicea in section Coccineae). Kühner included two species, H. laeta and H. unguinosa. Apparently Candusso (1997) interpreted Kühner's wording to indicate that the type species was H. laeta, but since Kühner's wording did not meet the criteria for designating a type, Candusso (1997) inadvertently designated $H$. laeta as the lectotype. We use Singer's (1951) concept, which excludes $H$. unguinosa and other graybrown species that lack a gelatinized lamellar margin. Sect. Glutinosae is readily recognized by the decurrent lamellae that have a gelatinized edge, and this monophyletic clade is strongly supported by all molecular phylogenies.

Gliophorus sect. Unguinosae Herink., Sb. Severocesk. Mus., Prír. Vedy 1: 81,

Type species: Agaricus unguinosus Fr. : Fr., Syst. mycol. (Lundae) 1: 101 (1821),

$\equiv$ Gliophorus unguinosus (Fr. : Fr.) Kovalenko, Mikol. Fitopatol. 22(3): 209 (1988),

$[\equiv$ "Gliophorus unguinosus" Herink, Sb. Severocesk. Mus., Prír. Vedy 1: 81 (1959), nom. invalid, Art. 41.5], 
三 Hygrocybe unguinosa (Fr. : Fr.) P. Karst., Bidr. Känn. Finl. Nat. Folk 32: 237 (1879),

= Hygrocybe irrigata (Pers. : Fr.) Bon, Doc. Mycol. 6(24): 4 (1976).

Characters as in Gliophorus but gray-brown in color, bright pigments absent; pileus broadly campanulate or convex, often umbonate; lamellae broadly attached, sinuate or adnate with a decurrent tooth or short-decurrent, edge not gelatinized; clamp connections infrequent in the context, toruloid in form at the base of basidia; basidia 5.5-6.5 times the length of the basidiospores; differs from most species in sects. Gliophorus and Glutinosae in absence of bright pigments; differs from sect. Gliophorus in having toruloid rather than modest medallion clamp connections in the hymenium; differs from sect. Glutinosae in having a convex or campanulate (not plane or indented) pileus shape and lacking a gelatinized lamellar edge with ixocheilocystidia.

Phylogenetic support Only one representative of this section, $H$. irrigata, is included in our analyses, so we cannot determine support values for this section. However, Ercole (Online Resource 3) shows $100 \%$ MLBS support for a clade comprising two collections of $H$. irrigata, from Europe and a related species from the SE USA (DJL05NC50). In our Supermatrix analysis (Fig. 2), H. irrigata is the most basal branch in the Gliophorus clade.

Type species: G. unguinosus (Fr. : Fr.) Kovalenko. Two unnamed species in the southeastern USA are included based on phylogenetic and morphological data. Arnolds (1990) and Bon (1990) recognized both G. unguinosus (Fr.) Kovalenko and $G$. irrigatus, but Boertmann $(1995,2010)$ and Candusso (1997) treat them as synonyms. Dentinger et al. (unpublished data) show a tight clade on a long branch for six collections from the UK and one each from Hungary and Denmark, which is consistent with the synonomy given in Boertmann (1995, 2010) and Candusso (1997).

Comments Herink (1959) described sect. Unguinosae for gray-brown species of Gliophorus lacking a gelatinized lamellar edge, citing as type "Gliophorus unguinosus (Fr.) comb. n.". The binomial combination was not validly published (Art. 41.5) as it lacked any citation (Art. 41.6) and accompanying description (Art. 41.8), but the fact that the genus Gliophorus was stated to be based on Hygrocybe (Fr.) Karsten p.p., and that he indicated an earilier name via citation of "(Fr.)" in that pool plus the fact that there is only one species with the validly published epithet 'unguinosa' in that limited pool, namely Agaricus unguinosus/Hygrocybe unguinosa, we believe he fulfilled the requirements for valid publication of the subgeneric sectional name by indicating the identity of the type (Art. 40.1). Singer (1986) recognized Herink's section, but his attempt to combine it in Hygrocybe was invalid because he failed to cite the original publication (Art. 33.4). Arnolds (1990), Bon (1990), Boertmann (1995, 2010) and Candusso (1997) placed H. unguinosa in sect. Glutinosae, and included the type species of Gliophorus, $H$. psittacina, in the section. The name, Gliophorus (1958), however, has priority over Psittacinae (Bataille) Arnolds ex Candusso (1997) at section rank, but that combination has not yet been made in Hygrocybe (Table 1).

Tribe Chromosereae Vizzini, Lodge, Norvell \& Redhead, tribe nov.

MycoBank MB804054.

Type genus: Chromosera Redhead, Ammirati \& Norvell, Beih. Sydowia 10: 161 (1995).

Emended by Vizzini \& Ercole, Micol. Veget. Medit. 26(2): 97 (2012) [2011].

Basidiomes omphalioid (small, with indented pileus and decurrent or arcuate-decurrent lamellae), sometimes with a gelatinized lamellar edge; pigments yellow and/or lilac; surfaces usually viscid; clamps present throughout (sometimes rare in the trama), may be medallion form but not toruloid at the basidial bases; basidia short relative to basidiospore lengths (ratio 3.6-5); basidiospores hyaline, thin-walled, inamyloid, not cyanophilic; cheilocystidia present if lamellar edge is gelatinized; lamellar trama subregular or interwoven, with or without a central subregular strand; ephemeral dextrinoid reactions occasionally present in context; pileipellis an ixotrichoderm when young, often an ixocutis with age (rarely a cutis), sometimes with ephemeral pigment bodies just below the epicutis; stipitipellis an ixocutis (rarely a cutis); mostly growing on ground in arctic-alpine habitats or on conifer wood, possibly associated with grasses and bryophytes.

Phylogenetic support Tribe Chromosereae is supported by all molecular phylogenies. Support is strong in our 4-gene backbone analysis (100\% MLBS, 1.0 BPP), Supermatrix (85\% MLBS), LSU (98 \%), ITS-LSU (100\% MLBS) and moderate in Dentinger et al.'s ITS analysis (unpublished data, $63 \%$ MLBS). Support for this clade is lower in our ITS analysis (54\% MLBS, Online Resource 3). Previous studies also support tribe Chromosereae (represented by C. cyanophylla and $C$. citrinopallida). Support shown is $90 \%$ MPBS in Moncalvo et al. (2002; LSU), $100 \%$ MLBS in Lawrey et al. (2009; ITS-LSU), and 1.0 BPP and $96 \%$ MLBS in Vizzini and Ercole (2012; ITS, with addition of $C$. viola and $C$. xanthochroa). The Supermatrix and ITS-LSU analyses place this group near Gliophorus, supporting Kühner (1980).

Genera included Tribe Chromosereae currently is comprised of the type genus, Chromosera, and a new genus, Gloioxanthomyces, erected for Hygrocybe nitida and $H$. vitellina. 
Chromosera Redhead, Ammirati \&Norvell, Beih. Sydowia 10: 161 (1995), Vizzini \& Ercole, Micol. Veget. Medit. 26(1): 97 (2012).

Type species: Agaricus cyanophyllus Fr., Öfvers. Kongl. Svensk Vet.-Akad. Förh. 18(1): 23 (1861)

$\equiv$ Chromosera cyanophylla (Fr.) Redhead, Ammirati \& Norvell, Mycotaxon 118: 456 (2012) [2011].

Emended by Vizzini \& Ercole, Micol. Veget. Medit. 26(2): 97 (2012) [2011].

Characters as in Tribe Chromosereae except for absence of gelatinization of lamellar edge and cheilocystidia; ephemeral dextrinoid reactions in the context, ephemeral pigment bodies in the pileipellis and lilac pigments sometimes present.

Phylogenetic support Except for our ITS analysis by Ercole which shows $62 \%$ MLBS support for Chromosera, support for this clade is the same as noted above for tribe Chromosereae. Greater taxon and gene sampling are needed to refine this group.

Subgenera included Comprising three subgenera: Chromosera, Subomphalia Vizzini, Lodge \& Padamsee, subg. nov. and subg. Oreocybe (Boertm.) Vizzini \& Lodge, comb. nov.

Comments Chromosera was proposed for what was believed a single amphi-Atlantic species, C. cyanophylla (Redhead et al. 1995, 2012) based on Agaricus cyanophyllus Fr. from Europe and A. lilacifolius Peck from the eastern USA. These species were originally classified among the omphalioid spp. in Agaricus (Omphalia), Omphalia, or Omphalina (Fries 1861; Peck 1872; Peck 1878; Quélet 1886; Murrill 1916). In the 20th century, some authors retained C. cyanophylla in Omphalina (Courtecuisse 1986; Krieglsteiner and Enderle 1987). Singer (1942) transferred A. lilacifolius to Clitocybe (a placement rejected by Bigelow, 1970), while Smith (1947) placed it in Mycena based on the dextrinoid hyphae in the stipe and pileus context and viscid stipe. While Singer (1949) [1951] accepted Smith's classification of A. lilacifolius in Mycena, Kühner (1980) placed A. cyanophyllus in Hygrocybe subg. Gliophorus but his new combination was not validly published. Maas Geesteranus (1992) subsequently excluded A. lilacifolius from Mycena based on its inamyloid spores, (erroneously) an absence of dextrinoid reaction in the lamellar context, and absence of cheilocystidia. Redhead et al. (1995) synonymized A. lilacifolius with A. cyanophylla and erected the genus Chromosera to accommodate this enigmatic taxon, believing it to be most closely allied with Mycena based on the dextrinoid context. While the genus Chromosera was validly published in 1995, an incorrect citation was used in recombining the type species as C. cyanophylla (Art. 33.5, 33.7, 33.8, MB563787), and the combination was made correctly in 2011 [2012]. Maximum parsimony analyses by
Moncalvo et al. (2002) support placement of ' $C$. cyanophylla' from western North America in the Hygrophoraceae.

Based on morphological and phylogenetic analyses, Vizzini and Ercole (2012 expanded Chromosera from a monotypic genus to include Hygrocybe viola and species formerly in Hygrocybe subg. Oreocybe Boertm. Unlike $C$. cyanophylla, dextrinoid reactions are absent from the context in subg. Oreocybe and C. viola (subg. Subomphalia). The characteristic but ephemeral pigment bodies found in the pileipellis $C$. cyanophylla are also present in subg. Oreocybe (DMB), but not in C. viola (verified in fresh material by AV). The combination of characters separating $C$. cyanophylla, $C$. viola, and subg. Oreocybe are so striking that we recognize them below as subgenera: Chromosera, Oreocybe, and Subomphalia.

Chromosera subg. Chromosera [autonym].

Type species: Agaricus cyanophyllus Fr., Öfvers. K. Svensk. Vetensk.-Akad. Förhandl. 18(1): 23 (1861),

$\equiv$ Chromosera cyanophylla Redhead, Ammirati \& Norvell in Redhead, Ammirati, Norvell, Vizzini \& Contu, Mycotaxon 118: 456 (2012) [2011].

Pileus and stipe surfaces viscid, pale yellow, sometimes with rosy vinaceous tints; lamellae arcuate-decurrent, bluish or rosy lilac; tramal tissues weakly dextrinoid, only demonstrable in fresh or recently dried collections; lamellar context regular or subregular, becoming more disorganized with age; basidiospores amygdaliform or ellipsoid, not strangulated, mean spore Q 2.3, hyaline, thin-walled, inamyloid, not cyanophilous; cheilocystidia absent; basidia short (20-25 (-29) $\mu \mathrm{m}$ long), basidium to basidiospore length ratio 3.6-5; pileipellis an ixotrichoderm, with extracellular (possibly also intracellular) pigment globules demonstrable only in fresh or recently dried collections; clamp connections throughout the basidiomes, none toruloid; lignicolous, growing on whiterotted conifer wood.

Subg. Chromosera differs from subg. Oreocybe in lignicolous habit, dextrinoid tramal tissues, regular rather than interwoven lamellar trama, and non-constricted spores. Subg. Chromosera shares non-constricted spores with $C$. viola (subg. Subomphalia) but differs in lignicolous habit rather than terrestrial among mosses, viscid pileus and stipe surfaces, dextrinoid reactions in tramal tissues, and a (sub)regular lamellar trama that lacks a subregular core of highly inflated elements flanked by strata of highly interwoven slender hyphae.

Phylogenetic support Our ITS-LSU analysis shows $100 \%$ ML BS support for a monophyletic clade on a relatively long branch comprising European and western North American ' $C$. cyanophylla' taxa. Subg. Chromosera is sister to members of subg. Oreocybe (C. citrinopallida, C. xanthochroa and/or $C$. lilacina) in our 4-gene backbone analyses (100\% MLBS, 1.0 B.P. Fig. 1 and Online Resource 6). Dentinger et al. 
(unpublished) show subg. Chromosera as a strongly supported terminal clade (96\% MLBS) emerging from a paraphyletic subg. Oreocybe grade in their ITS analysis. Others previously found high support for a sister relationship between $C$. cyanophylla and $H$. citrinopallida in analyses of LSU $(90 \%$ MPBS, Moncalvo et al. 2002), and ITS sequences (100\% BPP and $79 \%$ MLBS, Vizzini and Ercole 2012). Our Supermatrix analysis, however, places the European and western North American variants on separate branches, with $H$. citrinopallida making $C$. cyanophylla polyphyletic, but the only supported internal branch had representatives from two western US states, Washington and Wyoming. Low variation in the ITS region in Chromosera and removal of some ITS bases to align sequences across the entire Hygrophoraceae may have affected the Supermatrix analysis, and the western North American taxon may represent a separate species.

Species included Type species: Chromosera cyanophylla, currently monotypic, but likely a species complex.

Comments Subg. Chromosera was originally described as a monotypic genus for the presumed amphi-Atlantic species, $C$. cyanophylla. The type species of Chromosera, Agaricus cyanophyllus Fr., was described from Europe while Agaricus lilacifolius Peck (a replacement name for A. lilacinus Peck, illeg.) was described from eastern North America. While these two taxa were thought to be conspecific (Redhead et al. 1995), our ITS sequences from Europe and western North America are $5 \%$ divergent, and there are some morphological differences (SR) suggesting they likely represent different species. We were unsuccessful in sequencing collections of $A$. lilacifolius from eastern North America for comparison, so we are uncertain as to whether it is conspecific with the western North American taxon. Greater sampling of taxa, gene regions and geographic areas are needed in this group. A new species to be described from China may prove critical to future molecular analyses.

Chromosera subg. Oreocybe (Boertm.) Vizzini, Lodge \& Padamsee, comb. nov.

MycoBank MB804070.

Basionym: Hygrocybe sect. Oreocybe Boertm., Nordic J1 Bot. 10(3): 315 (1990),

Type species: Chromosera citrinopallida (A.H. Sm. \& Hesler) Vizzini \& Ercole, Micol. Veget. Medit. 26(2): 97 (2012) [2011]

$\equiv$ Gliophorus citrinopallidus (A.H. Sm. \& Hesler) Kovalenko (1999),

$\equiv$ Hygrocybe citrinopallida (A.H. Sm. \& Hesler) Kobayasi, Bull. natn. Sci. Mus., Tokyo 14(1): 62 (1971),

$\equiv$ Cuphophyllus citrinopallidus (A.H. Sm. \& Hesler) Bon, Docums. Mycol. 21(no. 81): 56 (1991), $\equiv$ Hygrophorus citrinopallidus A.H. Sm. \& Hesler, Sydowia (1-6): 327 (1954)].

$\equiv$ Hygrocybe subg. Oreocybe (Boertm.) Beis., Regensburger Mykologische Schriften 10: 11 (2002).

Basidiomes omphalioid (small, with indented pileus and decurrent or arcuate-decurrent lamellae); pigments yellow, buff, orange, and/or lilac to purple; surfaces viscid; lamellar context interwoven, some with a central strand of parallel hyphae; clamps present throughout and not toruloid at the basidial bases; basidia short relative to basidiospore lengths (ratio 3.6-5); some basidiospores constricted, Q 1-2.7; ephemeral greenish yellow extracellular pigment bodies present in the pileipellis; growing in soil among grasses, mosses and arctic-alpine plants. Differing from subg. Chromosera in having interwoven lamellar trama and some constricted spores, and terrestrial rather than lignicolous habit. Differing from C. viola in subg. Subomphalia by having viscid pileus and stipe surfaces, yellow to orange pigments, some constricted spores, an interwoven lamellar context lacking a differentiated central strand, presence of extracellular pigment bodies in the pileipellis, and growing in the arctic-alpine zone. Differing from subg. Chromosera in terrestrial rather than lignicolous habit, lacking dextrinoid reactions in context tissues, and having interwoven lamellar trama and some constricted spores. Differing from Glioxanthomyces nitidus and G. vitellinus in lamellar trama being interwoven rather than subregular with subglobose elements and absence of a gelatinized lamellar margin and cheilocystidia.

Phylogenetic support Subg. Oreocybe appears as a wellsupported, short-branched grade that is paraphyletic to the long-branched subg. Chromosera in our LSU, ITS-LSU and ITS analyses. MLBS support for the Oreocybe branch is $76 \%$ in our ITS-LSU, $64 \%$ in our LSU, and $68 \%$ in our ITS analysis by Ercole (Online Resource 3). Subg. Oreocybe has similar topology and support in the ITS analysis by Dentinger et al. (79 \% MLBS support for the subtending branch, and $93 \%$ MLBS support for it as sister to subg. Subomphalia, unpublished data). In our Supermatrix analysis and Vizzini \& Ercole's ITS analysis, C. citrinopallida and C. xanthochroa are intermixed with C. cyanophylla, but without support for the internal branches. This may be an artifact of including the ITS region, which varies little in this group, and editing out variation in order to align sequences across the family.

Species included Type species: Chromosera citrinopallida. Species included based on molecular phylogenies and morphology are C. xanthochroa (P.D. Orton) Vizzini \& Ercole, and C. lilacina (P. Karst.) Vizzini \& Ercole.

Comments Subgen. Oreocybe was originally described by Boertmann (1990) as a section in Hygrocybe subg. Cuphophyllus because of the interwoven lamellar trama and 
decurrent lamellae - a placement retained by Candusso (1997). Oreocybe was then raised to subgenus rank in Hygrocybe by Beisenherz (2002). Kovalenko (1999) placed these species in Gliophorus. There is a disagreement in ITS sequences between Boertmann's Danish and other Scandinavian collections deposited at $\mathrm{O}$ versus collections from the UK deposited at Kew with regard to determinations as C. citrinopallida and C. xanthochroa (they are reversed); here we use sequences of the Kew collections for reference as their determinations were verified by matching to sequences of the types and to facilitate comparisons with Dentinger et al. (unpublished). The Scandinavian collections were renamed by matching them to the Kew reference sequences. Boertmann has examined the Kew collections and agrees with their determinations, so the characters used to distinguish these two species need to be re-examined as they may not be reliable across the entire geographic range.

Chromosera subg. Subomphalia Vizzini, Lodge \& Padamsee, subg. nov.

MycoBank MB804071.

Type species: Chromosera viola (J. Geesink \& Bas) Vizzini \& Ercole, Micol. Veget. Medit. 26(2): 97 (2012) [2011].

$\equiv$ Hygrocybe viola J. Geesink \& Bas, in Arnolds, Persoonia 12(4): 478 (1985a),

$\equiv$ Cuphophyllus viola (J. Geesink \& Bas) Bon, Doc. Mycol. 19(76): 73 (1989).

Omphalioid, pileus indented in center, basidiomes purple or lilac, yellow pigments absent; surfaces dry; dextrinoid reactions absent from all context tissues; clamp connections rare in the trama, some medallion clamps present at base of basidia; basidiospores hyaline, thin-walled, inamyloid, not cyanophilic, broad, Q 1.0-1.9 (mean Q 1.5), not constricted; basidia short relative to the length of the basidiospores (ratio 3.6-5); lamellar context heterogeneous with a central, subregular strand composed of short, highly inflated elements, flanked by lateral strata with highly interwoven slender hyphae. Terrestrial, often among mosses, not in arctic-alpine habitats. Differing from subg. Chromosera in dry basidiome surfaces; absence of yellow pigments, extracellular pigment bodies in the pileipellis and dextrinoid reactions in tramal tissues; presence of a heterogeneous lamellar trama; and a terricolous (possibly moss-associated) rather than lignicolous habit. Differing from subg. Oreocybe in dry rather than viscid surfaces, absence of yellow pigments, absence of extracellular pigment bodies in the pileipellis, presence of a heterogeneous rather than interwoven lamellar trama, and broad non-constricted basidiospores. Differing from Gloioxanthomyces in dry rather than viscid surfaces, absence of gelatinization of the lamellar edge, absence of yellow pigments, and presence of a heterogeneous rather than interwoven lamellar trama.
Phylogenetic support Subg. Subomphalia appears on a basal branch that is long relative to others in the Chromosera clade. The branch placing the monotypic species, C. viola, as sister to subgenera Oreocybe and Chromosera has strong support: $96 \%$ MLBS and 1.0 BPP in ITS analyses by Vizzini and Ercole (Vizzini and Ercole 2012), and moderate support (62\% MLBS) in our ITS analysis (Online Resource 3) and $100 \%$ MLBS in Dentinger et al.'s (unpublished) ITS analysis.

Species included Type species: Chromosera viola.

Comments This new, currently monotypic subgenus in Chromosera is erected for C. viola. It was originally described in Hygrocybe by Geesink \& Bas, then transferred to Cuphophyllus by Bon because of the highly interwoven hyphae in the lateral strands of the lamellar context.

Gloioxanthomyces Lodge, Vizzini, Ercole \& Boertm., gen. nov.

MycoBank MB804073

Type species: Hygrophorus vitellinus Fr., Monogr. Hymenomyc. Suec. (Upsaliae) 2(2): 312 (1863),

$\equiv$ Gloioxanthomyces vitellinus (Fr.) Lodge, Vizzini, Ercole \& Boertm.

Lectotype here designated for Hygrophorus vitellinus $\mathrm{Fr}$. is an illustration cited in Fries, Monogr. Hymenomyc. Suec. (Upsaliae) 2(2): 312 (1863): Icon. t. 167, f. 3.

Pileus and stipe yellow or orangish yellow, viscid; lamellae arcuate-decurrent, yellow, with a gelatinized or subgelatinized edge, edged often darker (translucent). Basidiospores ellipsoid or subglobose, Q 1.0-1.6, mean Q 1.2-1.3, guttulate in $\mathrm{KOH}$, with a wide hilar appendix, inamyloid, acyanophilic, hyaline, smooth; basidia usually 4 -sterigmate, with basal clamp connection occasionally a moderate medallion type, short, $30-40 \mu \mathrm{m}$ long, ratio of basidia to basidiospore length $4-5$; pileipellis and stipitipellis an ixotrichodermium or ixocutis; trama not dextrinoid; lamellar trama subregular, central strand not differentiated, elements cylindric to subglobose, some subglobose cells highly inflated to $10-30 \mu \mathrm{m}$ diam., subhymenium of tightly interwoven small diameter hyphae, not gelatinized except at the lamellar edge; edge gelatinized or subgelatinized; cheilocystidia clavate, simple or slightly lobed. Clamp connections present throughout, occasionally a modest medallion type, not toruloid. It differs from Chromosera subg. Oreocybe in presence of a gelatinized lamellar edge and cheilocystidia, and basidiospores with smaller Q (1.2-1.3 vs. 1.4-1.8) and never constricted. It differs from Chromosera subg. Chromosera in absence of dextrinoid reactions in the context, absence of pigment globules in the pileipellis and lamellar edge gelatinized with cheilocystidia present. It differs from Chromosera subg. 
Subomphalia in absence of violaceous pigments, viscid rather than dry surfaces, and absence of a central strand in the lamellar trama.

Etymology Gloio - glutinous, xantho - yellow, myces fungus.

Gloioxanthomyces vitellinus (Fr.) Lodge, Vizzini, Ercole \& Boertm., comb. nov.

MycoBank MB804074

Basionym: Hygrophorus vitellinus Fr., Monogr. Hymenomyc. Suec. (Upsaliae) 2(2): 312 (1863),

$\equiv$ Gliophorus vitellinus (Fr.) Kovalenko (1988),

[=?Hygrocybe luteolaeta Arnolds].

Lectotype for Hygrophorus vitellinus Fr. is an illustration cited by Fries in Monogr. Hymenomyc. Suec. (Upsaliae) 2(2): 312 (1863): Hym. Eur. p. 417, Icon. T. 167, f. 3. Epitype designated by Lodge, Vizzini, Ercole \& Boertmann): SWEDEN: RT 90: 6139700; 1336190, in swampy coastal chalk pasture, coll. K. Bergelin, 8 Oct. 2011, LD 1617064. (Berlgin 2012, Svensk Mykologisk Tidskrift 33: 2-8)

Gloioxanthomyces nitidus (Berk. \& M.A. Curtis) Lodge, Vizzini, Ercole \& Boertm., comb. nov.,

MycoBank MB804075

Type: USA, South Carolina, on earth in damp swamp, M.A. Curtis no. 2893, coll. H.W. Ravanel, Esq., ex herb. Berkeley 1605, K(M) 181764.

Basionym: Hygrophorus nitidus Berk. \& M.A. Curtis, Ann. Mag. nat. Hist., Ser. 2, 12: 424 (1853),

$\equiv$ Hygrocybe nitida (Berk. \& M.A. Curtis) Murrill [as 'Hydrocybe'], N. Amer. Fl. (New York) 9(6): 378 (1916),

[三 Hygrocybe nitida (Berk. \& M.A. Curtis) Malloch (2010), superfluous],

$\equiv$ Gliophorus nitidus (Berk. \& M.A. Curtis) Kovalenko, Mikol. Fitopatol. 22(3): 209 (1988)].

[Not "Hygrophorus nitidus Fr." (1863) $\equiv$ Hygrophorus friesii Sacc. (1887)].

Phylogenetic support As only ITS sequences are available for G. vitellinus and G. nitidus, Gloioxanthomyces is included only in our ITS analysis. The clade representing Gloioxanthomyces has $97 \%$ MLBS support in our ITS analysis by Ercole (Online Resource 3). Both Ercole's and Zhang's (in Boertmann 2012) ITS phylogenies place Gloioxanthomyces as sister to Chromosera citrinopallida (54\% MLBS and significant BS, respectively). In ITS analyses by Dentinger et al. (unpublished data), G. vitellinus and G. nitidus appear in clade with $99 \%$ and $100 \%$ MLBS support (entire Hygrophoraceae, and tribe Chromosereae, respectively) that is sister to Chromosera (63\% MLBS).

Species included Type: Gloioxanthomyces vitellinus is European, while its sister species, G. nitidus is known from continental North America and Newfoundland (Boertmann 2012).

Comments Gloioxanthomyces falls between Gliophorus sect. Glutinosae and Chromosera based on morphology (Table 3) and ITS sequence divergences. Gloioxanthomyces sequences diverge more from Gliophorus sect. Glutinosae (30 \%) than from Chromosera (17\% divergent), which is concordant with placement of Gloioxanthomyces as sister to Chromosera in phylogenetic analyses by Ercole (Online Resource 3) and Zhang (in Boertmann 2012). Those results are concordant with the ITS analyses by Dentinger et al. (unpublished). Morphologically, G. vitellinus and G. nitidus share with Gliophorus sect. Glutinosae an indented pileus, gelatinized lamellar edge, subregular lamellar trama and presence of cheilocystidia, but they differ from sect. Glutinosae in having modest rather than toruloid clamps in the hymenium, absence of a gelatinized subhymenium, having cheilocystidia that are cylindric or clavate rather than undulating and forked, and mean ratio of basidia to basidiospore lengths of 4.3-5.5 rather than 5-7 (Fig. 14). Gloioxanthomyces vitellinus and G. nitidus share with Chromosera an indented pileus, yellow pigments, absence of toruloid clamp connections in the hymenium, and mean ratio of basidia to basidiospore lengths of $3.5-5.5$, but they differ in having a gelatinized lamellar edge, and presence of cheilocystidia. While further analyses with more gene regions are needed, we place G. nitidus and G. vitellinus in tribe Chromosereae based on a combination of molecular, phylogenetic and morphological data.

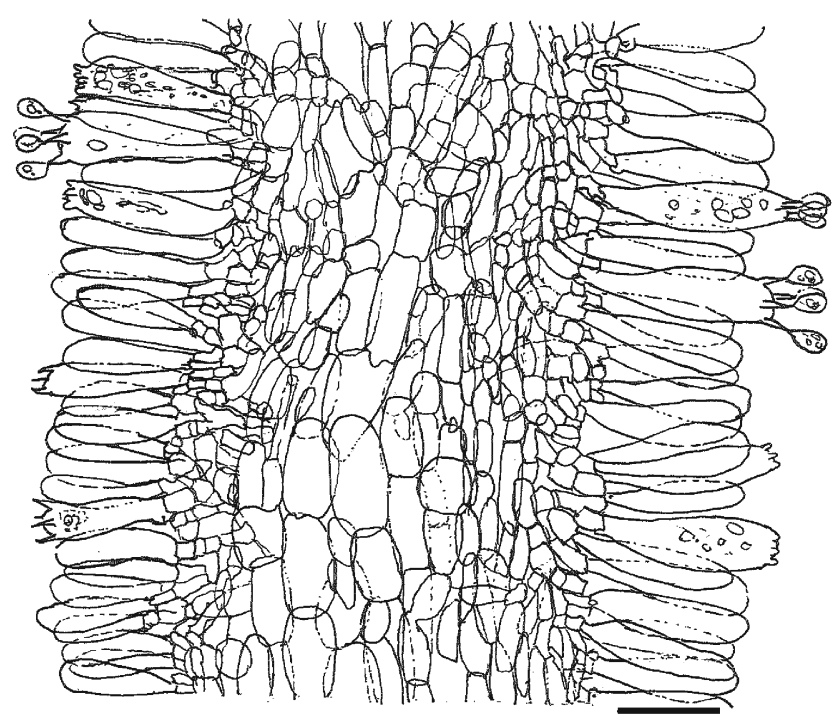

Fig. 14 Subf. Hygrocyboideae, tribe Chromosereae. Gloioxanthomyces nitidus (DJL06NC87, North Carolina, Great Smoky Mt. Nat. Park, USA). Scale bar $=20 \mu \mathrm{m}$ 
Subfam. Hygrophoroideae E. Larss., Lodge, Vizzini, Norvell \& Redhead, subf. nov.

Mycobank 804083.

Type genus Hygrophorus Fr., Fl. Scan.: 339 (1836) [1835].

Basidiomes gymnocarpous or secondarily mixangiocarpous; lamellae subdecurrent to deeply decurrent; trama inamyloid; lamellar trama 1) divergent, hyphae diverging from a central strand, or 2) bidirectional, horizontal hyphae that are parallel to the lamellar edge present, sometimes woven through vertically oriented, regular or subregular generative hyphae that are confined or not to a central strand; subhymenium lacking, cells giving rise to basidia originating from hyphae that diverge from the vertical generative hyphae, pachypodial hymenial palisade sometimes present, comprising buried hymenia, thickening over time via proliferation of candelabra-like branches that give rise to new basidia or subhymenial cells; basidiospores thin- or thick-walled, inamyloid, metachromatic or not, hyaline or lightly pigmented (ochraceous, salmon, green); pigments muscaflavin or carotenoids; habit ectomycorrhizal or xylophagous, rarely terricolous.

Phylogenetic support Our 4-gene backbone, Supermatrix and ITS-LSU analyses consistently place Chrysomphalina as sister to Hygrophorus with moderate support (62\%, $68 \%$ and $62 \%$ MLBS, respectively), with stronger MLBS support for placing the Hygrophoroideae as sister to the NeohygrocybeChromosera clade or the entire Humidicuteae clade (Neohygrocybe, Gliophorus, Humidicutis, Porpolomopsis, Chromosera) (79 \% for ITS-LSU; $77 \%$ for the 4-gene backbone). Matheny et al. (2006) shows the strongest support (1.0 B.P. for Chrysomphalina as sister to Hygrophorus ss using a 5-gene Supermatrix analysis. Similarly, using ITS alone, Vizzini and Ercole (2012) [2011] show moderate BPP support (0.91) for the clade comprising four Hygrophorus species with C. chrysophylla, C. grossula, and Haasiella splendidissima. An ITS-LSU analysis by Vizzini et al. (2012) shows the same topology, but with lower support. Although LSU sequence analyses by Moncalvo et al. (2002) do not show significant MP support for the ChrysomphalinaHygrophorus clade, this clade is found in all their most parsimonious weighted and unweighted MP trees and all bootstrap trees (Moncalvo et al. 2000, 2002).

Comments Molecular phylogenetic support for placing Chrysomphalina in a new subfamily with Hygrophorus is based on the consistency of this pairing in all current and previous analyses together with moderate to strong BPP values and moderate MLBS support. ITS-LSU sequence analyses by Vizzini and Ercole (2012 and Vizzini et al. (2012) show moderate to strong Bayesian support for placement of Haasiella in subf. Hygrophoroideae - a placement consistent with our ITS-LSU and ITS phylogenies (Fig. 15, Online Resource 3).
Phylogenetic support. subf. Hygrophoroideae is concordant with the suggestion by Redhead et al. (2002) and Clémençon et al. (2004, Fig. caption 9.38) that the pachypodial structure in Chrysomphalina may be homologous to the divergent trama in Hygrophorus (Figs. 17 and 19). In both, cells that produce basidia arise directly from hyphae that diverge from vertical generative hyphae, without a specialized subhymenium. Although Chrysomphalina, Haasiella, and Aeruginospora all have bidirectional trama and a pachypodial structure below the active hymenium (Figs. 17 and 18), authors have described these differently as they vary depending on the species, specimen age, and whether sections were taken close to the lamellar edge or pileus flesh (Clémençon et al. 2004; Redhead et al. 2002, Reijnders and Stalpers 1992). The pachypodial structure in this group was interpreted variously as a broad subhymenium (Kühner 1980: 847; Clémençon 1997: 656), a hymenial palisade (Reijnders and Stalpers 1992), or a trama (Clémençon 1982; Clémençon et al. 2004: 305). While Clémençon's term 'pachypodial' is a descriptive adjective, and the most widely used term in the literature, Reijnders and Stalpers (1992) 'hymenial palisade' accurately reflects the origin of this structure, which comprises old basidia and subhymenial cells that have given rise to basidia and thus buried through successive generation of new basidia and subhymenial cells. Here we use pachypodial structure as an adjective and refer to the tissue according to its origin as either a pachypodial hymenial palisade or buried hymenia. Knudsen and Vesterholt (Funga Nordica, 2007) accepted both Chrysomphalina and Haasiella in the Hygrophoraceae based on shared morphology and pigment chemistries (Vizzini and Ercole 2012). Support for placing Aeruginospora near Haasiella is based entirely on the shared characters of basidiome form, bidirectional lamellar trama, a thickening hymenium forming a pachypodial structure, and spores that are thick-walled, pigmented, and with a red metachromatic endosporium (not included in the molecular phylogenies, as we could not obtain molecular sequences from the 80-90 yearold collections stored in alcohol.) In Hygrophoroideae we recognize tribe Hygrophoreae P. Henn. and transfer tribe Chrysomphalineae Romagn. to the Hygrophoraceae.

Tribe Chrysomphalineae Romag., Doc. Mycol. 112: 135 (1996).

Type genus: Chrysomphalina Clémençon, Z. Mykol. 48(2): 202 (1982).

[ $\equiv$ Cantharellaceae tribe "Paracantharelleae" Romagn., Doc. Mycol. 25(98-100): 418, nom. invalid, Art. 18.1].

Tribe Chrysomphalineae emended here by Lodge, Padamsee, Norvell, Vizzini \& Redhead by transferring it from Cantharellaceae to Hygrophoraceae and to exclude Phyllotopsis.

Trama monomitic, inamyloid; bidirectional, with horizontal hyphae (parallel to the lamellar edge) woven through vertically oriented, regular or subregular hyphae that are 


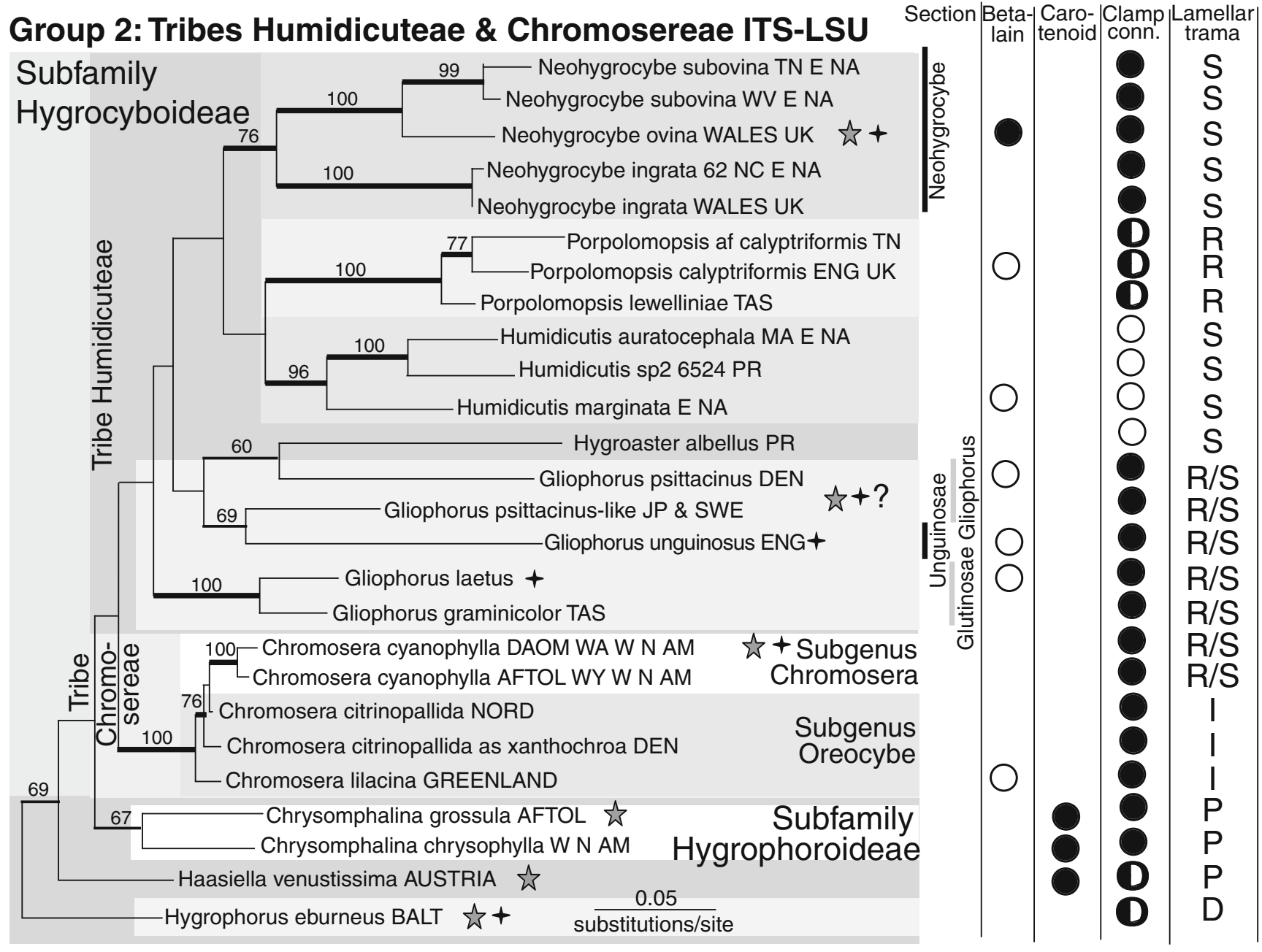

Fig. 15 Tribes Humidicuteae and Chromosereae (Group 2) ITS-LSU analysis rooted with Hygrophorus eburneus. Genes analyzed were ITS (ITS1, 5.8S \& ITS2), LSU (LROR-LR5). Presence of betalain (DOPA based) and carotenoid pigments and presence of clamp connections are denoted by filled circles, empty circles denote their absence and halffilled circles appear for species with clamp connections at the base of the

confined or not to a central strand; basidia arising from hyphae that diverge from the vertical generative hyphae, developing a pachypodial hymenial palisade consisting of chains of short segments with the same orientation as the basidia, thickening over time via proliferation of candelabra-like branches that give rise to new basidia or new subhymenial cells, thus burying older hymenial layers; spores thin- or thick-walled, often slightly pigmented, metachromatic or not, inamyloid; clamp connections usually absent (except in some Haasiella); yellow (and possibly green) pigments carotenoid, yellow colors may be absent because the carotenoid synthesis pathway is incomplete or may be obscured by encrusting pigments; growing on wood, woody debris, sclerophyllous dicotyledonous and bamboo litter, rarely on soil.

Phylogenetic support Two species of Chrysomphalina (C. chrysophylla and C. grossula) were included in all our basidia but absent from the context (Porpolomopsis spp.), and Haasiella venustissima that has a clampless form with 2 -spored basidia. Lamellar trama types are: $\mathrm{D}$ for divergent, I for interwoven, $\mathrm{P}$ for pachypodial, $\mathrm{R}$ for regular (parallel) and S for subregular. ML bootstrap values $\geq 50 \%$ appear above the branches. Heavily bolded branches have $\geq 70 \%$ and lightly bolded branches have 50-69 \% ML bootstrap support

analyses. Haasiella venustissima sequences were added late and thus included in only one of our two ITS-LSU analyses (Fig. 15) in which Haasiella falls between Hygrophorus and Chrysomphalina without significant branch support, and our ITS analysis (Online Resource 9) in which Haasiella is the basal member of a grade that includes Chrysomphalina and the terminal Hygrophorus clade. Although Chrysomphalineae is paraphyletic with the Hygrophorus clade in our analyses, an ITS analysis by Vizzini and Ercole (2012) [2011], shows support (0.91 B.P. for a Chrysomphalineae clade that is sister to Hygrophorus. As DNA was not successfully sequenced from Aeruginospora, it could not be included in molecular analyses and so is discussed after the other genera in this tribe.

Genera included Type genus: Chrysomphalina. Haasiella is included based on phylogenetic and morphological data, while Aeruginospora is included based on morphology. 
Comments Romagnesi (1995), who first published this group as tribe "Paracantharelleae" (invalid because it was not formed from the type genus name, Art. 18.1) replaced it (1996) as tribe Chrysomphalineae in the Cantharellaceae. Romagnesi (1995) discounted the absence of stichobasidia in tribe Chrysomphalineae since stichic basidial nuclear division varies in the Cantharellaceae (see Pine et al. 1999), and both Romagnesi (1995) and Redhead et al. (2002) emphasized the carotenoid pigments shared by these groups. Prior to sequencing and phylogenetic analyses of Haasiella, Redhead et al. (2002) postulated a close relationship between Haasiella and Chrysomphalina based on pigments and micromorphology, although Kost (1986) concluded that these two genera were not closely allied based on micromorphology. Clémençon 1982) placed Chrysomphalina grossula with Aeruginospora in Camarophyllus subg. Aeruginospora owing to shared lamallar trama structure (Figs. 17 and 18). Romagnesi (1995) included Haasiella and Phyllotopsis E.-J. Gilbert \& Donk ex Singer along with the type genus, Chrysomphalina, in this tribe. We emend Tribe Chrysomphalineae here to exclude Phyllotopsis, which lacks a hymenial palisade, and include Aeruginospora, which has pigmented spores and a pachypodial hymenial palisade and shares with Haasiella thick-walled spores with a metachromatic endosporium.

Chrysomphalina Clémençon, Z. Mykol. 48(2): 202 (1982).

Type species Chrysomphalina chrysophylla (Fr. : Fr.) Clémençon, Z. Mykol. 48(2): 203 (1982)

三Agaricus chrysophyllus Fr. : Fr., Syst. mycol. (Lundae) 1: 167 (1821).

Basidiomes gymnocarpous; lamellae decurrent; trama monomitic; lamellar trama bidirectional; subhymenium lacking, basidia arising directly from hyphae that diverge from vertically oriented generative hyphae; hymenium thickening and forming a pachypodial hymenial palisade over time via proliferation of candelabra-like branches that give rise to new basidia or subhymenial cells, thus burying older hymenia; spores thin-walled, lightly pigmented ochraceous salmon or green, not metachromatic, inamyloid; basidia five or more times longer than the basidiospores, variable in length; clamp connections absent; carotenoid pigments present, $\beta$-forms predominating over $\gamma$-forms; pileipellis not gelatinized; lignicolous habit. Differs from Aeruginospora and Haasiella in thin-walled and non-metachromatic basidiospores and from Haasiella in a non-gelatinized pileipellis, and from tetrasporic forms of Haasiella in the absence of clamp connections.

Phylogenetic support The Chrysomphalina clade has total support (100\% MLBS, 1.0 B.P. in our 4-gene backbone, Supermatrix and ITS analyses (Figs. 1 and 2, Online Resource 3), and moderate support in our LSU and ITS-
LSU analyses (70, $67 \%, 59 \%$ MLBS, Figs. 15 and 16). The LSU analysis by Moncalvo et al. (2002) also shows moderate support for Chrysomphalina (66\% MPBS). Lutzoni (1997) shows strong MPBS support in his analyses of LSU (98\%), ITS1 (99\%), and a combined ITS-LSU (99\%) data set with equally weighted parsimony analysis (Redhead et al. 2002, relabeled as the Lutzoni 1997 combined ITS-LSU tree). Similarly strong support for Chrysomphalina is shown by Vizzini et al. (2012) using a combined ITS-LSU data set (1.0 B.P. $94 \%$ MLBS), and Matheny et al. (2006) using a 5-gene Supermatrix analysis (1.0 B.P. $77 \%$ MLBS).

Species included Type species: Chrysomphalina chrysophylla. Additionally supported by molecular data is $C$. grossula (Pers.) Norvell, Redhead \& Ammirati var. grossula. We also include the morphologically supported $C$. aurantiaca (Peck) Redhead, C. chrysophylla var. hoffmanii (Peck) Norvell, Redhead \& Ammirati, C. chrysophylla var. salmonispora (H.E. Bigelow) Norvell, Redhead \& Ammirati, and C. grossula var. belleri (Bon) P.A. Moreau \& Courtec.

Comments The pachypodial hymenial construction (Fig. 17) is found in all species of Chrysomphalina, though the hymenial palisade is shallow in some species (Norvell et al. 1994). The yellowish and pinkish orange pigments in Chrysomphalina and Haasiella are carotenoids (Arpin 1966; Arpin and Fiasson 1971; Gill and Steglich 1987; Fig. 15), but they are predominantly $\beta$-forms in Chrysomphalina and mostly $\gamma$-forms in Haasiella (Fiasson and Bouchez 1968). Chrysomphalina grossula is initially intensely greenish yellow but these colors are later obscured or replaced by a brownish residue (Norvell et al. 1994). The spore color of $C$. grossula $(=$ Omphalina bibula,$=O$. wynneae $)$ also differs from the typical ochraceous salmon tint in spore deposits of other Chysomphalina spp., and is pale green or greenish cream (Josserand 1955; Norvell et al. 1994, Quélet 1882; 1888). The green pigment might be carotenoid as these are known in ascomycetes (Goodwin 1952).

Haas (1962) considered Agaricus chrysophyllus Fr. and A. venustissimus congeneric based on shared spore pigmentation, but his attempt to establish Chrysomphalina to accommodate them was invalid. Kotlaba and Pouzar (1966) subsequently established Haasiella, typified by A. splendidissima, and recombined $A$. venustissimus Fr. in Haasiella. Raithelhuber (1973) recombined A. chrysophyllus in Haasiella - a placement later rejected by Clémençon (1982), who instead validated Chrysomphalina Clémençon (typified by C. chrysophylla). Clémençon (1982) included $C$. strombodes (Berk. \& Mont.) Clémençon in Chrysomphalina. Norvell et al. (1994) later excluded $C$. strombodes from Chrysomphalina based on its lack of a 


\section{Group 3 ITS-LSU}

Subfamilies Hygrophoroideae \& Lichenomphalioideae Tribe/Subgenus/Section Genus

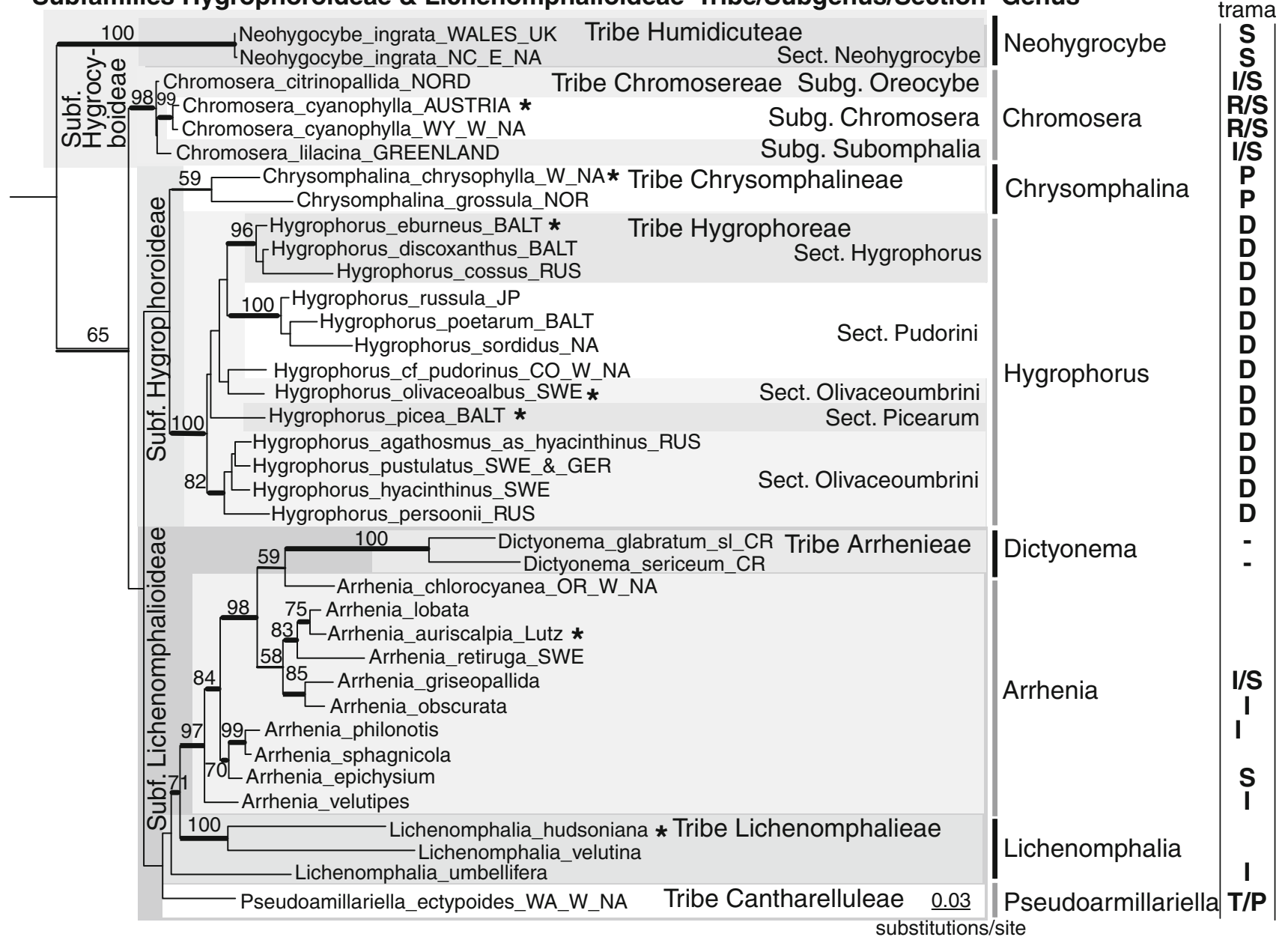

Fig. 16 Subfamilies Hygrophoroideae and Lichenomphalioideae (Group 3) ITS-LSU analysis rooted with Neohygrocybe ingrata. Genes analyzed were ITS (ITS1, 5.8S \& ITS2), LSU (LROR-LR5). Presence of betalain (L-DOPA based) and carotenoid pigments and presence of clamp connections are denoted by filled circles, empty circles denote their absence. Lamellar trama types are: D - divergent; I - interwoven; P pachypodial; R - regular/parallel; S - subregular; T - tri-directional. ML bootstrap values $\geq 50 \%$ appear above the branches. Heavily bolded branches have $\geq 70 \%$ and lightly bolded branches have $50-69 \% \mathrm{ML}$ bootstrap support pachypodial hymenial structure in favor of Singer (1962) [1961] and Redhead's (1986) placement in Gerronema. Redhead (1986) noted that sarcodimitic tissue in G. strombodes

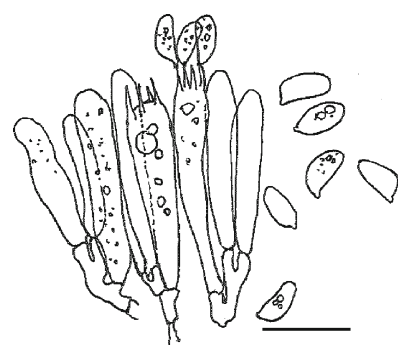

Fig. 17 Subf. Hygrophoroideae, tribe Chrysomphalineae, Chrysomphalina chrysophylla hymenial section (ID-3, T. Birbak, McCall, Idaho, 2008). Scale bar $=20 \mu \mathrm{m}$ differed from monomitic tissue of Chrysomphalina; Norvell et al. (1994) confirmed that the type of Gerronema also had sarcodimitic tissue. The molecular phylogeny by Moncalvo et al. (2002) placed G. strombodes in the hydropoid clade (Marasmiaceae) and Chrysomphalina in the Hygrophoraceae. Redhead (1986) transferred Omphalia aurantiaca to Chrysomphalina, based on the presence of a weak pachypodial hymenial palisade below the active hymenium. Norvell et al. (1994) transferred Agaricus grossulus Pers. from Omphalina to Chrysomphalina, recognizing $A$. umbelliferus var. abiegnus Berk. \& Broome [= Omphalina abiegna (Berk. \& Broome) Singer] and Hygrophorus wynneae Berk. \& Broome as synonyms.

Haasiella Kotl. \& Pouzar, Ceská Mykol. 20(3): 135 (1966). 
Type species Haasiella venustissima (Fr.) Kotl. \& Pouzar ex Chiaffi \& Surault (1996)

三Agaricus venustissimus Fr., Öfvers Kongl. Svensk Vet.Akad, Förh. 18: 21 (1861).

Basidiomes gymnocarpous; lamellae decurrent; trama monomitic; lamellar trama bidirectional; subhymenium lacking, basidia arising directly from hyphae that diverge from vertically oriented generative hyphae; hymenium thickening and forming a pachypodial hymenial palisade over time via proliferation of candelabra-like branches that give rise to new basidia or subhymenial cells, thus burying older hymenial layers; basidiospores pigmented pale yellowish salmon, thick-walled, endosporium (red) metachromatic; carotenoid pigments present, predominantly $\gamma$-forms; pileipellis gelatinized; clamp connections present if tetrasporic; mostly xylophagous habit. Differs from Chrysomphalina in presence of thick-walled spores with a metachromatic endosporium and a gelatinized pileipellis. Differs from Aeruginospora in yellowish salmon (not green) basidiospores, and abundant clamp connections if tetrasporic.

Phylogenetic support Haasiella, represented by a single $H$. venustissima collection, appears between Chrysomphalina and Hygrophorus in our ITS-LSU analysis, the topology of which agrees with classification based on micromorphology, pigment chemistry, and ecology. Our ITS (Online Resource 3) and one LSU analysis (not shown) place Haasiella as sister to Hygrophorus with low support (32\% and $55 \%$ MLBS). In the ITS-LSU analysis by Vizzini et al. (2012), one $H$. venustissima and four $H$. splendidissima collections are shown as conspecific, with the Haasiella clade (100\% MLBS, 1.0 BPP support) appearing as sister to Hygrophorus (65\% MLBS and 1.0 BPP support). Their analysis (Vizzini et al. 2012) places Chrysomphalina basal to Hygrophorus and Haasiella, but without backbone support.

Species included Haasiella is monotypic, as $H$. splendidissima Kotl. \& Pouzar is a tetrasporic, clamped, heterothallic form of the type species, $H$. venustissima (Vizzini et al. 2012).
Comments As noted by Vizzini et al. (2012) the type of Haasiella, Agaricus (Clitocybe) venustissimus Fr. (1861), has been classified in various genera beginning with Clitocybe (Karsten 1879), Omphalia (Quélet 1886), Hygrophoropsis (Haas 1958), Chrysomphalina (Haas 1962, nom. invalid), and Omphalina (Lange 1981; 1992; Ludwig 2001). Redhead (1986) distinguished Haasiella from Chrysomphalina based on the absence of a pachypodial trama, whereas Clémençon (1982), Clémençon et al. (2004) and Reijnders and Stalpers (1992) found a pachypodial hymenial palisade in both genera (Fig. 17). Though Kost (1986) and Norvell et al. (1994) reported Haasiella as terrestrial, most collections have been made on wood or woody debris (including the original described by Kotlaba and Pouzar 1966), as noted by Vizzini et al. (2012), which removes one purported contrast with Chrysomphalina. Haasiella differs from Chrysomphalina, however, in its thick-walled metachromatic spores and gelatinized pileipellis (Kost 1986; Norvell et al. 1994, Vizzini et al. 2012). Haasiella is morphologically most similar to Aeruginospora, and if found to be congeneric, Aeruginospora would have priority. Haasiella and Aeruginospora both have bidirectional trama, a thickening pachypodial hymenial palisade, and thick-walled spores with a metachromatic endosporium a combination of characters not found elsewhere in the Hygrophoraceae (Figs. 18 and 29; Online Resource 10). Haasiella differs from Aeruginospora in having abundant clamp connections in tetrasporic forms, yellowish salmon rather than green tinted spores, and Aeruginospora was reported on soil under bamboo whereas Haasiella is mostly lignicolous. As with Haasiella, basing a habit on few collections may mislead. It is unknown if Aeruginospora has carotenoid pigments - a character found in both Haasiella and Chrysomphalina.

Aeruginospora Höhn., Sber. Akad. Wiss. Wien, Math.naturw. Kl., Abt. 1 117: 1012 (1908),

Type species: Aeruginospora singularis Höhn., Sber. Akad. Wiss. Wien, Math.-naturw. Kl., Abt. 1 117: 1012 (1908).

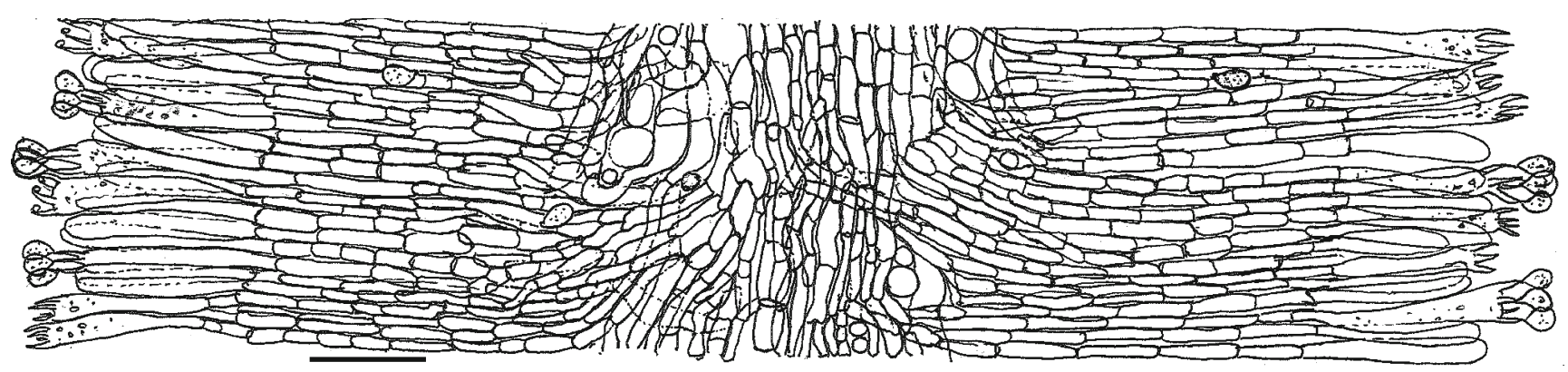

Fig. 18 Subf. Hygrophoroideae, tribe Chrysomphalineae, Aeruginospora singularis lamellar cross section (v. Overeem 601 A, BO-93, Bogor Botanical Garden, Indonesia, 1921). Scale bar $=20 \mu \mathrm{m}$ 
Aeruginospora emended here by Lodge \& E. Horak as hymenial pachypodial palisade present.

Basidiomes robust, cuphophylloid or cantharelloid; pileus cream colored with gray-brown or ochraceous tint in center, sometimes red-brown on margin or overall, weakly radially wrinkled or smooth. Lamellae decurrent, with 2-3 lengths of lamellulae inserted, occasionally forked, fleshy, waxy, hygrophanous, fragile, colored pale bluish-green from the basidiospores. Stipe cylindrical, flared at apex, sometimes bent; surface smooth, dry. Trama monomitic, hyphae thinwalled, some walls up to $0.8 \mu \mathrm{m}$ thick, narrow, 2-7(-10) $\mu \mathrm{m}$ wide; lamellar trama bidirectional, often with a subregular central strand 15-30 $\mu \mathrm{m}$ wide, especially toward the pileus, some hyphae parallel to the lamellar edge woven through these in the lateral strands, but not abundant; subhymenium lacking, basidia arising directly from hyphae that diverge from vertically oriented generative hyphae; hymenium thickening to $30-60 \mu \mathrm{m}$ and forming a pachypodial hymenial palisade over time via proliferation of candelabra-like branches that give rise to new basidia or subhymenial cells, thus burying older hymenial layers; basidia tetrasporic, 30-40(-45) $\times 4.8-$ $7.2 \mu \mathrm{m}$, sterigmata $6-8 \times 1-2 \mu \mathrm{m}$, basal clamp connection absent, chiastic nuclear division; basidiospores pale bluegreen in deposit, near sky blue microscopically when fresh, loosing color during storage, thin- and thick-walled (to $0.5 \mu \mathrm{m}$ ), smooth, short-ellipsoid, subglobose or rarely ovoid, 4.8-6×4-4.8(-5.2) $\mu \mathrm{m}$, inamyloid, not cyanophilic, red metachromatic endosporium in cresyl blue. Clamp connections almost completely absent, one observed in pileipellis. Pileipellis structure uncertain or variable, of repent or erect slender hyphae, possibly gelatinized. On ground in dense stand of bamboo.

Species included Aeruginospora is monotypic, consisting of the type, A. singularis Höhn. Various authors have added species to Aeruginospora, but the following excluded species were correctly placed in Camarophyllopsis: A. foetens (W. Phillips) M.M. Moser, A hiemalis Singer \& Clémençon, $A$. hymenocephala (A.H. Sm. \& Hesler) Singer, A. microspora (A.H. Sm. \& Hesler) Singer, A. paupertina (A.H. Sm. \& Hesler) Singer, and A. schulzeri (Bres.) M.M. Moser. Aeruginospora furfuracea Horak merits further study but may also belong in Camarophyllopsis.

Comments In addition to Horak's (1968) study of the 1908 type collection, Singer (1951, 1973, unpublished drawings) also annotated the type (Harvard University 00284744). While visiting Leiden, Singer copied Boedjin's annotation of a collection by Brink in 1931 as well as Boedjin's copy of Overeem's annotations of his 1921 collection, both from the type locality at the Bogor Botanical Garden in Indonesia, and he copied Maas Geesteranus' drawings of nuclear division in basidia of $A$. singularis in the type; there is no part of
Overeem's (BO 601A, 601B) or Brink's (BO 12204) collections at Leiden. Although Horak photographed Overeem's paintings of his 1931 (601 A and B) A. singularis collections (Online Resource 10) while at the herb. Bogoriensis, he was unable to examine them microscopically as the collection was being moved. Lodge examined parts of Overeem and Brink's collections that had been stored in alcohol, augmented the diagnosis from the type studies above with observations on the pileipellis structure, spore wall thickness, spore reactions (acyanophilic, red metachromatic endosporium in cresyl blue) and illustrated a lamellar cross section and hymenial palisade (Fig. 18).

Horak drew a narrow, regular mediostratum bounded by subregular strata of narrow, wavy hyphae in the lateral zones (Harvard University 00284744), and reported in the type study (Horak 1968) a $100 \mu \mathrm{m}$ wide hymenium with horizontally oriented short hyphae and basidia, with basidia long, 5$6 \mu \mathrm{m}$ broad and lacking clamp connections. Singer (1951, 1973) did not mention a distinct mediostratum in the type but did note that the central hyphae became more axillary (vertical) toward the pileus context. Singer (unpublished) drew a subregular stratum (but said there was no distinct mediostratum) bounded by vertical hyphae interwoven with horizontal hyphae in the lateral strata near the pileus (but described it as irregular); a bi-directional trama near the lamellar edge (vertical hyphae and cross sections of horizontal hyphae running parallel to the lamellar edge); and a pachypodial palisade below the basidia, basidia $29-45 \times 5-$ $6.3 \mu \mathrm{m}$, lacking clamps. Lodge found in v. Overeem 601 and Brink 12204 a subregular mediostratum 26-30 $\mu \mathrm{m}$ wide bounded by lateral strata $85-100 \mu \mathrm{m}$ wide comprised of vertical hyphae with some diverging toward the hymenium and giving rise to the pachypodial palisade, and a few cross sections of horizontal hyphae parallel to the lamellar edge. The pachypodial hymenial palisade is $30-60 \mu \mathrm{m}$ wide, which together with the 30-45 $\mu \mathrm{m}$ long basidia comprise a hymenium up to $100 \mu \mathrm{m}$ thick, comparable to the depth reported in Horak's (1968) type study. Studies of all collections reported spore dimensions in the same range (4.2-) 5-6.2(-8)×(4-)3.85(-5.6). The original diagnosis and Horak's (1968) and Singer's $(1951,1973)$ type studies did not mention thickwalled spores, though these are visible in Overeem's painting of part A (Online Resource 10). Lodge found that spores with slightly thickened $(0.2-0.4 \mu \mathrm{m})$, lightly pigmented walls were dominant in the most mature collection (Overeem 601A), rare in the less mature Overeem 601B, and absent in the least developed collection (Brink, hymenial palisade 20-30 $\mu \mathrm{m}$ deep). Lodge also found a metachromatic spores on basidia and a few metachromatic in Overeem 601A that were embedded in the pachypodial hymenial palisade $30-40 \mu \mathrm{m}$ below the active basidia. All descriptions of the type, Singer's (unpublished) notes, and annotations of Overeem's and Brink's collections agree that the context and pileipellis hyphae 
are narrow, 2-6(-10) $\mu \mathrm{m}$ wide, and lack clamp connections, though Lodge found one pileipellis clamp in Overeem $601 \mathrm{~A}$.

It is uncertain whether the pileipellis of Aeruginospora is gelatinized (as in Haasiella) or dry (as in Chrysomphalina) as reported for the type by Höhnel in Höhnel and Litschauer (1908) and Horak (1968). Neither descriptions of the type nor descriptions or paintings of subsequent collections by Overeem (601a\& b, 1921, BO-93) or Brink (1931, BO 12204 , det. and desc. by Boedjin) suggest a gelatinized pileipellis. Among the collections stored in alcohol at Herb. Bogoriensis, however, Lodge found a distinctly gelatinized ixotrichodermium in the v.d. Brink (youngest) collection, and part A of Overeem's collection had a little adhering debris and a slight gelatinous coating on the pileipellis hyphae. The erect hyphae in the Brink collection may match those found by Horak (1968) in his type study. It is possible that since the basidiomes of this enigmatic species are long-lived that the gelatinized surface is eroded with time. It is unknown whether Aeruginospora contains carotenoid pigments or a partial pigment pathway as was found in most other members of Tribe Chrysomphalineae. Some carotenoid pigments are green as in the discomycete, Caloscypha fulgens (Pezizales, Ascomycota).

Singer transferred A. singularis first to Armillariella, (1951, p. 216) and then Camarophyllus sect. Aeruginospora (1973) with emphasis on elongated basidia, small spores, and absence of clamp connections led to descriptions and new combinations of eight additional species in Aeruginospora. Several authors later transferred the added Aeruginospora species to Camarophyllopsis, including four spp. placed in Aeruginospora by Singer (1962), three Moser spp. (1967) and one species described by Singer and Clémençon (1971). Camarophyllopsis has since been excluded from the Hygrophoraceae based on molecular phylogeny (Matheny et al. 2006).

Tribe Hygrophoreae P. Henn., in Engler \& Prantl, Nat. Pflanzenfam. 1: 209 (1898),

Type genus: Hygrophorus Fr., Fl. Scan.: 339 (1836) [1835].

Tribe Hygrophoreae emended by Kühner in Bull. mens. Soc. linn. Lyon 48: 617 (1979).

Basidiomes medium to large, gymnocarpous or secondarily mixangiocarpous and then glutinous from a universal veil; white to pallid or colored grey, olive, brown, yellowish orange, or red; pileus broad, convex, obtuse or with a low umbo, sometimes with a depressed disc, margin often inrolled when young but flattening in age; lamellae thick, usually distant, broadly adnate, subdecurrent to deeply decurrent, waxy; stipe smooth or with a glutinous-fibrous annulus, sometimes floccose-fibrillose at the apex, usually tapering towards the base; trama inamyloid, lamellar trama divergent, generative hyphae diverging from a central strand giving rise directly to basidia; subhymenium lacking; basidiospores thin-walled, inamyloid, not metachromatic or cyanophilous, hyaline, white in mass; known pigments muscoflavin; antimicrobial compounds include hygrophorones and chrysotrione; host and odors are often diagnostic for species; habit ectomycorrhizal; most species fruit late in the season.

Phylogenetic support Support for a monophyletic tribe and gen. Hygrophorus is high in most of our analyses including the 4-gene backbone (100\% MLBS and 1.0 BPP), Supermatrix (96\% MLBS) and ITS-LSU (100\% MLBS). Similarly, Larsson (2010) shows $81 \%$ MPBS support for the tribe and gen. Hygrophorus in a four-gene phylogenetic analysis. Although Hygrophorus is monophyletic in our LSU and ITS analyses, support is not significant. However, the LSU analysis by Moncalvo et al. (2002) shows 97 \% MPBS support for a monophyletic Hygrophorus represented by two species, $H$. sordidus and $H$. bakerensis.

\section{Genera included Hygrophorus.}

Comments While tribe Hygrophoreae is often attributed to Kühner (1979) (e.g., in Arnolds 1990), it was previously published by P. Hennings in Engler and Prantl (1889) (see Young and Mills 2002).

Hygrophorus Fr., Fl. Scan.: 339 (1836) [1835].

Type species: Hygrophorus eburneus (Bull. : Fr.) Fr., Epicr. syst. mycol. (Upsaliae): 321 (1836) [1836-1838]

$\equiv$ Agaricus eburneus Bull., Herb. Fr. 3: tab. 118 (1780) : Fr.

Characters are the same as in tribe Hygrophoreae.

Phylogenetic support Support is same as for tribe Hygrophoreae.

Subgenera included We recognize three subgenera: Hygrophorus emend., Colorati (Bataille) E. Larss., subg. nov. and Camarophyllus Fr., emend.

Comments Species of Hygrophorus ss have a characteristic divergent lamellar trama (Fig. 19) which sets them apart from all other Hygrophoraceae (Young 1997; Hesler and Smith 1963, as Hygrophorus subg. Hygrophorus). The genus Hygrophorus was formally described by Fries in 1836. Later, in Epicrisis Sytematis Mycologici, Fries (1838) organized species into unranked, infrageneric 'tribes'. Most of the species now classified as Hygrophorus s.s. (including the type species, H. eburneus) were from part of Fries' Hygrophorus tribe Limacium and the remainder are from part of Fries' Clitocybe tribe Camarophyllus. Fries designated these tribes as Hygrophorus subgenera in 1849 , they were treated as subgenera by Karsten (1876), but treated as genera by Kummer (1871) and Karsten (1879). An overview of the major classifications from Fries (1821) to Bon (1990) is given 


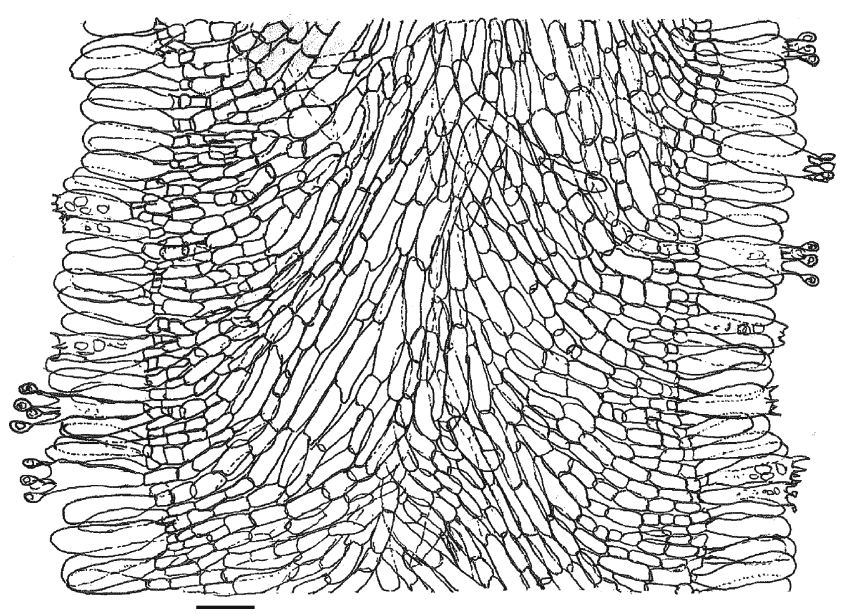

Fig. 19 Subf. Hygrophoroideae, tribe Hygrophoreae, Hygrophorus hypothejus var. aureus lamellar cross section (DR-2146, DJL02DR43, Dominican Republic). Scale bar $=20 \mu \mathrm{m}$

by Candusso (1997). As the micro-morphological characters are similar in most Hygrophorus species the current classifications are still based on basidiocarp color, color changes, and the presence or absence of a universal glutinous veil and specific odors (Hesler and Smith 1963, Singer 1986, Arnolds 1990, Candusso 1997; Kovalenko 2012).

In Epicrisis Fries (1838) recognized twenty species in the tribe Limacium. Fries (1874) introduced five groupings below tribes based on pileus color; Albi l. albolutescentes for the white to yellow species; Rubentes for the red to reddish species, Fulventes l. flavi for the brown to tan or bright yellow species; Olivaceoumbrini for the olivaceous species; Fuscocinerei l. lividi for the gray to blackish species. Bataille (1910) similarly did not designate ranks below subgenus in Hygrophorus, and he used part of Fries' classification. Many of Fries' and Battaille's names have subsequently been combined by other authors at designated ranks. Important modifications by Bataille (1910) were use of type species and addition of morphological characters besides pileus color. Bataille also inserted unranked names between subgen. Hygrophorus and species groups, Albi (from Fries), later renamed sect. Hygrophorus by Singer as it contains the type species (Art. 22.1), and Colorati. We emend the subgenera by removing Bataille's Colorati from subg. Hygrophorus and making it a new subgenus; we have retained subg. Camarophyllus (Fr.) Fr. and emend it by removing species of Cuphophyllus and other unrelated taxa.

As both morphological characters and ecology in Fries' time were broadly described, later mycologists applied the names based on their own experiences. Thus regional traditions in naming species have developed and it is obvious that the same name is used for different species but also that different names are applied to the same fungus. For example, Fries selected H. eburneus as type species for Hygrophorus the only white Hygrophorus species name sanctioned by Fries in Systema Mycologicum (Fries 1821). Fries described $H$. eburneus as a common species growing in deciduous forest. Most mycologists later interpreted H. eburneus as a species growing with Fagus, which is likely correct as Fagus forests were common in Femsjö and Lund near where Fries lived. In 1835 Fries moved to Uppsala where Fagus is absent and instead forests are dominated by Betula, Picea, and Pinus. This likely contributed to the change in species interpretation in later descriptions. In Sweden, the species growing with Picea that was long regarded as H. eburneus (Lundell and Nannfeldt 1939) is now known as H. piceae Kühner.

The number of Hygrophorus species recognized worldwide has grown to about 100 (Kirk et al. 2008) with contributions from Velenovsky (1920), Kühner (1949), Hesler and Smith (1963), Moser (1967), Arnolds (1979), Gröger (1980) and Orton (1984), and new species and varieties are continually discovered and described (eg. Jacobsson and Larsson 2007; Pérez-de-Gregorio et al. 2009). With the exception of the monograph by Hesler and Smith (1963), in which North American species are treated together with some of the European names, most monographs are regional. There is no recent monograph and classification that considers all described species.

In this study sequences of 19 species in Hygrophorus were generated including the types of the four sections of Hygrophorus accepted by Singer (1986); Hygrophorus $-H$. eburneus; Pudorini-H. pudorinus; Discoidei-H. discoideus; Colorati - H. olivaceoalbus. Our Supermatrix and ITS phylogenies show eight to nine clades, but their composition does not correspond well with the morphology based classifications of Hesler and Smith (1963), Singer (1986) or Arnolds (1990). A more detailed, five-gene analysis by Larsson (2010 and unpublished data) shows a 13-clade tree. The best concordance with our ITS and the five-gene phylogeny by E. Larsson (unpublished and 2010) is found with some infrageneric taxa delineated by Bataille (1910) and Candusso (1997), so we used or emended these to minimize changes.

Hygrophorus subgen. Hygrophorus [autonym] (1849).

Type species: Hygrophorus eburneus (Bull. : Fr.) Fr, Epicr. syst. mycol. (Upsaliae): 321 (1836) [1836-1838]

$\equiv$ Agaricus eburneus Bull., Herb. Fr. 3: tab. 118 (1780) : Fr.

Hygrophorus subgen. Hygrophorus emended here by E. Larss. to remove Bataille's Colorati.

Pileus usually glutinous or subviscid when moist, white or pallid, sometimes tinted yellow, salmon-buff, fulvous, gray, bistre or reddish brown in center, sometimes darkening with age and upon drying; lamellae adnate to decurrent, subdistant to distant, white or pallid, sometimes darkening with age and upon drying; stipe usually glutinous or viscid, apex dry, floccosefibrillose; sometimes with an aromatic odor. 
Phylogenetic support The four-gene analysis presented by Larsson (2010; unpublished data) shows a monophyletic clade comprising sects. Discoidei and Hygrophorus, except sect. Piceae appears as an adjacent clade; support for this topology is lacking. Our LSU analysis shows a monophyletic subg. Hygrophorus, but it also lacks significant BS support, and H. piceae appears on a separate branch. Subg. Hygrophorus is polyphyletic in our Supermatrix and ITS analyses.

Sections included Hygrophorus sects. Discoidei, Hygrophorus, and Picearum, E. Larss. sect. nov.

Comments We emend subg. Hygrophorus by removing Bataille's Colorati. The composition of this group is not concordant with any group in Bataille (1910), partly concordant with subsect. Hyrophorus in Singer (1986), mostly concordant with subsect. Hygrophorus in Kovalenko (1989, 1999, 2012), Arnolds (1990) and Candusso (1997), and entirely concordant with Bon's (1990) subsect. "Eburnei" Bataille [invalid].

\section{Hygrophorus [subgen. Hygrophorus] sect. Hygrophorus [autonym]. \\ Type species: Hygrophorus eburneus (Bull. : Fr.) Fr., Epicr. syst. mycol. (Upsaliae): 321 (1838). \\ Pileus glutinous to viscid, white or pallid, sometimes tinted yellow, salmon-buff, fulvous, reddish brown in center, some- times darkening with age and upon drying; lamellae white or pallid, sometimes darkening with age and upon drying; stipe usually glutinous or viscid, apex dry, floccose-fibrillose; when fresh sometimes with a distinct aromatic odor. Ectomycorrhizal, predominantly associated with deciduous trees.}

Phylogenetic support Strong support for a monophyletic sect. Hygrophorus is shown in our ITS-LSU (Fig. 16; $96 \%$ ) and in our ITS analysis (Online Resource 3; 97 \% MLBS). Sect. Hygrophorus appears as a grade in our Supermatrix analysis (Fig. 2). In our LSU analysis, sect. Discoidei appears in sect. Hygrophorus, rendering the latter polyphyletic, but there is no support for the supporting branches. In the four-gene analysis presented by Larsson (2010; unpublished data), sect. Hygrophorus appears as a monophyletic group with $54 \%$ MPBS support.

Subsections included Hygrophorus subsects. Fulventes subsect. nov. and Hygrophorus.

Comments Sect. Hygrophorus is delimited more narrowly here than traditionally. Most authors have included subsect. Chrysodontes (Singer 1986; Kovalenko 1989, 1999, 2012; Arnolds 1990; Candusso 1997) or Series Chrysodontini (Hesler and Smith 1963) and subsect. Pallidi ([invalid] Smith and Hesler 1939) = Pallidini [invalid] Singer Singer
1986; Arnolds 1990; Candusso 1997) which are now placed in subg. Camarophyllus and subg. Colorati, respectively.

\section{Hygrophorus [subgen. Hygrophorus sect. Hygrophorus]} subsect. Hygrophorus [autonym].

Type species Hygrophorus eburneus (Bull. : Fr.), Epicr. syst. mycol. (Upsaliae): 321 (1838).

Pileus glutinous, white or pallid, sometimes darkening with age and upon drying; lamellae white, often with salmon orange tinge, sometimes darkening with age and upon drying; stipe glutinous, concolorous with pileus, often with a salmon orange tinge at base, apex dry floccose-fibrillose; when fresh with a distinct aromatic odor (Cossus odor).

Phylogenetic support Our ITS analyses show subsect. Hygrophorus as a monophyletic group with either high or low support (Online Resources 3 and 8, $97 \%$ and $49 \%$ MLBS, respectively). Our LSU analysis shows a mostly monophyletic subsect. Hygrophorus except that $H$. discoideus of subsect. Discoidei is included; BS support is lacking. Our Supermatrix analysis shows subsect. Hygrophorus as a polyphyletic grade with $H$. leucophaeus of subsect. Fulventes embedded in it; backbone support is lacking. In the four-gene analysis presented by Larsson (2010; unpublished data), subsect. Hygrophorus is primarily a monophyletic clade with $58 \%$ MPBS, but $H$. hedrychii appears in an adjacent unsupported branch.

Species included Type species: Hygrophorus eburneus. Hygrophorus cossus (Sow.) Fr., H. discoxanthus (Fr.) Rea and $H$. hedrychii (Velen.) K. Kult are included based on morphological and phylogenetic support.

Comments This subsection contains H. eburneus, which is the type species of the gen. Hygrophorus, so the name must exactly repeat the genus name (Art. 22.1). Bataille (1910) included a mixture of species from subsect. Hygrophorus and sect. Olivaceoumbrini in his [unranked] Eburnei. Bon's sect. Hygrophorus subsect. Eburnei Bataille [invalid] however, is concordant with the four-gene molecular phylogeny presented by Larsson (2010; unpublished data). The composition of subsect. Hygrophorus in Arnolds (1990) and Candusso (1997) is also concordant with the molecular phylogeny presented by Larsson (2010) if H. gliocyclus (sect. Aurei) is excluded. Singer (1989) included H. flavodiscus and $H$. gliocyclus (both in sect. Aurei) in subsect. Hygrophorus, rendering it polyphyletic. Subsect. Hygrophorus in Kovalenko $(1989,1999,2012)$ is also polyphyletic. The controversy of name interpretation in subsect. Hygrophorus was disentangled by Larsson and Jacobsson (2004).

Hygrophorus subsect. Fulventes E. Larss., subsect. nov. MycoBank MB804961. 
Type species Hygrophorus arbustivus Fr., Anteckn. Sver. Ätl. Svamp.: 46 (1836).

= Hygrophorus, 'Tribus' Limacium [unranked] Fulventes 1 . flavi. Fr., Hymen. Eur.: 408 (1874)

Neotype here designated: Hygrophorus arbustivus Fr., Anteckn. Sver. Ätl. Svamp.: 46 (1836). SWEDEN, Öland Island, Lilla Vikleby Nature Reserve, Coll. Björn Norden BN001118, 18 Nov. 2000, deposited GB, ITS sequence UDB000585.

[= Hygrophorus subsect. "Fulvoincarnati" A.H. Sm. \& Hesler, Lloydia 2: 36 (1939), invalid, Art. 36.1].

Pileus glutinous to viscid, pallid, tinted yellow, salmonbuff, fulvous, reddish brown in center; lamellae subdecurrent, subdistant, white or pallid; stipe glutinous or viscid, pallid, apex dry floccose-fibrillose.

Phylogenetic support We included only $H$. arbustivus in our ITS analysis. In the four-gene analysis presented by Larsson (2010; unpublished data), subsect. Fulventes (H. arbustivus, H. carpini, H. leucophaeo-ilicis, H. lindtneri, $H$. roseodiscoideus, and $H$. unicolor) appears as a paraphyletic grade basal to subsect. Hygrophorus (54\% MPBS support for basal branch).

Species included Type species $H$. arbustivus. Hygrophorus carpini Gröger, H. leucophaeo-ilicis Bon \& Chevassut, $H$. lindtneri M.M. Moser, H. roseodiscoideus Bon \& Chevassut and $H$. unicolor Gröger are included based on morphological and phylogenetic data.

Comments Singer (1986) and Kovalenko (1989, 1999, 2012) placed the type of subsect. Fulventes together with species from sect. Pudorini in subsect. Fulvoincarnati A.H. Sm. \& Hesler (1939)[invalid] making it polyphyletic. Bon (1990) and Candusso (1997) placed a similar mixture of species in sect. Fulventes (Fr.) Bon. [invalid] Series Fulventes (Hesler and Smith 1963, invalid because basionym was three words) and is consequently also polyphyletic.

Hygrophorus [subgen. Hygrophorus] sect. Discoidei (Bataille) Konrad \& Maubl., Icon. Sel. Fung. 6: 428 (1937).

Type species: Hygrophorus discoideus (Pers. : Fr.) Fr., Epicr. syst. mycol. (Upsaliae): 323 (1838) [1836-1838]

$\equiv$ Agaricus discoideus Pers., Syn. meth. fung. (Göttingen) 2: 365 (1801) : Fr.

Basionym: Hygrophorus [unranked] Discoidei Bataille, Mém. Soc. émul. Doubs, sér. 8 4: 162 (1910).

Pileus viscid when moist, pale yellowish brown, fulvous, sometimes with a gray tone, or disc reddish brown; lamellae, concolorous, sometimes with a violaceous gray tone; stipe viscid, pale or fulvous, sometimes with a gray tinge, apex floccose-fibrillose.
Phylogenetic support Sect. Discoidei is only represented by the type species in our Supermatrix and LSU analyses, and $H$. subviscifer in our ITS analysis. In the analysis presented by Larsson (2010; unpublished data), sect. Discoidei is a monophyletic clade with $100 \%$ MPBS.

Species included Type species: H. discoideus. Hygrophorus subviscifer (P. Karst.) Harmaja is included based on morphology and phylogeny.

Comments Bataille (1910) included H. arbustivus (the type of subsect. Fulventes) and H. mesotephrus (sect. Olivaceoumbrini) along with the type in Discoidei. Series Discoidei (Hesler and Smith 1963) and sect. Discoidei (in Singer 1986; Kovalenko 1989, 1999, 2012; Arnolds 1990) are also polyphyletic. Bon (1990) only included $H$. roseodiscoideus (from the adjacent sect. Fulventes) in subsect. Discoideini Bataille [invalid]. Similarly, Candusso (1997) included $H$. roseodiscoideus and $H$. lindtnerii from the adjacent sect. Fulventes, (listing H. carpini, H. leucophaeus and $H$. unicolor as synonyms of the latter).

Hygrophorus [subgen. Hygrophorus] sect. Picearum E. Larss., sect. nov.

MycoBank MB804087.

Type species: Hygrophorus piceae Kühner, Bull. mens. Soc. linn. Lyon 18: 179 (1949).

Etymology: picea - Latin name for the host plant genus, Picea (spruce).

Pileus white, viscid when moist; lamellae decurrent, distant, white, sometimes with a weak yellowish or incarnate tint; stipe white, subviscid when moist, apex dry floccosefibrillose; no specific odor; ectomycorrhizal with Picea.

Phylogenetic support Sect. Piceae is a moderately supported (78\% MPBS) monophyletic group in the analysis presented by Larsson (2010; unpublished data).

Species included Type species $H$. piceae. This is currently monotypic, but the analysis presented by Larsson (2010; unpublished data) suggests this is a complex of several taxa.

Comments Hygrophorus piceae was placed by most authors in Sect. Hygrophorus together with other white and pale species, by Hesler and Smith (1963) in subsect. Camarophylli and series Clitocyboides, by Candusso (1997) in subsect. Pallidini [invalid], and by Kovalenko (2012) in subsect. Hygrophorus. It was not treated by Singer (1986) or Arnolds (1990).

Hygrophorus, subgen. Colorati (Bataille) E. Larss., stat. nov.

MycoBank MB804109. 
Type section: Olivaceoumbrini (Bataille) Konrad \& Maubl., Icon. Sel. Fung. 6: 137 (1937).

Type species Hygrophorus olivaceoalbus (Fr. : Fr.) Fr., Epicr. syst. mycol. (Upsaliae): 324 (1838) [1836-1838] designated by Singer, Lilloa 22: 148 (1951) [1949],

三Agaricus olivaceoalbus Fr., Observ. Mycol. (Havniae) 1: 5 (1815),

Basionym: Hygrophorus subgen. Limacium [unranked] Colorati Bataille, Mém. Soc. Émul. Doubs, sér. 8 4: 158 (1910) [1909].

Hygrophorus, subgen. Colorati emended here by Larsson to exclude sect. Discoidei.

Basidiomes glutinous from a universal veil or dry to subviscid, with or without a partial veil sometimes forming an annulus; pileus usually colored, at least in the center or white to lightly pigmented.

Phylogenetic support Our LSU analysis shows subg. Colorati as a paraphyletic grade with $72 \%$ MLBS support for the branch separating it from sect. Chrysodontes (subg. Camarophylli). Our Supermatrix analysis also shows subg. Colorati as a grade, but with sect. Chrysodontes within it; there is no significant support for these branches. Our ITSLSU analysis also shows a polyphyletic subg. Colorati. Our ITS analysis (Online Resource 9) shows subg. Colorati as a paraphyletic grade, but sect. Aurei is polyphyletic. In the analysis presented by Larsson (2010, unpublished), subg. Colorati is a monophyletic group lacking significant support, but the inner clade comprising subsects. Olivaceoumbrini, Pudorini and Tephroleuci has $71 \%$ MPBS.

Sections included Sects Aurei (Bataille) E. Larss., stat. nov., Olivaceoumbrini, and Pudorini.

Comments Bataille (1910) created five unranked groups within Colorati, of which one name was from Fries (1874) (i.e., Olivaceo-umbrini), and the new names were Aurei, Discoidei, Pudorini and Tephroleuci. Singer (1949) assumed section rank for Bataille's Colorati, and designated a type species, but sect. Colorati (Bataille) Singer is illegitimate because Konrad and Maublanc (1937) had previously erected sect. Olivaceoumbrini with the same type species (H. olivaceoalbus). Singer restricted sect. Colorati to subsects Olivaceoumbrini and Tephroleuci, and Kovalenko (1989, 1999, 2012) subsequently used Singer's (1951) narrower delimitation of sect. Colorati (Kew Bull. 54: 699). While the branch joining subsects. Olivaceoumbrini and Tephroleuci has $64 \%$ MPBS support in a four-gene analysis (Larsson 2010), this clade is embedded in a larger clade that is largely concordant with Bataille's (1910) Colorati; we therefore retained Bataille's broader classification for subg. Colorati, but emend it by removing sect. Discoidei as it is recovered on a separate branch (Online Resource 9 and Larsson 2010, unpublished data).
Hygrophorus [subgen. Colorati] sect. Olivaceoumbrini (Bataille) Konrad \& Maubl., Icon. Sel. Fung. 6: 137 (1937).

Type species: Hygrophorus olivaceoalbus (Fr. :Fr.) Fr., Epicr. syst. mycol. (Upsaliae): 324 (1838)

三Agaricus olivaceoalbus Fr., Observ. Mycol. (Havniae) 1: 5 (1815).

[ $\equiv$ sect. Olivaceoumbrini (Bataille) Bon 1990, superfluous, nom. illeg.,

$\equiv$ sect. Colorati (Bataille) Singer (1951)[1949], superfluous, illeg., Art. 52.1].

Basionym: Hygrophorus [unranked] Olivaceo-umbrini Bataille, Mém. Soc. émul. Doubs, sér. 8 4: 163 (1910).

Pileus glutinous when moist, gray, olive, olive bister or fuliginous, sometimes fading or yellowing with age, usually darker in center; lamellae adnate to subdecurrent; stipe glutinous, with or without remnants of a partial veil sometimes forming an annulus.

Phylogenetic support The analysis presented by Larsson (2010, unpublished data) shows sect. Olivaceoumbrini as monophyletic with $65 \%$ MPBS support comprising two strongly supported clades that are concordant with subsects Olivaceoumbrini and Tephroleuci. Our Supermatrix, LSU, ITS-LSU, and ITS analyses, however, show sect. Olivaceoumbrini as polyphyletic; all but the ITS-LSU analysis lack backbone support. Our ITS analysis (Online Resource 9) shows sect. Olivaceoumbrini as polyphyletic. Another ITS analysis (not shown) has low support for placing part of subsect. Olivaceoumbrini (i.e., $H$. persoonii $=H$. limacinus and $H$. latitabundus) as a sister clade to subsect. Tephroleuci (46\% MLBS).

Subsections included Olivaceoumbrini and Tephroleuci.

Comments Both Singer (1949) and Arnolds (1990) considered Bataille's (1910) Olivaceoumbrini and Tephroleuci as closely related, and placed them in the same section, (Singer in sect. Colorati Bataille, and Arnolds in sect. Olivaceoumbrini Bataille). However, Bataille's names were unranked, and Konrad and Maublanc (1937) were the first to combine Bataille's Olivaceoumbrini at section rank, making sect. Colorati (Bataille) Singer superfluous and thus illeg. Kovalenko (1989, 1999, 2012) and Arnolds (1990) followed Singer's classification, whereas Candusso recognized Olivaceoumbrini and Tephroleuci as separate sections. Bon (1990) recognized sect. Olivaceoumbrini Bataille but placed species belonging to the Tephroleuci clade in sect. Ligati Bataille [invalid]. Hesler and Smith (1963) recognized this group as a series in sect. Hygrophorus, but included species from other clades, rendering it polyphyletic.

Hygrophorus [subgen. Colorati sect. Olivaceoumbrini] subsect. Olivaceoumbrini (Bataille) Singer, Lilloa 22: 146, (1951) [1949]. 
Type species: Hygrophorus olivaceoalbus (Fr. : Fr.) Fr., Epicr. syst. mycol. (Upsaliae): 324 (1838)

EAgaricus olivaceoalbus Fr. (1815), Observ. Mycol. (Havniae) 1: 5 (1815) : Fr.

Basionym: Hygrophorus [unranked] Olivaceo-umbrini Bataille, Mém. Soc. émul. Doubs, sér. 8 4: 163 (1910).

Pileus glutinous, bistre, grayish brown, fuliginous or olivaceous at least in center, sometimes fading or yellowing with age; lamellae subdecurrent, distant, white; stipe glutinous, white with grayish olive-brown fibrils from veil remnants, sometimes with a partial veil forming an annulus, apex white, dry, floccose.

Phylogenetic support Our ITS analysis (Online Resource 9) includes five taxa in subsect. Olivaceoumbrini (two clades of H. olivaceoalbus corresponding to western North America and Europe $=H$. korhonenii respectively, $H$. persoonii, $H$. latitabundus $=H$. limacinus and $H$. mesotephrus). In our Supermatrix, LSU and ITS analyses $H$. olivaceoalbus appears in a separate clade, but without backbone support. In the fourgene analysis presented by Larsson (2010, unpublished data), subsect. Olivaceoumbrini (represented by $H$. bakerensis, $H$. korhonenii, H. latitabundus, H. mesotephrus, $H$. olivaceoalbus, and $H$. persoonii) appears as a paraphyletic grade with $65 \%$ MPBS support for the basal branch and $78 \%$ MPBS support for the branch separating it from the monophyletic subsect. Tephroleuci.

Species included Type species: Hygrophorus olivaceoalbus. Species included based on morphology and phylogeny are $H$. bakerensis A.H. Sm. \& Hesler, H. korhonenii Harmaja, H. latitabundus Britzelm., H. mesotephrus Berk., and $H$. persoonii Arnolds (=H. limacinus Fr.). Morphology indicates that Hygrophorus occidentalis A.H. Sm. \& Hesler also belongs here (Hesler and Smith 1963; Kovalenko 1989, 1999).

Comments Subsect. Olivaceoumbrini is polyphyletic in our Supermatrix, LSU and ITS analyses, and a grade in the analysis presented by Larsson (2010). The composition of subsect. Olivaceoumbrini is mostly concordant with the morphologically based groups of Hesler and Smith (1963), Singer (1986), Kovalenko (1989, 1999) Arnolds (1990), Bon (1990) and Candusso (1997).

Hygrophorus [subgen. Colorati sect. Olivaceoumbrini] subsect. Tephroleuci (Bataille) Singer, Lilloa 22: 146 (1951) [1949].

Type species: Hygrophorus tephroleucus (Pers. : Fr.) Fr., Epicr. syst. mycol. (Upsaliae): 325 (1838)

$\equiv$ Agaricus tephroleucus Pers. (1801) : Fr.

= Hygrophorus pustulatus (Pers.) Fr. (1838),

= Agaricus pustulatus Pers. (1801) : Fr.,
[Bataille's name is automatically typified by the type species epithet upon which the taxon name was based, thus type is NOT Hygrophorus agathosmus (Fr. : Fr.) Fr., as in Singer (1951, 1986) and Candusso (1997), Art. 22.6].

Basionym: Hygrophorus [unranked] Tephroleuci Bataille, Mém. Soc. émul. Doubs, sér. 8 4: 164 (1910).

Pileus viscid, white or gray, cinereous, bistre or grayishbrown; lamellae distant, subdecurrent, white; stipe usually dry or subviscid, white, basally with grayish tinges, sometimes with dark grayish brown fibrils or granules from veil remnants; often with a distinct odor.

Phylogenetic support Subsect. Tephroleuci is a monophyletic group with low MLBS support in our Supermatrix analysis (55\%), a clade lacking significant support in our ITS analysis (Online Resource 9) but is polyphyletic in our ITS-LSU analysis (Fig. 6). In a four-gene analysis presented by Larsson (2010, unpublished data), the subsect. Tephroleuci clade, comprising $H$. agathosmus, $H$. pustulatus and $H$. hyacinthinus, has $100 \%$ MP BS support.

Species included Type species: Hygrophorus pustulatus $=H$. tephroleucus. Hygrophorus agathosmus (Fr.) Fr., H. agathosmus f. albus Candusso, H. hyacinthinus Quél. and H. odoratus A.H. Sm. \& Hesler are included based on molecular phylogenies and morphology.

Comments Singer (1951) assumed Bataille's (1910) unranked name Tephroleuci was a designated subsection. Thus Singer (1951) inadvertently published the combination Hygrophorus subsect. Tephroleuci (Bataille) Singer. Bataille's groups were named for type species, so the type of Tephroleuci Bataille is Hygrophorus tephroleucus (Art. 22.6), not H. agathosmus as stated by Singer (1951, 1986) and Candusso (1997). Fries (1821) and Bataille recognized both $H$. tephrolucus and $H$. pustulatus (Pers.) Fr., though Konrad (1936) and Konrad and Maublanc (1937) apparently considered them conspecific and selected $H$. pustulatus over the competing name $H$. tephroleucus; $H$. pustulatus is the name in current use. The clade corresponding to subsect. Tephroleuci is concordant with Bataille's (1910) with exclusion of $H$. fuscoalbus Lasch., H. lividoalbus Fr., H. lucandi Gill., and H. marzuolus Fr. The composition of Tephroleuci in Singer (1986), Candusso (1997) and Kovalenko (1989, 1999) is only partly concordant with our phylogenies because they included species from subg. Camarophyllus (i.e., H. camarophyllus, $H$. calophyllus, and $H$. atramentosus). Bon (1990) included $H$. agathosmus and $H$. odoratus, which are all in the Tephroleuci clade, but he placed the type species, H. pustulatus $(=H$. tephroleucus), in sect. Hygrophorus subsect. Fuscocinerei (Fr.) Bon [illeg.], while including H. mesotephrus. from subsect. Olivaceoumbrini. 
Hygrophorus [subgen. Colorati] sect. Pudorini (Bataille) Konrad \& Maubl., Sel. Fung. 6: 427 (1937).

Type species Hygrophorus pudorinus (Fr.), Fr. Anteckn. Sver. Ätl. Svamp.: 46 (1836)

三Agaricus pudorinus Fr., Syst. mycol. (Lundae) 1: 33 (1821),

= Hygrophorus persicolor Ricek, Z. Pilzk. 40(1-2): 6 (1974).

Basionym: Hygrophorus [unranked] Colorati [unranked] Pudorini Bataille, Mém. Soc. émul. Doubs, sér. 8 4: 158 (1910).

Basidiomes usually dry, lacking a glutinous universal veil, sometimes with a cortinoid partial veil, usually white to pallid, with pinkish buff, pinkish tan, russet, pinkish orange or vinaceous tints or spots, or colored apricot, rose, red, purple or vinaceous purple, rarely completely white or cream colored; lamellae crowded to subdistant, adnate to subdecurrent; stipe dry, often with pruina, glandular dots or a cortinoid fugacious annulus.

Phylogenetic support Sect. Pudorini is an unsupported monophyletic group in our expanded Hygrophorus ITS (Online Resource 9) and Supermatrix analyses (21\% and $23 \%$ MLBS, respectively). Sect. Pudorini is polyphyletic in our LSU analysis, but there is no significant backbone support. In the four-gene analysis presented by Larsson (2010; unpublished data), sect. Pudorini appears as a grade that is paraphyletic with regard to sect. Olivaceoumbrini (basal branch placing subsect. Salmonicolores as sister to subsects. Pudorini and Olivaceoumbrini with $71 \%$ MPBS).

Subsections included Clitocyboides (Hesler \& A.H. Sm.) E. Larss., stat. nov., Pudorini, and Salmonicolores E. Larss., subsect. nov.

Comments Bataille (1910) named an unranked group Pudorini and divided it into two parts, 1) Exannulati (lacking an annulus) with $H$. miniaceus Beck, $H$. queletii Bres., $H$. pudorinus Fr. var. rubescens Beck, H. russula var. rubescens Fr., and H. capreolarius, and 2) Subannulati (subannulate) with H. purpurascens (Alb. \& Schwein.) Fr. and H. persicinus Beck. With one exception, the composition of Bataille's [unranked] Pudorini is consistent with sect. Pudorini in our analyses, though the subgroups Exannulati and Subannulati are not concordant with the main branches corresponding to subsections. Konrad and Maublanc (1937) combined Bataille's Pudorini at section rank in Hygrophorus. Singer (1986) recognized sect. Pudorini (Bataille) Konrad \& Maubl., with subsects "Erubescentes" Hesler \& A.H. Sm. and "Fulvoincarnati" Hesler \& A.H. Sm. Neither subsect. "Erubescentes" nor "Fulvoincarnati" (Smith and Hesler 1939) are valid, however, because they lacked Latin diagnoses that were required beginning in 1935 (Art. 36.1). Singer's circumscription of subsect. "Erubescentes" (invalid) corresponds to a strongly supported (95\% MP BS) clade in the four-gene analysis presented by Larsson (2010; unpublished data) that combines subsects. Pudorini and Clitocyboides. Subsect. "Fulvoincarnati" [invalid] is largely concordant with the new subsect., Salmonicolores. Arnolds (1990) placed species belonging to the Pudorini clade in sect. Hygrophorus, with species of subsect. Pudorini in subsect. "Erubescentes" [invalid], and species of subsect. Clitocyboides in subsect. Pudorini owing to the misapplication of the name $H$. pudorinus. The type species of $H$. pudorinus Fr. matches $H$. persicolor Ricek, but the name has been misapplied to $H$. abieticola. The North American taxon called H. 'pudorinus' appears in a sister clade to $H$. persicolor in our ITS analysis (Online Resource 9), so it is close to the original concept of $H$. pudorinus. Both Arnolds (1990) and Candusso (1997) incorrectly assumed Bataille's (1910) unranked name Pudorini was published at subsection rank, but only Candusso (1997, p 112) provided sufficient information (a full and direct reference to Bataille) to inadvertently combine it in Hygrophorus as subsect. Pudorini (Bataille) Candusso. Candusso (1997) divided sect. Pudorini into subsects Aurei, "Erubescentes", and Pudorini, with subsect. "Erubescentes" [invalid] largely corresponding to subsects. Pudorini plus Clitocyboides. Bon (1990) attempted to resurrect a descriptive heading from Fries [unranked] Rubentes as a named section, but the name is invalid as Bon did not fully cite the basionym; further, the group is polyphyletic and thus not useful.

Hygrophorus [subgen. Colorati sect. Pudorini] subsect. Clitocyboides (Hesler \& A.H. Sm.) E. Larss., stat. nov.

MycoBank MB804112.

Type species: Hygrophorus sordidus Peck, Torrey Bot. Club Bull. 25: 321 (1898)

[= subsect. "Pallidi" A.H. Sm. \& Hesler, Llyodia 2:32 (1939) invalid, Art. 36.1].

Basionym: Hygrophorus [sect. Hygrophorus subsect. Hygrophorus] series Clitocyboides Hesler \& A.H. Sm., North American Species of Hygrophorus: 309 (1963).

Basidiomes robust, dry to subviscid, lightly pigmented; pileus white to pallid cream, or colored incarnate to orange ochre or vinaceous purple; lamellae adnate to decurrent, mostly crowded, white sometimes turning incarnate or spotted vinaceous purple with age; stipe dry, white to pallid incarnate or with vinaceous purple spots.

Phylogenetic support Subsect. Clitocyboides, represented by $H$. poetarum, $H$. russula and $H$. sordidus, is strongly supported as monophyletic by our ITS-LSU analysis (100\% ML BS). Subsect. Clitocyboides, represented by $H$. poetarum, $H$. russula, and $H$. aff. russula is strongly supported in our 
Supermatrix analysis and our ITS analysis by Ercole (Online Resource 3) (84\% and $100 \%$ MLBS, respectively). Similarly, support for a monophyletic subsect. Clitocyboides $(H$. nemoreus, $H$. penarius, $H$. penarioides, $H$. poetarum, $H$. russula, and $H$. sordidus) is high in a four-gene analysis presented by Larsson (2010, unpublished data) (95\% MPBS). Our expanded ITS analysis of Hygrophorus (Online Resource 9) shows moderate support for a monophyletic subsect. Clitocyboides comprising H. nemoreus, H. penarius, $H$. penarioides, $H$. poëtarum, $H$. russula, $H$. aff. russula, and $H$. sordidus (55\% MLBS support), and $H$. purpurascens appears basal to the subsect. Clitocyboides clade (41\% MLBS) instead of being in the subsect. Pudorini clade.

Species included Type species: H. sordidus. Hygrophorus nemoreus (Pers.) Fr., H. penarius Fr., H. penarioides Jacobsson \& E. Larss., H. poetarum R. Heim, H. russula (Schaeff.) Kauffman, and $H$. aff. russula are all included based on morphological and phylogenetic data.

Comments Smith and Hesler (1939) attempted to erect subsect. "Pallidi" with $H$. sordidus Peck, H. subsordidus Murr. and H. subalpinus A.H. Sm. in sect. Clitocyboides Hesler \& A.H. Sm., but it was invalid (Art. 36.1). Singer first (1951) placed subsect. "Pallidini" [invalid] (Clitocyboides) in sect. Candidi, then changed the section name to Hygrophorus (1986). Singer (1986) tentatively included $H$. penarius (plus $H$. karstenii), but placed more highly pigmented H. nemoreus and $H$. russula together with $H$. erubescens and $H$. purpurascens in sect. Pudorini subsect. "Erubescentes" A.H. Sm. \& Hesler [invalid]. Kovalenko $(1989,1999)$ distributed the species of subsect. "Pallidini" [invalid, = Clitocyboides, valid] among sect. Hygrophorus subsects. Hygrophorus, Pudorini and "Fulvoincarnati "A.H. Sm. \& Hesler [invalid]. Arnolds (1990) only included H. penarius with the type species of subsect. "Pallidini "[invalid] (= Clitocyboides $)$ and distributed the other species among subsects. "Erubescentes" [invalid] and Pudorini. Bon (1990) placed H. penarius in "sect. Clitocyboides Hesl. \& Sm." "[nonexistent - combination was never made at this rank], but assembled the other species into sect. "Rubentes" Fr. [invalid], subsect. Exannulati Bataille [possibly valid as subsect. Exannulati (Bataille) Bon], stirps Russula and Erubescens. Papetti (1997) provided a Latin diagnosis to validate Konrad and Maublanc's [unranked] Nemorei as sect. Nemorei Konrad \& Maubl. ex Papetti with H. nemoreus as the type species and included $H$. leporinus, but other related species were placed elsewhere. Finally, Candusso (1997) placed species of the Clitocyboides clade in subsects. "Pallidini" [invalid] and "Erubescentes" [invalid], together with a mixture of species from other clades. Thus none of the previous classifications adequately reflect the composition of the well-supported subsect. Clitocyboides clade, and most of the infrageneric names they assigned were invalid.

Hygrophorus [subgen. Colorati sect. Pudorini] subsect. Pudorini (Bataille) Candusso, Hygrophorus. Fungi europ. (Alassio) 6: 212 (1997).

[= subsect. "Erubescentes" A.H. Sm. \& Hesler, Llyodia 2: 4 (1939), invalid, Art. 36.1].

Type species: Hygrophorus pudorinus (Fr. : Fr.) Fr., Anteckn. Sver. Ätl. Svamp.: 46 (1836), (1836),

$\equiv$ Agaricus pudorinus Fr., Syst. mycol. (Lundae) 1: 33 (1821),

= Hygrophorus persicolor Ricek, Z. Pilzk. 40(1-2): 6 (1974).

Basionym: Hygrophorus [unranked] Colorati [unranked] Pudorini Bataille, Mém. Soc. émul. Doubs, sér. 8 4: 158 (1910).

Pileus viscid, white or white with vinaceous or pink tinges, often spotted vinaceous purple by age; lamellae adnate to subdecurrent, subdistant, white as young, then often turning vinaceous purple; stipe subviscid or dry, white as young and then often with vinaceous or pink tinges, sometimes becoming yellowish or spotted vinaceous purple by age, apex floccosefibrillose, or with a partial veil giving rise to a fibrillose fugacious annulus.

Phylogenetic support We show an unsupported monophyletic subsect. Pudorini (H. pudorinus as H. persicolor and H. erubescens) in our ITS analysis, but $H$. purpurascens appears at the base of the adjacent clade (Online Resource 9). In the analysis presented by Larsson (2010; unpublished data), subsect. Pudorini (H. erubescens, H. pudorinus and H. purpurascens) appears as a paraphyletic group with $95 \%$ support for the basal branch while subsect. Clitocyboides appears as a monophyletic clade.

Species included Type species: Hygrophorus pudorinus ( $=H$. persicolor Ricek). Hygrophorus erubescens ( $\mathrm{Fr}$.) Fr. and $H$. purpurascens (Alb. \& Schwein. : Fr.) Fr. are included based on morphological and phylogenetic data.

Comments The name $H$. pudorinus has been misapplied to a Hygrophorus species associated with Abies, now named $H$. abieticola. Examination of the type painting and comparisons with the protologue of $H$. pudorinus revealed that $H$. persicolor is a synonym. Candusso (1997) assumed Bataille's name, Pudorini, was published at subsection rank and inadvertently combined it at that rank in Hygrophorus.

Hygrophorus [subgen. Colorati sect. Pudorini] subsect. Salmonicolores E. Larss., subsect. nov.

MycoBank MB804113. 
Type species Hygrophorus abieticola Krieglst. ex Gröger et Bresinsky, Regensb. Mykol. Schr.: 15: 211 (2008).

Etymology: salmon - salmon, colores - colored, for the salmon colored basidiomes.

Pileus subviscid, pale incarnate, salmon or ochraceous orange, universal and partial veil absent; lamellae distant, adnate to decurrent, white or with a pale salmon tinge; stipe dry or subviscid, white, yellowish or pale salmon orange, apex floccose-fibrillose; odor none or like turpentine.

Phylogenetic support The subsect. Salmonicolores clade $(H$. abieticola and $H$. queletii) is moderately supported (68\% MPBS) as a monophyletic clade in the analysis presented by Larsson (2010, unpublished data). These species were not included in our analyses.

Species included Type species: Hygrophorus abieticola. Hygrophorus queletii Bres. is included based on morphological and phylogenetic data. The ITS sequence from the western North America taxon diverges from European H. abieticola and likely needs a new name at species or variety rank.

Comments The name H. pudorinus has been misapplied to a Hygrophorus species associated with Abies. Krieglsteiner was the first to recognize the species associated with Abies as $H$. abieticola. The name was later validated by Gröger and Bresinsky (Bresinsky 2008) and it is the type of the new section, Salmonicolores. In Singer (1986), subsect. "Fulvoincarnati "Hesler \& A.H. Sm. (1939, invalid, Art. 36.1) included H. abieticola (as H. pudorinus, but apparently a mixed species concept) and $H$. queletii, corresponding to subsect. Salmonicolores, except that the subsection also included the type species of sect. Fulventes (H. arbustivus Fr.). In addition to subsect. "Fulvoincarniti "being invalid, it would also be illegitimate if it had been validly published. The type species indicated for subsect. "Fulvoincarnati" was $H$. pudorinus, and not the taxon to which the name H. pudorinus was applied (i.e., H. abieticola), subsect. "Fulvoincarnati "thus would have been a superfluous (therefore, illegitimate) name for subsect. Pudorini rather than being a legitimate name for the new subsect. Salmonicolores if it had been validly published. Kovalenko $(1989,1999)$ followed Singer's classification, but included in subsect. "Fulvoincarnati" [invalid, illeg.] H. secretanii - a species that belongs in sect. Aurei.

Hygrophorus [subgen. Colorati] sect. Aurei (Bataille) E. Larss., stat. nov.

MycoBank MB804114.

Type species Hygrophorus aureus Arrh., in Fr., Monogr. Hymenomyc. Suec. (Upsaliae) 2: 127 (1863)

$\equiv$ Hygrophorus hypothejus (Fr. : Fr.) Fr. var. aureus (Arrh.) Imler, Bull. trimest. Soc. mycol. Fr. 50: 304 (1935) [1934]
= Hygrophorus hypothejus (Fr. : Fr.) Fr., Epicr. syst. mycol. (Upsaliae): 324 (1838),

三Agaricus hypothejus Fr., Observ. Mycol. (Havniae) 2: 10 (1818).

Basionym Hygrophorus [unranked] Aurei Bataille, Mém. Soc. émul. Doubs, sér. 8 4: 161 (1910) [1909].

Pileus glutinous or subviscid when moist, color cream buff, yellow, olive, brown, gold or orange; stipe glutinous with a partial veil sometimes forming an annulus or dry. Ectomycorrhizal, predominantly associated with conifers.

Phylogenetic support Sect. Aurei appears as a monophyletic group in the analysis presented by Larsson (2010; unpublished data), including $H$. hypothejus ( $=H$. aureus), $H$. hypothejus var. aureus, $H$. gliocyclus, $H$. flavodiscus and $H$. speciosus in subsect. Aurei and H. karstenii and H. secretanii in subsect. Discolores, but MPBS support for the branch is lacking. Sect. Aurei is polyphyletic in our ITS analysis (Online Resource 9).

Subsections included Subsect. Aurei and subsect. Discolores, E. Larss., subsect. nov.

Comments We added H. karstenii and H. secretanii to this distinctive group and raised the rank to section.

Hygrophorus [subgen. Colorati sect. Aurei] subsect. Aurei (Bataille) Candusso, Hygrophorus. Fungi europ. (Alassio) 6: 222 (1997).

Type species Hygrophorus aureus Arrh., in Fr., Monogr. Hymenomyc. Suec. (Upsaliae) 2: 127 (1863)

$\equiv$ Hygrophorus hypothejus (Fr. : Fr.) Fr. var. aureus (Arrh.) Imler, Bull. trimest. Soc. mycol. Fr. 50: 304 (1935) [1934],

= Hygrophorus hypothejus (Fr. : Fr.) Fr., Epicr. syst. mycol. (Upsaliae): 324 (1838),

三Agaricus hypothejus Fr., Observ. Mycol. (Havniae) 2: 10 (1818).

Basionym Hygrophorus [unranked] Aurei Bataille, Mém. Soc. émul. Doubs, sér. 8 4: 161 (1910) [1909].

Pileus glutinous, colored citrine, gold, yellow, orange, olive or brown; lamellae subdecurrent, pale, yellowish to orange; stipe glutinous with a partial veil sometimes forming an annulus, pale or stained yellowish, orange or brown.

Phylogenetic support Our LSU analysis shows high support (89\% MLBS) for the subsect. Aurei clade comprising $H$. hypothejus (as $H$. speciosus and H. lucorum) and $H$. flavodiscus. Support is high for a subsect Aurei clade comprising $H$. flavodiscus and H. hypothejus (as H. lucorum) in our Supermatrix analysis (100\% MLBS) and is also high (76\% MLBS) in our ITS analysis for the clade comprising $H$. gliocyclus and H. hypothejus. Larsson's (2010; unpublished 
data) presentation shows $100 \%$ MPBS support for subsect. Aurei including $H$. hypothejus, $H$. hypothejus var. aureus, $H$. gliocyclus, H. flavodiscus and H. speciosus.

Species included Type species: Hygrophorus hypothejus. Taxa included based on both molecular and morphological data are H. hypothejus var. aureus ( $\equiv$ H. aureus), H. gliocyclus Fr., H. flavodiscus Frost, $H$. lucorum Kalchbr. and $H$. speciosus Peck. H. whiteii Hesler \& A.H. Sm. is included based on morphology .

Comments The well supported clade representing subsect. Aurei is concordant with the morphology-based subsect. Aurei delineated by Bon (1990) and Candusso (1997), partly concordant with series Aurei in Hesler and Smith (1963), but not concordant with the classifications by Singer (1986), Kovalenko $(1989,1999,2012)$ or Arnolds (1990).

Hygrophorus, subsect. Discolores E. Larss., subsect. nov. MycoBank MB804115.

Type species Hygrophorus karstenii Sacc. \& Cub., Syll. Fung. (Abellini) 5: 401 (1887),

= Hygrophorus bicolor P. Karst. (1878), nom. illeg. homonym of $H$. bicolor Berk. \& Broome (1871).

Etymology: dis - different, colores - color, for the contrasting color of the lamellae and pileus.

Pileus surface subviscid when moist, soon dry, dull, yellowish beige, sometimes with a red tint; lamellae decurrent, cream or egg yolk-yellow, more or less darkening upon drying; stipe dry, dull, pale yellowish beige or with age more ochre brown; odor none or like marzipan.

Phylogenetic support Hygrophorus secretanii and $H$. monticola A.H. Sm. \& Hesler are included in our ITS analysis (Online Resource 9), while H. karstenii and H. secretanii are included in the 4-gene analysis presented by Larsson (2010, unpublished data). Although there is $100 \%$ MLBS support for the subsect. Discolores clade in our ITS analysis, H. monticola is a synonym of $H$. secretanii. In the multigene phylogeny of Larsson (not shown), subsect. Discolores appears as a paraphyletic grade that is basal to subsect. Aurei. There is no significant support for the branches in this grade, except for the species (100\% MPBS).

Species included Type species: Hygrophorus karstenii. The inclusion of $H$. secretanii Henn. $=H$. monticola is supported by both morphological and molecular data.

Comments Hygrophorus karstenii and H. secretanii (syn. H. monticola Hesler \& A. H. Sm.) are both northern boreal species associated with Picea and Pinus. The species were not treated by Arnolds (1990), but partly treated by Hesler and Smith (1963) and Singer (1986). The name H. melizeus Fr. is used for H. karstenii in both Candusso (1997) and Kovalenko (2012). The rather convoluted naming of these species will not be further discussed here.

Hygrophorus subgen. Camarophylli (as Camarophyllus) Fr., Summa veg. Scand., Section Post. (Stockholm) 2: 307 (1849).

Type species Agaricus camarophyllus Alb. \& Schwein., Consp. Fung. Lusat.: 177 (1805) : Fr., [Art. 22.6]

$\equiv$ Hygrophorus camarophyllus (Alb. \& Schwein. : Fr.) Dumée, Grandjean \& L. Maire, Bull. Soc. mycol. Fr. 28: 292 (1912),

[= Hygrophorus caprinus (Scop.) Fr. (1838), superfluous to a sanctioned name, nom. illeg., Art. 13.1].

Hygrophorus subgen. Camarophylli emended here by $\mathbf{E}$. Larss. to exclude $A$. pratensis and related species now placed in Cuphophyllus.

Pileus surface usually dry, gray, grayish blue, buff brown, reddish brown, bistre or fuliginous, or if glutinous then white with yellow floccose-fibrillose veil remnants on the margin; lamellae subdecurrent to decurrent; stipe surface dry, smooth or fibrillose, usually pale gray, grayish blue, buff brown, bistre or fuliginous, if white glutinous with yellow floccules from veil remnants especially near the apex; lamellar trama divergent giving rise directly to basidia, thus differing from the genus Cuphophyllus.

Phylogenetic support Our LSU analysis shows moderately high support (72\% MLBS) for H. chrysodon (subg. Camarophylli) as basal to the rest of the genus Hygrophorus. One ITS analysis (Online Resource 3) shows the same topology while another (Online Resource 9) shows $H$. chrysodon near the base, both without significant BS support. A four-gene analysis with more species presented by E. Larsson (2010 and unpublished data) also shows subg. Camarophylli as a basal group in Hygrophorus, where it appears as a paraphyletic grade (55\% MPBS for the branch separating it from subg. Colorati). Hygrophorus chrysodon and $H$. camarophyllus appear together in a basal clade in one of our ITS ML analyses (not shown), but H. subviscifer also appears in the clade, and BS support is lacking. Our Supermatrix analysis places $H$. chrysodon among sections of subg. Colorati, but without backbone support.

Sections included Type section Camarophylli P. Karst., sect. Chrysodontes (Singer) E. Larss., stat. nov. and a new section to accommodate H. inocybiformis, sect. Rimosi E. Larss., sect. nov., are included based on morphology and molecular phylogenies.

Comments Agaricus camarophyllus was included by Fries 1821 in his 'subtrib. Camarophylli' (invalid, Art. 33.9). In 1838, Fries presented this taxon in his'trib. Camarophyllus' (invalid, Art. 33.9) as Agaricus caprinus Scop., with A. 
camarophyllus in synonymy. The first valid publication of subgen. Camarophyllus by Fries was in 1849. Fries' Hygrophorus subg. Camarophylli comprised the type species (H. camarophyllus), H. nemoreus (now placed in Hygrophorus subg. Colorati) and two species of Cuphophyllus (C. pratensis and $C$. virgineus), so we only retain Fries' type species. Fries (1874), Bataille (1910), Singer (1943, 1949), Hesler and Smith (1963), Arnolds (1990), Kovalenko (1989, 1999) and Candusso (1997) all treated sect. Chrysodontes (as subsect. Chrysodontini) within sect. Hygrophorus. Bon (1990) however, placed H. chrysodon in subg. Hygrophorus sect. Ligati (invalid). The yellow color and the glutinous pileus and stipe of sect. Chrysodontes differs from the dull colors and dry basidiomata in sect. Camarophyllus, but the placement is supported by Larsson's (2010) and our LSU analysis. Most authors did not classify $H$. inocybiformis (sect. Rimosi), but Fries (1874) placed it in subg. Camarophyllus, and Bon (1990), placed it in subg. Neocamarophyllus Bon [illeg.] sect. Neocamarophyllus Bon [illeg.] together with $H$. camarophyllus, H. calophyllus, and H. marzuolus. Although Bon's (1990) group is most concordant with our molecular phylogenies, his attempts to erect subgenus and sect. Neocamarophyllus were illegitimate because they lacked designated type species and Latin diagnoses. As noted by Bas (1990), the citation by Arnolds (1990) as tribe Hygrophoreae (Kühner) Bas \& Arnolds was incorrect in two respects: 1. tribe Hygrophoreae was published earlier than Kühner by $\mathrm{P}$. Hennings (1898), and 2. only names below genus are recombined (Art. 6.7), so authors of higher taxa remain the same when they are transferred to another family. Bas (1990) and Arnolds (1990) treated tribe Hygrophoreae in the fam. Tricholomataceae rather than Hygrophoraceae.

Hygrophorus [subgen. Camarophylli] sect. Camarophylli P. Karst. [as Hygrophorus sect. Camarophyllus], Bidr. Känn. Finl. Nat. Folk. 25: 197 (1876).

Type species Agaricus camarophyllus Alb. \& Schwein. Consp. Fung. Lusat.: 177 (1805) : Fr. [Art. 22.6] [as $H$. caprinus (Scop.) Fr.],

$\equiv$ Hygrophorus camarophyllus (Alb. \& Schwein. : Fr.) Dumée, Grandjean \& L. Maire, Bull. Soc. mycol. Fr. 28: 292 (1912),

[= Hygrophorus caprinus (Scop.) Fr. (1838), superfluous to a sanctioned name, nom. illeg., Art. 13.1].

Basidiomes dry; pileus grayish blue, grayish brown, buff brown, reddish brown bistre or fuliginous; lamellae decurrent to deeply decurrent, white, sometimes with a grey or salmonorange tinge; stipe grayish blue, grayish brown, buff brown, bistre or fuliginous; surface smooth or fibrillose. Lamellar trama divergent.

Phylogenetic support Species in this clade are not represented in our LSU, ITS-LSU or Supermatrix analyses. Our ITS analysis places $H$. camarophyllus on a separate branch near the base of Hygrophorus, but without backbone support. Sect. Camarophylli is also basal in the four-gene analysis presented by E. Larsson (2010, unpublished data), comprising $H$. atramentosus, $H$. camarophyllus, H. calophyllus, $H$. capriolarius, and H. marzuolus, but without backbone support.

Species included Type species: Hygrophorus camarophyllus. Additional phylogenetically supported species are $H$. atramentosus (Alb. \& Schwein.) H. Haas \& R. Haller Aar., H. calophyllus P. Karst., H. capreolarius Kalchbr. and $H$. marzuolus (Fr.) Bres.

Comments Fries $(1821 ; 1838)$ used the name Camarophylli for an unrecognized infrageneric rank, "subtribu" (name invalid because "subtribu" were not included in the exception outlined in the Vienna Code, Art. 33.12), in "Tribu" Clitocybe, then validly published as Hygrophorus subg. Camarophyllis Fr. in 1849. Karsten (1876) validly published Hygrophorus sect. Camarophylli (as sect. Camarophyllus), and included a Latin diagnosis. Bon (1990) attempted to erect a section, Neocamarophyllus, which is superfluous and thus illegitimate, and he listed Fries' group as a synonym but erred in citing it (p. 90) as sect. Camarophylli (Fr.) Hesl. \& A.H. Smith. Hesler and Smith (1963), however, classified Camarophylli at ranks of subsect. and series rather than section, and they only cited Fries as the basionym of series Camarophylli (Fr.) Hesler \& A.H. Smith (p. 379) and not subsect Camarophylli A.H. Smith \& Hesler (p. 309). Subsect. Camarophylli A.H. Smith \& Hesler is invalid as Hesler and Smith (1963) cited Lloydia 2: 32 (1939), but only the description of sect. Clitocyboides (without authors or Latin diagnosis) appears on that page and there are no infrageneric taxa named 'Camarophylli' anywhere in Smith and Hesler (1939). Nevertheless, Bon (1990) was the only author besides Fries (1849), Bataille (1910) and Hesler and Smith (1963) to recognize this group, in Bataille as Hygrophorus subg. Camarophyllus, [unranked] Caprini). Singer (1986) and Kovalenko $(1989,1999)$ classified $H$. camarophyllus and H. marzuolus in sect. Hygrophorus subsect. Tephroleuci, while Hesler and Smith (1963) included species from subsect. Tephroleuci with those of series Camarophylli. The composition of Bon's (1990) invalid sect.Neocamarophyllus (H. atramentosus, $H$. camarophyllus, $H$. calophyllus, $H$. hyacinthinus and $H$. inocybiformis) is closest to the composition of Sect. Camarophylli based on the four-gene analysis of Larsson (2010 and unpublished data).

Hygrophorus [subgen. Camarophylli] sect. Chrysodontes (Singer) E. Larss., stat. nov.

MycoBank MB804117. 
Type species: Hygrophorus chrysodon (Batsch : Fr.) Fr., Epicr. syst. mycol. (Upsaliae): 320 (1838) [1836-1838]

三Agaricus chrysodon Batsch, Elench. Fung., cont. sec. (Halle): 79 (1789) : Fr.

Basionym: Hygrophorus sect. Hygrophorus subsect. Chrysodontes Singer (as Chrysodontini), Ann. Mycol. 3: 41 (1943).

Basidiomes glutinous when moist; pileus white with golden yellow floccose-fibrillose veil remnants on margin; lamellae decurrent, white, sometimes with yellow granules on the edges; stipe white with golden yellow floccose granules, especially at stipe apex, which may form an vague annulus.

Phylogenetic support There is high support (98 \%-100\% MLBS) for sect. Chrysodontesin our Supermatrix, LSU and ITS analyses, as well as in a four-gene analysis presented by Larsson (2010, unpublished data). Our LSU analysis has strong support (72\% MLBS) for placing Chrysodontes as sister to the rest of the genus Hygrophorus. Sect. Chrysodontes is basal in the genus in the LSU, ITS and four-gene analyses, but not our Supermatrix analysis.

Species included Type species: Hygrophorus chrysodon. This was thought to be a monotypic group, but our ITS analysis suggests the taxon from western N. America is distinct, and the analysis presented by Larsson (2010, unpublished data) shows two distinct clades in N. Europe. Hygrophorus chrysodon var. cistophilus Pérez-De-Greg., Roqué \& Macau is also divergent in its ITS sequence (E. Larsson, unpublished data). While specimens from the divergent $H$. chrysodon clades do not differ appreciably in morphology, they occur with different hosts or are geographically disjunct and may represent different varieties or species. Hygrophorus chrysodon var. leucodon Alb. \& Schwein. is thought to be a color variant, but has not been sequenced.

Comments Chrysodontes was described as 'Chrysodontini' by Singer (1943) as a subsection of sect. Hygrophorus, following the placement by Bataille (1910). All subsequent authors also placed Chrysodonteswithin sect. Hygrophorus (Kovalenko 1989, 1999; Arnolds 1990; Bon 1990; Candusso 1997) or as a series in subsect. Hygrophorus (Hesler and Smith 1963). Our LSU analysis shows strong support (72\% ML BS) for placing Chrysodontes as sister to the rest of the genus Hygrophorus, and the four-gene analysis presented by Larsson (2010, unpublished data) shows sect. Chrysodontes basal while sect. Hygrophorus is the most distal in the phylogeny, making the placement by Singer and others untenable. We have therefore raised this phylogenetically supported and morphologically distinctive group to section rank.

Hygrophorus [subgen. Camarophylli] sect. Rimosi E. Larss., sect. nov.
MycoBank MB804118.

Type species Hygrophorus inocybiformis A.H. Sm., Mycologia 36(3): 246 (1944).

Basidiomes dry; pileus appearing rimose from dark grayish brown fibrils on a pale ground, darker in the centre, fibrillose veil remnants on margin; lamellae white, distant, decurrent; stipe white with dark grayish brown fibrils from veil remnants, apex white; growing with Abies and Picea.

Etymology.-rimose $=$ cracked, referring to the cracked appearance of the pileus surface.

Phylogenetic support Only the analysis presented by Larsson (2010) includes $H$. inocybiformis. In that analysis, $H$. inocybiformis is the most basal member of the subg. Camarophyllus grade; there is high support (81\% MPBS) for placing $H$. inocybiformis as sister to the rest of the genus Hygrophorus. Support for this monotypic clade is $100 \%$ MPBS.

Species included Type species: Hygrophorus inocybiformis. The section is monotypic.

Comments Hesler and Smith (1963) placed H. inocybiformis in series Camarophylli, together with a mixture of species from subg. Camarophylli and Colorati. The dry basidiomes, dull colors, and cortinoid fibrillose veil fit well in subg. Camarophylli.

Subfamily Lichenomphalioideae Lücking \& Redhead subf. nov.

MycoBank MB804120.

Type genus: Lichenomphalia Redhead, Lutzoni, Moncalvo \& Vilgalys, Mycotaxon 83: 38 (2002).

Basidiomes omphalinoid, pleurotoid, stereoid-corticioid or lentoid-cyphelloid, rarely absent, usually fuscous, green or colorless, rarely orange or yellow; hymenium lamellate, cantharelloid, merulioid or smooth; basidia elongated or not; clamp connections present or absent; L-DOPA and (to date) carotenoid pigments absent; habit primarily bryophilous or phycophilous, often lichenized, rarely parasitic or saprobic.

Phylogenetic support Subf. Lichenomphaloideae appears as a moderately to well-supported monophyletic clade in our fourgene backbone analyses (81 \% MLBS, 1.0 Bayesian PP), a monophyletic clade in our ITS-LSU analysis, a monophyletic clade with low support in our Supermatrix analysis $(38 \% \mathrm{ML}$ BS), but as a paraphyletic grade lacking BS support in our LSU analysis. Previous LSU analyses show Lichenomphaloideae as a moderately supported monophyletic clade (Lutzoni 1997, $68 \%$ and $53 \%$ MP BS for unpruned and pruned data sets) or as three clades emerging from a backbone (Moncalvo et al. 2002). Using ITS together with LSU data improved support for a monophyletic Lichenomphaloideae in Lutzoni (1997; MPBS 
$83 \%$ in equally weighted and $70 \%$ in unequally weighted data sets) and Redhead et al. (2002; $79 \%$ MP BS), but not in Lawrey et al. (2009). In the ITS-LSU analysis by Lawrey et al. (2009), Lichenomphalia umbellifera was separated from the other species in subf. Lichenomphaloideae, making it polyphyletic. Association with plant symbionts increased the rate of nucleotide substitutions after the adoption of a mutualistic lifestyle in four separate lineages of subf. Lichenomphaloideae (Lutzoni and Pagel 1997), and this affects topology in phylogenetic analyses (Lawrey et al. 2009). Subf. Lichenomphaloideae and Hygrophoroideae appear as sister clades in Redhead et al. (2002, represented by Chrysomphalina), a Supermatrix analysis presented by Lodge et al. (2006), the Supermatrix analysis presented here (68\% MLBS), and our four-gene backbone analyses (81\% MLBS; 1.0 BPP).

Tribes included Arrhenieae Lücking, tribe nov., Cantharelluleae Lodge \& Redhead, tribe nov. and Lichenomphalieae Lücking \& Redhead, tribe nov.

Comments The existence of a monophyletic clade within the Hygrophoraceae in which the species are primarily associated with bryophytes algae and cyanobacteria was shown by Lutzoni (1997), Redhead et al. (2002) and Lawrey et al. (2009), and this group is more strongly supported by our analyses. We also show the strongest support for subf. Lichenomphalioideae and Hygrophoroideae as sister clades - a relationship suggested by Redhead et al. (2002).

Tribe Arrhenieae Lücking, tribe nov.

MycoBank MB804121.

Type genus: Arrhenia Fr., Summa Veg. Scand., Section Post. (Stockholm): 312 (1849).

Basidiomes omphalinoid, pleurotoid, lentoid-cyphelloid or stereoid-corticioid, gray, gray-brown, green or white; hymenium lamellate, cantharelloid, merulioid or smooth; basidia elongated or not; clamp connections present or absent; DOPA and carotenoid pigments absent; habit primarily bryophilous, rarely phycophilous; parasitic and/or pathogenic on mosses and algae, lichenized, or saprotrophic; associated with scytonematoid bacteria if lichenized; thallus absent undifferentiated, squamose or foliose.

Phylogenetic support Tribe Arrhenieae appears as a strongly supported monophyletic clade in our four-gene backbone (97\% MLBS; 1.0 BPP), Supermatrix (99\% MLBS) and ITS-LSU (97 \% MLBS) analyses, and moderately supported in our LSU analysis (67 \% MLBS). Similarly, Lawrey et al. (2009) show strong support for a monophyletic Arrhenieae using a combined ITS-LSU data set (96\% MPBS and $100 \%$ MLBS). Only our ITS analysis shows tribe Arrhenieae as a paraphyletic grade.
Genera included Arrhenia, Acantholichen, Cora, Corella, Cyphellostereum, Dictyonema and Eonema.

Comments The monophyly of the new tribe Arrhenieae, established by Lawrey et al. (2009), is confirmed here. It includes the non-lichenized genera Arrhenia s.l. (paraphyletic) and Eonema and the genera lichenized with cyanobacteria - Acantholichen, Cora, Corella, Cyphellostereum, and Dictyonema (Dal-Forno et al. 2013). In the analyses by Dal-Forno et al. (2013), Corella appears as a sister clade to Acantholichen with strong support in their combined ITS-LSU-RPB2 analysis (91 \% MLBS; 0.98 BPP).

Acantholichen P.M. Jørg., Bryologist 101: 444 (1998).

Type species: Acantholichen pannarioides P.M. Jørg., Bryologist 101: 444 (1998).

Basidiomata absent; lichenized, thallus small, squamulosesordiate, appearing on the margins of the foliose lichen; acanthohyphidia present; internal structure homomerous, composed of jigsaw cells; clamp connections absent.

Phylogenetic support Acantholichen is represented only by the type of this monotypic genus in our Supermatrix analysis ( $57 \%$ MLBS), where it appears as sister to Corella. Similarly, the combined ITS-LSU- RPB2 analyses by Dal-Forno et al. (2013), show Acantholichen as sister to Corella (91\% MLBS, 1.0 B.P. with $88 \%$ MLBS and 1.0 BPP support for the branch that subtends both).

Species included Type species: Acantholichen pannarioides. The genus is currently monotypic, but two undescribed species have been found in Brazil and the Galapagos Islands.

Comments Acantholichen was originally classified as an ascolichen because basidiomata are absent, and the spiny structures indicated placement in the Pannariaceae. Jørgensen (1998) reinterpreted the spiny structures as basidiomycete dendrohyphidia.

Cora Fr., Syst. orb. veg. (Lundae) 1: 300 (1825).

Type species: Cora pavonia (Sw.) Fr., Syst. orb. veg. (Lundae) 1: 300 (1825),

$\equiv$ Thelephora pavonia Sw., Fl. Ind. Occid. 3: 1930 (1806).

Basidiomes stereoid-corticioid; hymenium smooth; lichenized with cyanobacteria, thallus thelephoroid or foliose-lobate, gray and white; jigsaw shaped sheath cells present; clamp connections present.

Phylogenetic support Only a few representatives of Cora were included in our analyses - as Dictyonema minus isotype, Cora glabrata R06 \& C. glabrata s.l. AFTOL. The ITS-LSU analysis of Lawrey et al. (2009) places D. minus in the same clade with $D$. sericeum (100\% MLBS) whereas our 
Supermatrix analysis places $D$. minus as sister to $D$. glabratum s.l. AFTOL with strong support ( $80 \%$ MLBS). The combined ITS-LSU-RPB2 analysis of Dal-Forno et al. (2013) shows Cora as sister to a clade formed by Acantholichen and Corella.

Species included Type Cora pavonia (Sw.) Fr., C. byssoidea, C. glabrata (Spreng.) Fr., D. hirsutum Moncada \& Lücking and D. minus Lücking, E. Navarro \& Sipman, as well as a large number of undescribed species are included (Dal-Forno et al. 2013).

Comments The generic name Cora was resurrected by Lawrey et al. (2009) and Yánez et al. (2012) based on correlations between phylogeny and thallus morphotypes in the Dictyonema s.l. clade. Cora is a monophyletic clade characterized by macrosquamulose to foliose thalli with a loose, palisadic upper cortex.

Dictyonema C. Agardh ex Kunth, Syn. pl. (Paris) 1: 1 (1822).

Type species: Dictyonema excentricum C. Agardh, in Kunth, Syn. pl. (Paris) 1: 1 (1822) = Dictyonema thelephora (Spreng.) Zahlbr., Cat. Lich. Univers. 7: 748 (1931) [current name],

= Dictyonema sericeum (Sw.) Berk., London J. Bot. 2: 639 (1843), 三 Dictyonema sericeum f. thelephora (Spreng.) Parmasto, Nova Hedwigia 29: 111 (1978) [1977].

Basidiomata stereoid-corticioid or lentoid-cyphelloid; hymenium smooth; clamp connections absent; lichenized with cyanobacteria, thallus present, undifferentiated, jigsaw shaped hyphal sheath cells present.

Phylogenetic support Dictyonema, represented by $D$. sericeum, is strongly supported as a sister to Cora (as $D$. glabratum and D. minus) in our 4-gene backbone, ITS-LSU and LSU analyses (100 \% MLBS). In our Supermatrix and ITS analyses, Dictyonema appears basal to the Cora clade (100\% MLBS). The Dictyonema-Cora clade appears on a long branch emerging from the Arrhenia grade in our 4-gene backbone analyses and our ITS-LSU analysis. The analyses by Dal-Forno et al. (2013) shows the most closely related groups that are basal to Dictyonema are Eonema and Cyphellostereum rather than the more distantly related Arrhenia included in our analyses. In the analysis by Lawrey et al., Acantholichen separates the Cora $(D$. sericeum-D. minus) and Dictyonema ss. (D. aeruginosulum, D. phyllophilium and $D$. schenkianum) clades, but without support for the branching order.

Species included Type Dictyonema excentricum $[=D$. sericeum (Sw.) Berk.). Additional species included based on molecular phylogenies of Lücking et al. (2009) and Dal-Forno et al. (2013) are D. hernandezii Lücking, Lawrey \& DalForno, D. irpicinum Mont., D. minus Lücking, D. sericeum f. phyllophilum Parmasto, D. schenkianum (Müll. Arg.) Zahlbr, and two new Dictyonema spp. aff. D. sericeum.

Comments While Dictyonema appears as a grade in most analyses, the combination of morphological and ecological characters set it apart, and topological tests cannot reject its potential monophyly. Resurrection of generic names Cora by Lawrey et al. (2009) and Corella by Dal-Forno et al. (2013) for the disjunct Dictyonema clades shown in Lawrey et al. (2009) resolves the problem of polyphyly in this group.

Cyphellostereum D.A. Reid, Beih. Nova Hedwigia, 18: 336 (1965).

Type species: Cyphellostereum pusiolum (Berk. \& M.A. Curtis) D.A. Reid, Beih. Nova Hedwigia 18: 342 (1965),

$\equiv$ Stereum pusiolum Berk. \& M.A. Curtis, J. Linn. Soc., Bot. 10 (no. 46): 330 (1869) [1868].

Basidiomata usually absent, cyphelloid when present; hymenium irregular; cystidia absent; clamp connections absent; lichenized with cyanobacteria; thallus appressed filamentosecrustose, undifferentiated, gray or white, hyphal sheath cells simple, not jigsaw puzzle shaped.

Phylogenetic support We included only one species of Cyphellostereum in our Supermatrix analysis (as Dictyonema phyllogenum), where it appears as sister to the Dictyonema-Cora clade with $100 \%$ MLBS support, and distal to Arrhenia. Previous analyses by Lawrey et al. (2009) show D. phyllogenum together with the type of Cyphellostereum, C. pusiolum, in a strongly supported monophyletic clade (98\% MP and $100 \%$ MLBS). Dal-Forno et al. (2013) show strong support for a monophyletic Cyphellostereum in their combined ITS-LSU-RPB2 analysis (73\% MLBS, 0.99 BPP). In Lawrey et al. (2009), Cyphellostereum is distal to Eonema and Arrhenia and basal to the Dictyonema-Cora clade. The topology shown in the combined ITS-LSU-RPB2 analyses of Dal-Forno et al. (2013) is similar, but Cyphellostereum appears as sister to Dictyonema, while Eonema is basal to both.

Species included Type Cyphellostereum pusiolum. Dictyonema phyllogenum (Müll. Arg.) Zahlbr. is included based on molecular phylogenies (Dal-Forno et al. 2013; Lawrey et al. 2009). Several undescribed species also belong in this clade. Cyphellostereum laeve (Fr. : Fr.) D.A. Reid is excluded based on phylogenetic analyses of Larsson (2007) that place it in the Hymenochaetales.

Comments Lawrey et al. (2009) were the first to show the type of Cyphellostereum is near the base of the clade named here as subf. Lichenomphalioideae, and they also confirmed 
Oberwinkler's (1970) observations of an associated lichenized thallus. The genus is similar to Dictyonema s.s. in overall morphology but lacks the jigsaw-puzzle-shaped hyphal sheath cells.

Arrhenia Fr., Summa Veg. Scand., Section Post. (Stockholm): 312 (1849).

Type species: Arrhenia auriscalpium (Fr.) Fr., Summa Veg. Scand., Section Post. (Stockholm): 312 (1849),

$\equiv$ Cantharellus auriscalpium Fr., Elench. fung. (Greifswald) 1: 54 (1828)].

Basidiomes omphalinoid or pleurotoid, gray or grayish brown or bluish gray, rarely dark and scaly at center with beige or tan margin and then growing on sphagnum; hymenium paler, lamellate, cantharelloid, merulioid or smooth; basidia elongated or not; clamp connections present or absent; DOPA and carotenoid pigments absent; habit primarily bryophilous, rarely phycophilous; parasitic and/or pathogenic on mosses or algae, possibly saprobic on dung, not lichenized (thus lacking a thallus) as found in Acantholichen, Dictyonema or Lichenomphalia.

Phylogenetic support Arrhenia consistently appears as a paraphyletic grade in all analyses, and the same is true for tribe Arrhenieae.

Species included Type species: Arrhenia auriscalpium. Species included based on molecular phylogeny are $A$. chlorocyanea (Pat.) Redhead et al., Lutzoni, Moncalvo \& Vilgalys, A. epichysium (Pers. : Fr.) Redhead et al., A. griseopallida (Desm.) Watling, A. lobata (Pers.) Kühner \& Lamoure ex Redhead, A. obscurata (D.A. Reid) Redhead et al., A. philonotis (Lasch) Redhead et al., A. sphagnicola (Berk.) Redhead et al. and A. velutipes (P.D. Orton) Redhead et al. Species included in Arrhenia based on morphology in Redhead et al. (2002) are A. acerosa (Fr.) Kühner, A. alnetora (Singer) Redhead, A. australis (Clel.) Grgurinovic, A. andina (Corner) Redhead et al., A. antarctica (Singer) Redhead et al., A. baeospora (Singer) Redhead et al., A. chilensis (Mont.) Redhead et al., A. elegans (Pers.) Redhead et al., A. fissa (Leyss.) Redhead, A. hohensis (A.H. Sm.) Redhead et al., $A$. lundellii (Pilát) Redhead et al., A. obatra (J. Favre) Redhead et al., A. obscurata (D. A. Reid) Redhead et al., A. omnivora (Agerer) Redhead et al., A. onisca (Fr.:Fr.) Redhead et al., $A$. parvivelutina (Clémençon \& Irlet) Redhead et al., A. pauxilla (Clémençon) Redhead et al., A. peltigerina (Peck) Redhead et al., A. pubescentipes (H.E. Bigelow) Redhead et al., $A$. rainierensis (H.E. Bigelow) Redhead et al., A. retiruga Redhead, A. rickenii (Hora) Watling, A. rigidipes (Lamoure) Redhead et al., A. salina (Høil.) Bon \& Courtec., A. spathulata (Fr.) Redhead, A. rustica (Fr.) Redhead et al., A. sphaerospora (Lamoure) Redhead et al., A. stercoraria (Barrasa, EsteveRav. \& Sánchez Nieto) Redhead et al., A. subglobispora (G.
Moreno, Heykoop \& E. Horak) Redhead et al., A. subobscura (Singer) Redhead et al., A. subumbratilis Redhead et al., $A$. trigonospora (Lamoure) Redhead et al., A. umbratilis (Fr.:Fr.) Redhead et al., A. viridimammata (Pilát) Redhead et al. and $A$. volkertii (Murrill) Redhead et al.

Comments Omphalinoid Arrhenia species were once classified in Omphalina (type species, O. pyxidata), a genus that is also bryophilous, but Arrhenia are gray-brown throughout while Omphalina have a reddish brown surface and colorless context (Redhead et al. 2002). Arrhenia was erected for species with drooping or pendant basidiomata with cantharelloid (wrinkled) hymenia (Corner 1966, Høiland 1976; Pilát and Nannfeldt 1954), but later expanded to include species with pleurotoid basidiomata, such as Leptoglossum and Phaeotellus, and omphalinoid basidiomata (Redhead et al. 2002). Because Arrhenia includes reduced species (e.g., $A$. auriscalpium, the type of Arrhenia, and A. lobata, the type of Dictyolus Quél.) as well as omphalinoid species, some are not readily distinguishable from other genera in the subfamily based on macromorphology. The ecology of Arrhenia often differs, however, in its association with mosses, or more rarely with microbial films, and it lacks a lichenized thallus.

Lawrey et al. (2009) note the paraphyly of Arrhenia in relation to Dictyonema and Cora using parsimony (MP) and likelihood (ML) methods whereas as a distance based method (ME) shows Arrhenia as monophyletic. Lawrey et al. (2009) suggested that the paraphyly of Arrhenia is likely real, and that the difference in topology using a distance method may be an artifact of having few synapomorphies in a rapidly evolving group.

Corella Vain., Acta Soc. Fauna Flora fenn. 7(2): 243 (1890). Type species: Corella brasiliensis Vain., Acta Soc. Fauna Flora fenn. 7(2): 243 (1890),

$\equiv$ Dictyonema pavonium f. brasiliense (Vain.) Parmasto, Nova Hedwigia 29 (1-2): 106 (1978).

Basidiomes stereoid-corticioid; hymenium smooth; spores inamyloid; clamp connections absent; lichenized with cyanobacteria; thallus foliose, jigsaw shaped cells present.

Phylogenetic support Corella was not represented in our phylogenetic analyses. Analyses by Dal Foro et al. (2013) suggest the type species is part of a complex.

Species included Type species: Corella brasiliensis Vain. Dictyonema melvinii Chaves et al. (2004) is included.

Comments Corella brasiliensis was not accepted as a separate species or genus by Parmasto (1978) but is phylogenetically and morphologically distinct, differing from Cora in the presence of a paraplectenchymatous upper cortex and being more closely related to Acantholichen (Dal-Forno et al. 2013). 
Eonema Redhead, Lücking \& Lawrey, Mycol. Res. 113(10): 1169 (2009).

Type species: Eonema pyriforme (M.P. Christ.) Redhead, Lücking \& Lawrey

$\equiv$ Athelia pyriformis (M.P. Christ.) Jülich, Willdenowia, Beih. 7: 110 (1972),

三 Xenasma pyrifome M.P. Christ., Dansk bot. Ark. 19(2): 108 (1960).

Basidiomes corticioid-athelioid; hymenium smooth; spores hyaline, inamyloid; clamp connections absent; saprotrophic, thallus is absent.

Phylogenetic support As Eonema is monotypic, branch support is not relevant. However, support for Eonema as sister to Cyphellostereum is strong in MP and ML analyses of ITSLSU in Lawrey et al. (2009, $96 \%$ and $100 \%$ MP and MLBS).

Species included Type species: Eonema pyriforme, is the only known species.

Comments The type, E. pyriforme, was previously classified among the corticioid fungi as a species of Xenasma, Athelia and Athelidium. In a review of corticioid fungi, Larsson (2007) suggested that a new genus be erected in the Hygrophoraceae to accommodate this species, hence the erection of Eonema by Redhead et al. in Lawrey et al. (2009).

Tribe Lichenomphalieae Lücking \& Redhead tribe nov. MycoBank MB804122.

Type genus: Lichenomphalia Redhead, Lutzoni, Moncalvo \& Vilgalys, Mycotaxon 83: 36 (2002).

Basidiomata mostly omphalinoid, rarely arrhenioid and drooping; pileus usually convex-umbilicate, typically colored fuscous from melanized intraparietal or encrusting pigments and/or yellow from dissolved pigments; stipe present, cartilaginous or tough, surface usually pubescent; mostly uninucleate; clamp connections absent; lichenized stromata present, undifferentiated, squamulose or rarely foliose, totally enveloping Coccomyxa algal cells, in non-perforated sheaths of polygonal cells (not jigsaw shaped), forming either scattered spherules or irregular granules usually less than $1 \mathrm{~mm}$ diameter connected by filamentous hyphae.

Phylogenetic support Lichenomphalieae is strongly supported as a monophyletic clade in our 4-gene backbone Bayesian analysis (0.99 PP), moderately supported in our 4-gene ML analysis (69 \% MLBS) but weakly supported in our Supermatrix and ITS analyses ( $<50 \%$ MLBS). Analyses by Lutzoni (1997) also show a monophyletic Lichenomphalieae clade with support varying from $<50 \%$ to $70 \%$ MPBS. The inner Lichenomphalieae clade (excluding L. umbellifera $=L$. ericetorum) is strongly supported in all analyses ( $90 \%-100 \%$ ML or MPBS; $1.0 \mathrm{BPP})$. Lichenomphalieae appears polyphyletic in some analyses because of the divergent $L$. umbellifera (Lawrey et al. 2009, and our LSU and ITS-LSU analyses).

Genera included Lichenomphalia and tentatively Semiomphalina, based on morphology.

Comments Lutzoni (1997) showed that the lichenized omphalinoid fungi are a monophyletic clade, while Kranner and Lutzoni (1999) showed this group shares many characters including mononucleate basidiomes, a Coccomyxa algal host and lack of growth in axenic culture. Semiomphalina is a rare fungus with drooping, pale basidiomes that has not yet been sequenced, but it shares with Lichenomphalia stipe and thallus characters, and it is thought to be a sister genus based on morphology (Redhead et al. 2002).

Lichenomphalia Redhead, Lutzoni, Moncalvo \& Vilgalys, Mycotaxon 83: 36 (2002).

Type species: Lichenomphalia hudsoniana (H.S. Jenn.) Redhead et al., Mycotaxon 83: 38 (2002),

$\equiv$ Hygrophorus hudsonianus H.S. Jenn., Mem. Carn. Mus., III 12: 2 (1936).

Basidiomes omphalinoid, lamellae decurrent; stipe cartilaginous or tough, usually pubescent; pigments of two types, intracellular pigments bright orangish yellow, intraparietal and encrusting pigments fuscous and melanized; pileus trama hyphae thin walled, large diameter generative hyphae together with smaller diameter connective hyphae; lamellar trama bidirectional or subregular; subhymenial cells elongated, forming a loose structure; hymenium slightly thickening; basidia of variable lengths; basidiospores hyaline, white in mass, inamyloid, not metachromatic in cresyl blue; cystidia absent; clamp connections absent; lichenized thallus squamulose, rarely foliose or undifferentiated, totally enveloping Coccomyxa algal cells, in non-perforated sheaths of polygon-shaped cells, not jigsaw shaped, forming either scattered sphaerules or irregular granules usually less than $1 \mathrm{~mm}$ diameter connected by filamentous hyphae, hyphal walls thickened; xeric habitats in arctic-alpine areas.

Phylogenetic support Support for a monophyletic clade comprising Lichenomphalia is presented above under tribe Lichenomphalieae.

Subgenera included Lichenomphalia and Protolichenomphalia Lücking, Redhead \& Norvell, subg. nov.

Comments Lichenomphalia species are primarily found in arctic-alpine zones, though $L$. umbellifera extends into the boreal zone (Lutzoni 1997). Lutzoni (1997) found that $L$. umbellifera (as L. ericetorum) had the slowest molecular substitution rate within the lichenized omphalinoid group, 
and is likely an extant species that most closely resembles the ancestral species that gave rise to this lichenized lineage. As noted above under phylogenetic support for Tribe Lichenomphalieae, L. umbellifera is also the most divergent species. We therefore recognize L. umbellifera as the type of a new subgenus, Protolichenomphalia.

The history of nomenclature in this group is complex, and as it was reviewed thoroughly in Redhead et al. (2002), only a short synopsis is presented here. Some of the names applied to this group were based on oldest named anamorphic, lichenized states, namely Phytoconis Bory (1797), Botrydina Bréb. (1839), and Coriscium Vain. (1890). Although the sexual states of ascolichens have long been named from types representing their lichenized state, an attempt to apply asexual names to the sexual state of basidiolichens (Clémençon 1997; Redhead and Kuyper 1988; Norvell et al. 1994 and many others listed in Redhead et al. 2002 and Gams 1995) was rejected and the asexual basidiolichen names were placed on a list of rejected names (Gams 1995; Greuter et al. 2000). Lichenomphalia was proposed by Redhead et al. (2002) to replace the rejected names. Although anamorph names were placed on equal footing with teleomorph names with regards to priority when the nomenclatural code was changed to eliminate dual nomenclature in January of 2013, a previously rejected name cannot be resurrected, leaving Lichenomphalia as the only available name for this genus.

Lichenomphalia subgen. Lichenomphalia [autonym], subg. nov.

Type species Lichenomphalia hudsoniana (H.S. Jenn.) Redhead et al., Mycotaxon 83: 38 (2002)

$\equiv$ Hygrophorus hudsonianus H.S. Jenn., Mem. Carn. Mus., III 12: 2 (1936).

Characters as in Lichenomphalia, basidiomes highly pigmented; lichenized with Coccomyxa algae; thallus usually squamulose, rarely foliose or undifferentiated, hyphal walls thickened; growing in xeric arctic-alpine habitats.

Phylogenetic support Subg. Lichenomphalia has strong support in our 4-gene backbone (99\% MLBS; 1.0 B.P. and Supermatrix (95\% MLBS) analyses, and moderate support in our LSU analyses (63\% MLBS). Analyses by Lutzoni (1997) also show strong support using LSU (95\% MPBS) combined ITS-LSU (92\%-93\% MPBS), and ITS1 and ITS2 ( $86 \%$ and $82 \%$ MPBS, respectively). ITS-LSU analyses by Redhead et al. (2002) and Lawrey et al. (2009) also show high support (83 \%-98 \% MPBS and $100 \%$ ML BS) for a monophyletic subg. Lichenomphalia.

Species included Type Lichenomphalia hudsoniana. Additional species included based on phylogenies and morphology are L. alpina (Britzelm.) Redhead et al., L. grisella (P. Karst.) Redhead et al., and L. velutina (Quél.) Redhead et al. Species included based on morphology (Redhead et al. 2002) are L. aurantiaca (Redhead \& Kuyper) Redhead et al., $L$. chromacea (Cleland) Redhead et al., and L. lobata (Redhead \& Kuyper) Redhead et al.

Comments Subg. Lichenomphalia forms a well-supported, monophyletic clade that is concordant with the morphological and ecological characters that define the group. Species in subg. Lichenomphalia are found in high-light habitats that are more subject to drought than in subg. Protolichenomphalia, but they are presumably protected from ionizing radiation and desiccation by strong pigments and thick hyphal walls in the thalli (Redhead et al. 2002; Redhead and Kuyper 1987).

Lichenomphalia subgen. Protolichenomphalia Lücking, Redhead \& Novell, subg. nov.

Mycobank MB 804123.

Type species: Lichenomphalia umbellifera (L.) Redhead, Lutzoni, Moncalvo \& Vilgalys, Mycotaxon 83: 38 (2002)

$\equiv$ Agaricus umbelliferus L., Sp. pl. 2: 1175 (1753), sanctioned by Fr., Elench. fung. 1: 22 (1828).

Etymology-proto - first, lichenomphalia Lichenomphalia.

Characters as in Lichenomphalia, basidiomes lightly pigmented; lichenized thallus undifferentiated, hyphal walls thin; growing in mesic habitats in arctic and boreal zones.

Phylogenetic support Phylogenetic support is irrelevant as this subgenus is monotypic.

Species included Type species: Lichenomphalia umbellifera.

Comments Redhead et al. (2002) noted that L. umbellifera has more ancestral features than other species now placed in subg. Lichenomphalia, i.e., the hyphae in the thallus are broader and not as thick-walled, so presumably more susceptible to desiccation (Redhead and Kuyper 1988). Furthermore, the type of subg. Protolichenomphalia has a broader geographical distribution, occupies wetter habitats, and its basidiomata are less protected by strong pigments than species in subg. Lichenomphalia (Redhead et al. 2002; Lawrey et al. 2009).

Semiomphalina Redhead, Can. J. Bot. 62(5): 886 (1984). Type species: Semiomphalina leptoglossoides (Corner) Redhead, Can. J. Bot. 62(5): 886 (1984),

$\equiv$ Pseudocraterellus leptoglossoides Corner, Monogr. Cantharelloid Fungi: 161 (1966).

Basidiomes arrhenioid, drooping, pale; stipe and thallus similar to those of Lichenomphalia umbellifera.

Comments There are currently no published sequences of this lichenized, monotypic genus described from Papua New Guinea by Corner, but Redhead et al. (2002) suggested that it was related to Lichenomphalia based on morphology and 
ecology. If Semiomphalina leptoglossoides and Lichenomphalia hudsoniana are later found to be congeneric, Article 14 in the Melbourne Code (2012) allows for selection of a widely used name, such as Lichenomphalia, over a more obscure one (Semiomphalina).

Tribe Cantharelluleae Lodge, Redhead, Norvell \& Desjardin, tribe nov.

MycoBank MB804125.

Type genus: Cantharellula Singer, Revue Mycol., Paris 1: 281 (1936).

Basidiomata clitocyboid or omphalinoid; pileus convex, indented or infundibuliform, opaque; pileus and stipe surfaces yellowish or grayish brown; pileipellis hyphae with dissolved pigments, with or without encrusting pigments; lamellae decurrent, repeatedly forked, sometimes staining reddish brown; stipe central or eccentric; spores smooth, the length usually at least twice the diameter, hyaline, white in deposit, distinctly amyloid, acyanophilic; basidia with basal clamp connections, about 4 times the length of the basidiospores; cheilocystidia and pleurocystidia absent; lamellar trama partly gelatinized at the lamellar edge, tridirectional, with a subregular or regular central strand, lateral strands with frequent hyphae parallel to the lamellar edge woven through a few vertically oriented hyphae, and abundant generative hyphae oriented predominantly parallel to the basidia and giving rise to the subhymenial cells, but obliquely angled (divergent) at the lamellar edge; subhymenium subramose or pachypodial, of short- or long celled hyphal segments predominantly parallel and oriented in the same direction as the basidia, but a few highly curved and intertwined; forming a weak hymenial palisade via proliferation of basidia from subhymenial cells; habit bryophilous or lignicolous.

Phylogenetic support Support for a monophyletic clade corresponding to tribe Cantharelluleae is strong in our 4-gene backbone analyses (87 \% MLBS; 1.0 B.P. and Supermatrix analysis ( $83 \%$ MLBS), and moderate in our ITS-LSU (65\% ML, $60 \%$ MP BS) and LSU analyses (64\% MLBS). Moncalvo et al. (2002; LSU), Lodge et al. (2006; four-gene Supermatrix) and Lawrey et al. (2009; ITS-LSU) show the same monophyletic clade, but only Lodge et al. (2006) shows significant support $(>0.95$ Bayesian PP).

\section{Genera included Cantharellula and Pseudoarmillariella.}

Comments The long, smooth, amyloid spores and tridirectional lamellar trama is a unique combination of characters that unite Cantharellula and Pseudoarmillariella. Singer (1986) described the hymenium of Cantharellula and Pseudoarmillariella as subirregular to almost intermixed, and the subhymenium as intermixed-subramose. Clémençon et al. (2004), however, listed Cantharellula among the genera with bilateral lamellar trama, defined as having vertically oriented hyphae woven through others that are parallel to the lamellar edge. Drawings by Lodge of Cantharellula and Pseudoarmillariella (Figs. 20 and 21) show typical bidirectional architecture, but they also show an abundance of hyphae that are perpendicular to both sets of hyphae in the bidirectional structure, making it tridirectional. The latter hyphae emerge from the mediostratum, are mostly parallel to the basidia and give rise to the subhymenial cells, in places forming a pachypodial structure in the subhymenium. The appearance of lamellar cross sections in tribe Cantharelluleae resembles the bilateral trama and pachypodial hymenium seen in Aeruginospora and Chrysomphalina Figs. 17 and 18), albeit with few signs of proliferation of basidia from candelabra-like branching of subhymenial cells and thus only forming a weak hymenial palisade such as found in subf. Hygrophoroideae tribe Chrysomphalineae. Our 4-gene backbone analyses, however, show strong support for placing Cantharellula in subf. Lichenomphalioideae rather than Hygrophoroideae. Nevertheless, subfamilies Lichenomphalioideae and Hygrophoroideae, are in adjacent clades, so the appearance of similar hymenial architecture in both clades suggests a possible homologous origin.

Tribe Cantharelluleae is the only group retained in the Hygrophoraceae with amyloid spores. Neohygrophorus angelesianus (A.H. Sm. \& Hesler) Singer (= Hygrophorus subg. Pseudohygrophorus A.H. Sm. \& Hesler) is shown as sister to Tribe Clitocybeae (Tricholomataceae) in a multigene Supermatrix analysis by Matheny et al. (2006), sister to the type of Pseudoomphalina, P. kalchbrenneri, (in the Tricholomataceae), in our 4-gene backbone analyses (100\% MLBS; 1.0 BPP), and sister to Pseudoomphalina felloides in previous Supermatrix (Lodge et al. 2006) and LSU analyses (Moncalvo et al. 2002; $70 \%$ MPBS). Another species with amyloid spores, Hygrophorus metapodius (Fr.) Fr. [ $\equiv$ Camarophyllus metapodius (Fr.) Wünsche, $\equiv$ Hygrocybe metapodia (Fr.) M.M. Moser, $\equiv$ Neohygrocybe metapodia

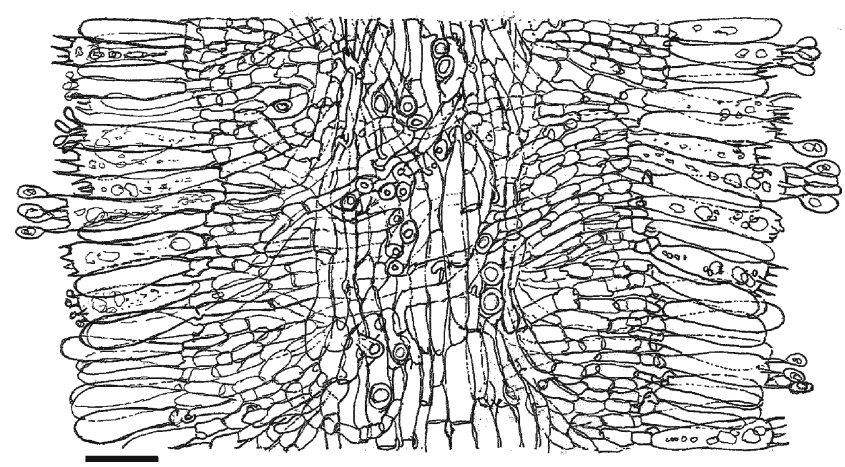

Fig. 20 Subf. Lichenomphalioideae, tribe Cantharelluleae, Pseudoarmillariella ectypoides lamellar cross section (DJL05, North Carolina, Great Smoky Mt. National Park, USA). Scale bar $=20 \mu \mathrm{m}$ 


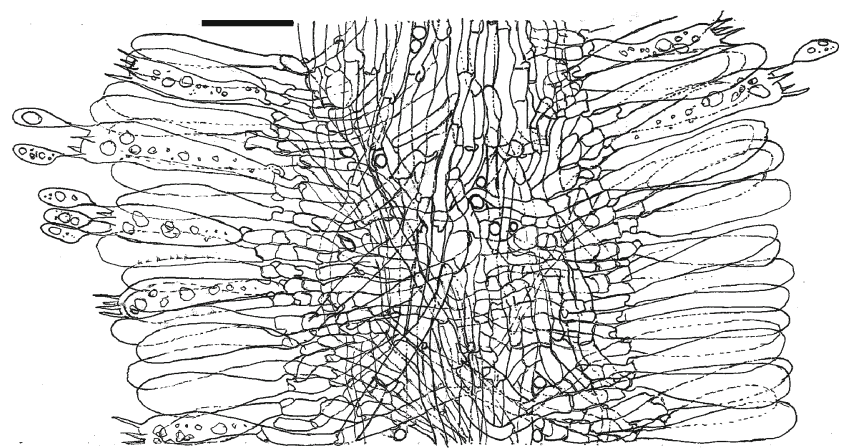

Fig. 21 Subf. Lichenomphalioideae, tribe Cantharelluleae, Cantharellula umbonata lamellar cross section (RDY-1366, R. Youst, California, USA). Scale bar $=20 \mu \mathrm{m}$

(Fr.) Herink], was also transferred to the Tricholomataceae and recombined in gen. Porpoloma by Singer (1973).

Pseudoarmillariella ectypoides has been variously placed in Clitocybe (Saccardo 1887), Clitocybula (Raithelhuber 1980) and Omphalina (Bigelow 1982), while Cantharellula has been placed in Cantharellus (Persoon 1794), and Hygrophoropsis (Kühner and Romagnesi 1953). Singer (1942; 1948; 1986) recognized the close relationship between Cantharellula umbonata and Pseudoarmillariella ectypoides, but placed them together with other amyloid spored genera in the Tricholomataceae, tribe Leucopaxilleae. Singer transferred Peck's Agaricus ectypoides to Cantharellula in 1942, erected subg. Pseudoarmillariella Sing. in 1948 for C. umbonata and C. ectypoides (Peck) Singer, then raised subg. Pseudoarmillariella to genus rank for P. ectypoides in 1965. Moncalvo et al. (2002) were the first to show inclusion of tribe Cantharelluleae in the Arrhenia-Lichenomphalia clade (as cantharelloid clade 62) using an LSU analysis, but without significant branch support. Using a four-gene Supermatrix analysis, Lodge et al. (2006) were the first to show significant support for the Cantharelluleae clade, while Matheny et al. (2006) were the first to show significant Bayesian support (1.0 PP) for including Pseudoarmillariella in the Hygrophoraceae and subf. Lichenomphalioideae. Our 4-gene backbone analyses presented here strongly supports that placement.

Cantharellula Singer, Revue Mycol., Paris 1: 281 (1936). Type species: Cantharellula umbonata (J.F. Gmel.) Singer, Revue Mycol., Paris 1: 281 (1936),

$\equiv$ Merulius umbonatus J.F. Gmel., Systema Naturae, Edn. 13, 2: 1430 (1792).

Basidiomata clitocyboid; pileus convex, indented or infundibuliform, opaque; pileus and stipe surfaces yellowish or grayish brown; lamellae decurrent, repeatedly forked, often staining reddish brown; stipe fleshy or fleshy-fibrous; spores smooth, hyaline, white in deposit, distinctly amyloid, acyanophilic, cylindric or ellipsoid-oblong; basidia mostly four times the length of the basidiospores; cheilocystidia and pleurocystidia absent; lamellar trama subgelatinized at the lamellar edge, with a subregular central strand 15-30 $\mu \mathrm{m}$ wide, lateral strands tridirectional, hyphae parallel to the lamellar edge woven through vertically oriented hyphae, and other hyphae that diverge more or less perpendicularly from the vertical hyphae, but obliquely angled (divergent) at the lamellar edge; subhymenial cells arising from similarly oriented hyphae that diverge from vertically oriented hyphae; subhymenium sometimes pachypodial, of short- or longcelled, mostly parallel hyphal segments oriented in the same direction as the basidia, but forming only a weak hymenial palisade via proliferation of basidia from candelabra-like branches of subhymenial cells; clamp connections present; habit bryophilous. Differs from Chrysomphalina in amyloid spore reaction and presence of clamp connections, and from Chrysomphalina and Pseudoarmillariella in the absence of encrusting pigments on the cuticular hyphae and presence of bright ochraceous pigments in the hymenium.

Phylogenetic support As only the type of Cantharellula was included in our analyses, branch support is irrelevant. Support for Cantharellula as sister to Pseudoarmillariella is strong in our 4-gene backbone (87 \% MLBS; 1.0 B.P. and Supermatrix analyses ( $83 \%$ MLBS), but moderate in our LSU and ITS-LSU analyses (60\%-65 \% BS). Lodge et al. (2006) in a previous iteration of the 4-gene Supermatrix analysis show the same topology with high BPP support $(>0.95)$ but lower MPBS support (50\% to $69 \%$ ). ITS-LSU analyses by Lawrey et al. (2009) show the Cantharellula-Pseudoarmillariella clade with Hygrophorus basal to it, but without branch support.

Species included Type Cantharellula umbonata. Singer (1986) included C. infundibuliformis Singer from Argentina based on morphology. Cantharellula waiporiensis (G. Stev.) E. Horak and C. humicola Corner are excluded.

Comments Singer (1936) erected gen. Cantharellula to accommodate Merulius umbonatus J.F. Gmel. We have excluded C. humicola as it appears in tribe Leucopaxilleae (Tricholomataceae) in our 4-gene backbone analysis (98\% MLBS), and it differs in having a regular hymenial trama and presence of cheilocystidia. Singer excluded C. waiporiensis based on presence of encrusting pigments on the pileipellis hyphae, and suggested it belonged in Pseudoomphalina. As noted above under tribe Cantharelluleae, the hymenophoral trama in Cantharellula is comprised of a subregular central strand and lateral strands with three sets of mutually perpendicular hyphae woven together, the subhymenial cells originate from hyphae that diverge at nearly a right angle from vertical generative hyphae and form an incipient hymenial palisade as indicated by some basidia originating at different depths and a pachypodial structure (Fig. 19). 
Pseudoarmillariella (Singer) Singer, Mycologia 48: 725 (1956).

Type species: Pseudoarmillariella ectypoides (Peck) Singer [as 'ectyloides'], Mycologia 48(5): 725 (1956),

$\equiv$ Agaricus ectypoides Peck, Ann. Rep. N.Y. St. Mus. 24: 61 (1872) [1871].

Basionym: Cantharellula subg. Pseudoarmillariella Singer, Mycologia 48(5): 725 (1956).

Pseudoarmillariella is emended here by Lodge to have a tri-directional lamellar trama with an incipient pachypodial hymenial palisade.

Basidiomata omphalinoid; pileus deeply infundibuliform, opaque; pileus and stipe surfaces yellowish or grayish brown, appressed-fibrillose; lamellae decurrent, repeatedly forked, deep ochraceous or yellowish clay color; stipe central or eccentric; spores smooth, hyaline, white in deposit, distinctly amyloid, acyanophilic, cheilocystidia and pleurocystidia absent; pileipellis hyphae nodulose-encrusted; lamellar trama subgelatinized at the lamellar edge, central strand subregular 15-30 $\mu \mathrm{m}$ wide, hyphae mostly thin-walled and 2-6 $\mu \mathrm{m}$ wide, and some larger diameter hyphae $(3-7 \mu \mathrm{m})$ with thickened walls $(1.0-1.2 \mu \mathrm{m})$ toward the pileus and adjacent pileus context; lamellar context lateral strands tridirectional, hyphae parallel to the lamellar edge woven through vertically oriented hyphae, and other hyphae that diverge more or less perpendicularly from the vertical hyphae, but obliquely angled (divergent) at the lamellar edge; subhymenial cells arising mostly from similarly oriented hyphae that diverge from vertically oriented hyphae; subhymenium sometimes pachypodial, of short- or long-celled, mostly parallel hyphal segments oriented in the same direction as the basidia, forming a weak hymenial palisade via proliferation of basidia from candelabra-like branches of subhymenial cells; clamp connections present; habit lignicolous. Differs from Cantharellula in presence of encrusting pigments on the cuticular hyphae and presence of bright ochraceous pigments in the hymenium. Differs from Chrysomphalina in amyloid reaction of the spores, presence of clamp connections and encrusting pigments on the cuticular hyphae.

Phylogenetic support As we only included the type species, $P$. ectypoides, branch support is irrelevant. Support for placing Pseudoarmillariella as sister to Cantharellula is high, as described above under tribe Cantharelluleae.

Species included Type species: Pseudoarmillariella ectypoides. This genus may be monotypic, but $P$. fistulosa (Stevenson) Horak is tentatively included based on morphology.

Comments The description of the lamellar trama and hymenium of Pseudoarmillariella are emended here. Pseudoarmillariella shares with Cantharellula a unique combination of spores that are amyloid and elongated, and tridirectional lamellar trama (Fig. 20). The pachypodial structure and insipient hymenial palisade in Pseudoarmillariella (Fig. 20) more closely resembles the pachypodial structure of Chrysomphalina chrysophylla (Fig. 17) than the description given by Singer $(1956,1986)$, i.e., "subirregularly intermixedsubramose, its elements short, strongly interlaced-curved in all directions and therefore at times appearing cellular (much like the hymenium of Cantharellula)". Pseudoarmillariella and Chrysomphalina also share a thickened hymenium (Norvell et al. 1994). A microphotograph of the hymenium of $P$. ectypoides (DJL05NC106, from the Great Smoky Mountain National Park) shows spores and former basidia embedded in a hymenial palisade, candelabra-like branching of subhymenial cells and basidia that originate at different depths, as are found in Chrysomphalina and Aeruginospora. The 'thickened hymenium' noted by Norvell et al. (1994) in Pseudoarmillariella is reported as a "thickening hymenium" in Redhead et al. (2002), as found also found in Chrysomphalina. As reported in Norvell et al. (1994), Bigelow stated to Redhead in 1985 that he had transferred $P$. ectypoides to Omphalina in 1982 based on its similarities to Chr. chrysophylla, which he also placed in Omphalina, and our reinterpretation of the lamellar and hymenial architecture in P. ectypoides (Fig. 20) supports Bigelow's observations. Pseudoarmillariella is lignicolous, but it is unknown if it produces a white rot (Redhead et al. 2002), and it frequently occurs on mossy logs and branches.

\section{The Cuphophylloid grade.}

While most phylogenetic analyses show Ampulloclitocybe, Cantharocybe and Cuphophyllus at the base of the hygrophoroid clade (Binder et al. 2010; Matheny et al. 2006; Ovrebo et al. 2011), together they suggest an ambiguity as to whether they belong in the Hygrophoraceae s.s. In our fourgene backbone analyses, Cuphophyllus is only weakly supported as sister to the rest of the Hygrophoraceae; furthermore, support for a monophyletic family is significant if Cuphophyllus is excluded and not significant if it is included. In a six-gene analysis by Binder et al. (2010) and the LSU analysis by Ovrebo et al. (2011), two other genera in the cuphophylloid grade, Ampulloclitocybe and Cantharocybe, appear between Cuphophyllus and the rest of the Hygrophoraceae, but without support, while in the ITS analysis by Vizzini et al. (2012) [2011], genera belonging to the Tricholomataceae s.l. make the genus Cuphophyllus polyphyletic. The branching order along the backbone in this part of the Agaricales is unresolved and unstable so it is not clear if Cuphophyllus, Cantharocybe and Ampulloclitocybe should be included in the Hygrophoraceae s.s. or left with other genera in the basal Hygrophoroid clade. The ecological analysis of stable $\mathrm{C}$ and $\mathrm{N}$ isotope ratios by Seitzman et al. (2011) indicates that a large component of the Hygrophoraceae is 
likely biotrophic, including Cuphophyllus, and Cuphophyllus sequences that have been recovered from rhizosphere and root samples. On the other hand, while Hygrophoraceae in general have not been sustained in axenic culture (Griffith et al. 2002), Ampulloclitocybe clavipes (Merlini et al. 2000), and putatively, Cuphophyllus virgineus (Farrell et al. 1977), have been cultured on agar media - a trait shared with saprotrophic species of the basal Hygrophoroid clade such as Aphroditeola (Redhead 2013), Phyllotopsis nidulans (Jayasinghe and Parkinson 2008), Sarcomyxa serotina (Kim et al. 2012), Tricholomopsis rutilans (Murphy and Mitchell 2001), Xeromphalina spp. (Johnson and Petersen 1997), Typhula phacorrhiza and Macrotyphula spp. (Dentinger and McLaughlin 2006). The pink cantharelloid genus, Aphroditeola Redhead \& Manfr. Binder (IF550119) that was described in Redhead (2013) to accommodate Cantharellus olidus Quél. [= Hygrophoropsis morganii (Peck) H.E. Bigelow $=$ Cantharellus morganii Peck $]$ is strongly supported as basal to Xeromphalina campanella (100\% ML BS) in the basal hygrophoroid clade rather than in the cuphophylloid grade in our LSU analysis (not shown), and thus outside Hygrophoraceae s.s. While the stable isotope analyses of Seitzman et al. (2011) support retaining Cuphophyllus in Hygrophoraceae, the branching order in the phylogenies is too unstable and the support levels for the branching order along the backbone are too low to definitively include or exclude it from the Hygrophoraceae. The instability of the branching order among analyses in this basal region of the phylogenetic tree suggests that new/different genes or approaches will likely be needed to resolve these deep branches. We have tentatively retained Cuphophyllus in Hygrophoraceae s.s. because it has been traditionally placed there, its similar $\mathrm{N}$ and $\mathrm{C}$ isotope signatures imply similar trophic relations, and it is close to the base of family, but Cuphophyllus and the related genera, Ampulloclitocybe and Cantharocybe, may eventually be recognized in a separate family.

Cuphophyllus (Donk) Bon, Doc. Mycol. 14(56): 10 (1985)[1984].

Type species: Cuphophyllus pratensis (Fr.) Bon, Doc. Mycol. 14(56): 10 (1985)[1984]

$\equiv$ Hygrocybe pratensis (Fr.) Murrill, Mycologia 6(1): 2 (1914),

三Agaricus pratensis Fr., Observ. mycol. (Havniae) 2: 116 (1818), sanctioned by Fr., Syst. mycol. 1: 99 (1821).

Basionym: Hygrocybe subg. Cuphophyllus Donk (1962), Beih. Nova Nedwigia 5: 45 (1962)

[Camarophyllus P. Kumm., (1871) is an incorrect name for this group].

Cuphophyllus is emended here by Lodge to include species with subregular lamellar trama.

Basidiomes mostly clitocyboid, rarely omphalinoid or mycenoid; veils absent; pileus surface dry, lubricous or rarely viscid, smooth, pruinose or pubescent; pileus often white, cream, salmon, or orangish brown, sometimes brown, gray, grayish brown, or reddish brown, rarely yellow, orange, pinkish orange, lilac, pinkish lilac or reddish violet; lamellae mostly arcuate-decurrent, subdecurrent or decurrent, rarely sinuate, usually thick near the pileus, often forked or veined, usually brittle, often acquiring a chalky opaque appearance; stipe often stout, usually solid or hollow near apex, rarely hollow throughout, surface smooth or fibrous, moist or dry, not viscid; basidiospores frequently broadly ellipsoid, subglobose or globose, sometimes ellipsoid or oblong, hyaline, thin-walled, guttulate in $\mathrm{KOH}$, white in mass, inamyloid, not metachromatic in cresyl blue; basidia long, typically $7-8$ (rarely 5-6) times the length of the basidiospores, with basal clamp connection; cystidia absent; lamellar trama usually highly interwoven (rarely subregular), with or without a regular or subregular central strand; hyphae usually cylindrical, sometimes inflated, walls usually swollen to $0.5-1 \mu \mathrm{m}$ thick and refractive in $\mathrm{KOH}$ mounts, pileipellis a cutis, ixocutis or trichoderm, hyphae predominantly or partly interwoven, usually with dissolved pigments, sometimes with intraparietal and encrusting pigments; clamp connections usually abundant, large, often medallion-form. Differing from Hygrophorus in absence of veils or glandular dots on the stipe apex, typically interwoven rather than divergent lamellar trama, presence of a subhymenium and non-ectomycorrhizal habit. Differing from Cantharocybe in absence of cheilo- and caulocystidia, ratio of basidia to basidiospore length exceeding 5 and usually having an interwoven (rarely subregular) rather than regular lamellar trama. Differing from Ampulloclitocybe in the ratio of basidia to basidiospore length exceeding 5 , and pileipellis predominantly or partly interwoven rather than subparallel.

Phylogenetic support Cuphophyllus appears as a strongly supported monophyletic group in our 4-gene backbone analyses (80 \% MLBS; 1.0 Bayesian PP) and Supermatrix analysis ( $86 \%$ MLBS). Similarly, a strongly supported monophyletic Cuphophyllus is shown in the multigene Supermatrix analysis by Matheny et al. (2006; 96 \% MPBS; 1.0 BPP). In their ITS-LSU analyses, Vizzini et al. (2012) show a strongly supported monophyletic Cuphophyllus separated from the hygrophoroid clade (71 \% MLBS, 1.0 BPP), while we show a moderately supported (55\% MLBS) Cuphophyllus within the hygrophoroid grade (Fig. 22). Cuphophyllus appears as a paraphyletic grade lacking support in our LSU analysis whereas Ovrebo et al. (2011) show a monophyletic Cuphophyllus lacking support in their LSU analysis.

Support for Cuphophyllus as sister to the Hygrophoraceae is weak in our 4-gene backbone analysis (28\% MLBS; 0.87 B.P. and moderate in our Supermatrix analysis $(65 \%$ MLBS). Seitzman et al. (2011) show a strongly supported (82\% MPBS) Cuphophyllus as sister to the rest of the 
Group 4 ITS-LSU

Cuphophyllus, Cantharocybe \& Ampulloclitocybe

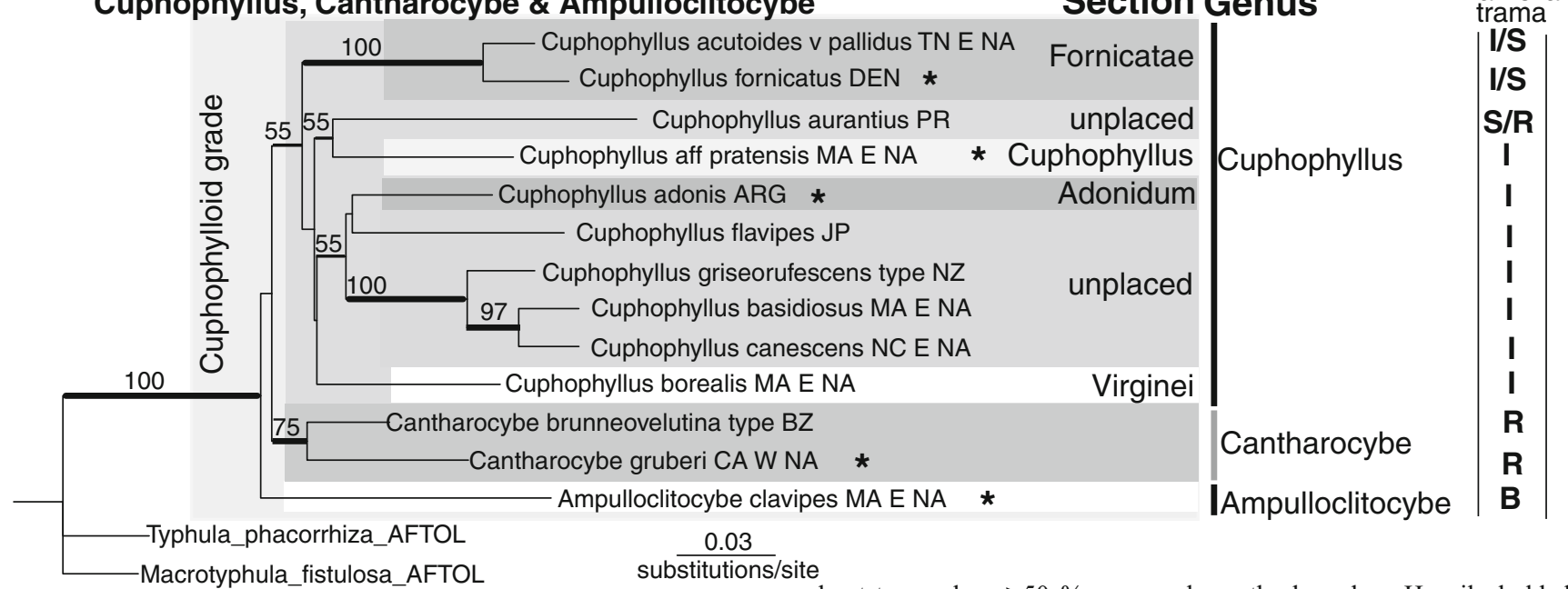

Fig. 22 Cuphophylloid grade (Group 4) ITS-LSU analysis rooted with Macrotyphula fistulosa. Genes included in the analysis were partial ITS (5.8S \& ITS2), LSU (LROR-LR5). Lamellar trama types are: B bidirectional; I - interwoven; R - regular/parallel; S - subregular. ML

Hygrophoraceae using primarily ITS (5.8S) data. In contrast, the five-gene Supermatrix analysis by Matheny et al. (2006) places Ampulloclitocybe between Cuphophyllus and the rest of the Hygrophoraceae, while the six-gene RAxML analysis by Binder et al. (2010) places both Ampulloclitocybe and Cantharocybe between Cuphophyllus and the rest of the Hygrophoraceae. An LSU analysis by Moncalvo et al. (2002) shows the only true Cuphophyllus (C. pratensis) as an independent clade apart from the Hygrophoraceae. In their ITS-LSU analyses, Vizzini et al. (2012) show Cuphophyllus as basal to part of the Tricholomataceae and Hygrophoraceae, making the Hygrophoraceae a paraphyletic grade and the Tricholomataceae polyphyletic if Cuphophyllus is included in the Hygrophoraceae (64 \% MLBS and 1.0 B.P. whereas Lawrey et al. (2009) show it among the genera of the basal hygrophoroid clade.

While the majority of species named in Cuphophyllus are ones with interwoven lamellar trama hyphae, the type species of its often applied synonym Camarophyllus, Agaricus camarophyllus Alb. \& Schwein. :Fr., has divergent lamellar trama and is placed in gen. Hygrophorus s.s. Thus, the name, Camarophyllus, can only be applied to a group in Hygrophorus typified by A. camarophyllus Fries (1836). Singer (1986) argued that A. pratensis should be the type species for subgen. Camarophyllus as it was the one (of four noted) that most closely matched the protologue. Contrary to Singer's arguments, A. camarophyllus was automatically the type of the subgenus named after it under Art. 22.6. Thus, Singer was incorrect in selecting a new type, A. pratensis, as the type of subgen. Camarophyllus, which he raised to genus rank. Donk (1962) recognized the nomenclature problem and erected subgen. Cuphophyllus in Hygrocybe for the species with interwoven lamellar trama (Fig. 23), which Bon (1985) bootstrap values $\geq 50 \%$ appear above the branches. Heavily bolded branches have $\geq 70 \%$ and lightly bolded branches have 50-69 \% ML bootstrap support

[1984] subsequently raised to genus rank. Thus, Cuphophyllus (Donk) Bon is the correct name for this genus. Further discussion can be found in Donk (1962), Courtecuisse and Fiard (2005), Melot (2005) and Young (2005).

Sections included Adonidum, Cuphophyllus, Fornicati comb. nov., and Virginei.

Comments As noted previously, Cuphophyllus is the correct name of this genus, and the name Camarophyllus that was

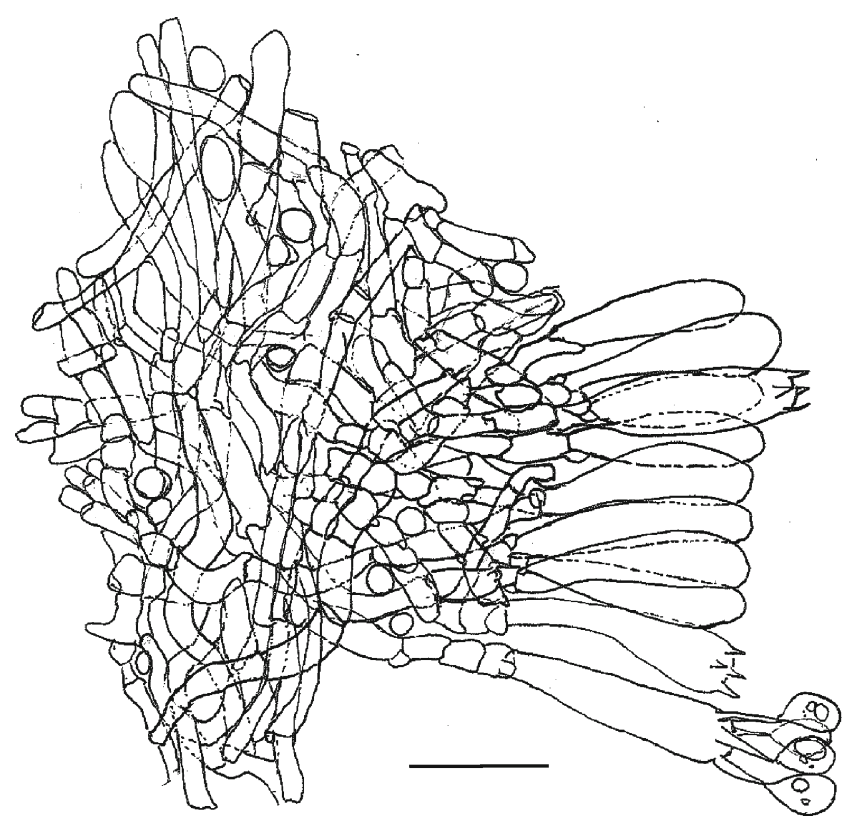

Fig. 23 Cuphophyllus, sect. Fornicati, Cuphophyllus acutoides var. pallidus lamellar cross section (DJL06TN124, Tennessee, Great Smoky Mt. Nat. Park, USA). Scale bar $=20 \mu \mathrm{m}$ 
applied to this group by Singer (1986) and others can only be referred to a group in Hygrophorus s.s. typified by $H$. camarophyllus. Donk (1962) erected subgen. Cuphophyllus in gen. Hygrocybe to establish a valid name for the group, and Bon raised Cuphophyllus to generic rank in 1984. Though many persist in using combinations in Hygrocybe for species of Cuphophyllus, these genera appear at opposite ends of molecular phylogenies of Hygrophoraceae, which would render Hygrocybe polyphyletic. If Cuphophyllus and Hygrocybe were included in the same genus, it would necessitate applying the oldest name, Hygrophorus, to the entire family, including species with amyloid spores (Cantharellula and Pseudoarmillariella), lignicolous species (Chrysomphalina) and lichenized species (Acantholichen, Cyphellostereum, Dictyonema and Lichenomphalia) to keep it monophyletic.

Cuphophyllus has traditionally been placed in the Hygrophoraceae based on the highly elongated basidia and waxy hymenium. Relative length of basidia to basidiospores is variable in the Hygrophoraceae (Table 3), and some genera outside the Hygrophoraceae yield a waxy substance when crushed (e.g., Camarophyllopsis in the Clavariaceae, and Neohygrophorus in Tricholomataceae sl), so neither character is diagnostic for the family (Lodge et al. 2006). With the exception of sect. Fornicati in which there is a broad subregular mediostratum with more interwoven lateral strata (Fig. 24), and the C. aurantius complex in which the lamellar trama is subregular (Fig. 25), the trama hyphae in Cuphophyllus are typically highly interwoven (Fig. 23, at least in the lateral strands, if a subregular central strand is present), and in most species they are cylindrical with slightly thickened, refractive walls. The refractive, interwoven context hyphae probably accounts for the brittle texture and chalky appearance of the lamellae in many Cuphophyllus species.

We retain two sections, Cuphophyllus and Virginei, and recombine Hygrocybe sect. Fornicati (Bataille) Bon and Camarophyllus sect. Adonidum (as Adonidi) Singer as

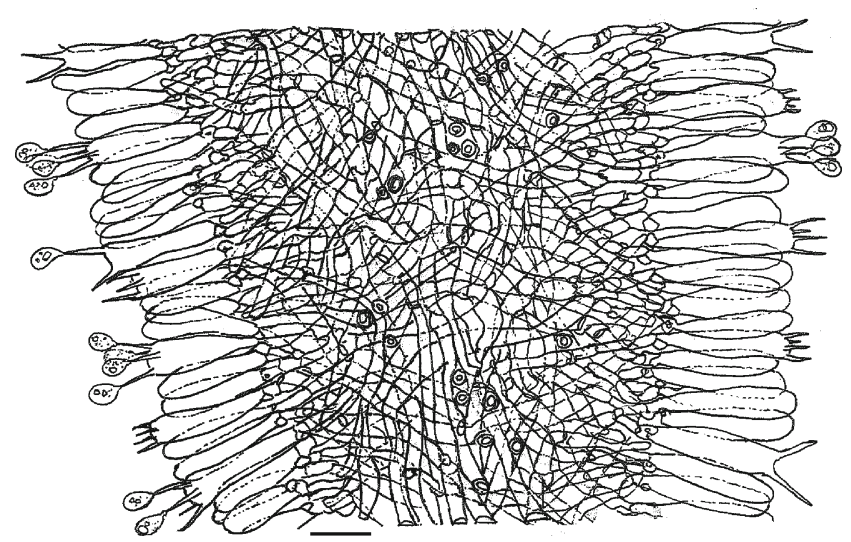

Fig. 24 Cuphophyllus, sect. Cuphophyllus, Cuphophyllus aff. pratensis lamellar cross section, (TN-177, DJL06TN51, Tennessee, Great Smoky Mt. Nat. Park, USA). Scale bar $=20 \mu \mathrm{m}$

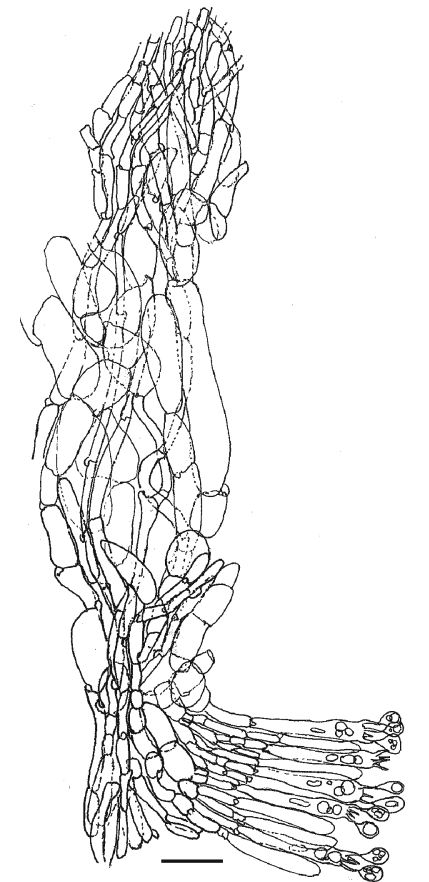

Fig. 25 Cuphophyllus aurantius lamellar cross section composite drawing comprised of an upper, middle and lamellar edge sections (PR-6601, Puerto Rico). Scale bar $=20 \mu \mathrm{m}$

sections in Cuphophyllus, but we have refrained from making additional infrageneric changes for several reasons. The positions of several species are unstable, including Camarophyllus adonis Singer (type of Camarophyllus sect. Adonidi Singer), C. basidiosus, C. canescens and C. flavipes - a situation unlikely to be resolved without greater taxon sampling, especially from Australasia (e.g., C. griseorufescens from NZ in Fig. 22). In 2012, there were ca. 80 species with combinations in Camarophyllus, Cuphophyllus or Hygrocybe, and we have sequenced an additional ten unnamed species, so we conservatively estimate there are at least 100 species belonging in Cuphophyllus globally. Of the total, only 25 Cuphophyllus species are represented by an ITS or LSU sequence, and only seven have had four or more gene regions sequenced. It is clear from the support levels for Cuphophyllus, however, that multigene analyses are needed to resolve the structure and branching order of this group; new genes are also needed. There are no sequences of $C$. cinereus $(\mathrm{Fr}$,$) Bon or C$. hygrocyboides (Kühner) Bon, the respective types of sect. Cinerei (Bataille) Bon (1989, p. 56) and Hygrocyboideini (Clémençon) Bon. Only ITS sequences are available for $C$. subviolaceus, the type of Cuphophyllus subsect. "Viscidini :(A.H. Sm. \& Hesler) Bon and sect. "Viscidi" (Hesler \& A.H. Sm.) Singer $(1972 *)$ (both invalid, Art. 36.1 - the basionym in Smith and Hesler 1942 lacked a Latin description; *Singer 1986 cited Singer 1972, but this reference was not found); preliminary analyses (Matheny, unpublished data) suggest $C$. subviolaceus is not conspecific with C. lacmus, despite being currently listed as a synonym of the latter. ITS 
analyses by Dentinger et al. (unpublished) indicate that misapplied names resulted in polyphyletic phylogenies, and it will require considerable work to redetermine the vouchers, sequence types or authentic material and designate neotypes or epitypes to stabilize the nomenclature. The following new combinations are required so that sequences deposited in GenBank have the same (correct) generic name.

Cuphophyllus acutoides (A.H. Sm \& Hesler) Lodge, Matheny \& Sánchez-García, comb. nov.

MycoBank MB804126.

Basionym: Hygrophorus acutoides A.H. Sm. \& Hesler, Sydowia 8: 325 (1954).

Type: USA: MICHIGAN, Mackinaw City, Sept. 16, 1950, H. Thiers and A.H. Smith 35847, MICH; paratype AHS 42960, MICH, ITS sequence GenBank HQ179684.

Cuphophyllus acutoides var. pallidus (A.H. Sm. \& Hesler) Lodge, comb. nov.

MycoBank MB804127.

Basionym: Hygrophorus acutoides var. pallidus A.H. Sm. \& Hesler, North American Species of Hygrophorus: 132 (1963).

Type: USA, MICHIGAN, Milford, A.H. Smith 15421, Sept. 17, 1940, MICH.

Comments Cuphophyllus acutoides var. acutoides and $C$. acutoides var. pallidus resemble the European $C$. fornicatus. The ITS sequences diverge more between the N. American and European collections (9.5\%) than between the two American taxa (5.2\%). As noted by Hesler and Smith (1963), H. acutoides var. pallidus differs from H. acutoides var. acutoides in having a pale pileus margin, basidiospores that are smaller (mostly $6-8 \times 4-5$ vs. $7-8 \times 5-6 \mu \mathrm{m}$ ), and a thin gelatinous coating on the pileipellis instead of an ixocutis 18-30 $\mu \mathrm{m}$ thick. Although the morphological differences together with ITS sequence divergence between $H$. acutoides var. acutoides (AHS 42960, paratype from Michigan, GenBank HQ179684, and PBM3897 from North Carolina) and $H$. acutoides var. pallidus (DJL06TN124 from Tennessee, GenBank KF291096) warrant recognition of the latter at species rank, we are not changing its status at this time. The combination 'Cuphophyllus pallidus' is available, but using the variety name 'pallidus' for this taxon as the species epithet would cause confusion in the future with a species that may be recombined in Cuphophyllus, i.e., Camarophyllus pallidus (Peck) Murrill, and another that will be raised to species rank [Cuphophyllus pratensis var. pallidus (Cooke) Bon] by Dentinger et al. Furthermore, the basidiomes of $C$. acutoides var. pallidus are only pale relative to var. acutoides.

Cuphophyllus adonis (Singer) Lodge \& M.E. Sm., comb. nov.

MycoBank MB804128.
Basionym: Camarophyllus adonis Singer 1952, Sydowia 6(1-4): 172 ,

TYPE: ARGENTINA, TIERRA DEL FUEGO, Nueva Argentina, Singer M351, LIL.

$\equiv$ [Hygrocybe adonis (Singer) Boertm., 2002].

Cuphophyllus aurantius (Murrill) Lodge, K.W. Hughes \& Lickey, comb. nov.

MycoBank MB804129.

Basionym: Hygrocybe aurantia Murrill, 1911, [as 'Hydrocybe'], Mycologia 3(4): 195.

TYPE: JAMAICA: ST. ANDREW PARISH; Morce's Gap, 5,000 ft. elev., Dec. 29-30, 1908, 2 Jan. 1909, W.A. and Edna L. Murrill 743, NY.

Cuphophyllus basidiosus (Peck) Lodge \& Matheny, comb. nov.

MycoBank MB804130.

Basionym: Clitocybe basidiosa Peck, Bull. N,Y. St. Mus. Nat. Hist. 1(no. 2):5 (1887),

[三 Camarophyllus basidiosus (Peck) Murrill, N. Am. Fl. (New York) 9(6): 389 (1916)].

Cuphophyllus bicolor (Dennis) Lodge \& S.A. Cantrell, comb. nov.

Type: Sandlake. Rensselaer County, New York, August, NYS.

MycoBank MB804131.

Basionym: Clitocybe bicolor Dennis, Kew Bull 7(4): 490 (1952),

[三 Omphalia bicolor Baker \& Dale, illeg. (homonym), Fungi of Trinidad and Tobago, Comm. Mycol. Inst. Mycol. Pap. 33:91 (1951),

इClitocybe ferrugineoalba Singer, Sydowia 9: (1-6): 371 (1955), superfluous, nom. illeg.,

$\equiv$ Camarophyllus ferrugineoalbus (Singer) Singer, Beih. Sydowia 7: 3 (1973), illeg.,

= Camarophyllus umbrinus (Dennis) Singer ex Pegler, var. clarofulvus Lodge \& Pegler].

Type: TRINIDAD: Omphalia bicolor Baker \& Dale, Comm. Mycol. Inst. Mycol. Pap. 33: 91 (1951), coll. TRINIDAD, RED Baker and WT Dale, 1947, ICTA 1494, K.

Baker and Dale (1951) described Omphalia bicolor from Trinidad, but it is an illegitimate later homonym of $O$. bicolor (Murrill) Murrill (1946). Dennis (1952), cited Omphalia bicolor Baker \& Dale as the basionym of a 'new combination', Clitocybe bicolor. Because an illegitimate name cannot serve as a basionym, Clitocybe bicolor is treated as a nom. nov. under ICN Art. 58.1, as Clitocybe bicolor Dennis (1952). Singer (1955) replaced the illegitimate Baker and Dale name with Clitocybe ferrugineoalba Singer, but this name is superfluous and hence illegitimate (ICN Art. 52) since the legitimate Clitocybe bicolor should have been adopted under the rules.

Cuphophyllus fornicatus (Fr.) Lodge, Padamsee \& Vizzini, comb. nov. 
MycoBank MB804132.

Basionym: Hygrophorus fornicatus Fr., Epicr. Syst. mycol. (Upsaliae): 327 (1838) [1836-1838], [三 Camarophyllus fornicatus (Fr.) P. Karst., 1879, Bidr. Känn. Finl. Nat. Folk 32: 227],

$\equiv$ Hygrocybe fornicata $($ Fr.) Singer, Lilloa 22: 152,

$\equiv$ Hygrophorus fornicatus Fr., Epicr. Syst. mycol. (Upsaliae): 327 (1838) [1836-1838].

Lectotype here designated is an illustration cited by Fries, Epicr. Syst. mycol. (Upsaliae): 327 (1838) [1836-1838]: Battarra 1755, Fungorum Agri Arimensis Historia. Tab. XXI [21], fig. C.

Cuphophyllus griseorufescens (E. Horak) Lodge \& Padamsee, comb. nov.

MycoBank MB804133.

Basionym: Camarophyllus griseorufescens E. Horak, N.Z. Jl Bot. 28(3): 277 (1990).

Type: NEW ZEALAND: AUCKLAND, Little Barrier Island, Mt. Hauturu, E. Horak ZT0919, Dec. 6, 1981, PDD 27230.

Cuphophyllus sect. Fornicati (Bataille) Vizzini \& Lodge, comb. nov.

MycoBank MB804134.

Basionym: Hygrophorus Fr. [subg. Camarophyllus Fr.] [unranked] Fornicati Bataille, Mém. Soc. émul. Doubs. ser. 8 4: 170 (1909) [1910],

$\equiv$ Hygrocybe, subg. Neohygrocybe (Herink) Bon (1989), sect. Fornicatae (Bataille) Bon, Doc. Mycol 14 (75): 56 (1989),

$\equiv$ Dermolomopsis Vizzini, Micol. Veget. Medit. 26 (1): 100 (2011).

Type species: Hygrophorus fornicatus Fr., Epicr. syst. mycol. (Upsaliae): 327 (1838)

$\equiv$ Cuphophyllus fornicatus (Fr.) Lodge, Padamsee \& Vizzini, comb. nov.

Basidiomes tricholomatoid, broadly conical or paraboloid, usually umbonate; surface dry or slightly greasy, smooth, often radially fibrillose-silky near margin, sometimes minutely squamulose at center, gray, grayish brown or pallid with brown tint; lamellae narrowly or broadly attached, often sinuate, not decurrent, broad, white or pale gray, drying opaque; stipe surface dry, fibrillose or fibrillose-silky, often squamulose; stipe context stuffed; pileus margin, lamellar edge and stipe base sometimes bruising rusty red; basidiospores hyaline, smooth, thin-walled, broadly ellipsoid, or obovoid, rarely phaseoliform, mean Q 1.4-1.6, inamyloid, not metachromatic in cresyl blue, uninucleate; basidia 4.8-6 times the length of the basidiospores; lamellar trama subregular or with a subregular mediostratum and interwoven lateral strata, hyphae 20-150 $\mu \mathrm{m}$ long, walls refractive, $0.6-0.8 \mu \mathrm{m}$ thick in $\mathrm{KOH}$; pileipellis hyphae interwoven near center and more radially arranged near margin, lacking encrusting pigments, hyphae with a thick gelatinous coating but not an ixocutis; clamp connections abundant, large, medallion form. Lamellae not subdecurrent or decurrent as in other sections of Cuphophyllus.

Phylogenetic support We show strong support for placing sects. Fornicati and Cuphophyllus together in a group that is sister to sect. Virginei (80\% MLBS; 1.0 BPP in the 4-gene backbone analysis, and $86 \%$ MLBS in the Supermatrix analysis, Figs. 1 and 2). In our 4-gene backbone analysis, sect. Fornicati is one of four clades in a polytomy that has strong basal branch support (73\% MLBS, $100 \%$ BPP). In contrast, the ITS analysis by Vizzini and Ercole (2012) [2011] shows Cuphophyllus as polyphyletic, with sects. Cuphophyllus and Fornicati as separate clades in a polytomy, while our ITSLSU analysis (Fig. 22) shows sect. Fornicati as part of a moderately supported (55\% MLBS) monophyletic Cuphophyllus; none of these analyses, however, have significant backbone support. Our Supermatrix (Fig. 2) analysis includes an unknown species from New Zealand (PDD 81871) at the base of the clade.

Species included Type species: Cuphophyllus fornicatus. Cuphophyllus acutoides and C. acutoides var. pallidus,(DJL06TN124) are included based on morphological and molecular data. Un-named species identified via molecular phylogenies include a second UK/European clade (KM KM118132, EU784306; Vizzini and Ercole 2012 that may correspond to Hygrocybe fornicatus var. lepidopus (Rea) Boertm. \& Barden (Dentinger et al., unpublished), a third UK clade that corresponds to Hygrocybe clivalis (Fr.) P.D. Orton, a collection from Russia identified as Neohygrocybe ingrata (AK9), and an un-named species from New Zealand (PDD 81871).

Comments While taxa in the $C$. fornicatus complex generally resemble other groups in Cuphophyllus, they differ in having lamellae that are usually narrowly attached and often sinuate rather than subdecurrent or decurrent. Cuphophyllus fornicatus resembles species of Neohygrocybe in having brownish gray pigments, reddish brown staining reactions, and often narrowly attached lamellae, leading Bon (1990) and Kovalenko (1989) to place it in that group (Bon in Hygrocybe subg. Neohygrocybe sect. Fornicati and Kovalenko in Neohygrocybe sect. Neohygrocybe). The interwoven lateral strata in the lamellar context of sect. Fornicati (Fig. 24), however, is consistent with placement in Cuphophyllus; the subregular central mediostratum in the lamellar context has likely been interpreted by some as the context in toto and the interwoven lateral strata as part of the subhymenium, leading some to place this group in Hygrocybe or Neohygrocybe. Kühner (1977a, b, 1980), however, considered H. fornicata a true Camarophyllus (now Cuphophyllus) based on the irregular mediostratum, mononucleate spores and stipitipellis structure. Papetti (1985) also noted the 
similarity of the aerifrerous hyphae on the stipe with Camarophyllus but retained $H$. fornicata in Hygrocybe. The type of sect. Fornicati, H. fornicatus, was described by Fries in 1838, and later placed by Fries (1849: 308) in Hygrophorus subg. Camarophyllus together with what are now the types of Cuphophyllus sect. Cuphophyllus (C. pratensis) and sect. Virginei (C. virgineus). Karsten (1879) classified H. fornicatus in the same group as Fries, but raised the rank of Camarophyllus from subgenus to genus. Bataille (1910) retained Fries' placement of H. fornicatus in Hygrophorus subg. Camarophyllus, but assigned it to a new unranked subgroup, Fornicati. Later authors placed $H$. fornicatus among species of Hygrocybe: in sect. Hygrocybe, subsect. Puniceae (Hesler and Smith 1963), Hygrocybe sect. Tristes (Bataille) Singer, Hygrocybe sect. Fornicatae (Bataille) Arnolds (illeg., failure to cite the basionym or place of publication), Hygrocybe subg. Neohygrocybe sect. Fornicatae (Bataille) Bon, or N. sect. Neohygrocybe (Herink 1959, Kovalenko 1989). Vizzini and Ercole (2012) [2011] placed H. fornicatus in a separate genus, Dermolomopsis, based on its divergent morphology and an ITS analysis that shows it on a separate branch in a polytomy in Hygrophoraceae.

Cuphophyllus acutoides from the eastern USA is related to the European C. fornicatus. Hygrocybe clivalis (Fr.) P.D. Orton \& Watling was originally described as a variety of Hygrophorus fornicatus $\mathrm{Fr}$., and is currently considered as such by most authors (Arnolds 1985b, Bon 1989, Boertmann 2010). A collection from the UK identified by E. Arnolds as $H$. fornicata var. clivalis, however, appears with a second UK collection in a distinct, highly supported clade in Dentinger et al.'s ITS analysis (100\% MLBS), supporting recognition at of $H$. clivalis at species rank. Hygrocybe fornicatus var. lepidopus (Rea) Boertm. \& Barden is also currently recognized by most authors as a variety, but a collection from the UK identified as H. lepidopus (Rea) P.D. Orton \& Watling appears in a separate, highly supported (100\% MLBS) clade in the ITS analysis by Dentinger et al. (unpublished), and if confirmed, this taxon should also be recognized at species rank.

Cuphophyllus, sect. Adonidum (Singer) Lodge \& M.E. Sm., comb. nov.

MycoBank MB804136.

$\equiv$ Cuphophyllus adonis (Singer) Lodge \& M.E. Sm., comb. nov.

Basionym: Camarophyllus sect. Adonidum (as Adonidi) Singer, Sydowia Beih. 7: 2 (1973).

Type species: Camarophyllus adonis Singer, Sydowia 6(1-4): 172 (1952)

Characters as in Cuphophyllus; basidiomes clitocyboid; pileus surface dry; pileus and lamellae pigmented violet, lilac or mauve; stipe white, cream or yellow; basidiospore Q mostly $1.1-1.5$; ratio of basidia to basidiospore length $6.5-8$; pileipellis a cutis, not an ixocutis.
Phylogenetic support Only the type species has been sequenced, so phylogenetic support is irrelevant. There is no significant support for placing $C$. adonis as sister to sect. Cuphophyllus in our Supermatrix, or as sister to the unplaced C. basidiosus - C. canescens - C. griseorufescens clade in our ITS-LSU analysis (Figs. 2 and 22, respectively).

Species included Type Cuphophyllus adonis. Hygrocybe cheelii A.M. Young and H. reesiae A.M. Young from Australia are placed in sect. Adonidum based on morphology and pigments.

Comments Sect. Adonidum most closely resembles sect. Cuphophyllus except for having violet and lilac rather than salmon and reddish brown pigments. These two sections share robust basidiomes with a dry pileus surface; lamellae that are thick and appear opaque from the refractive, interwoven context hyphae, subglobose to broadly ellipsoid spores, and long basidia relative to the length of the spores. Sects. Adonidum and Cuphophyllus may eventually be assigned to the same subgenus, possibly together with $C$. aurantius, and possibly also $C$. basidiosus, $C$. griseorufescens and $C$. canescens, but branch supports in our Supermatrix and ITS-LSU analyses are weak and the topology varies among analyses.

\section{Cuphophyllus sect. Cuphophyllus [autonym]}

Type species: Cuphophyllus pratensis (Fr.) Bon, Doc. Mycol. 14(56): 10 (1985) [1984]

$\equiv$ Hygrocybe pratensis (Fr.) Murrill, Mycologia 6(1): 2 (1914),

三Agaricus pratensis Fr., Observ. mycol. (Havniae) 2: 116 (1818), sanctioned by Fr., Syst. mycol. 1: 99 (1821).

Characters as in Cuphophyllus; basidiomes clitocyboid, pileus usually pigmented brown, orange, salmon, or buff, rarely cream; surface not or scarcely viscid; lamellae usually appearing opaque (chalky); pileipellis usually a cutis, not an ixocutis; basidiospores usually globose, subglobose or broadly ellipsoid, mean spore Q mostly 1.2-1.4, rarely up to 1.8 .

Phylogenetic support In our Supermatrix analysis (Fig. 2), sect. Cuphophyllus is a strongly supported (99\% MLBS) monophyletic group. Sect. Cuphophyllus is also highly supported in our LSU analysis (Fig. 3), but only species in the $C$. pratensis complex are included. The ITS analysis by Dentinger et al. (unpublished) shows a strongly supported $C$. pratensis clade (100\% MLBS) comprising a terminal clade (100\% MLBS) and a subtending grade with very deep divergences, while $C$. pratensis var. pallida appears as a separate clade nearby (100\% MLBS).

Species included Type species: Cuphophyllus pratensis. Molecular phylogenies indicate $C$. pratensis is a species complex. Cuphophyllus bicolor is included based on strong 
support in our Supermatrix analysis, morphology and pigments. Species included based on morphology alone are Camarophyllus panamensis Lodge \& Ovrebo, Cuphophyllus neopratensis Courtec. \& Fiard, Camarophyllus subpratensis (Beeli) Heinem., Camarophyllus subrufescens (Peck) Murrill, Cuphophyllus umbrinus (Dennis) Courtec., Hygrocybe austropratensis A.M. Young, and Hygrocybe watagensis A.M. Young. Cuphophyllus pratensis var. pallidus (Cooke) Bon. is strongly supported in an ITS analysis by Dentinger et al. (unpublished data).

Comments Sect. Cuphophyllus is strongly supported, but greater taxon sampling is needed as sequences are limited to the $C$. pratensis species complex. Support for inclusion of $C$. bicolor in sect. Cuphophyllus is strong in our Supermatrix analysis (99\% MLBS) and weak in our ITS-LSU analysis (55\% MLBS). Cuphophyllus bicolor, Cam. panamensis and Cuph. umbrinus differ from other species in sect. Cuphophyllus in having a central strand of nearly parallel hyphae bounded by lateral strata with interwoven hyphae in the lamellar context.

Cuphophyllus sect. Virginei (Bataille) Kovalenko, in Nezdoiminogo, Opredelitel' Gribov SSSR (Leningrad): 37 (1989)

Type species: Cuphophyllus virgineus (Wulfen : Fr.) Kovalenko (1989)

$\equiv$ Hygrocybe virginea P.D. Orton \& Watling, Notes R. bot. Gdn Edinb. 29(1): 132 (1969),

$\equiv$ Agaricus virgineus Wulfen, in Jacquin, Miscell. austriac. 2: 104 (1781), sanctioned by Fr., Syst. mycol. 1: 100 (1821).

Characters as in Cuphophyllus; basidiomes clitocyboid, pileus white or cream, sometimes with buff, pinkish buff or pale brown tints, not strongly pigmented orange, brown or gray; surface lubricous, viscid, or subviscid; lamellae often translucent; pileipellis an ixocutis; at least some basidiospores more elongated than in sect. Cuphophyllus, ellipsoid, ovoid or oblong, rarely strangulated, mean spore Q mostly (1.3-) 1.5-1.9.

Phylogenetic support Sect. Virginei (represented by $C$. borealis) is strongly supported as sister to the clade with most of the remaining species of Cuphophyllus in our four-gene backbone analysis (80\% MLBS; $1.0 \mathrm{BPP}$ ), and our Supermatrix analysis with C. lacmus ( $86 \%$ MLBS). Support for sect. Virginei (represented by C. borealis and C. virgineus) is strong in our Supermatrix analysis (96\% MLBS); the darkly pigmented C. lacmus appears in a sister clade (82\% MLBS).

Species included Type species: Cuphophyllus virgineus. Species included based on molecular phylogenies and morphology include C. borealis (Peck) Bon ex Courtec. (1985) and C. russocoriaceus (Berk. \& Jos. K. Mill.) Bon. Cuphophyllus ceraceopallidus (Clémençon) Bon is also thought to belong in sect. Virginei based on morphology.

Comments Sect. Virginei is restricted here to pale species, as in Kovalenko $(1989,1999)$. Deeply pigmented brown and gray-brown species with a viscid pileus $[C$. colemannianus (Bloxam) Bon and C. lacmus (Schumach.) Bon] appear in a sister clade to the pale species in an ITS analysis by Dentinger et al. (unpublished), and C. lacmus appears basal to sect. Virginei s.s. Kovalenko in our LSU and Supermatrix analyses. In our LSU analysis, the darkly pigmented species $(C$. colemannianus, C. lacmus, $C$. subviolaceus and possibly $C$. flavipes), are concordant with Kovalenko's (1989) delineation of Cuphophyllus sect. "Viscidi" (A.H. Sm. \& Hesler) Bon (nom. invalid as Smith and Hesler's 1942 basionym lacked a Latin diagnosis, Art. 36.1). Bon (1990) treated this group as subsect. "Viscidini" (A.H. Sm. \& Hesler) Bon, which is similarly invalid. Papetti (1996) named a subsect. "Colemanniani" Papetti in Camarophyllus, which is also invalid (Art. 36.1). In the ITS analysis by Dentinger et al. (unpublished data), C. radiatus (Arnolds) Bon] appears with C. flavipes and not near $C$. lacmus and C. colemannianus. The darkly pigmented species with a viscid pileus $(C$. colemannianus (A. Bloxam) P.D. Orton \& Watling, $C$. lacmus, C. subviolaceus, and C. flavipes) are left unplaced here, pending further revisions to Cuphophyllus.

\section{Additional unplaced Cuphophyllus species.} Cuphophyllus aurantius, C. basidiosus, C. canescens, C. cinerella, $C$. flavipes and $C$. griseorufescens.

Comments Cuphophyllus flavipes is unstable in its position between analyses (sequences of four gene regions from a single collection from Japan). Similarly, the positions of $C$. basidiosus and $C$. canescens are unstable, so we have therefore left this group of species unplaced. Cuphophyllus griseorufescens from New Zealand is strongly supported as being basal in the $C$. basidiosus $-C$. canescens clade in our ITS-LSU analysis (Fig. 22).

Cuphophyllus aurantius and related species differ from other species of Cuphophyllus in having mycenoid basidiomes, bright pinkish orange pigments, and a subregular rather than interwoven lamellar trama (Fig. 25). In addition, $C$. aurantius differs from most species of Cuphophyllus in the absence of thickened hyphal walls and presence of highly inflated subglobose elements in the lamellar trama. Analysis of the lamellar trama by Lodge (Fig. 25) shows it is subregular near the pileus while below it has a regular mediostratum and lateral strata comprised of subregular elongated elements mixed with many inflated subglobose elements and somewhat divergent hyphae especially near the lamellar edge; the basidia arise from elongated subhymenial cells resembling a hymenial 
palisade. It is therefore not surprising that $C$. aurantius has previously been classified in Hygrocybe. Analyses based on single genes and sequences from different collections and laboratories were consistent, negating the possibility of error. While $C$. aurantius always appears in the larger clade together with $C$. pratensis, it appears in a poorly supported internal clade with $C$. pratensis in our four-gene backbone analysis, paired with Cantharocybe in a clade that is sister to sect. Cuphophyllus in our LSU analysis, but basal to $C$. canescens in our Supermatrix analysis, all without support. One of our three ITS-LSU analyses weakly pairs $C$. aurantius with $C$. aff.. pratensis (55\% MLBS; Fig. 22), another as basal to $C$. flavipes, $C$. canescens (not shown) and $C$. aff. pratensis while the third pairs $C$. aurantius and $C$. fornicatus together (not shown), the latter two placements without significant support. While greater taxon and gene sampling are needed to resolve this group, there is strong phylogenetic support that $C$. aurantius belongs to the Cuphophyllus clade, whether the four gene regions are analyzed separately or together. ITS sequences of $C$. aurantius from the Smoky Mountains in SE USA are divergent from Greater Antillean sequences (the type is from Jamaica), and there are morphological differences between these and collections from Europe and Japan, indicating this is a species complex.

Cuphophyllus cinereus (Kühner) Bon is the type of sect. Cinerei (Bataille) Bon, but it has not been sequenced. Cuphophyllus sect. Cinerei might correspond to the unplaced, strongly supported C. basidiosus $-C$. canescens $-C$. griseorufescens clade in our ITS-LSU analysis (Fig. 22) based on shared morphology, but this hypothesis should be tested using molecular phylogeny. Bon (1989) cited p. 47 for the basionym of Bataille (1910), but the description of Cinerei appears on p. 173, a correctable error that does not invalidate publication (Art. 33.5). Boertmann (2010) interprets $C$. cinereus as a synonym of $C$. lacmus (Schum.) Bon.

Ampulloclitocybe Redhead, Lutzoni, Moncalvo \& Vilgalys, Mycotaxon 83: 36 (2002).

Type species: Ampulloclitocybe clavipes (Pers.) Redhead, Lutzoni, Moncalvo \& Vilgalys, Mycotaxon 83: 36 (2002)

$\equiv$ Clitocybe clavipes (Pers.) P. Kumm., Führ. Pilzk. (Zwickau): 124 (1871),

[ $\equiv$ Clavicybe clavipes (Pers.) Harmaja, Karstenia 42(2): 42 (2002), nom. illeg., Art. 52.1]

$\equiv$ Agaricus clavipes Pers., Syn. meth. fung. (Göttingen) 2: 353 (1801)].

Basidiomes clitocyboid, gymnocarpous (veils absent), medium-sized, not lichenized; pileus at first convex with an inrolled margin, becoming indented or infundibuliform with age, often with a low umbo in center; surface not hygrophanous (but context hygrophanous), smooth or with appressed fibers in center, brown, tan, grayish or olivaceous brown. Lamellae decurrent, close or subclose, white or cream. Stipe sub-bulbous, cylindrical or tapered to base, context spongy, often becoming hollow, surface silky-fibrillose or fibrillose and often minutely hairy. Basidiospores broadly fusiform, ellipsoid or subglobose, hyaline, strongly guttulate, not cyanophilous, inamyloid, appearing smooth with light microscopy, minutely roughened-rugose when viewed with SEM; basidia 4-sterigmate; cystidia absent; lamellar trama hyphae cylindric, mostly thin-walled, some walls up to $0.5 \mu \mathrm{m}$ thick, bidirectional (Fig. 26); subhymenium interwoven; pileipellis a cutis of subparallel hyphae, pigments intracellular; medallion clamp connections present. Type species produces aldehyde dehydrogenase and tyrosine kinase inhibitors. Gregarious or caespitose, growing saprotrophically in forest litter, often under conifers. Differs from Clitocybe s.s. (typified by $C$. nebularis) in having acyanophilous spores; differs from Cuphophyllus in having basidia less than 5 times the length of the basidiospores and subparallel rather than interwoven pileipellis hyphae; differs from Infundibulicybe (Tricholomataceae) in having basidiospores that are uniguttulate and ellipsoid, broadly fusoid or subglobose rather than lacrymoid with few small guttules, and walls roughened rather than smooth under SEM; differs from Lichenomphalia in being saprotrophic rather than biotrophic with bryophytes and having roughened rather than smooth spores under SEM (Figs. 27, 28 and 29).

Phylogenetic support Only our Supermatrix analysis includes more than one species of Ampulloclitocybe (A. clavipes and A. avellaneoalba (Murrill) Harmaja), which shows $100 \%$ MLBS support for the Ampulloclitocybe clade, and $65 \%$ support for it being sister to Cantharocybe. Our 4-gene backbone analysis also shows Ampulloclitocybe as sister to Cantharocybe, but with low support (35\% MLBS). Binder et al. (2010) show the same pairing of Ampulloclitocybe and Cantharocybe, also without significant support in their six-gene analysis. Our

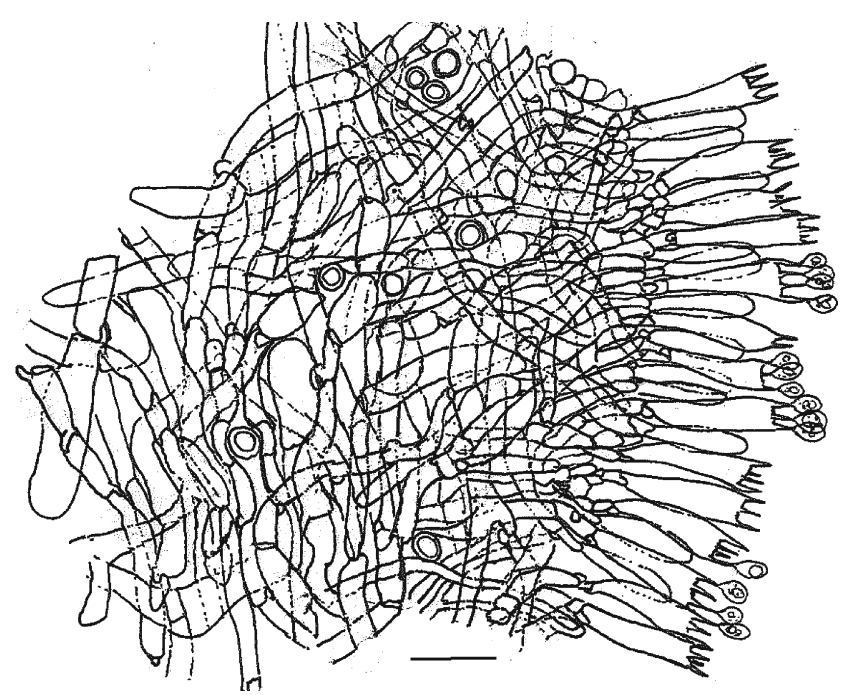

Fig. 26 Ampulloclitocybe clavipes lamellar cross section (DJL06TN40, Tennessee, Great Smoky Mt. Nat. Park, USA). Scale bar $=20 \mu \mathrm{m}$ 
ITS-LSU analysis places Ampulloclitocybe as basal to both Cantharocybe and Cuphophyllus, but with low support Fig. (41 \% MLBS; Fig. 22). In contrast, our LSU analysis places Cantharocybe near Cuphophyllus but Ampulloclitocybe as sister to Omphalina s.s., but without significant support. Moncalvo et al. (2002) show MPBS support for placing Ampulloclitocybe as basal in the Omphalina clade in their LSU analysis.

Species included Type Ampulloclitocybe clavipes (Pers.) Redhead, Lutzoni, Moncalvo \& Vilgalys, and $A$. avellaneoalba. Harmaja (2003) also placed Clitocybe squamulosoides P.D. Orton in Ampulloclitocybe, but this needs to be verified by molecular analyses.

Comments As discussed in Redhead et al. (2002), Bigelow's lectotypification of gen. Clitocybe with Clitocybe clavipes is rejected because of earlier typifications (Greuter et al. 2000, Art. 9.17). Harmaja (2002) also described a new genus, "Clavicybe" Harmaja, illeg., based on the same type as Ampulloclitocybe (Agaricus clavipes), but publication of Ampulloclitocybe preceded by 2 months the publication of "Clavicybe", rendering the latter illegitimate. Scanning electron micrographs of spores of the type, A. clavipes, by Pegler and Young (1971) showed they were minutely ornamented. Ampulloclitocybe clavipes is known to produce a coprine-like (antabuse-like) aldehyde dehydrogenase inhibitor (Cochran and Cochran 1978; Yamaura et al. 1986) as well as a tyrosine kinase inhibitor named clavilactone (Cassinelli et al. 2000).

Cantharocybe H.E. Bigelow \& A.H. Sm., Mycologia 65(2): 486 (1973), emend. Ovrebo, Lodge \& Aime, Mycologia 103(5): 1103 (2011).

Type species: Cantharocybe gruberi (A.H. Sm.) H.E. Bigelow, Mycologia 65: 486 (1973)

三Clitocybe gruberi A.H. Sm., Mycologia 36(3): 245 (1944).

Basidiomes large, clitocyboid, pileus convex-hemispheric to broadly convex with inrolled margin; surface dry, smooth or finely velutinous or finely tomentose, sometimes areolate, margin not striate, yellow, dark brown or brownish gray. Lamellae broad, long decurrent or adnate with decurrent tooth, often anastomosing or forming a reticulum at the stipe apex. Stipe 30-95 mm long, 8-25 mm thick, slightly clavate, often tapered, surface dull, moist, glabrous or pruinose, concolorous with the pileus or brownish gray over lower half. Spores elliptical or narrowly elliptical to oblong, often slightly tapered to hilar appendage end, smooth, thin-walled, hyaline, inamyloid, acyanophilous. Basidia clavate, four-sterigmate, 4-4.4 times the length of the basidiospores. Cheilocystidia of two types: (i) lecythiform but sometimes with a mucronate apex, basal portion clavate to ventricose and narrowing toward the base, upper portion extending into an elongated neck with or without a rounded capitulum; (ii) body clavate with 14 sterigmoid or apical (or rarely lateral) appendages, extending at oblique angles and frequently swollen or capitate at the apex. Hyphae of lamellar trama parallel, becoming subregular toward the margin, with walls swelling slightly to $0.5-0.8 \mu \mathrm{m}$ thick. Subhymenium ca. $15-20 \mu \mathrm{m}$ deep, pseudoparenchymatous. Pileus surface either a cutis of appressed, slightly interwoven hyphae or a trichodermium with hyphal end segments or end cells vertical, angled or sometimes interwoven. Pileus trama of interwoven, radially disposed hyphae. Stipe surface often with appressed slightly interwoven hyphae near the base, and scattered caulocystidia like those of the lamellar edge, rarely secretory, sometimes mixed with fertile basidia on the upper part. Clamp connections present but not on all hyphal septa or at the base of every basidium. Differing from Cuphophyllus in having regular rather than typically interwoven lamellar trama, basidia to basidiospore length less than 5 and presence of cheilo- and caulocystidia; differing from Ampulloclitocybe in presence of cheilo- and caulocystidia and regular rather than bidirectional lamellar trama; differing from Xeromphalina in having inamyloid spores and a clitocyboid rather than marasmioid or collybioid form.

Phylogenetic support Support for a monophyletic Cantharocybe is strong in all of our analyses (99 \% MLBS in the 4-gene backbone and Supermatrix analyses; 1.0 BPP in the backbone analysis; $97 \%$ MLBS in LSU analysis; $75 \%$ MLBS in the ITS-LSU). Similarly, Ovrebo et al. (2011) show $98 \%$ MP and $100 \%$ MLBS support for the monophyletic clade comprising C. gruberi and C. brunneovelutina in their analysis of the LSU region, while Esteves-Raventós et al. (2011) show 1.0 Bayesian support for C. brunneovelutina as sister to $C$. gruberi in their LSU analysis. In our 4-gene backbone analyses, support for placing Cantharocybe as sister to Ampulloclitocybe is high in the Bayesian (0.98 PP) but low in the ML analysis (35\% BS), and there is no significant support for the Cantharocybe-Ampulloclitocybe clade as basal to Cuphophyllus. In a six-gene analysis by Binder et al. (2010), MLBS support for the Cantharocybe Ampulloclitocybe clade is also below $50 \%$, as is the branch supporting Cuphophyllus (as Camarophyllus) and Cantharocybe, though there is $1.0 \mathrm{BPP}$ support for the latter branch. Similarly, our ITS-LSU analysis and an analysis of the LSU region by Ovrebo et al. (2011) place Cantharocybe as sister to Cuphophyllus with less than $50 \%$ MLBS support. Ovrebo et al. (2011) show no significant support for Xeromphalina or Ampulloclitocybe as basal to the Cantharocybe-Cuphophyllus clade.

Species included Type species: Cantharocybe gruberi. C. gruberi var. luteosaturatus (Malençon) Esteve-Rav., Reyes \& Alvarado and C. brunneovelutina Lodge, Ovrebo \& Aime are included based on morphological and phylogenetic data. 

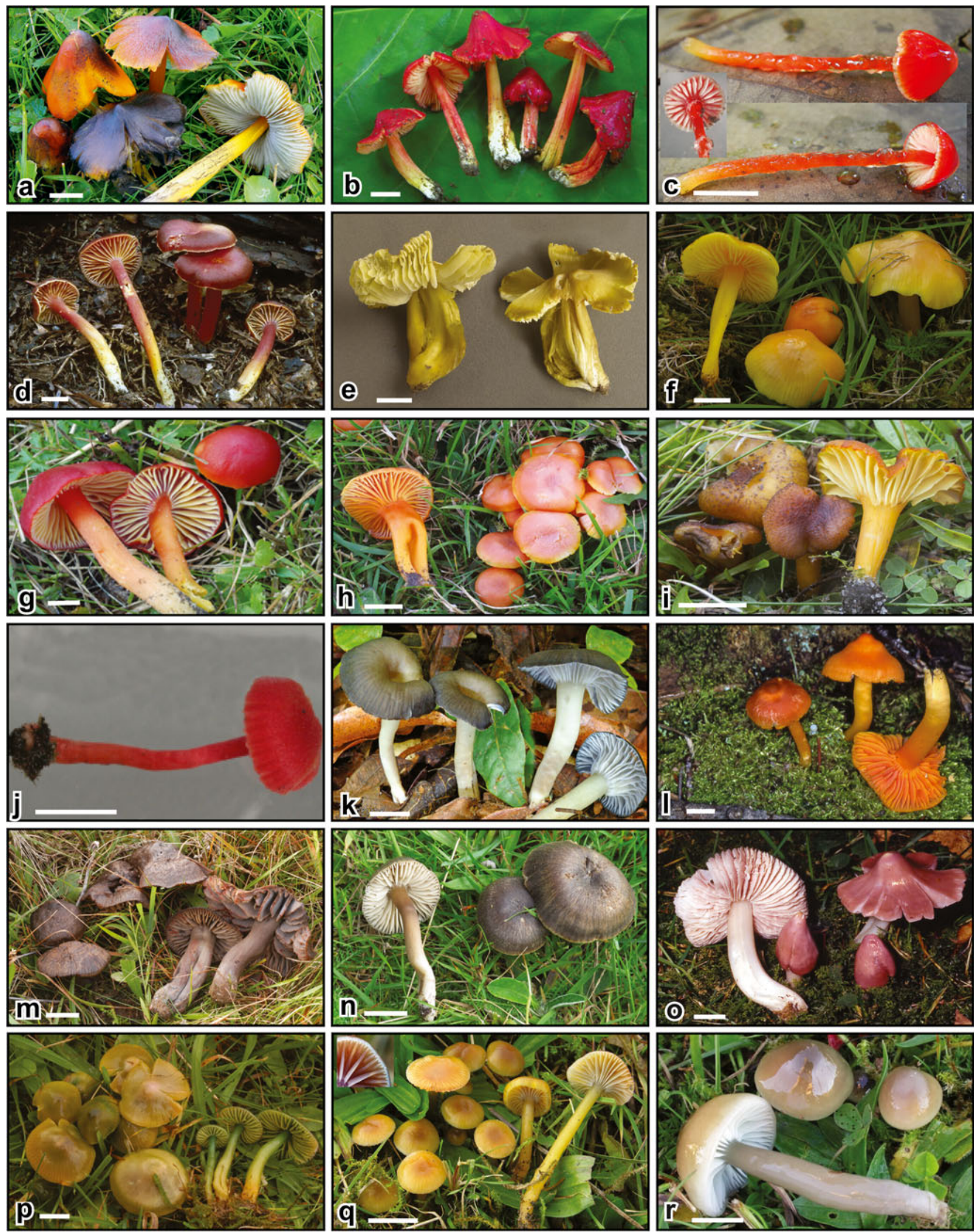
4Fig. 27 Color photographs of examples of subfamily Hygrocyboideae. a-k. Tribe Hygrocybeae. a-j. Hygrocybe. a-f. Subg. Hygrocybe. a-b. Sect. Hygrocybe. a. Subsect. Hygrocybe, H. conica (Jens H. Petersen/ Mycokey, Denmark). b. Subsect. Macrosporae, H. acutoconica (D. Jean Lodge, Tennessee, USA). c. Sect. Velosae, H. aff. hypohaemacta (Claudio Angelini, Dominican Republic; inset showing pseudoveil by D.J. Lodge, Puerto Rico). d. Sect. Pseudofirmae, H. appalachianensis (Steve Trudell, Great Smoky Mt. National Park, USA). e. Sect. Microsporae, H. citrinovirens (Geoffrey Kibbey, Wales, UK). f. Sect. Chlorophanae, H. chlorophana (Jan Vesterholt, Denmark). g-j. Hygrocybe subg. Pseudohygrocybe. g-i. Sect. Coccineae. g. Subsect. Coccineae, H. coccinea (Jens H. Petersen/Mycokey, Denmark). h. Subsect. Siccae, H. reidii (David Boertmann, Denmark). i. Subsect. Squamulosae, H. turunda (Jens H. Petersen/Mycokey, Denmark). j. Sect. Firmae, H. firma (J.A. Cooper, New Zealand). k. Hygroaster nodulisporus (Jean-Luis Cheype, Guyana). i-r. Tribe Humidicuteae. i. Humidicutis marginata (Raymond McNeil, Quebéc, Canada). m-n. Neohygrocybe. m. Sect. Neohygrocybe, N. ovina (Jan Vesterholt, Denmark). n. Sect. Tristes, N. nitrata (David Boertmann, Denmark). o. Porpolomopsis, P. calyptriformis (Antonio Brigo, Italy). p-r. Gliophorus. p. Sect. Gliophorus, G. psittacinus (Jan Vesterholt, Denmark). q. Sect. Glutinosae, G. laetus (Jan Vesterholt, Denmark). r. Sect. Unguinosae, G. unguinosus (Jens H. Petersen/Mycokey). Scale bar $=1 \mathrm{~cm}$

Comments The regular to subregular lamellar context (Ovrebo et al. 2011, Fig. 7), forking and anastamosing lamellae, and presence of ornamented cheilocystidia set Cantharocybe apart from other genera in the cuphophylloid grade. As noted by Ovrebo et al. (2011), the type species of Cantharocybe has previously been placed variously in Clitocybe (Smith 1944), Laccaria (Singer 1951), and unplaced within the family Paxillaceae (Singer 1986), while Esteves-Raventós et al. (2011) show that a European variety of the type species had been placed in Pleurotus. The placement of Cantharocybe relative to other genera remains unresolved and sampling of other gene regions and additional taxa, especially from the Australasian region, will be needed to resolve the branching order of clades with strong bootstrap support for these very deep branches.

\section{Excluded genera}

Several genera have been excluded from the Hygrophoraceae based on either morphological or molecular phylogenetic data. Camarophyllopsis Herink (1959; syn. Hygrotrama Singer 1959) had been included in Hygrophoraceae at various ranks, but was excluded from the family by phylogenetic analyses (Matheny et al. 2006). Kühner (1980) noted that Camarophyllopsis had a hymeniform pileipellis and that the basidia were relatively short for Hygrophoraceae, but other taxa confirmed by molecular phylogenies to belong in Hygrophoraceae also have short basidia (Lodge et al. 2006). The placement of Camarophyllopsis in Matheny et al. (2006) varies depending on whether Maximum Parsimony or
Bayesian analysis methods are used. Matheny et al. (2006) show Camarophyllopsis in the Plicaturopsis clade at the base of the Agaricales, whereas the six-gene analysis by Binder et al. (2010) places it in the Clavariaceae, also at the base of the Agaricales.

Singer described the monotypic genus Neohygrophorus to accommodate Hygrophorus angelesianus A.H. Sm. \& Hesler (1963). Though Neohygrophorus has long basidia as in typical of Hygrophoraceae, it also has amyloid spores and the context turns red in weak potassium hydroxide (Hesler and Smith 1963). While amyloid spores are now known to occur in the Hygrophoraceae in Pseudoarmillariella (Lodge et al. 2006 and Matheny et al. 2006) and Cantharellula (Lawrey et al. 2009), the red reaction to alkali in Pseudohygrophorus is a distinctive character (Redhead et al. 2000). In 2000, Redhead et al. expanded Pseudohygrophorus to include two additional species with red staining reactions in alkali and amyloid spores. The analysis by Binder et al. (2010) shows Neohygrophorus in the tricholomatoid clade, but without support. Matheny et al. (2006) and Lawrey et al. (2009) included Pterula in their analyses, but the Pterulaceae falls outside the hygrophoroid clade in a six-gene analysis (Binder et al. 2010), and near Radulomyces among the corticioid fungi in Dentinger et al. (2009).

Previously, species of Lichenomphalia were often treated in Omphalina Quél. Analyses by both Lawrey et al. (2009) and our data, however, indicate that the Omphalina s.s. clade is basal to the Hygrophoraceae s.l. while Lichenomphalia falls within the family. Thus, we do not include infrageneric classification of Omphalina s.s. here but Omphalina has been treated elsewhere (Lamoure 1974; 1975, Lange 1981, Lutzoni 1997; Redhead et al. 2002).

The genus Porpoloma has been reassigned to the tricholomatoid clade. Herink (1959) made an attempt to erect a provisional section, "Metapodiae", nom. invalid, in Neohygrocybe for a fuscous, red-staining species with smooth, amyloid spores, Porpoloma metapodium. Singer (1952) erected gen. Porpoloma for three Argentinian species of Nothofagus forest, then combined the European Hygrophorus metapodius (Fr.) Fr. in Porpoloma in 1973. Porpoloma metapodium was treated as Hygrophorus by Hesler and Smith (1963, as H.sect. Amylohygrocybe), and as Hygrocybe by Moser (1967). Singer (1986) later placed Porpoloma in the Tricholomataceae, tribe Leucopaxilleae a placement supported by molecular phylogenetic analysis of LSU sequences (Moncalvo et al. 2002).

\section{General Discussion and Conclusions}

For this partial revision of the Hygrophoraceae, we used a combination of previous and new molecular phylogenetic analyses together with morphological, chemical and 

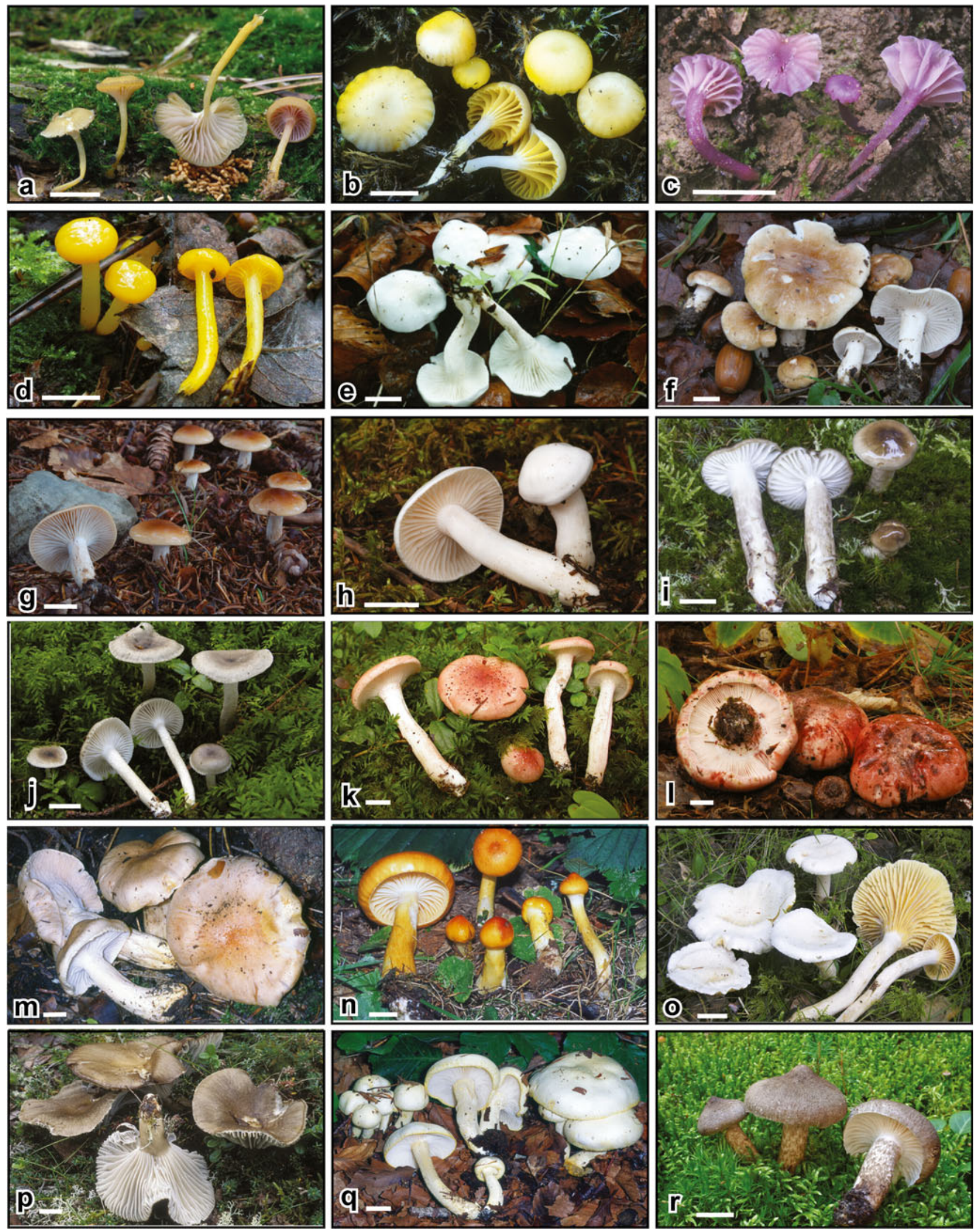
4 Fig. 28 Color photographs of examples of subfamilies Hygrocyboideae (a-d) and Hygrophoroideae (e-r). Subf. Hygrocyboideae, tribe Chromosereae. a-d. Chromosera. a. Subg. Chromosera, C. cyanophylla (Thomas Læssøe, Russia). b. Subg. Oreocybe, C. citrinopallida, Jens $H$. Petersen/Mycokey, Fareo Islands). c. Subg. Subomphalia, C. viola (Giorgio Baiano, Italy). d. Gloioxanthomyces vitellinus (Jens H. Petersen/Mycokey, Denmark). e-r. Subf. Hygrophoroideae, genus Hygrophorus. e-h. Subg. Hygrophorus. e-h. Sect. Hygrophorus. e. Subsect. Hygrophorus, H. eburneus (Jens H. Petersen/Mycokey, Denmark). f. Subsect. Fulventes, H. arbustivus var. quercetorum (Fabrizio Boccardo, Italy). g. Sect. Discoidei, H. discoideus (Gaêtan Lefebvre, Quebéc, Canada). h. Sect. Picearum, H. piceae (Renée LeBeuf, Quebéc, Canada). i-o. Subg. Colorati. i-j. Sect. Olivaceoumbrini. i. subsect. Olivaceoumbrini, H. olivaceoalbus (Jens H. Petersen/Mycokey). j. Subsect. Tephroleuci, H. pustulatus (Jens H. Petersen/Mycokey, Denmark). k-m. Sect. Pudorini. k. Subsect. Pudorini, H. pudorinus (Ellen Larsson, Sweden). I. Subsect. Clitocyboides, H. russula (Renée LeBeuf, Quebéc, Canada). m. Subsect. Salmonicolores, H. abieticola (Luigi Perrone, Italy). n-o. Sect. Aurei. n. Subsect. Aurei, H. hypothejus var. aureus (Luigi Perrone, Italy). o. Subsect. Discolores, H. karstenii (Jan Vesterholt, Finland). p-r. Subg. Camarophyllus. p. Sect. Camarophyllus, H. camarophyllus (Jan Vesterholt, Sweden). q. Sect. Chrysodontes, H. chrysodon (Luigi Perrone, Italy).r. Sect. Rimosi, H. inocybiformis (Raymond McNeil, Quebéc, Canada). Scale bar $=1 \mathrm{~cm}$

ecological traits to evaluate previously proposed Linnaeanbased higher-level classifications of taxa (above species rank). The use of cladistic approaches (Donoghue and Cantino 1988; De Queiroz and Guathier 1992; De Queiroz 1996a, b) versus classical Linnaean nomenclature (Brummitt 1996a, b; Orchard et al. 1996) has been hotly debated in biology, including mycology (Hibbett and Donoghue 1998). Two of the most vexing disparities between the Linnaean and cladistic approaches are recognition of paraphyletic groups in the Linnaean but not the cladistic system, and the temptation to proliferate Linnaean ranks based on cladistic analyses. Here, we only changed existing classifications if there was strong phylogenetic inference that groups were polyphyletic, we only named new groups that were strongly supported by phylogenetic and/or morphological data, we provide diagnoses - often emended - for all groups, but we did not alter named paraphyletic grades. This approach was largely successful in generating a coherent, integrated, holistic classification for the Hygrophoraceae that is based on nested Linnaean ranks and is phylogenetically supported.

The family Hygrophoraceae is among the early diverging lineages of the Agaricales (Matheny et al. 2006; Binder et al. 2010), and it comprises a relatively large number of genera (26) with many infrageneric taxa that have been proposed over the past two centuries. While the species appear to be primarily biotrophic, the genera vary in their morphology and ecology to the extent that there are few mycologists who have studied all of the genera in Hygrophoraceae. This challenge was addressed by using teams of experts to review different aspects and revise taxonomic groups, resulting in many coauthors (see attribution in Suppl. Table 3).
Our sampling design of using two representatives per clade for the 4-gene backbone analysis was successful in providing strong backbone support throughout most of Hygrophoraceae. The Supermatrix analysis was useful for incorporating more species into the analyses though it sometimes showed lower bootstrap support for branches and a few species and clades are oddly placed relative to other analyses despite our efforts to maintain a balanced data set. LSU and ITS analyses, alone and in combination, were especially helpful in resolving the composition of sections and subsections as more species are represented by sequences of one or both gene regions. Sampling short, overlapping segments of the family based on the branching orders in the backbone and Supermatrix analyses and using new alignments to limit data loss were part of that strategy. Incorporating a basal and distal member of each clade was informative and shows that most of the characters that are used to define groups do not correspond to the branching points for the corresponding clades and are thus not synapomorphic (TABLE IV).

The dearth of synapomorphic characters has been previously documented in the AFTOL publications on the Agaricales and Russulales (Matheny et al. 2006; Miller et al. 2006), so their absence in this study is not surprising. Some characters that are likely adaptive, such as hymenial proliferation of basidia in pachypodial structures and production of dimorphic basidiospores and basidia, appear in separate phylogenetic branches. Multiple independent origins were previously noted for other adaptive traits in the Basidiomycota, e.g.: fruit body morphology (Hibbett and Donoghue 2001; Hibbett and Binder 2002; Miller et al. 2006), ectomycorrhizal trophic habit (Bruns and Shefferson 2004), and brown rot of wood (Hibbett and Donoghue 2001). Many of the characters that are used in taxonomy of Hygrophoraceae are developmental morphological features, such as construction of the lamellar trama and subhymenium/hymenium, pileipellis and hypodermium, and presence of ornaments on the spores. With a few exceptions, such as production of regenerating hymenial surfaces in genera with a pachypodial hymenial palisade and production of dimorphic spores and basidia, most developmental characters are unlikely to be adaptive and thus may not be under strong selection pressure. If a trait is highly adaptive, it can lead to an adaptive radiation with the synapomorphic character defining the clade, but we rarely see this pattern with morphological characters in Hygrophoraceae. It may be coincidental that these developmental traits sometimes correspond to the branching points for subfamilies, tribes (e.g., divergent and pachypodial trama/hymenium in subf. Hygrophoroideae, tribes Hygrophoreae and Chrysomphalineae), genera (e.g., lamellar trama divergent in Hygrophorus; regular with long hyphae in Porpolomopsis vs. subregular with short elements in Humidicutis - its sister genus) and subgenera (mostly short basidia and long lamellar trama hyphal elements in subg. Hygrocybe vs. long basidia and short lamellar trama elements 

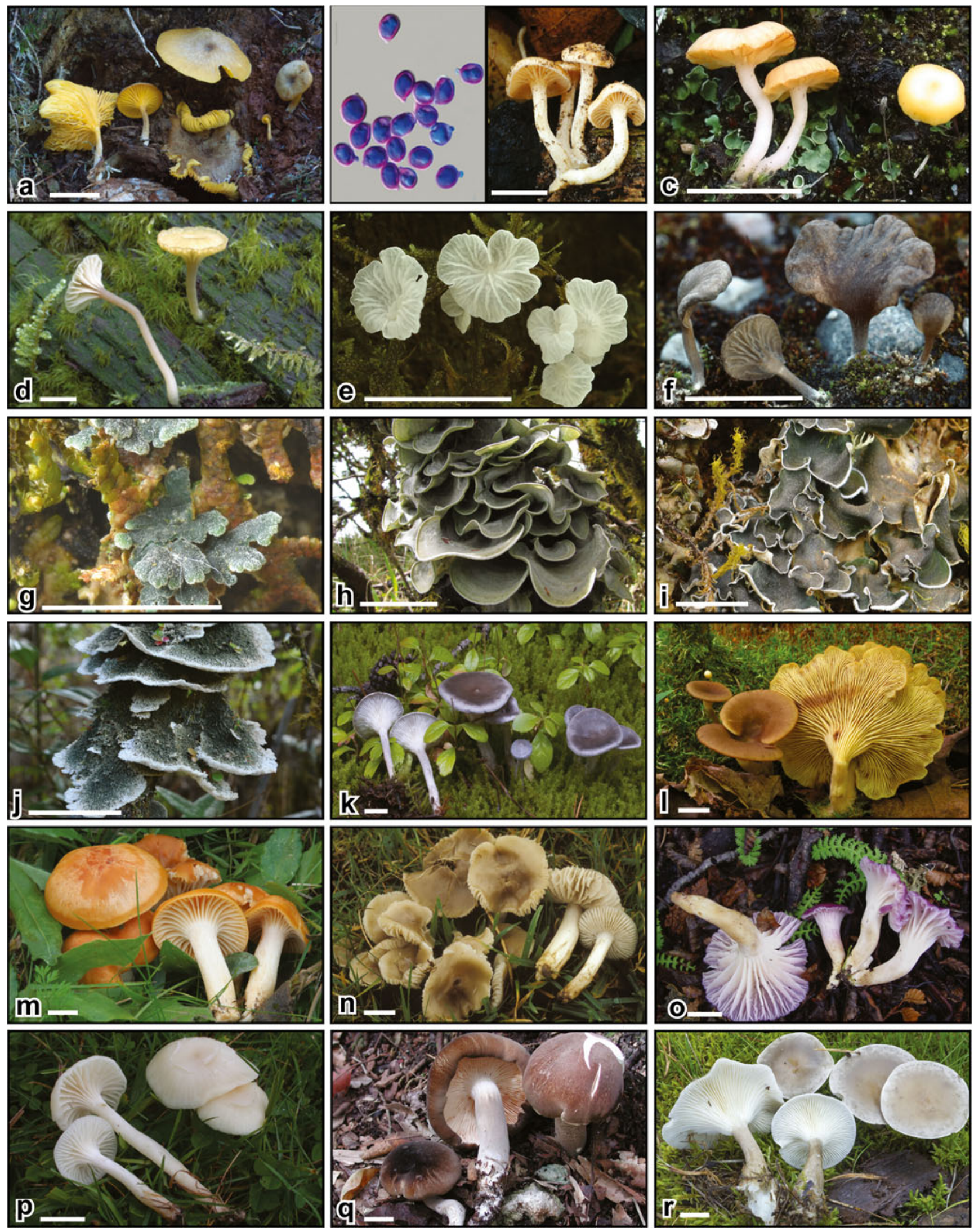
4Fig. 29 Color photographs of examples of subfamily Lichenomphalioideae and the Cuphophylloid grade. a-b. Subfamily Hygrophoroideae, tribe Chrysomphalineae. a. Chrysomphalina chrysophylla (Luigi Perrone, Italy). b. Haasiella venustissima (macrophoto by Thomas Læssøe in Russia; microphoto of metachromatic spores by Ledo Setti, Italy). c-l. Subfamily Lichenomphalioideae. c-e. Tribe Lichenomphaleae. c-d. Lichenomphalia. c. Subg. Lichenomphalia, L. hudsoniana (Steen A. Elborne, Norway). d. Subg. Protolichenomphalia, L. umbellifera (Joszef Geml, Alaska, USA). e. Semiomphalina aff. leptoglossoides (Robert Lücking, Costa Rica). $\mathbf{f}-\mathbf{j}$. Tribe Arrhenieae. f. Arrhenia auriscalpium (Jens H. Petersen/Mycokey, Denmark). g. Acantholichen pannarioides (Chaves 3910, Robert Lücking 9582a, Costa Rica). h. Cora aff. glabrata (Robert Lücking, Colombia). i. Corella brasiliensis (Robert Lücking, Colombia). j. Dictyonema sericeum (Robert Lücking 0411, Colombia). k-l. Tribe Cantharelluleae. k. Cantharellula umbonata (Drew Parker, California, USA). I. Pseudoarmillariella ectypoides (Renée LeBeuf, Quebéc, Canada). m-r. Cuphophylloid grade. $\mathbf{m}-\mathbf{p}$. Cuphophyllus. m. Section Cuphophyllus, C. pratensis (F. Boccardo, Italy). n. Section Fornicati, C. fornicatus (Jan Vesterholt, Denmark). o. Section Adonidum, C. adonis (Mathew Smith, Argentina). p. Section Virginei, C. virgineus (Jan Vesterholt, Denmark). q. Cantharocybe brunneovelutina (D. Jean Lodge, Belize). r. Ampulloclitocybe clavipes (Jens H. Petersen/Mycokey, Denmark). Scale bar $=1 \mathrm{~cm}$

in subg. Pseudohygrocybe). A case in point is a reversion in lamellar tramal hyphae to shorter lengths in part of sect. Pseudofirmae of subg. Hygrocybe. Characters that provide no selective advantage may become fixed in a lineage by being physically close to a gene under selection pressure on the same chromosome, and via random events such as founder effects and genetic drift following geographic or reproductive isolation. Diversification in lineages unrelated to adaptations have been called nonadaptive radiation and nonecological radiation (Rundell and Price 2009; Benton 2010; Venditti et al. 2010). Though most of the characters used in taxonomy of Hygrophoraceae are not diagnostic by themselves, as seen by the sweeps of character states in the synoptic key that is arranged by phylogenetic branching order (TABLE IV), combinations of traits are usually diagnostic.

In contrast to the likely nonadaptive characters noted above, some non-pigmented compounds are shown to be informative taxonomically and many are also bioactive, such as dehydrogenase and kinase inhibitors in Ampulloclitocybe (Farrell et al. 1977; Cochran and Cochran 1978; Yamaura et al. 1986; Cassinelli et al. 2000; Lübken et al. 2006) and are thus likely to be under selection pressure. Pigments are often antimicrobial; it is not known if the pigments in the Hygrophoraceae have these properties, but some of the bioactive compounds noted above may be pigment metabolic precursors. Given the presumed biotrophic habit of most Hygrophoraceae based on stable $\mathrm{C}$ and $\mathrm{N}$ isotope signatures, genes that are responsible for transfers of host $\mathrm{N}$ and especially $\mathrm{C}$ are more likely to be the basis of adaptive radiations and thus correspond to divergence points of clades than most of the developmental morphological features. The ectomycorrhizal habit of Hygrophorus s.s. is likely a synapomorphy (Seitzman et al. 2011), though the fungus may not be entirely beneficial to its host (Agerer 2012). The habit of parasitizing bryophytes and different types of algae (i.e., in bryophilous and lichen-forming species) is likely involved in several adaptive radiations within subfamily Lichenomphalioideae, though the most basal group, (Arrhenia, tribe Arrheniae) is apparently free-living (Lawrey et al. 2009). The trophic habits for many Hygrophoraceae remains unknown, but circumstantial evidence from environmental sequencing projects suggests the possibility that Hygrocybe s.l. and Cuphophyllus may obtain recent plant carbon as rhizosphere or endophytic symbionts.

Fungal systematists, parataxonomists and fungal conservationists use named subgenera, sections and subsections in Hygrocybe s.1. Many authors, but especially Donk (1962), Clémençon (1982), Redhead et al. (1995, 2002, 2011), Kovalenko (1988, 1989, 1999, 2012), Candusso (1997) and Lawrey et al. (2011) were instrumental in verifying and publishing correct generic and infrageneric names and combinations in the Hygrophoraceae, and we hope we have corrected most of the remaining errors. Some systematists and many conservationists and parataxonomists primarily use infrageneric names in Hygrocybe rather than the segregate genera recognized in this paper. With the exception of Cuphophyllus, the use of Hygrocybe s.l. is not incorrect as long as Hygroaster is assigned an infrageneric rank in Hygrocybe, so we provide a dual nomenclature of Hygrocybe s.l. for all user groups. Cuphophyllus appears at the base of the Hygrophoraceae near the backbone of the Agaricales whereas Hygrocybe is terminal, so placing these in the same genus would require using the oldest genus name, Hygrophorus, for the entire family.

Further work remains to be done in making new combinations, especially recombining species of Camarophyllus, Hygrocybe and Hygrophorus in Cuphophyllus. Many species previously believed to be amphi-Atlantic were found to not be conspecific as they belong to separate clades, and those that are not from the same region as the type locality will need new or resurrected names. Predominantly arctic-alpine taxa (e.g., Lichenomphalia spp.) likely are exceptions to this general trend, as they apparently are capable of frequent dispersals on a circumpolar scale (Geml et al. 2012). Sequencing more gene regions and new genes are needed to provide the basis for further higher level revisions, especially in Hygrocybe subg. Pseudohygrocybe, Gliophorus and Neohygrocybe in tribe Humidicuteae, and Cuphophyllus. Sequencing of more species is also needed in undersampled groups such as Humidicutis, Gliophorus, Neohygrocybe and Cuphophyllus, especially species from Australasia. The most basal species in several clades in our analyses are from the Australasian region, e.g., Porpolomopsis lewelliniae, Gliophorus graminicolor from Tasmania and a $G$. psittacinus-like collection from Japan, and two species from New Zealand, PDD81871 
in Cuphophyllus sect. Fornicatae and Cuphophyllus griseorufescens in the unplaced $C$. canescens - C. basidiosus clade. The Australasian region may be the origin of the crown group for these lineages, or that region may have retained more ancestral species. Refining the synoptic key and diagnoses for tribes, genera, subgenera and sections requires inclusion of basal species within lineages because the character states that are used to delineate these groups often do not correspond to the branching point for the clades. Despite these gaps and shortcomings, we succeeded in establishing a higher-order structure for Hygrophoraceae that integrates morphological, ecological, chemotaxonomic and phylogenetic data, and where possible, determined which are the correct, legitimate, validly published names that can be applied to each group under the Linnaean system.

Acknowledgements We thank the International Institute of Tropical Forestry (IITF), USDA Forest Service for maintaining facilities of the Center for Forest Mycology Research (CFMR) in Puerto Rico, and the Forest Products Laboratory for maintaining facilities and support at CFMR on the University of Wisconsin campus in Madison, WI. Dentinger and Ainsworth were partly supported by grants from Defra, Natural England and the Scottish Natural Heritage. A Long-Term Ecological Research grant DEB 0620910 from the US National Science Foundation (NSF) to the University of Puerto Rico - Rio Piedras in collaboration with IITF, USDA FS augmented laboratory equipment used in this research. The USDA Forest Service, CFMR, provided most of the support. This work was not directly supported by grants, but the following grants were essential in obtaining collections and some sequences used in this work: US NSF Biodiversity Surveys and Inventories Program grants to the Research Foundation of the State University of New York, College at Cortland (DEB-9525902 and DEB-0103621), in collaboration with the USDA-Forest Service, Center for Forest Mycology Research, Forest Products Laboratory in Madison supported collecting in Belize, the Dominican Republic and Puerto Rico. US NSF grant DBI 6338699 to K.W. Hughes and R.H. Peterson at the University of Tennessee, Knoxville supported collecting by E. Lickey, D.J. Lodge, K.W. Hughes, R. Kerrigan, A. Methven, V.P. Hustedt, P.B. Matheny and R.H. Petersen in the Great Smoky Mountain National Park, and sequencing by K.W. Hughes and Lickey. A National Geographic Society's Committee for Research and Exploration grant to T.J. Baroni (SUNY Cortland) supported the 2007 expedition to Doyle's Delight in Belize by M.C. Aime, T.J. Baroni and D.J. Lodge. An Explorer's Club, Washington Group Exploration and Field Research Grant to M.C. Aime and a National Geographic Society's Committee for Research and Exploration grant to T. Henkel supported collecting in Guyana.

In addition to the herbarium curators among our co-authors (D. Desjardin, B. Ortiz Santana, T.J. Baroni, J. Geml and M. Padamsee) we thank the following curators for loans of specimens and providing data: B. Aguirre-Hudson at Kew, C. Robertson and M. McMullen at Duke in North Carolina, G. Lewis-Gentry at Harvard, A. Retnowati at the Bogor Botanical Garden in Indonesia, R.H. Petersen at TENN in Tennessee, curators at Oslo $(\mathrm{O})$ and W. Daley at PDD in New Zealand. Professional and paraprofessional mycologists answered our pleas by providing specimens from specified regions and photographs. Specimens were offered by K.K. Bergelin, K.K. Berget, R. Braga-Neto, E. (Ted) Brown, E. Cancerel, E.E. Emmett, I. Greihuber, V.P. Huhstad, R. Kerner, R. Kerrigan, G. Koller, S. Kudo, A. Gminder, M. Harrington, C. Laboy, J. Mercado, A. Methven, D. Mitchell, R.H. Petersen, P. Roberts, W. Roody, J.C. Slot, B.M. Spooner, A. Voitk, A. Weir and R. Youst. In addition to co-authors (D. Boertmann, J. Geml, T. Læssøe, E. Larsson, D.J. Lodge, R. Lücking and M. Smith), we thank the following people for photographs C. Angelini, G. Baiano, F. Boccardo, A. Brigo, J.-L. Cheype, J.A. Cooper, S.A. Elborne, G. Kibby, R. LeBeuf, R. McNeil, D. Parker, L. Perrone, J. Petersen/Mycokey, L. Setti, S. Trudell, J. Vesterholt and T. Wheeler. T. Gough (USDA-FS, FPL) kindly reformatted the photographic plates.

Sequences by co-authors (M.C. Aime, M. Binder, S.A. Cantrell, K.W. Hughes, D.J. Lodge, J. Haight, B. Ortiz Santana, E. Lickey, D. Lindner, P.B. Matheny, J.-M. Moncalvo and M. Padamsee, A. Vizzini, E. Ercole) were augmented by sequences and analyses by P. Baymon, B. Dentinger, K.K. Nakasone, and D. Rizzo. Dentinger provided initial and final ITS analyses and M. Ainsworth re-determined collections deposited at Kew from an unpublished manuscript. Andrew Rodriguez assisted Aime and Padamsee in preparing sequin files for GenBank submission. In addition to advice from co-authors (R. Courtecuisse, A. Minnis, L. Norvell, S. Redhead), S. Pennycook provided invaluable advice on nomenclature, J. David advised on proper name endings in Latin and Greek, and R.H. Petersen provided sage advice on taxonomy and systematics. We thank curators of the Index Fungorum, P.M. Kirk, and Mycobank, J. Stalpers and A. de Cock for correcting and updating records in their databases.

We thank the following pre-reviewers of manuscript sections: pigment chemistry by A. Bresinsky and N. Arnold, and introduction, ecology and discussion by D. Hibbett and B. Seitzman. We especially thank K.K. Nakasone, M.J. Richardson and J. Glaeser for full manuscript pre-review, and anonymous journal referees.

Open Access This article is distributed under the terms of the Creative Commons Attribution License which permits any use, distribution, and reproduction in any medium, provided the original author(s) and the source are credited.

\section{References}

Agerer R (2012) Asexual reproduction of Hygrophorus olivaceoalbus by intracellular microsclerotia in root cells of Picea abies - a winner of ozone stress? Mycol Prog 11:425-434

Agerer R, Schloter M, Hahn C (2000) Fungal enzymatic activity in fruitbodies. Nova Hedw 71:315-336

Agerer R, Christan J, Mayr C, Hobbie E (2012) Isotopic signatures and trophic status of Ramaria. Mycol Prog 11:47-59

Aime MC, Matheny PB, Henk DA, Friders EM, Nilsson RH, Piepenbring M, McLaughlin DJ, Szabo LJ, Begerow D, Sampaio JP, Bauer R, Weiss M, Oberwinkler F, Hibbett DS (2006) An overview of the higher-level classification of Pucciniomycotina based on combined analyses of nuclear large and small subunit rDNA sequences. Mycologia 98:896-905

Ainsworth AM, Cannon PF, Dentinger BTM (2013) DNA barcoding and morphological studies reveal two new species of waxcapmushrooms (Hygrophoraceae) in Britain. MycoKeys 7:45-62

Altekar G, Dwarkadas S, Huelsenbeck JP, Ronqust F (2004) Parallel Metropolis-coupled Markov chain Monte Carlo for Bayesian phylogenetic inference. Bioinformatics 20:407-415

Arnolds E (1979) Notes on Hygrophorus III. Persoonia 10:357-382

Arnolds E (1985a) Notes on Hygrophorus - IV. Persoonia 12:475-478

Arnolds E (1985b) Notes on Hygrophorus - V. A critical study of Hygrocybe fornicata (Fr.) Sing. sensu lato. Agarica 6:178-190

Arnolds E (1986a) Notes on Hygrophorus - VI. Observations on some new taxa in Hygrocybe. Persoonia 13:57-68

Arnolds E (1986b) Notes on Hygrophorus - VII. Taxonomic and nomenclatural notes on some taxa of Hygrocybe. Persoonia 13:137-160

Arnolds E (1990) Tribus Hygrocybeae (Kühner) Bas \& Arnolds. In: Bas C, Kuyper TW, Noordeloos ME, Vellinga EC (eds) Flora agaricina neerlandica, critical monographs on families of agarics and boleti 
occurring in the Netherlands, vol 2. AA Balkema Publishers, Rotterdam, pp 71-115

Arnolds E (1995) Hygrophoraceae (Agaricales) in New York State and adjacent areas. 1. Introduction and Hygrocybe subsection Squamulosae. Mycotaxon 53:1-27

Arora D (1986) Mushrooms demystified, 2nd edn. Ten Speed Press, Berkeley

Arpin N (1966) Recherches chimiotaxinomiques sur les champignons. Sur la présence carotènoïds Clitocybe venustissima. Compt Rend Hebd Séances Acad Sci 262:347-349

Arpin N, Fiasson JL (1971) The pigments of Basidiomycetes: their chemotaxonomic significance. In: Petersen RH (ed) Evolution of the higher Basidiomycetes. University of Knoxville Press, Knoxville, pp 63-98

Babos M, Halász K, Zagyva T, Zöld-Balogh A, Szegö D, Bratek Z (2011) Preliminary notes on dual relevance of ITS sequences and pigments in Hygrocybe taxonomy. Persoonia 26:99-107

Baker RED, Dale WT (1951) Fungi of Trinidad and Tobago. Mycol Pap $33: 1-123$

Bakker ES, Olff H, Vandenberghe C, De Maeyer K, Smit R, Gleichman JM, Vera FWM (2004) Ecological anachronisms in the recruitment of temperate light-demanding tree species in wooded pastures. $\mathrm{J}$ Appl Ecol 41:571-582

Baroni TJ (1981) A revision of the genus Rhodocybe (Agaricales. Beih Nova Hedw 67:1-194

Bas C (1988) Orders and families in agarics and boleti. In: Bas C, Kuyper TW, Noordeloos ME, Vellinga EC (eds) Flora agaracina neerlandica, vol 1. AA Balkema Publishers, Rotterdam, pp 40-49

Bas C (1990) Notulae ad floram agaricinam neerlandicam-XVII on tribus names in the family Tricholomataceae sensu lato. Persoonia 14:233-235

Bataille F (1910) Flore monographique des Hygrophores. Mém Soc ému Doubs, sér 8(4):132-189

Beisenherz (2002) Zur ökologie und taxonomie der saftlinge und ellerlinge (Hygrocybe, Agaricales). Regensburger Mykologische Schriften 10:3-65

Benton MJ (2010) New take on the Red queen. Nature 463:306-307

Bergelin K (2012) Kromvaxskivling (Hygrocybe vitellina) funnen i Sverige. Svensk Myko Tidisdrift 33:2-8

Bigelow HE (1970) Omphalina in North America. Mycologia 62:1-32

Bigelow HE (1982) Species described in Clitocybe by H. Peck and W.A. Murrill. Sydowia 35:37-74

Bigelow HE, Smith AH (1973) Cantharocybe, a new genus of Agaricales. Mycologia 65:485-488

Binder M, Larsson K-H, Matheny PB, Hibbett DS (2010) Amylocorticiales ord. nov. And jaapiales ord. nov.: early diverging clades of agaricomycetidae were dominated by corticioid forms. Mycologia 102: $865-880$

Boertmann D (1990) The identity of Hygrocybe vitellina and related species. Nord J Bot 10:311-317

Boertmann D (1995) The genus Hygrocybe. Fungi of Northern Europe v I, 1st edn. Danish Mycological Society, Greve

Boertmann D (2010) The genus Hygrocybe. Fungi of Northern Europe v I, 2nd edn. Danish Mycological Society, Denmark

Boertmann D (2012) Update on Hygrocybe nitida. Omphalina 3(1):12-13

Bon M (1976) Novetates. Docums Mycol 24(6):41-46

Bon M (1985) [1984] Le genre Cuphophyllus (Donk) st. nov. Docums Mycol 14:9-12

Bon M (1989) Nouveaux taxons (Hygrophoraceae). Docums Mycol 75:55-56

Bon M (1990) Flore mycologique d'Europe 1. Les Hygrophores. Docums Mycol Memoire hors série 1

Bon M (1991) Novitates. Docums Mycol 81:55-56

Bory de St. Vincent JBGM (1797) Mèmoires sur les genres conferva et byssus, du Chevaller C. Linnè. 1-58
Brébisson (1839) Botrydina Bréb. Mém Soc Acad Agric Industr Instruct Arrond Falaise :36

Bresinsky A (2008) Belträge zu einer Mykoflora Deutschlands (2): Die Gattungen Hydropus bis Hypsizygus mit Angaben zur Ökologie und Verbreitung der Arten. Regensburger Mykol Schriften 15:1-304

Bresinsky A, Kronawitter I (1986) Zur Kenntis der Hygrocybenpigmente (A contribution to the knowledge of the pigments of Hygrocybe) Zeit Mykol 52:321-334

Brock PM, Döring H, Bidartondo MI (2009) New Phytol 181:719-724

Brummitt RK (1996a) In defense of paraphyletic taxa. In: van der Maeson LJG, van der Burgt XM, Van Medebach De Rooy JM (eds) The biodiversity of African plants. Klewar Academic Publishers, Dordrecht, pp 371-384

Brummitt RK (1996b) Quite happy with the present code, thank you. In: Reveal JL (ed) Biological nomenclature in the 21st century, proceedings of a mini-symposium at the Univ. Maryland 4 Nov 1996. http://www.plantsystematics.org/reveal/pbio/nomcl/brum.html. Accessed 12 Nov 2010

Bruns T, Shefferson RP (2004) Evolutionary studies of mycorrhizal fungi: milestones and future directions. Can J Bot 82:1122-1132

Candusso M (1997) Fungi Europaei 6. Hygrophorus s.l. Libreria Basso, Alassio

Cantrell SA, Lodge DJ (2000) Hygrophoraceae (Agaricales) of the Greater Antilles. Hygrocybe subgenus Hygrocybe. Mycol Res 104:873-878

Cantrell SA, Lodge DJ (2001) Hygrophoraceae (Agaricales) of the Greater Antilles, subgenus Pseudohygrocybe section Firmae. Mycol Res 103:215-224

Cantrell SA, Lodge DJ (2004) Hygrophoraceae of the greater Antilles: section Coccineae. Mycol Res 108:1301-1314

Cassinelli G, Lanzi C, Pensa T, Gambetta RA, Nasini G, Cuccuru G, Cassinis M, Pratesi G, Polizzi D, Tortoreto M, Zunino F (2000) Clavilactones, a novel class of tyrosine kinase inhibitors of fungal origin. Biochem Pharmacol 59:1539-1547

Chaves JL, Lücking R, Sipman HJM, Umaña L, Navarro E (2004) A first assessment of the ticolichen biodiversity inventory in Costa Rica: the genus Dictyonema (Polyporales: Atheliaceae). Bryologist 107:242-249

Cibula WG (1976) The pigments of Hygrophorus section Hygrocybe and their significance in taxonomy and phylogeny. Dissertation, University of Massachusetts

Clémençon H (1982) Kompendium der Blätterpilze: Europäische omphalinoide Tricholomataceae. Z Mykol 48(2):195-237

Clémençon H (1997) Anatomie der Hymenomyceten. F. Flück-Wirth, Teufen

Clémençon H, Emmett V, Emmett EE (2004) Cytology and plectology of the Hymenomycetes. Bibl Mycol, vol 199. J. Cramer, Berlin

Cochran KW, Cochran MW (1978) Clitocybe clavipes: antabuse-like reaction to alcohol. Mycologia 70:1124-1126

Cooke MC (1891) British edible Fungi, London

Corner EJH (1936) Hygrophorus with dimorphous basidiospores. Trans Brit Myc Soc 20:157-184

Corner EJH (1966) A monograph of cantharelloid fungi. Oxford University Press, Oxford

Courtecuisse R (1986) Contribution à la connaissance de la flore fongique du Morbihan et de quelques departments voisins - I. Doc. Mycol 16:1-22

Courtecuisse R (1989) Élements pour un inventaire mycologique des environs du Saut Pararé (Arataye) et de l'inselberg de Norages (Guyane Française). I. Introduction. II. Hygrophoraceae. Crypto Mycol 10:181-216

Courtecuisse R, Fiard J-P (2005) Cuphophyllus neopratensis, un nouvel hygrophore des Antilles (Premier contribution au programme inventaire mycologique de Petites Antilles). Bull Soc Mycol Fr 120:441-462

Dal-Forno M, Lawrey JD, Sikaroudi M, Bhattarai S, Gillevet PM, Sulzbacher MA, Luecking R (submitted) Starting from scratch: 
evolution of the lichen thallus in the basidiolichen Dictyonema (Agaricales: Hygrophoraceae). Fungal Biology (submitted Jan 2013)

Davies RW, Waring RB, Ray JA, Brown TA, Scazzocchio C (1982) Making ends meet: a model for RNA splicing in fungal mitochondria. Nature 300:719-724

Della Maggiora M, Matteucci S (2010) Three interesting Hygrocybe collected from Lucchesia. Rivista di Micologia 53:219-233

De Queiroz K (1996a) Phylogenetic approaches to classification and nomenclature, and the history of taxonomy (an alternative interpretation). Herp Rev 26:79-81

De Queiroz K (1996b) The definitions of species and clade names: a reply to ghiselin. Biol Phil 10:223-228

De Queiroz K, Guathier J (1992) Phylogenetic taxonomy. Annu Rev Syst 23:449-480

De Wachter R, Neefs J-M, Goris A, Van de Peer Y (1992) The gene coding for small ribosomal subunit RNA in the basidiomycete Ustilago maydis contains group I intron. Nucleic Acids Res 20:1251-1257

Dennis RWG (1952) Lepiotota and allied genera in Trinidad, British West Indies. Kew Bull 7(4):459-500

Dennis RWG (1953) Some West Indian collections referred to Hygrophorus Fr. Kew Bull 8:253-268

Dentinger BTM, McLaughlin DJ (2006) Reconstructing the Clavariaceae using nuclear large subunit rDNA sequences and a new genus segregated from Clavaria. Mycologia 98:746-762

Dentinger BTM, Lodge DJ, Munkasci AB, Desjardin DE, McLaughlin DJ (2009) Phylogenetic placement of an unusual coral mushroom challenges the classic hypothesis of strict coevolution in the Apterostigma pilosum group ant-fungus mutualism. Evolution 61:2172-2178

Desjardin DE, Hemmes DE (1997) Agaricales of the Hawaiian Islands. 4. Hygrophoraceae. Mycologia 89:615-638

Donk MA (1962) The generic names proposed for the Agaricaceae. Beih Nova Hedw 5:1-320

Donoghue MJ, Cantino PD (1988) Paraphyly, ancestors, and the goals of taxonomy: a botanical defense of cladism. Bot Rev 54:107-128

Dumée P, Grandjean M, Maire R (1912) Sur la synonymie et les affinities de l'Hygrophorus marzuolus (Fr.). Bres Bull Soc Mycol Fr 28:285298

Ellis JB (1876) New fungi found at Newfield, New Jersey. Bull Torrey Bot Club 6:75-77

Engler HGA, Prantl KAE (1898) Nat. Pflanzenfam. 1

Esteves-Raventós F, Alvarado P, Reyes JD, Manjón JL (2011) Nuevos datos sobre la identidad de Pleurotus dryinus var. luteosaturatus (Agaricales) sobre la base de estudios morfológicos y moleculares. Bol Soc Micol Madrid 35:77-83

Fang W, St. Leger RJ (2010) Mrt, a gene unique to fungi, encodes an oligosaccharide transporter and facilitates rhizosphere competency in Metarhizium robertsii. Plant Physiol 154:1549-1557

Farrell IWV, Thalier V, Turner JL (1977) Natural acetylenes. Part 52. Polyacetylenic acids and aromatic aldehyds from cultures of the fungus Camarophyllus virgineus (Wulfen ex Fr.) Kummer. J Chem Soc (London) Perkin Trans 1:1886-1888

Fayod (1889) Podrome d'une histoire naturelle des Agaricines. Proc Nat Agar Ann Scient Nat (Paris) 7 iteme serie. Botanique 9:181-411

Fiasson JL, Bouchez MP (1968) Recherches chimiotaxonomiques sur les champignons. Les carotènes de Omphalia chrysophylla Fr. Compt Rend Hebd Séances Acad Sci 266:1379-1381

Franco-Molano AE, López-Quintero CA (2007) A new species of Hygroaster (Hygrophoraceae, Agaricales) from Colombia. Mycotaxon 99:189-195

Frank AB (1888) Uber die physiologische Bedeutung der mycorrhiza. Ber Dtsch Bot Ges 6:248-269

Fries EM (1818) Observationes mycologicae, vol 2. Gerh Bonnier, Copenhagen, pp 1-372

Fries EM (1821) Systema Mycologicum. Vol I. Lund
Fries EM (1825) Systema orbis vegetabilis. Typographia Academica, Lund

Fries EM (1836) Corpus Florarum provincialium suecicae 1. Floram Scanicam, Uppsala

Fries EM (1838) Epicrisis systematis mycologici seu synopsis Hymenomycetum. Uppsala

Fries EM (1849) Summa vegetabilium Scandinaviae. II. Typographica Academica, Uppsala, pp 259-572

Fries EM (1861) Hymenomycetes novi vel minus cogniti, in Suecia 1852-1860 observati. Öfvers K Vetensk Akad Förh 18:19-34

Fries EM (1874) Hymenomycetes europaei sive Epicriseos systematis mycologici $1-755$

Gams W (1995) Report of the committee for fungi: 5. Taxon 44:411-414

Gärdenfors U (ed) (2010) The 2010 redlist of Swedish species. ArtDatabanken, SLU, Swedish Species Information Centre, Uppsala, Sweden (www.artdata.slu.se/rodlista)

Gardes M, Bruns TD (1993) ITS primers with enhanced specificity for basidiomycetes - application to the identification of mycorrhizae and rusts. Mol Ecol 2:113-118

Gargas A, DePriest PT, Grube M, Tehler A (1995) Multiple origins of Lichen Symbioses in fungi suggested by SSU rDNA phylogeny. Science 268:1492-1496

Geml J, Kauff F, Brochmann C, Lutzoni F, Laursen GA, Redhead SA, Taylor DL (2012) Frequent circumpolar and rare transequatorial dispersals in the lichenised agaric genus Lichenomphalia (Hygrophoraceae, Basidiomycota). Fungal Biol 116:388-400

Gill M, Steglich W (1987) Pigments of fungi (Macromycetes). Prog Chem Org Nat Prod 51:1-317

Gillardoni G, Claricuzio M, Tosi S, Zanoni G, Vidari G (2006) Antifungal acylcyclopentenediones from fruiting bodies of Hygrophorus chrysodon. J Nat Prod 70:137-139

Goodwin TW (1952) Fungal carotenoids. Bot Rev 18:291-316

Gouy M, Guindon S, Gascuel O (2010) SeaView ver. 4: a multiplatform graphical user interface for sequence alignment and phylogenetic tree building. Mol Biol Evol 27:221-224

Greuter W, McNeill J, Barrie FR, Burdet HM, Demoulin V, Filgueiras TS, Nicolson DH, Silva PC, Skog JE, Trehane P, Turland NJ, Hawksworth DL (eds) (2000) International code of botanical nomenclature (Saint Louis code). Adopted by the Sixteenth International Botanical Congress St. Louis, Missouri, July-August 1999. (Regnum Veg. 238). Koeltz Scientific Books, Königstein

Griffith GW (2004) The use of stable isotopes in fungal ecology. Mycologist 18:177-183

Griffith GW, Easton GL, Jones AW (2002) Ecology and diversity of waxcap (Hygrocybe spp.) fungi. Bot J Scot 54:7-22

Griffith GW, Bratton JL, Easton GL (2004) Charismatic megafungi: the conservation of waxcap grasslands. Brit Wildlife 15:31-43

Gröger F (1980) Was ist Hygrophorus leucophaeus Scop. Ex Fr. (H. carpini, H. unicolor sp. nov.). Zeit Mykol 46:157-164

Grotewold E (2006) The genetics and biochemistry of floral pigments. Ann Rev Plant Biol 57:761-780

Haas H (1958) Clitocybe venustissima Fr. in Stuttgart wiederentdeckt. Zeitschr Pilzk 4:9-12

Haas H (1962) Die systematische Stellung von Clitocybe venustissima Fries. Zeitschr Pilzk 28:12-13

Halling RE, Mueller GM (2005) Common mushrooms of the Talamanca mountains, Costa Rica. Mem New York Bot Gard 90:1-195

Harmaja H (2002) Amylolepiota, Clavicybe and Cystodermella, new genera of Agaricales. Karstenia 42:39-48

Harmaja H (2003) Notes on Clitocybe s. lato (Agaricales). Ann Bot Fennici 40:213-218

Heim R (1936) Observations sur la flore mycologique malgache IV. Etude de quelques Agarics a latex non résinoïde. Revue Mycol, Paris 1:223-256 
Heim R (1967) Hygrophores tropicaux recueillés par Roger Heim 1: Espéces de Guyan française et de Nouvelle-Guinée australienne. Rev Mycologie 32:16-27

Heinemann P (1963) Champignons récolétes au congo par madame M. Gossens-Fontana. V. Hygrophoraceae. Bull Jard Bot Bruxelles 33:421-458

Hennings P (1898) In Engler HGA, Prantl KAE. Nat Pflanzenfam 1:209

Herink J (1959) Species familieae Hygrophoracearum. (Stavnatkovité houby parhorku "Velká Horka" u Mnichova Hradiste). Sb., Severocesk. Mus., Prír. Vedy 1:53-86

Hesler LR, Smith AH (1963) North American species of Hygrophorus. University of Tennessee Press, Knoxville

Hibbett D (1996) Phylogenetic evidence for horizontal transmission of Group I introns in the nuclear ribosomal DNA of mushroomforming fungi. Mol Biol Evol 13:903-917

Hibbett D, Binder M (2002) Evolution of complex fruiting-body morphologies in homobasidiomycetes. Proc R Soc Lond B 269:19631969

Hibbett DS, Donoghue MJ (1995) Progress toward a phylogenetic classification of the Polyporaceae through parsimony analysis of mitochondrial ribosomal DNA sequences. Can J Bot 73:S853-S861

Hibbett D, Donoghue MJ (1998) Integrating phylogenetic analysis and classification of fungi. Mycologia 90:347-356

Hibbett D, Donoghue MJ (2001) Analysis of character correlations among wood decay mechanisms, mating systems, and substrate ranges in Homobasidiomycetes. Syst Biol 50:215-242

Hibbett DS, Gilbert L-B, Donoghue MJ (2000) Evolutionary instability of ectomycorrhizal symbioses in basidiomycetes. Nature 407:506-508

Hobbie EA, Agerer R (2010) Nitrogen isotopes in ectomycorrhizal sporocarps correspond to belowground exploration types. Plant Soil 327:71-83

Hobbie EA, Jumpponen A, Trappe J (1999) Interpretation of nitrogen isotope signatures using the NIFTE model. Oecologia 120:405-415

Høiland K (1976) The genera Leptoglossum, Arrhenia, Phaeotellus, and Cyphellostereum in Norway and Svalbord. Nor J Bot 23:201-212

Horak E (1966) Bemerkungen zur gattung Hygroaster Singer (1955). Schweiz Z Pilzk 44:87-92

Horak E (1968) Synopsis generum Agaricalium (die gattungstypen der Agaricales). Beit zur Kryptogamenflora der Schweiz 13:1-741

Horak E (1971) A contribution towards the revision of the Agaricales (Fungi) from New Zealand. NZ J Bot 9:403-462

Horak E (1990) Monograph of the New Zealand Hygrophoraceae (Agaricales). NZ J Bot 28:255-309

Huelsenbeck JP, Ronquist F (2001) MrBayes: Bayesian inference of phylogeny. Bioinformatics 17:754-755

Hughes KW, Petersen RH, Lickey EB (2009) Using heterozygosity to estimate a percent DNA sequence similarity for environmental species delimitation across basidiomycete fungi. New Phytol 182:795-798

Hughes K, Petersen R, Lodge DJ, Bergemann S (2010) A driver of fungal biodiversity? The consequences of intertaxon agaric hybridization. Inoculum 61(4):56

Hughes KW, Petersen R, Lodge DJ, Bergemann S, Baumgartner K, Tulloss RE, Lickey E, Cifuentes J. Evolutionary consequences of putative intra- and interspecific hybridization in agaric fungi. Mycologia, in press

Huhndorf SM, Lodge DJ, Wang CJK, Stokland J (2004) Macrofungi on woody substrata. In: Mueller GM (ed) Measuring and monitoring biological diversity: standard methods for fungi. University of Chicago Press, Chicago, pp 159-163

ICN (2012) [2011] International code for nomenclature of algae, fungi and plants (Melbourne Code). In: McNeill J, Barrie FR, Buck WR, Demoulin V, Greuter W, Hawksworth D, Herendeen PS, Knapp S, Marhold K, Prado J, Prud'homme van Reine WF, Smith GF, Wiersema JH, Turland NJ (eds) Regnum vegetablile, vol 154. Koeltz Scientific Books, Koenigstein
Jacobsson S, Larsson E (2007) Hygrophorus penarioides, a new species identified using morphology and ITS sequence data. Mycotaxon 99:337-343

Jayasinghe BATD, Parkinson D (2008) Actinomycetes as antagonists of litter decomposer agarics. Appl Soil Ecol 38:109-118

Johnson JE, Petersen RH (1997) Mating systems in Xeromphalina species. Mycologia 89:393-399

Jorgensen PM (1998) Acantholichen pannarioides, a new basidiolichen from South America. Bryologist 101:444-447

Josserand M (1955) Notes critiques sur quelques champignons de la region Lyonnaise. Bull Soc Mycol Fr 71:65-125

Karsten P (1876) Mycologica Fennica III, Basidiomycees in Bidrag till Kannedom af Finlands. Natur och Folk, in Petter Adolf Karsten (1834-1917) Collected Mycological Papers, vol 1. A. Asher \& Co. reprint, Amsterdam

Karsten PA (1879) Rysslands, Finlands och den Skandinaviska halföns Hattsvampar. Förra Delen: Skifsvampar. Bidrag till Kännendom av Finlands. Natur och Folk 32:1-571

Katoh K, Toh H (2008) Recent developments in the MAFFT multiple sequence alignment program. Brief Bioinf 9:286-298

Kauserud H, Mathiesen C, Ohlson M (2008) High diversity of fungi associated with living bryophytes. Botany-Botanique 86:13261333

Kearney R, Kearney E (2000) Significance of the Hygrocybeae community of Lane Cove Bushland Park in listings under the NSW Threatened Species Conservation Act 1995 and under the Australian Heritage Commission Act 1975. Austr Mycologist 19:64-70

Keizer PJ (1993) The influence of nature management on the macromycete fungi. In: Pegler DN, Boddy L, Ing B, Kirk PM (eds) Fungi in Europe: investigations, recording and conservation. Royal Botanic Gardens, Kew, pp 251-269

Kim JH, Lee JS, Lee KR, Shim MJ, Lee MW, Shin PG, Cheong JC, Yoo YB, Lee TS (2012) Immunomodulating and antitumor activities of Panellus serotinus polysaccharides. Mycobiology 40:181-188

Kirk PM, Cannon PF, Minter DW, Stalpers JA (2008) Ainsworth \& Bisby's dictionary of the fungi, 10th edn. CABI International, Wallingford

Kjøller R, Clemmensen K (2009) Belowground ectomycorrhizal fungal communities respond to liming in three southern Swedish coniferous forest stands. For Ecol Manage 257:2217-2225

Konrad P (1936) Notes critiques sur quelques champignons du Jura. Quat série Bill Trimestr Soc Mycol Fr 52:35-53

Konrad P, Maublanc A (1937) Icones selectae fungorum, vol 6. Paul Lechevalier, Paris

Konrad P, Maublanc A (1953) Les Agaricales 2: Russulacées, Hygrophoracées, Gompkidiacées, Paxillacées, Boletacées. Encyclopédie Mycologique, XX. P. Lechevalier, Paris, pp 202

Kost G (1986) Morphologie, anatomie und systematic carotinoidhaltiger blätterpilze. Ber Deutsch Bot Ges 99:43-58

Kotlaba F, Pouzar Z (1966) Haasiella, a new agaric genus and $H$. splendidissima sp. nov. Ceská Mykol 20:135-140

Kovalenko A (1988) New combinations within the Hygrophoraceae Lotsy. Mikol Fitopatol 22:207-209

Kovalenko A (1989) Definitorium fungorum URSS. Ordo Hygrophorales. Nauka 37, Leningrad

Kovalenko A (1999) The arctic-subarctic and alpine-subalpine component of the Hygrophoraceae in Russia. Kew Bull 54:695-704

Kovalenko A (2012) In: Knudsen H, Vesterholt J (eds) Funga Nordica. Agaricoid, boletoid cyphelloid and gasteroid genera. Nordsvamp, Copenhagen, pp 282-293

Krieglsteiner GJ, Enderle M (1987) Über neue, seltene, kritische makromyzeten in der Bundesrepulik Deutschland (Mitteleuropa) IX. Z Mykol 53:3-38

Kranner I, Lutzoni F (1999) Evolutionary consequences of transition to a lichen symbiotic state and physiological adaptation to oxidative damage associated with poikilohydry. In: Lerner HR (ed) Plant 
response to environmental stresses: from phytohormones to genome reorganization. Marcel Dekker, New York, pp 591-628

Kropp BR, Trappe JM (1982) Ectomycorrhizal fungi of Tsuga heterophylla. Mycologia 74:479-488

Kühner R (1926) Contribution à l'Étude des Hyménomycètes et spécialement des agaricacées. Botaniste 17:53

Kühner R (1947) Quelques agarics rares, critiques, ou noveaux de la région de Besancon. Ann Scient Franche-Comté 2:26-42

Kühner R (1949) Hygrophorus picea sp. nov. Champignon meconnu des sapinieres de Montagne. Voisin de eburneus. Bull Mens Soc Linn de Lyon 18:179-182

Kühner R (1976) Agaricales de la zone alpine. Genre Hygrocybe (Fries) Kummer. Bull Soc Myc Fr 92:455-515

Kühner R (1977a) Agaricales de la zone alpine. Hygrophoracées. Genre Camarophyllus (Fries) Kummer. Bull Soc Myc Fr 93:121-144

Kühner R (1977b) Vers un system phylogénetique des Camarophyllus (Fr.) et Hygrocybe (Fr.) (Agaricales-Hygrophoraceae). Rev Mycol 41:73-90

Kühner R (1980) Les Hymenomycetes agaricoides. Bull mens Soc Linn Lyon 49:1-1027

Kühner R, Romagnesi H (1953) Flore Analytique de Champignons Supérieurs. Masson et cie, Paris

Kummer P (1871) Der Führer in die Pilzkunde. C. Luppe, Zerbst

Kunth CS (1822) Synop Plant 1:1-491

Lamarche J, Hamelin R (2007) No evidence of an impact on the rhizosphere diazotroph community by the expression of Bacillus thuringiensis Cry $1 \mathrm{Ab}$ toxin by Bt white spruce. Appl Env Microbiol 73:6577. doi:10.1128/AEM.00812-07

Lamoure (1971) Agaricales de la zone alpine. Rhodocybe borealis Lange $\&$ Skifte, et sa position systematique. Svensk Bot Tidskrift 65:278282

Lamoure (1974) Agaricales de la zone alpine. Genre Omphalina. 1è $\mathrm{e}^{\text {re }}$ partie. Travaux Scientifiques du Parc National de la Vanoise 5:149 164

Lamoure (1975) Agaricales de la zone alpine. Genre Omphalina. $2^{\mathrm{e}}$ partie. Travaux Scientifiques du Parc National de la Vanoise 6:153-166

Lange M (1981) Typification and delimitation of Omphalina Quél. Nord J Bot 1:691-696

Lange M (1992) Omphalina Quél. In: Hansen L, Knudsen H (eds) Nordic macromycetes, vol 2. Nordsvamp, Copenhagen

Larsson K-H (2007) Re-thinking the classification of corticioid fungi. Mycol Res 111:1040-1063

Larsson E (2010) Hygrophorus, a monophyletic genus with species showing strong host preferences. Int Mycol Congr (IMC9), Edinburgh, Scotland. Poster Abstract P4:111

Larsson E, Jacobsson S (2004) Controversy over Hygrophorus cossus settled using ITS sequence data from 200 year-old type material. Mycol Res 108:781-786

Larsson E, Jacobsson S, Stridvall A (2011) Släktet Hygrophorus, skogsvaxskivlingar I sverige. En fältguide till SMF's svampväkteri "Vaxvakt". SMT. Mykol publik 3:1-56

Lawrey JD, Lücking R, Sipman HJM, Chaves JL, Redhead SA, Bungartz F, Sikaroodi M, Gillevet PM (2009) High concentration of basidiolichens in a single family of agaricoid mushrooms (Basidiomycota: Agaricales: Hygrophoraceae). Mycol Res 113:1154-1171

Lickey EB, Hughes KW, Petersen RH (2003) Variability and phylogenetic incongruence of an SSU nrDNA group intron in Artomyces, Auriscalpium, and Lentinellus (Auriscalpiaceae: Homobasidiomycetes). Mol Biol Evol 20:1909-1916

Lilleskov EA, Fahey TJ, Lovett GM (2001) Ectomycorrhizal fungal aboveground community change over an atmospheric nitrogen deposition gradient. Ecol Appl 11:397-410

Lilleskov EA, Fahey TJ, Horton TR, Lovett GM (2002) Belowground ectomycorrhizal community change over a nitrogen deposition gradient in Alaska. Ecology 83:104-115
Lindner DL, Banik MT (2009) Effects of cloning and root-tip size on observations of fungal ITS sequences from Picea glauca roots. Mycologia 101:157-165

Lodge DJ, Ovrebo CL (2008) First records of Hygrophoraceae from Panama including a new species of Camarophyllus and a new veiled species in Hygrocybe section Firmae. Fungal Div 28:69-80

Lodge DJ, Pegler DN (1990) The Hygrophoraceae of the Luquillo Mountains of Puerto Rico. Mycol Res 94:443-456

Lodge DJ, Matheny PB, Cantrell SA, Moncalvo J-M, Vilgalys R, Redhead SA (2006) Delineating the Hygrophoraceae: character myths vs. gene trees. Inoculum 57:27; poster (uploaded to the following website17 Apr 2013) http://www.aber.ac.uk/waxcap/links/index.shtml

Lotsy JP (1907) Vorträge über botanische Stammesgeschichte. Gustav Fischer, Jena

Lübken T (2006) Hygrophorone Neue antifungische Cyclopentenonderivate aus Hygrophorus-Arten (Basidiomycetes). Doctoral dissertation, Dept. Chemistry, Mathematisch-Naturwissenschaftlich-Technischen Falultät der Martin-Luther-Universität Halle-Wittenberg, Germany

Lübken T, Arnold N, Wessjohann L, Böttcher C, Schmidt J (2006) Analysis of fungal cyclopentenone derivatives from Hygrophorus spp. by liquid chromatography/electrospray-tandem mass spectrometry. J Mass Spectrom 41:361-371

Lücking R, Lawrey JD, Sikaroodi M, Gillevet PM, Chaves JL, Sipman HJM, Bungartz F (2009) Do lichens domesticate photobionts like farmers domesticate crops? Evidence from a previously unrecognized lineage of filamentous cyanobacteria. Am J Bot 96:1409-1418

Ludwig E (1997) Ein neuer Sternsporling - Hygroaster lacteus und die gattungen Hygroaster/Omphaliaster aus heutinger sicht. Z Mykol 63:155-158

Ludwig E (2001) Pilzkompendium Band 1. Beschreibungen Eching. IHW-Verlag, Germany

Lundell S, Nannfeldt JA (1939) Fungi Exiccati Suecici

Lutzoni FM (1997) Phylogeny of lichen- and non-lichen forming omphalinoid mushrooms and the utility of testing for compatibility among multiple data sets. Sys Biol 46:373-406

Lutzoni FM, Pagel M (1997) Accelerated evolution as a consequence of transitions to mutualism. Proc Natl Acad Sci USA 94:11422-11427

Maas Geesteranus RA (1992) Mycenas of the Northern Hemisphere, vols I \& II. Koninklijke Nederlandse Akademie van Wetenschappen Verhandelingen, Amsterdam

Maire (1902) Recherches cytologiques et taxonomiques su les basidiomycètes. Bull Soc Mycol France 18(Suppl):1-212

Mata JL, Hughes KW, Petersen RH (2007) An investigation of/ omphalotaceae (Fungi: Euagarics) with emphasis on Gymnopus. Sydowia 58:191-289

Matheny PB (2005) Improving phylogenetic inference of mushrooms with RPB1 and RPB2 nucleotide sequences (Inocybe, Agaricales). Molec Phylogenet Evol 35:1-20

Matheny PB, Curtis JM, Hofstetter V, Aime MC, Moncalvo JM, Ge ZW, Yang ZL, Slot JC, Ammirati JF, Baroni TJ, Bougher NL, Hughes KW, Lodge DJ, Kerrigan RW, Seidl MT, Aanen DK, DeNitis M, Daniele G, Desjardin DE, Kropp BR, Norvell LL, Parker A, Vellinga EC, Vilgalys R, Hibbett DS (2006) Major clades of Agaricales: a multilocus phylogenetic overview. Mycologia 98:982-995

Melot J (2004) [2005] La légitimité du nom générique Cuphophyllus. Bull Soc Mycol Fr 120:463-465

Merlini L, Nasini G, Scaglioni L, Cassinelli G, Lanzi C (2000) Structure elucidation of clavilactone D: an inhibitor of protein kinases. Phytochemistry 53:1039-1041

Mier N, Canete S, Klaebe A, Chavant L, Fournier D (1996) Insecticidal properties of mushroom and toadstool carpophores. Phytochemistry 41:1293-1299

Miller SL, Larsson E, Larsson K-H, Verbeken A, Nuytinck J (2006) Perspectives in the new Russulales. Mycologia 98:96-970 
Molina R, Massicotte H, Trappe JM (1992) Specificity phenomena in mycorrhizal symbiosis: Community-ecological consequences and practical implications. In: Allen MF (ed) Mycorrhizal functioning: and integrative plant-fungal process. Chapman \& Hall, New York

Moncalvo J-M, Lutzoni FM, Rehner SA, Johnson J, Vilgalys R (2000) Phylogenetic relationships of agaric fungi based on nuclear large subunit ribosomal DNA sequences. Syst Biol 49:278-305

Moncalvo J-M, Vilgalys R, Redhead SA, Johnson JE, James TY, Aime MC, Hofstetter V, Verduin SJW, Larsson E, Baroni TJ, Thorn RG, Jacobsson S, Clémençon H, Miller OK (2002) One hundred and seventeen clades of euagarics. Molec Phylogenet Evol 23:357-400

Moser M (1967) Kleine kryptogamenflora von mitteleruopa - die blätterund baupilze (Agaricales un Gastromycetes). G. Fischer, Jena

Mui D, Feibelman T, Bennett JW (1998) A preliminary study of the carotenoids of some North American species of Cantharellus. Int J Plant Sci 159:244-248

Murphy EA, Mitchell DT (2001) Interactions between Tricholomopsis rutilans and ectomycorhizal fungi in paired culture and in association with seedlings of lodgepole pine and Sitka-spruce. For Pathol 31:331-344

Murrill WA (1911) The Agaricaceae of tropical North America. III. Mycologia 3:189-199

Murrill WA (1916) Agaricaceae Tribe Agaricae. North American flora 9:297-374

Murrill WA (1917) New combinations. Mycologia 9:40

Musso H (1979) The pigments of the fly agaric Amanita muscaria. Tetrahedron 35:2843

Noack F (1889) Uber mykorhizenbildende Pilze. Bot Zeit 24:391404

Noordeloos ME (1983) Notulae ad floram agaricinam neerlandicam I-III. Marasmiellus, Macrocystidia and Rhodocybe. Persoonia 12:29-49

Norvell LL, Redhead SA, Ammirati JF (1994) Omphalina sensu lato in North America 1-2. 1: Omphalina wynniae and the genus Chrysomphalina. 2: Omphalina sensu Bigelow. Mycotaxon 50: 379-407

Novotna J, Honzatko A, Bednar P, Kopecky J, Janata J, Spizek J (2004) L-3,4-dihydroxyphenyl alanine-estradiol cleavage is followed by intramolecular clyclization in lincomycin biosynthesis. Eur J Biochem 271:3678-3683

Oberwinkler F (1970) Die Gattungen der basidiolichenen. Dtsch Bot Ges Neue Folge 4:139-169

Orchard AE, Anderson WR, Gilbert MG, Sebsebe D, Stearn WT, Voss EG (1996) Harmonised bionomenclature - a recipe for disharmony. Taxon 45:287-290

Orton PD (1984) Notes on British agarics VIII. Hygrophorus quercorum P.D. Orton n. sp. Notes R Bot Garden Edinburgh 41:585-586

Ovrebo CL, Lodge DJ, Aime MC (2011) A new Cantharocybe from Belize with notes on the type of Cantharocybe gruberi. Mycologia 103:1102-1109

Papetti C (1985) Le Hygrophoraceae del territorio bresciano. Boll C M Carini 10:10-19

Papetti C (1996) Note introduttive allo studio delle Hygrophoraceae. Pag Micol 6:1-49

Papetti C (1997) Genre Hygrophorus Fr. sectio Nemorei sect. nov. Boll C M Carini 33:48

Parmasto E (1978) [1977] The genus Dictyonema (Thelephorolichenes). Nova Hedw 29:99-144

Peck CH (1872) Report of the Botanist. Ann Rept NewYork St Museum Nat Hist 23:29-82

Peck CH (1876) Report of the Botanist. Ann Rept NewYork St Museum Nat Hist 18:31-88

Peck CH (1878) Report of the Botanist. Ann Rept NewYork St Museum Nat Hist 29:29-82
Peck CH (1887) Descriptions of new species of New York fungi. Bull NY St Mus 1:5-24

Pegler DN, Fiard JP (1978) Hygrocybe sect. Firmae (Agaricales) in Tropical America. Kew Bulletin 32:297-312

Pegler DN (1983) Agaric flora of the Lesser Antilles. Kew Bull Adit Ser 9. HMSO, London

Pegler DN (1986) Agaric flora of Sri Lanka. Kew Bull Adit Ser 12. HMSO, London

Pegler DN, Young TWK (1971) Basidiospore morphology in Agaricales. Beih Nova Hedw 35:1-210

Pena R, Offermann C, Simon J, Naumann PS, Geßler A, Holst J, Dannenmann M, Mayer H, Kögel-Knabner I, Rennenberg H, Polle A (2010) Girdling affects ectomycorrhizal fungal (EMF) diversity and reveals functional differences in EMF community composition in a beech forest. Appl Environ Microbiol March 76:1831-1841

Pérez-de-Gregorio MÀ, Roqué C, Macau N (2009) Apuntes sobre un Hygrophorus Fr. común en las comunidades cistícolas mediterráneas. Errotari 6:22-28

Persoh D (2013) Factors shaping community structure of endophytic fungi-evidence from Pinus-Viscum-system. Fungal Diversity. doi:10.1007/s13225-013-0225-x

Persoon CH (1794) Neuer versuch einer systematischen eintheilung der schwamme. Neues Mag Bot 1:63-80

Pilát A, Nannfeldt JA (1954) Notulae ad cognitionem Hymenomycetum Lapponiae tornensis (Sueciae). Fresia 5:6-38

Pine EM, Hibbett DS, Donoghue MT (1999) Phylogenetic relationships of cantharelloid and clavarioid Homobasidiomycetes based on mitochondrial and nuclear rDNA sequences. Mycologia 91:944-963

Quélet L (1882) [1883] Quelques espéces critiques ou nouvelles de la flore mycologique France. C R Assoç. Frand Av Sci (La Rochelle) 11:390

Quélet L (1886) Enchiridion fungorum in Europa media et praesertum in Gallia Vigentium. Octave Dion, Paris

Quélet L (1888) Flore mycologique. Octave Dion, Paris

Rabenhorst L (1844) Deutschlands kryptogamenflora 1:1-614

Raithelhuber J (1973) Zur abgrenzung der gattungen Gerronema, Omphalina, Clitocybe un Haasiella. Metrodiana 4:61-73

Raithelhuber J (1980) Descript. fung. nov. vel comb. nov. non val. publ. Metrodiana 9:47-48

Rambaut A (2002) Se-Al. Sequence alignment editor, V2.0a11. University of Oxford, UK

Redhead SA (1981) Parasitism of bryophytes by agarics. Can J Bot 59:63-67

Redhead SA (1984) Arrhenia and Rimbachia, expanded generic concepts, and a reevaluation of Leptoglossum with emphasis on muscicolous North American taxa. Can J Bot 62:865-892

Redhead SA (1986) Mycological observations: 17-20, nomenclatural notes on some omphalioid genera in Canada: Chrysomphalina, Rickenella, Gerronema, Omphalina. Acta Mycol Sinica Suppl 1:297-3-297-4

Redhead SA (2013) Nomenclatural novelties. Index Fungorum 15:1-2

Redhead SA, Kuyper TW (1987) Lichenized agarics: taxonomic and nomenclatural riddles. In: Laursen GA, Ammirati JF, Redhead SA (eds) Arctic and alpine mycology II. The second international symposium on arcto-alpine mycology. Plenum Press, New York, pp 319-348

Redhead SA, Kuyper TW (1988) Phytoconis, the correct generic name for the basidiolichen Botrydina. Mycotaxon 31:221-223

Redhead SA, Ammirati JF, Norvell LL (1995) Omphalina sensu lato in North America: Chromosera gen. nov. Beih. Sydowia 10:155-167

Redhead SA, Ammirati JF, Norvell LL, Seidl MT (2000) Notes on western North American snowbank fungi. Mycotaxon 76:321-328

Redhead SA, Lutzoni F, Moncalvo J-M, Vilgalys R (2002) Phylogeny of agarics: partial systematics solutions for core omphalinoid genera in the Agaricales (Euagarics). Mycotaxon 83:19-57 
Redhead SA, Ammirati JF, Norvell LL, Vizzini A, Contu M (2012) [2011] Validation of combinations with basionyms published by Fries 1861. Mycotaxon 118:455-458

Reid DA (1965) A monograph of the stipitate stereoid fungi. Beih Nova Hedw 18:1-382

Reijnders AFM, Stalpers JA (1992) The development of the hymenophoral trama in the Aphyllophorales and the Agaricales. Stud Mycol 34:1-109

Roderick K (2009) The ecology of grassland macrofungi. Dissertation, IBERS, Aberystwyth University.

Romagnesi H (1995) Prodrome à une flore analytique des hyménomycètes agaricoïdes III. Fam. Cantharellaceae Schroeter. Doc Mycol 25: $417-424$

Romagnesi H (1996) Validations. Bull Soc Myc Fr 112:134-135

Ronquist F, Huelsenbeck JP (2003) MrBayes 3: Bayesian phylogenetic inference under mixed models. Bioinformatics 19:1572-1574

Roze E (1876) Eassai d'une nouvelle classification des agaricinées. Bull Soc Bot Fr 23:45-54

Rundell J, Price TD (2009) Adaptive radiation, nonadaptive radiation, ecological speciation and nonecological speciation. Trends Ecol Evol 24:394-399

Saccardo (1887) Sylloge Fungorum 5:152

Seitzman BH, Ouimette A, Mixon RL, Hobbie AE, Hibbett DS (2011) Conservation of biotrophy in Hygrophoraceae inferred from combined stable isotope and phylogenetic analysis. Mycologia 103:280290

Singer R (1936) Notes sur quelques Basidiomycetes. II. Rev Mycol 1:279-293

Singer R (1942) Type studies on agarics. Lloydia 5:97-135

Singer R (1943) Das System der Agaricales. III. Ann Mycologici 41:1-189

Singer R (1948) Diagnoses fungorum novorum Agaricalium. Sydowia 2:26-42

Singer R (1949) [1951] The Agaricales in modern taxonomy. Lilloa 22:1832

Singer R (1952) The agarics of the Argentine sector of Tierra del Fuego and limitrophous regions of the Magellanes area 6:165-226

Singer R (1955) Type studies on basidiomycetes. VIII. Sydowia 9(1-6): $367-431$

Singer R (1956) New genera of fungi. VII. Mycologia 48:719-727

Singer R (1958) Fungi Mexicana, Series Segunda - Agaricales. Sydowia $12: 221-243$

Singer R (1962) [1961] Diagnoses fungorum novorum Agaricalium II. Sydowia 15:45-83

Singer R (1973) Diagnoses fungorum novorum Agaricalium III. Beih zur Sydowia 7:1-106

Singer R (1986) The Agaricales in modern taxonomy, 4th edn. Koeltz Scientific Books, Koenigstein

Singer R (1989) New taxa and new combinations of Agaricales (diagnoses fungorum novorum Agaricalium 4). Fieldiana Botany 21:1-133

Singer R, Clémençon H (1971) Neu arten von Agaricales. Schweiz ZPilk 49:118-128

Smith AH (1944) New North American agarics. Mycologia 36:242-262

Smith AH (1947) North American species of Mycena. Univ of Michigan Press, Ann Arbor

Smith AH, Hesler LR (1939) Studies in North American species of Hygrophorus: I. The subgenus Limacium. Lloydia 2:1-62

Smith AH, Hesler LR (1942) Studies in North American species of Hygrophorus: II. Lloydia 5:1-94

Smith AH, Hesler LR (1954) Additional North American Hygrophori. Sydowia 8:304-333

Stamatakis S (2006a) RAxML-VI-HPC: maximum likelihood-based phylogenetic analyses with thousands of taxa and mixed models. Bioinformatics 22:2688-2690

Stamatakis S (2006b) Phylogenetic models of rate heterogeneity: a high performance computing perspective. Proceedings 20th IEEE
International Parallel \& Distributed Processing Symposium, p 278. Rhodes Island, Greece. 25-29 April, 2006

Stamatakis S, Hoover P, Rougemont J (2008) A rapid bootstrap algorithm for the RAxML web servers. Syst Biol 57:758-771

Steglich W, Preuss R (1975) L-3,4-Dihydroxyphenylalanine from carpophores of Hygrocybe conica and Hygrocybe ovina. Phytochemistry 14:1119

Steglich W, Strack D (1990) Betalains. In: Brossi A (ed) The alkaloids, chemistry and pharmacology. Adademic Press, London, pp 1-62

Swofford DL (2002) PAUP*. phylogenetic analysis using parsimony (* and other methods). version 4.0 b10. Sinauer Associates, Sunderland

Taylor AFS, Högberg P, Högberg MN (2003) Species level patterns in ${ }^{13} \mathrm{C}$ and ${ }^{15} \mathrm{~N}$ abundance of ectomycorrhizal and saprotrophic fungal sporocarps. New Phytol 159:757-774

Tedersoo L, May TW, Smith ME (2010) Ectomycorrhizal lifestyle in fungi: global diversity, distribution, and evolution of phylogenetic lineages. Mycorrhiza 20:217-263

Tejesvi MV, Ruotsalainen AL, Markkola AM, Pirttila AM (2010) Root endophytes along a primary succession gradient in northern Finland. Fungal Divers 41:125-134

Tello SA, Silva-Flores P, Agerer R, Halbwachs H, Andreas Beck A Peršoh D (2013) Hygrocybe virginea is a systemic endophyte of Plantago lanceolata. Mycological Progress, in press

Terradas F, Wyler H (1991a) 2,3- and 4,5-Secodopa, the biosynthetic intermediates generated from 1-dopa by an enzyme system extracted from the fly agaric, Amanita muscaria L. and their spontaneous conversion to muscaflavin and betalamic actid, respectively, and betalains. Helv Chim Acta 74:124-140

Terradas F, Wyler H (1991b) The secodopas, natural pigments in Hygrocybe conica and Amanita muscaria. Phytochemistry 30: 3251-3253

Trudell SA, Rygiewicz PT, Edmonds R (2004) Patterns of nitrogen and carbon stable isotope ratios in macrofungi, plants and soils in two old-growth conifer forests. New Phytol 164:317-335

Vainio EA (1890) Étude sur la classification naturelle et la morphologie des Lichens du Brésil. Pars prima. Acta Soc Fauna Flora Fennica $7: 1-174$

Velenovsky J (1920) Ceske Houby 1:1-200. Prague

Venditti C, Meade A, Pagel M (2010) Phylogenies reveal new interpretation of speciation and the Red Queen. Nature 463: $349-252$

Vineis J, Horton TR, Hobbie EA (2010) Ectomycorrhizal exploration along a nitrogen gradient. Joint meeting of the International Symposium of Fungal Endophytes of Grasses and the Mycological Society of America. Lexington Kentucky, June 28 -July 1, 2010, Genbank accessions 2010, NCBI

Visser S (1995) Ectomycorrhizal fungal succession in Jack pine stands following wildfire. New Phytol 129:389-401

Vizzini A, Ercole E (2012) [2011] Considerazioni sul genere Hygrocybe s. lato: il novo genere Dermolomopsis e nuove combinazioni in Chromosera. Micol Veget Medit 26:91-106

Vizzini A, Consiglio G, Setti L, Ercole E (2012) [2011] The phylogenetic position of Haasiella (Basidiomycota, Agaricomycetes) and the relationship between $H$. venustissima and $H$. splendidissima. Mycologia 104:777-784

Von Ardenne R, Döpp H, Musso H, Steglich W (1974) Über das vorkommen von Muscaflavin bei hygrocyben (Agaricales) und seine Dihydroazepin-struktur (Isolation of Muscaflavin from Hygrocybe species (Agaricales) and its Dihydroazepine structure). Zeit für Naturfor C 29:637-639

von Höhnel F, Litschauer V (1908) Fragmente zur Mykologie. V. Mitteilung (nr. 169 bis181). Sitzungsberichte der Kaiserlichen Akademie der Wissenschaft Math-naturw Klasse Abt I 117:9851032 
Vrinda KB, Varghese SP, Pradeep CK (2012) A new species of Hygroaster (Hygrophoraceae) from Kerala State, India. Mycosphere 10:399-402. doi: $10.5943 /$ mycosphere/3/4/1

Wang C-L, Chang P-FL, Lin Y-H, Malkus A, Gao L-Y, Ueng PP (2009) Group I introns in small subunit ribosomal DNA (SSU-rDNA) of cereal Phaeosphaeria species. Bot Stud 50:137-147

White TJ, Bruns TD, Lee S, Taylor JW (1990) Amplification and direct sequencing of fungal ribosomal RNA genes for phylogenetics. In: Innis MA, Gelfand DH, Sninsky JJ, White TJ (eds) PCR protocols: a guide to methods and applications. Academic, San Diego, pp 315-322

Wünsche O (1877) Die Pilze. Eine Anleitung zur Kenntniss derselben :1324

Yamaura Y, Fukuhara M, Kawamata S, Satsumabayashi H, Takabatake E, Hashimoto T (1986) Effects of Clitocybe clavipes extract on the components and enzymes related to ethanol metabolism in mice. $\mathrm{J}$ Food Hyg Soc Jpn 27:522-527

Yánez A, Dal-Forno M, Bungartz F, Lücking R, Lawrey JD (2012) A first assessment of Galapagos basidiolichens. Fungal Div 52:225-244
Young AM (1997) Preliminary observations on the limitations of the Australian Hygrophoraceae (Agaricales). Muelleria 10:131-138

Young AM (2003) Brief notes on status of family Hygrophoraceae Lotsy. Australaisian Mycol 21:114-116

Young AM (2005) Fungi of Australia: Hygrophoraceae. CSIRO Publishing, Australian Biological Resources Study, Canberra

Young AM, Mills AK (2002) The Hygrophoraceae of Tasmania. Muelleria 16:3-28

Young AM, Wood AE (1997) Studies on the Hygrophoraceae (Fungi, Homobasidiomycetes, Agaricales) of Australia. Aust Sys Bot 10:911-1030

Zeller B, Brechet C, Maurice J, le Tacon F (2007) ${ }^{13} \mathrm{C}$ and ${ }^{15} \mathrm{~N}$ isotopic fractionation in trees, soils and fungi in a natural forest stand and a Norway spruce plantation. Ann For Sci 64:419-429

Zwickl DJ (2006) Genetic algorithm approaches for the phylogenetic analysis of large biological sequence datasets under the maximum likelihood criterion. Dissertation, The University of Texas at Austin 